\title{
ASIA-PACIFIC REGIONAL COOPERATION AND INTEGRATION INDEX
}

ENHANCED FRAMEWORK, ANALYSIS, AND APPLICATIONS

OCTOBER 2021 



\section{ASIA-PACIFIC REGIONAL COOPERATION AND INTEGRATION INDEX ENHANCED FRAMEWORK, ANALYSIS, AND APPLICATIONS}

OCTOBER 2021 
(C) 2021 Asian Development Bank

6 ADB Avenue, Mandaluyong City, 1550 Metro Manila, Philippines

Tel +632 8632 4444; Fax +63286362444

www.adb.org

Some rights reserved. Published in 2021.

ISBN 978-92-9269-049-6 (print); 978-92-9269-050-2 (electronic); 978-92-9269-051-9 (ebook)

Publication Stock No. TCS210342-2

DOI: http://dx.doi.org/10.22617/TCS210342-2

The views expressed in this publication are those of the authors and do not necessarily reflect the views and policies of the Asian Development Bank (ADB) or its Board of Governors or the governments they represent.

ADB does not guarantee the accuracy of the data included in this publication and accepts no responsibility for any consequence of their use. The mention of specific companies or products of manufacturers does not imply that they are endorsed or recommended by ADB in preference to others of a similar nature that are not mentioned.

By making any designation of or reference to a particular territory or geographic area, or by using the term "country" in this document, $A D B$ does not intend to make any judgments as to the legal or other status of any territory or area.

This work is available under the Creative Commons Attribution 3.0 IGO license (CC BY 3.0 IGO)

https://creativecommons.org/licenses/by/3.0/igo/. By using the content of this publication, you agree to be bound by the terms of this license. For attribution, translations, adaptations, and permissions, please read the provisions and terms of use at https://www.adb.org/terms-use\#openaccess.

This CC license does not apply to non-ADB copyright materials in this publication. If the material is attributed to another source, please contact the copyright owner or publisher of that source for permission to reproduce it. $\mathrm{ADB}$ cannot be held liable for any claims that arise as a result of your use of the material.

Please contact pubsmarketing@adb.org if you have questions or comments with respect to content, or if you wish to obtain copyright permission for your intended use that does not fall within these terms, or for permission to use the ADB logo.

Corrigenda to ADB publications may be found at http://www.adb.org/publications/corrigenda.

Note:

In this publication, “\$” refers to United States dollars.

Cover design by Erickson D. Mercado. 


\section{Contents}

Tables, Figures, and Boxes $\quad$ v

Foreword viii

Acknowledgments $\quad x$

Abbreviations $\quad$ xii

$\begin{array}{ll}\text { Highlights } & \text { xiii }\end{array}$

$\begin{array}{lr}\text { I. Introduction } & 1\end{array}$

An Enhanced Framework for Measuring Regional Cooperation and Integration $\quad 1$

Trends in Regional Integration in Asia and the Pacific $\quad 2$

Looking Forward $\quad 6$

$\begin{array}{ll}\text { References } & 7\end{array}$

II. About the Asia-Pacific Regional Cooperation and Integration Index 8

$\begin{array}{ll}\text { Evolution of the ARCII Framework } & 8\end{array}$

$\begin{array}{ll}\text { Methodology Overview } & 61\end{array}$

$\begin{array}{ll}\text { Interpretation } & 63\end{array}$

$\begin{array}{ll}\text { References } & 65\end{array}$

III. Measuring Regional Integration through the Enhanced ARCII Framework 72

Key Findings and Results of the Enhanced ARCII Framework $\quad 72$

Main Trends in Dimensional Indexes $\quad 80$

Contribution to ARCII Dimensional Indexes by Indicator $\quad 82$

Regional Integration by Income Level $\quad 84$

Comparison of the Baseline and Enhanced ARCII Estimates 85

Index Customization $\quad 88$

$\begin{array}{ll}\text { References } & 94\end{array}$

IV. Balancing ARCII Downsides: Sensitivity Analysis and Robustness Checks 96

Denominator Choice in ARCII Indicators $\quad 97$

Selection of Regional or Worldwide Normalization $\quad 102$

Regionalization Bias 103

Spatial Autocorrelation Bias in ARCII Estimates and Correction 106

Spatial Dependence: Why Does It Matter? 106

References 116 
V. Conclusions and Way Forward

Possible Extensions and Applications

118

References

122

APPENDIXES

1. Explanatory Note on the ARCII Framework

124

2. Dimensional Weights and Overall ARCII Estimates by Economy

138

3. Supplementary Information on Alternative Indicators

141 


\section{Tables, Figures, and Boxes}

\section{TABLES}

2.1 Dimensions and Indicators in the Enhanced ARCII Framework

2.2 Top 10 Liner Shipping Bilateral Connectivity Index Scores for Asia and the Pacific Routes, $2018 \quad 32$

2.3 Proportion of Passenger Seats Sold on Intraregional Flights

2.4 International Internet Bandwidth by Regional Routes

2.5 International Internet Bandwidth Traffic for Selected Asia and the Pacific Economies

2.6 Principal Component Analysis for Aggregation

3.1 ARCII Dimensions and Indicators, Panel Principal Component Analysis-Derived Weights for Asia and the Pacific

3.2 Weights of Dimensions in the ARCII for Eurasia

3.3 Indicators in Eurasia and Customized Eurasia Index

4.1 Comparison of Alternative Denominators for ARCII

4.2 Ordinary Least Squares Regression and Lagrange Multiplier Tests Results

4.3 Regression Results from Ordinary Least Squares, Spatial Autoregressive Model, and Spatial Error Model 114

A1.1 Summary of the Enhanced ARCII Framework-Data Sources, Year Coverage, Indicator Formula 130

A1.2 ARCII Dimensions and Indicators-Baseline Framework

A2 Dimensional Weights by Region

A3 Dimensions and Indicators in the Enhanced ARCII Framework using Gross Domestic Product or Population as the Denominator

\section{FIGURES}

1.1 The Enhanced ARCII Framework

1.2 Overall ARCII and Dimensional Indexes-Asia and the Pacific

1.3 Enhanced ARCII Dimensional Indexes, 2018

1.4 Distribution of ARCII by Income Group-World, 2018

1.5 Indicator Contribution to the Overall ARCII Estimates-Asia and the Pacific, 2018

1.6 Addressing Downsides in ARCII Estimates

1.7 Enhanced ARCII Estimates, Economic Development, and Inequality

2.1 Asia-Pacific Regional Cooperation and Integration Index Baseline Framework

2.2 The Enhanced ARCII Framework

2.3 New Indicators Added to the ARCII Dimensions

2.4 Intra and Extraregional Goods Trade-Asia and the Pacific

2.5 Intraregional Goods Trade, 2018

2.6 Intraregional Trade Intensity, 2018

2.7 Distribution of Foreign Direct Investment Inflows 19

2.8 Intraregional Foreign Direct Investment, $2018 \quad 20$

2.9 Intraregional Cross-Border Equity and Bond Liabilities, 2018 
2.10 Pair-wise Dispersion of Deposit Rates

2.11 Capital Account Openness: Chinn-Ito Index, 2018

2.12 Exchange Rate Correlation

2.13 Average Trade Complementarity Index, $2018 \quad 25$

2.14 Trade Concentration Index, 2018

2.15 Intraregional Intermediate Goods Trade, 2018

2.16 Value-Added Contributions 29

2.17 Ad-Valorem Trade Cost by Sector, 2018

2.18 Change in the Intraregional to World Average Trade Cost Ratio, 2006 versus 2018

2.19 Average Liner Shipping Bilateral Connectivity Index-Intraregional to World Ratio 33

2.20 Logistics Performance Index, 2018

2.21 Doing Business Index, $2020 \quad 36$

2.22 Outbound Migration Map, 2019

2.23 Intraregional Outbound Migration 38

2.24 Intraregional Tourists $\quad 39$

2.25 Intraregional Outward Remittances $\quad 40$

2.26 Cultural Proximity $\quad 41$

2.27 Intraregional Cultural Goods Trade $\quad 42$

2.28 Intraregional Trademark Applications 43

2.29 Free Trade Agreements Signed with Intraregional Economies, 2018

2.30 Bilateral Investment Treaties Signed with Intraregional Economies 46

2.31 Double Taxation Treaties Signed with Intraregional Economies 46

2.32 Number of Intergovernment Organizations Memberships 47

2.33 Embassy Presence in Intraregional Economies 48

2.34 Information and Communication Technology Intraregional Goods Trade 49

2.35 Research Outputs with Intraregional Collaboration $\quad 50$

2.36 Number of Intraregional Research Outputs in Asia and the Pacific 51

2.37 Number of Intraregional Patent Applications in Selected Asia and the Pacific Economies 52

2.38 Intraregional Patent Applications

2.39 Internet Penetration $\quad 53$

2.40 Internet Penetration for Selected Asia and Pacific Economies 54

2.41 Mobile Subscriptions $\quad 54$

2.42 Intraregional Internet Bandwidth $\quad 56$

2.43 Intraregional Environmental Goods Trade

2.44 Number of International Environmental Agreements Ratified, 2018

2.45 Ecological Footprint of Production $\quad 59$

2.46 Environmental Health Score, $2018 \quad 60$

2.47 Flowchart of ARCII Construction $\quad 62$

3.1 Overall ARCII and Dimensional Indexes-Asia and the Pacific 73

3.2 Dimensional Contribution to the ARCII in Asia and the Pacific 75

3.3 Overall ARCII and Dimensional Indexes-Asia and the Pacific 77

3.4 Regional Integration Index-Asia and the Pacific versus Other Regions 78

3.5 Enhanced ARCII Dimensional Indexes by Subregion 80

3.6 Enhanced ARCII Dimensional Indexes by Region 82

3.7 Contribution to Dimensional Indexes by Indicator-Asia and the Pacific 83

3.8 Distribution of ARCII by Income Group-World, 2018

3.9 Distribution of ARCII Dimensional Indexes by Income Group 86

3.10 Overall ARCII Estimates: Baseline versus Enhanced Framework 87 
3.11 ARCII Dimensional Indexes for Asia and the Pacific: Baseline versus Enhanced 88

3.12 Comparison of Baseline and Customized Eurasia Index, 2018

4.1 Identifying Bias in ARCII Estimation 96

4.2 Overall ARCII and Dimensional Indexes for Selected Economies, 2018

4.3 Enhanced ARCII Dimensional Scores with Gross Domestic Product or Population as Denominator 98

4.4 Overall ARCII in Selected Asian Economies, 2018

4.5 Distribution for Selected Indicators in ARCII Framework-World, $2018 \quad 100$

4.6 Distribution on Indicators in Trade and Investment Integration 102

4.7 ARCII Estimates by Region and Type of Normalization, $2018 \quad 103$

4.8 Economic Integration Indexes $\quad 105$

4.9 Economic Integration Indexes, by Region 105

4.10 Spatial Distribution of the ARCII in Asia and the Pacific, 2018

4.11 Addressing Spatial Autocorrelation 111

4.12 Results for Global Moran's I Statistic for the ARCII and Dimensional Subindexes 112

4.13 Comparison of ARCII Estimates, Actual versus Corrected, 2018

A1 Flowchart of ARCII Construction 126

A2 Economy-Level Regional Integration Indexes 139

\section{BOXES}

2.1 ADB's Strategy 2030 Operational Plan for Regional Cooperation and Integration 10 and Asia-Pacific Regional Cooperation and Integration Index

3.1 A Glance at ARCII Estimates for the Middle East 79

3.2 Measuring Regional Integration in Non-Regional Groupings: Asia-Pacific Economic Cooperation 92

4.1 Treating Extreme Values When Using Alternative Denominator in ARCII Indicators 101

A1 Applying Regression Imputation Method to Address Data Gaps 127 


\section{Foreword}

The journey to prosperity for the Asia and Pacific region has been driven by regional cooperation and integration $(\mathrm{RCl})$ for over five decades. Against this backdrop, $\mathrm{RCl}$ has been one of the seven operational priorities under Strategy 2030 of the Asian Development Bank (ADB), and core to ADB's mission to foster inclusive and sustainable growth in the region. $\mathrm{RCl}$ is a fundamental driver underlying $A D B$ 's investments and technical assistance support to its developing member countries. It is critical to ADB's development strategy to support recovery from the coronavirus disease (COVID-19) pandemic in the region by leveraging $\mathrm{RCl}$.

Generating and strengthening data and indicators on $\mathrm{RCl}$ is an essential starting point to inform $\mathrm{RCl}$ policies and guide strategic and coordinated action. From its inception, the Asia-Pacific Regional Cooperation and Integration Index (ARCII) has provided policy makers, practitioners, and researchers with key indicators to track the scale, mode, and pace of $\mathrm{RCl}$ in the region and enabled $\mathrm{ADB}$ to effectively leverage $\mathrm{RCl}$ as a development strategy. It is now a leading indicator of ADB's corporate results framework.

The widening ARCII framework introduced in this report helps economies identify opportunities and challenges for concerted action to achieve sustainable and inclusive growth by introducing several innovations, both conceptual and methodological. It captures trends that go beyond traditional areas of regional integration such as trade, investment, and institutional arrangements, expanding the range of economic activities from six to eight dimensions to include areas of digital connectivity and environmental cooperation. The new framework also introduces innovative indicators in other dimensions and gives individual economies the ability to adapt increasingly complex information to guide their own development strategies.

Acknowledgment in the expanded ARCIl of the transformative role of digitalization and the regional scope for tackling cross-border environmental concerns is particularly significant. It offers new opportunities to track how these two areas are driving change and impacting other economic trends. Digital platforms, whose presence in Asian economies has been accelerated in part by the COVID-19 pandemic, play a pivotal role in the growth of e-commerce, information exchanges, and the delivery of cross-border services. Alongside this technological advance, economies continue to work toward achieving sustainable growth by adapting practices that promote environmental cooperation.

The index also facilitates comparison with other regions and cooperation with institutions across the world that have built similar measures of regional integration. Estimates show, for example, that Asia's regional integration in technology and digital connectivity remains ahead globally, while progress in trade and investment activity, better infrastructure, and improved technology transfers are particularly encouraging. However, significant scope exists to improve performance in money and finance and institutional arrangements. Among the next steps in its evolution, the index will reflect global linkages and the potential role of regional integration in supporting globalization. As coverage grows from 158 to 173 economies, there is also scope for further development in research to evaluate the impact of regional integration on multiple areas, from income inequality to inclusive growth and income convergence. 
Developing better metrics helps researchers, practitioners, and policy makers weigh the costs and benefits of $\mathrm{RCl}-$ related policies in greater detail. The ARCII enhancement reflects the ADB's goal to improve the availability, quality, and consistency of data on $\mathrm{RCl}$. Of special note as the index evolves, methodological innovations are improving its adaptability and flexibility for small and less developed economies. Together with other advances featured in this report, these improvements will ensure the enhanced ARCII can comprehensively evaluate the individual progress of economies and adequately capture the substance of regional integration.

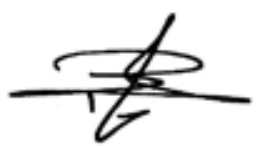

Yasuyuki Sawada

Chief Economist and Director General

Economic Research and Regional Cooperation Department

Asian Development Bank 


\section{Acknowledgments}

The publication was prepared by the Regional Cooperation and Integration Division (ERCl) of the Economic Research and Regional Cooperation Department (ERCD) of the Asian Development Bank (ADB), with support from Technical Assistance (TA) 9763: Enhancing the Measures of Regional Cooperation and Integration: The Asia-Pacific Regional Cooperation and Integration Index (ARCII).

Under the guidance of ERCI Director Cyn-Young Park, the preparation of this report was led by Rolando Avendano (economist, ADB), with the support of Mara Claire Tayag (senior economics officer, ADB), Clarisa Joy Flaminiano (TA-9763 consultant), and Lovely Ann Tolin (TA-9763 consultant); and inputs from Hyeon-Seung Huh (professor, Yonsei University).

The enhanced ARCII framework and estimates were based on the research led by Hyeon-Seung Huh, with advice from Cyn-Young Park and inputs from Racquel Claveria, Rolando Avendano, Clarisa Joy Flaminiano, and Lovely Ann Tolin. Bahodir Ganiev (TA-9763 consultant) provided inputs on subregional analysis. Kijin Kim (economist, ADB) provided helpful comments on the report and TA-9763 management support. ADB consultants from TA-9657 Asian Economic Integration: Building Knowledge for Policy Dialogue, 2018-2021 (Subproject 1) provided data support: Marife Bacate, Clemence Cruz, Pilar Dayag, Joshua Gapay, Ana Kristel Lapid, Ma. Concepcion Latoja, Paul Mariano, Dorothea Ramizo, and Dominique Sy. Data support and advice on the ADB Multiregional Input-Output Tables was provided by Mahinthan J. Mariasingham from ERCD's Statistics and Data Innovation Unit and his team, Krizia Anne Garay and Angelo Jose Lumba.

The report team is grateful for the helpful feedback provided by participants at the ADB inception workshop on New Approaches to Measuring and Assessing Regional Cooperation and Integration held virtually on 16-17 April 2020: Alexander Chirmiciu (European Bank for Reconstruction and Development), Yann Duval (United Nations Economic and Social Commission for Asia and the Pacific or UNESCAP), Janos Ferencz (Organisation for Economic Co-operation and Development or OECD), Behrooz Gharleghi (Dialogue of Civilizations Research Institute), Shigeru Kimura (Economic Research Institute for ASEAN and East Asia), Philippe De Lombaerde (United Nations University Institute on Comparative Regional Integration Studies), Syed Shakeel Shah (CAREC Institute), Dániel Vértesy (International Telecommunication Union); and ADB colleagues-Thomas Abell, Ronald Antonio Butiong, Yesim Elhan-Kayalar, Arjun Goswami, Smita Nakhooda, Safdar Parvez, Alfredo Perdiguero, Emma Veve, and Joseph E. Zveglich Jr. Comments were also provided by panelists at the Regional Cooperation and Integration Policy Open Dialogue (RCI-POD) Webinar No. 15: Measuring Regional Cooperation and IntegrationEarly Results and Extensions held on 26 October 2020: Hans Holzhacker (CAREC Institute), Alfredo Perdiguero (ADB), and Christopher MacCormac (ADB consultant). Helpful comments were also provided by Mia Mikic (UNESCAP), Witada Anukoonwattaka (UNESCAP), Nanno Mulder (Economic Commission for Latin America and the Caribbean), Antonella Liberatore (OECD), Paolo Giordano (Inter-American Development Bank), and Areef Suleman (Islamic Development Bank). 
The team is also grateful for internal ADB consultations done in October-December 2019 at the inception of the project with Zhinjun Cheng, Jin Lu, and Jie Qin (People's Republic of China Representative Office, Board of Directors); Rosalind McKenzie, Zulfia Khamitovna Karimova, Dorothea Lazaro, and Julius Irving Santos (East Asia Department); Saad Abdullah Paracha, Guoliang Wu, Tess del Rosario, Ronaldo Oblepias, Karlo Adriano, and Sarah Cueno (Central and West Asia Department); Rommel Flores (Pacific Department); Aileen Pangilinan and Jesusito Tranquilino (South Asia Department); Anthony Gill (Southeast Asia Department); Smita Luthra Nakhooda (Strategy, Policy and Partnerships Department); and Yuebin Zhang and Christopher McCormac (Sustainable Development and Climate Change Department-Regional Cooperation and Integration Thematic Group). The team also received valuable comments on the draft report from these ADB departments.

Rolando Avendano and Mara Claire Tayag coordinated the production of this report, with administrative support from Carol Ongchango (operations coordinator, ADB). Carol Ongchangco, Maria Criselda Aherrera (senior operations assistant, $A D B$ ), and Marilyn Parra (senior operations assistant, ADB) provided logistics support in organizing the workshops, launch events, and other seminars and briefings.

James Unwin edited the report. Joseph Manglicmot and Edith Creus typeset and produced the layout, and Erickson Mercado created the cover design. Monina Gamboa proofread the report, while Layla Yasmin Tanjutco handled the page proofs checking. Carol Ongchangco helped in proofreading the report. Support for printing and publishing was provided by the Logistics Management Unit (Printing) of ADB's Corporate Services Department and by the Publishing and Dissemination Unit of the Department of Communications. 


\section{Abbreviations}

$\begin{array}{ll}\text { ADB } & \text { Asian Development Bank } \\ \text { ADBI } & \text { Asian Development Bank Institute } \\ \text { AIC } & \text { Akaike Information Criterion } \\ \text { APEC } & \text { Asia-Pacific Economic Cooperation } \\ \text { ARCII } & \text { Asia-Pacific Regional Cooperation and Integration Index } \\ \text { ASEAN } & \text { Association of Southeast Asian Nations } \\ \text { CAREC } & \text { Central Asia Regional Economic Cooperation } \\ \text { DEA } & \text { Data Envelopment Analysis } \\ \text { DESTA } & \text { Design of Trade Agreements } \\ \text { EU } & \text { European Union } \\ \text { FDI } & \text { foreign direct investment } \\ \text { FTA } & \text { free trade agreement } \\ \text { GDP } & \text { gross domestic product } \\ \text { GEII } & \text { global economic integration index } \\ \text { GMS } & \text { Greater Mekong Subregion } \\ \text { ICT } & \text { information and communication technology } \\ \text { IEA } & \text { international environmental agreement } \\ \text { IMF } & \text { International Monetary Fund } \\ \text { Lao PDR } & \text { Lao People's Democratic Republic } \\ \text { LM } & \text { Lagrange Multiplier } \\ \text { LPI } & \text { Logistics Performance Index } \\ \text { LSBCI } & \text { liner shipping bilateral connectivity index } \\ \text { OECD } & \text { Organisation for Economic Co-operation and Development } \\ \text { OLS } & \text { ordinary least squares } \\ \text { PCA } & \text { principal component analysis } \\ \text { PRC } & \text { People's Republic of China } \\ \text { RVC } & \text { regional value chain } \\ \text { SASEC } & \text { South Asia Subregional Economic Cooperation } \\ \text { SEM } & \text { Spatial Error Model } \\ \text { UN } & \text { United Nations } \\ \text { UNCTAD } & \text { United Nations Conference on Trade and Development } \\ \text { UNEP } & \text { United Nations Environment Programme } \\ \text { UNESCAP } & \text { United Nations Economic and Social Commission for Asia and the Pacific } \\ \text { UNESCO } & \text { United Nations Educational, Scientific and Cultural Organization } \\ \text { US } & \text { United States } \\ \text { WDI } & \text { World Development Indicators } \\ \text { WIPO } & \text { World Intellectual Property Organization } \\ \text { WTO } & \end{array}$




\section{Highlights}

- Regional cooperation and integration is a multifaceted and multidimensional process in which neighboring economies expand linkages and coordinate policies to attain common objectives. Progress in this regard has been pivotal in Asia and the Pacific to improving economic growth and social inclusion, and for reducing poverty and enhancing financial and institutional stability. Initiatives have therefore emerged to capture the increasingly complex dimensions of regional cooperation and integration, including in areas such as digitalization, health security, and environmental policy.

- As channels of regional cooperation and integration evolve, there is a need to review and strengthen the framework of the Asia-Pacific Regional Cooperation and Integration Index (ARCII). The enhanced ARCII framework aims at ensuring the index adequately captures the drivers and mechanisms of regional cooperation and integration as well as improving the availability, quality, and consistency of data. Improvements to the baseline ARCII draw in a wider range of factors involved in regional integration, with two new dimensions-measuring the contributions of digital connectivity and environmental cooperation-and new indicators included to better measure existing dimensions. The index coverage has been expanded from 158 to 173 economies and from 26 to 41 indicators. The framework will continue improving data coverage in underrepresented economies, including in the Pacific, and explore new indicators to strengthen its reliability.

- New dimensions and indicators added to the ARCII framework will better capture underlying dynamics in regional integration. Indicators on capital account openness and exchange rate interdependencies in the money and finance dimension, for example, can better highlight financial integration trends. For the regional value chain dimension, a new indicator on value-added contributions provides a useful gauge of economy participation. A new measure of intraregional passenger flight capacity adds to the infrastructure and connectivity dimension by portraying air transportation in more detail. And the institutional arrangements dimension has been expanded to capture participation in international intergovernment organizations. Inclusion of the two new dimensions reflects how technology and digital connectivity and efforts toward environmental collaboration help strengthen integration.

- Further innovations in the enhanced framework can improve the inclusiveness and applicability of ARCII as a measure of regional cooperation and integration. A novel feature is the flexibility to customize the index structure, which allows users to adapt the ARCII framework to their specific needs, improve the accuracy of underlying data, and develop in-depth analysis on specific dimensions. Examples on index customization for Eurasia and members of the Asia-Pacific Economic Cooperation (APEC) forum can be replicated for other economy groupings. Economies can tailor the ARCII framework to fit their needs and objectives. Capacity-building activities will be needed to help developing member countries to apply the ARCII framework befitting their economies and better inform their regional integration strategies. 
- The enhanced ARCII results show that regional integration trends in Asia remain positive. Updated estimates of overall ARCII for Asia and the Pacific show a gradual uptrend, with a moderate $7 \%$ increase from 2006 to 2018. ARCII 2018 estimates on Asia's trade and investment, regional value chains, people and social integration are equal to those of the European Union, while performance in the new technology and digital connectivity dimension - with a 44\% improvement between 2006 and 2018-is higher than that of the European Union for the same period. However, gaps remain in the money and finance dimension, where Asia's estimate is only half that of the European Union.

- Regional integration across Asian subregions continues to exhibit diverse performance, with Southeast Asia and East Asia reporting the highest overall regional integration. The largest subregional differences are in the trade and investment, infrastructure and connectivity, and the people and social integration dimensions. Subregional gaps in technology and digital connectivity and environmental cooperation dimension are less pronounced, reflecting the more borderless nature of such dimensions and integration efforts. Overall, South and Central Asian economies show the most scope for improvement across different dimensions of regional integration.

- Developments in the technology and digital connectivity dimension reflect Asia's rapid digital transformation, characterized by high internet traffic, wider digital access, and growing research collaboration. International internet bandwidth capacity within Asia reflects high traffic among economies, from 1.7 terabytes per second (Tbps) in 2010 to 41.5 Tbps in 2018. Trends in internet penetration show a steady increase over the last decade, with one in every two Asians gaining internet access in 2018 from one out of five in 2010. Asian economies have improved regional collaboration as shown by the steadily rising share of intraregional research outputs to total outputs produced, from 38\% in 2006 to $49 \%$ in 2018.

- The new environmental cooperation dimension suggests Asia's performance in this area is comparable to other developing regions, though the gap with Europe and North America remains substantial. Asia's environmental cooperation has increased gradually since 2006 with its level of efforts now close to threequarters of the European Union and North America, the top performing regions. Asia's trend may be induced by marginal improvements in intraregional environmental goods trade or environmental agreements ratified, while regional environmental health decreased. The ARCII will continue enriching this dimension with more accurate proxies for regional environmental cooperation.

- While the ARCII estimates are robust to analyze the trends and drivers of regional integration, its accuracy and interpretation may be refined. The report explores solutions that can provide nuanced analysis and facilitate the interpretation of ARCII results; in the case of small and less developed countries, for example. A new globalization index is being developed, using the enhanced ARCII as blueprint for providing a more complete synopsis of an economy's full economic integration profile, taking regional and nonregional channels separately into consideration. Also, spatial analysis can be applied to assess the influence of neighboring economies or location on an economy's level of regional integration.

- Looking forward, the ARCII will be utilized as a research tool to gain deeper understanding of the impact of economic integration on development outcomes. ARCIl estimates suggest that an economy's level of regional integration tends to be associated not only with income levels, but also with income inequality. This warrants further empirical analysis to understand the relationship between regional integration and development goals. The analysis can be extended to examine whether regional integration may contribute to income convergence among regional economies and to develop measures of efficiency on the potential of regional integration to drive economic development by constructing unbiased estimates of the impacts of regional integration. 


\section{Introduction}

Regional cooperation and integration describes the process in which neighboring economies expand linkages and coordinate policies among each other to attain common objectives. Progress in this regard has been pivotal to improving economic growth, financial stability, and social inclusion, and has been important for tackling poverty and enhancing institutional stability. Deeper regional integration can facilitate access to markets, improve resource allocation and regional productivity, while promoting other objectives such as political stability and greater security. Asia has taken significant steps toward regional integration, driven by trade and investment networks linked to global supply chains (Asian Development Bank [ADB] 2021).' Institutional arrangements have followed to support this market-driven and bottom-up process.

Initiatives have, therefore, emerged to improve measurement and capture the increasingly complex dimensions of regional cooperation and integration. Traditional approaches have aimed at capturing regional integration in areas such as trade, foreign direct investment, financial integration, regional value chains, migration, and institutional and social integration. In recent years, regional integration has also become predominant in other policy areas, including digitalization, health security, and environmental policy. As digital connectivity and infrastructure expands, the potential gains and implications for Asia are growing.

\section{An Enhanced Framework for Measuring Regional Cooperation and Integration}

The Asia-Pacific Regional Cooperation and Integration Index (ARCII) was introduced in 2017 (Huh and Park 2017; 2018) and then enhanced to respond to the need for improved measures of cooperation and integration in the region. The ARCII enhanced framework complements ADB's Strategy 2030, which includes fostering regional cooperation and integration among seven operational priorities to achieve a more prosperous, inclusive, resilient, and sustainable Asia and Pacific region (ADB 2018). The refinements also provide quantifiable measures of ADB's Regional Cooperation and Integration Operational Plan's strategic operational priorities, including greater and higherquality connectivity among economies, expanded trade and investment opportunities, and increased and diversified regional public goods (ADB 2019).

The new framework introduces several innovations. First, it improves the coverage and data quality of the index by expanding from 158 to 173 economies, including a new region, the Middle East, and filling data gaps for a number of economies. Second, as presented in Chapter 2, it enhances the six-dimensional framework to include two new dimensions for assessing regional integration: technology and digital connectivity and environmental cooperation

Asia refers to the 48 ADB members in Asia and the Pacific. It includes Australia, Japan, and New Zealand, in addition to the 45 developing member economies. It does not include Niue due to limited data availability. 
(Figure 1.1). It also includes seven new indicators in existing dimensions, aiming to improve, for example the measurement of financial integration (through exchange rate interdependencies and capital account openness), the movement of people (measuring intraregional air transportation), and regional value chains (including a trade in value added indicator). The framework is also expanded from 26 to 41 indicators. Third, building on years of policy use and research, it proposes alternatives to address the potential downsides in the measurement approach and suggests areas for improvement, in particular, for subregional analysis.

Figure 1.1: The Enhanced ARCII Framework

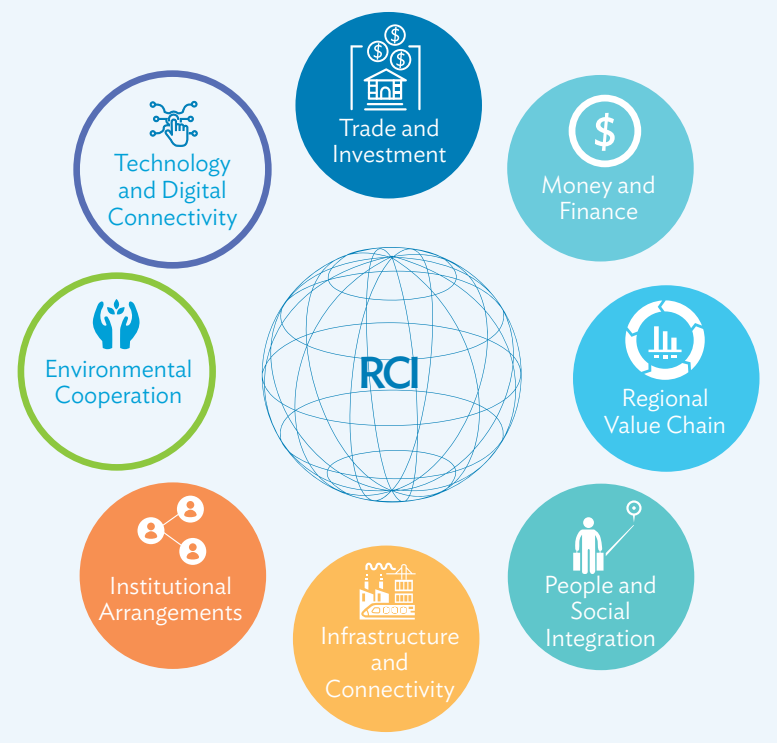

$\mathrm{ARCII}=$ Asia-Pacific Regional Cooperation and Integration Index, $\mathrm{RCI}$ = regional cooperation and integration .

Source: Asian Development Bank.

\section{Trends in Regional Integration in Asia and the Pacific}

The enhanced ARCII estimates for Asia indicate that the trajectory of regional integration in Asia remains stable over time, as presented in Chapter 3. The increase is due mainly to progress in trade and investment activity, better infrastructure, and improved technology transfer and digital connectivity within the region (Figure 1.2). Improvements in the technology and digital connectivity dimension reflect the region's digital transformation. Asia's demand for international bandwidth grew at a 53\% annual rate from 2014 to 2018, the highest among all regions. Asia scores highly in the people and social integration and regional value chain dimensions, whereas institutional arrangements integration remains low.

Asia's dimensional indexes in trade and investment, regional value chains, and people and social integration are high and equal to those of the European Union (Figure 1.3, panel a). Asia's integration levels in some dimensions remain low relative to other regions, including for the money and finance and institutional arrangements dimensions. In contrast, the region's performance in technology and digital connectivity dimension is the highest among all regions. The Middle East region, included for the first time in the framework, shows comparable integration to other emerging regions, while regional integration indexes in Africa and, to some extent, Latin America are lower across most dimensions. 
Figure 1.2: Overall ARCII and Dimensional Indexes-Asia and the Pacific

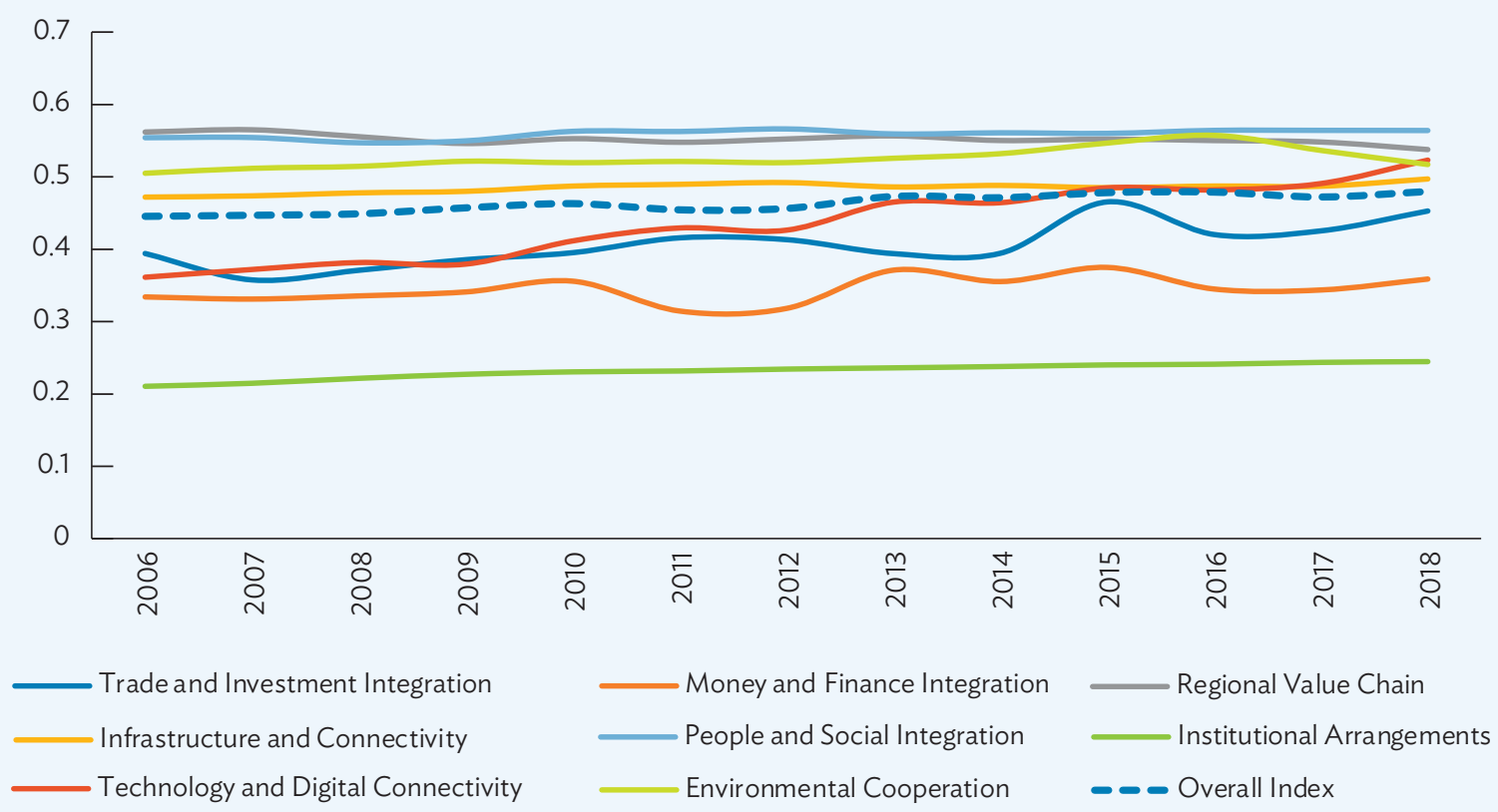

ARCII = Asia-Pacific Regional Cooperation and Integration Index.

Notes: Worldwide normalization is used for all estimations, where the indicators are normalized using global maximum and minimum values across all regions. Higher values denote greater regional integration.

Source: Asian Development Bank. Asia-Pacific Regional Cooperation and Integration Index Database. https://aric.adb.org/database/ arcii (accessed May 2021).

Within subregions in Asia, Southeast Asia and East Asia report overall the highest integration indexes (Figure 1.3, panel b). The largest subregional differences are in the people and social integration dimension, while gaps between subregions in trade and investment and infrastructure and connectivity remain important. Subregional indexes in technology and digital connectivity and the environmental cooperation dimension are more convergent. Overall, South and Central Asian economies show the most scope for improvement across different dimensions of regional integration.

The enhanced ARCII results suggest that regional integration may increase with economic development. High-income countries, as measured by the World Bank income per capita classification, report considerably higher ARCII estimates, with an average index close to 0.6 against 0.4 for other income groups, suggesting a possible link between regional integration and economic development (Figure 1.4). Results also indicate different levels of dispersion among income groups, with high-income countries reporting greater variance in ARCIl estimates. Furthermore, indexes by dimension tend to increase with income per capita, particularly in the cases of money and finance, institutional arrangements, and environmental cooperation.

The enhanced ARCII framework also underscores the contributions of individual dimensions and indicators to the regional integration process (Figure 1.5). An important feature of the ARCII approach is that the relative contribution (or weights) of the dimensions and indicators that form the framework is determined by a principal component analysis (PCA). This approach uses the data structure and extracts maximum common information from individual indicators, shedding light on the driving factors explaining trends in dimensional and overall level of regional integration. 


\section{Figure 1.3: Enhanced ARCII Dimensional Indexes, 2018}

\section{(a) Dimensional Indexes by Region}

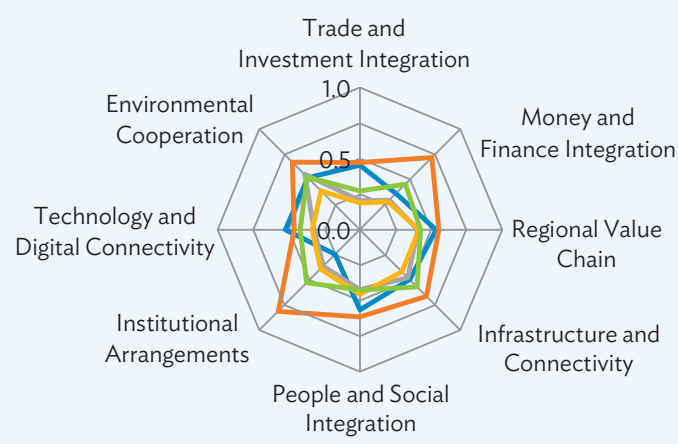

-Asia and the Pacific $-\mathrm{EU}$ Latin America
Africa (b) Dimensional Indexes by Subregion

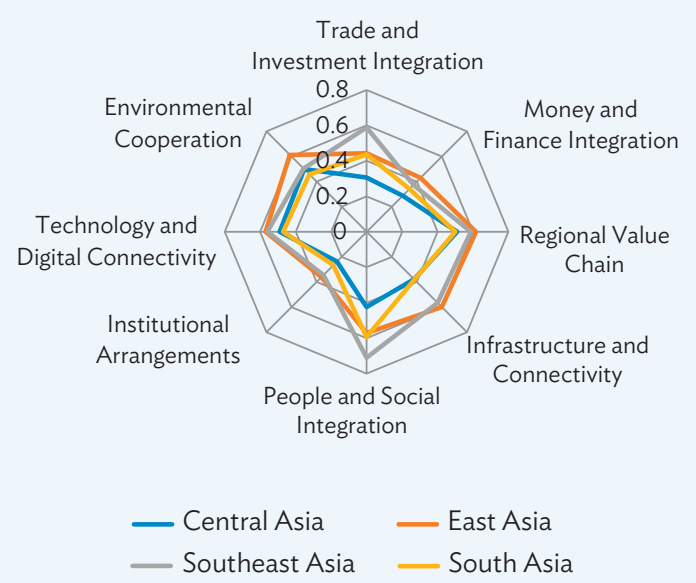

ARCII = Asia-Pacific Regional Cooperation and Integration Index, EU = European Union.

Notes: Worldwide normalization is used for all estimations, where the indicators are normalized using global maximum and minimum values across all regions. Higher values denote greater regional integration.

Source: Asian Development Bank. Asia-Pacific Regional Cooperation and Integration Index Database. https://aric.adb.org/database/ arcii (accessed May 2021).

While the ARCII estimates are robust to analyze the trends and drivers of regional integration, their accuracy and interpretation may be refined by addressing some methodological downsides (Figure 1.6). Chapter 4 explores solutions that can complement and provide nuanced analysis and facilitate the interpretation of ARCII results. For example, computation of the index can employ alternative indicators to address the issue of under or overestimation of regional integration, in particular, for small and less developed economies. Also, spatial analysis can be applied to take into account the influence that neighboring economies or location exerts on an economy's level of regional integration.

Figure 1.4: Distribution of ARCII by Income Group-World, 2018

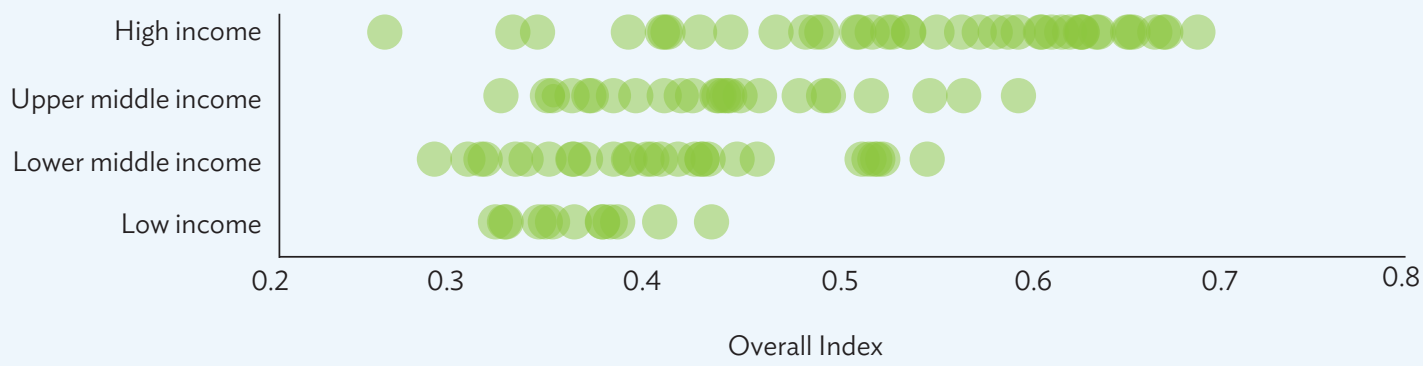

ARCII = Asia-Pacific Regional Cooperation and Integration Index.

Note: Higher values denote greater regional integration. Worldwide normalization is used for all estimations, where the indicators are normalized using global maximum and minimum values across all regions.

Source: Asian Development Bank. Asia-Pacific Regional Cooperation and Integration Index Database. https://aric.adb.org/database/ arcii (accessed May 2021). 
Figure 1.5: Indicator Contribution to the Overall ARCII Estimate-Asia and the Pacific, 2018

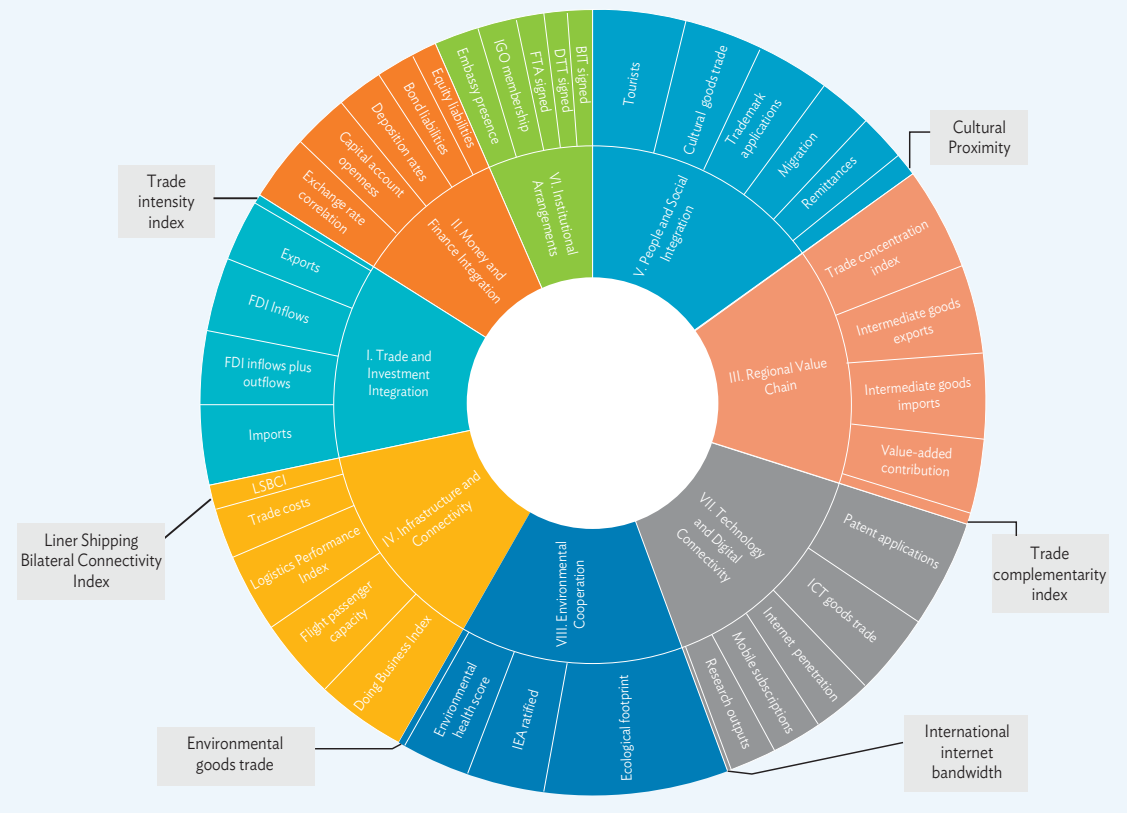

ARCII = Asia-Pacific Regional Cooperation and Integration Index, BIT = bilateral investment treaty, DTT = double taxation treaty, $\mathrm{FDI}=$ foreign direct investment, $\mathrm{FTA}=$ free trade agreement, ICT = information and communication technology, IEA = international environmental agreement, $\mathrm{LSBCl}=$ Liner Shipping Bilateral Connectivity Index.

Notes: The contribution of indicators to dimensional indexes is calculated for each region as the product of indicator's weight and indicator normalized value. The contribution of dimensional index to overall ARCIl estimate is calculated as the product of dimension's weight and dimension's normalized values.

Source: Asian Development Bank.

This may be important in cases where the ARCIl estimates are used to assess the impact of regional integration on development outcomes. Finally, a broader measure of integration, capturing both the regional and nonregional components is explored (Huh and Park 2021). Such measure could complement the ARCII and provide a complete picture of an economy's integration process.

Figure 1.6: Addressing Downsides in ARCII Estimates

Denominator Choice
- Alternative denominator
(GDP or population) could
address possible under and
overrepresentation of
economies.
Regional and Worldwide
Comparison
- Worldwide normalization
on regional and global
comparison could improve
comparability and
communication of results.

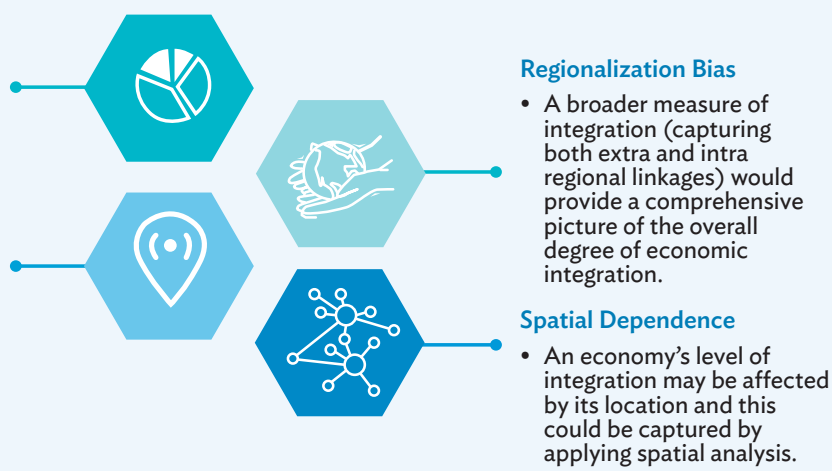

ARCII = Asia-Pacific Regional Cooperation and Integration Index .

Source: Asian Development Bank. 


\section{Looking Forward}

The enhancements introduced in the ARCII framework reflect the efforts of ADB to revisit the measures and ensure that the ARCII estimates accurately captures the current scenario. The framework will gradually continue improving the data coverage in underrepresented economies, including the Pacific subregion, and exploring other indicators that may improve the reliability of the index. The index also acknowledges the pivotal role of digitalization in transforming the nature of economic integration and the synergies between the environment and regional integration.

Looking forward, as presented in Chapter 5, the ARCII and globalization index will be utilized as research tools to gain deeper understanding of the impact of economic integration on development outcomes, from economic growth to income inequality and economic convergence. ARCII estimates stress that an economy's level of regional integration tends to be associated not only to income levels, but also with income inequality (Figure 1.7). This warrants further empirical analysis to understand the dynamics and construct unbiased estimates on the impacts of regional integration. The analysis can be extended further still to examine whether regional integration may contribute, for example, to income convergence among regional economies. It can also be used to develop measures of efficiency on the potential of regional integration to drive economic development.

Finally, the ARCII initiative will continue to provide knowledge sharing activities and materials. Capacity building activities with developing member countries will be implemented to assist economies in using the ARCII to measure regional integration. Economies can tailor the ARCII framework to fit their needs and objectives. Technical materials including manuals, data sets, and software codes will be accessible for this purpose. These activities will equip developing member countries to make the most of the ARCII framework and better inform their regional integration strategies.

\section{Figure 1.7: Enhanced ARCII Estimates, Economic Development, and Inequality}

(a) ARCII and GDP per Capita, 2018

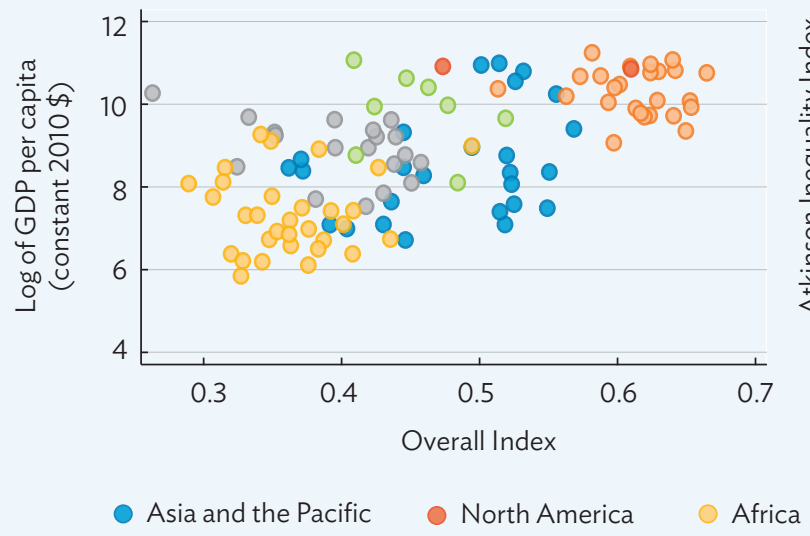

(b) ARCII and Income Inequality, 2018

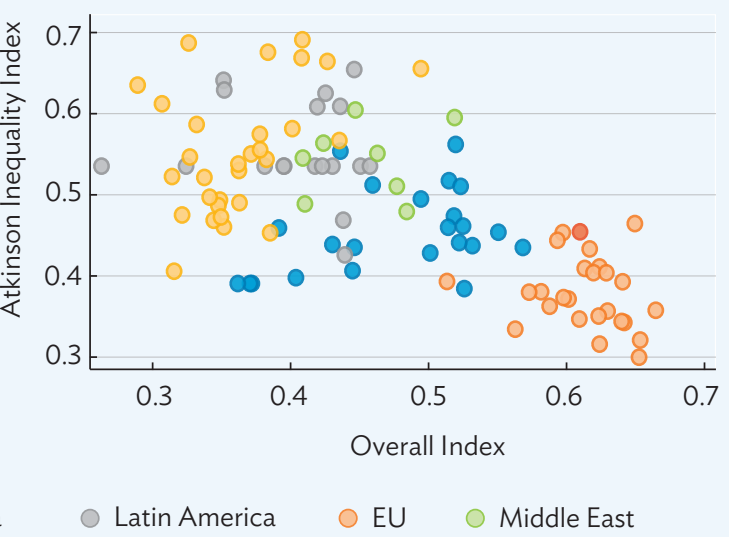

$\mathrm{ARCII}=$ Asia-Pacific Regional Cooperation and Integration Index, EU = European Union, GDP = gross domestic product.

Sources: ADB calculations using data from ADB. Asia-Pacific Regional Cooperation and Integration Index Database. https://aric. adb.org/database/arcii; World Bank. World Development Indicators. https://databank.worldbank.org/source/world-developmentindicators (all accessed May 2021). 


\section{References}

Asian Development Bank (ADB). 2018. Strategy 2030: Achieving a Prosperous, Inclusive, Resilient, and Sustainable Asia and the Pacific. Manila.

- 2019. Strategy 2030 Operational Plan for Priority 7: Fostering Regional Cooperation and Integration, 2019-2024. Manila.

_. 2021. Asian Economic Integration Report 2027: Making Digital Platforms Work for Asia and the Pacific. Manila. https://doi.org/10.22617/TCS210048-2.

Huh, H. S. and C. Y. Park. 2017. Asia-Pacific Regional Integration Index: Construction, Interpretation, and Comparison. ADB Economics Working Paper Series. No. 511. Manila: Asian Development Bank. https://ideas. repec.org/p/ris/adbewp/0511.html.

2018. Asia-Pacific Regional Integration Index: Construction, Interpretation, and Comparison. Journal of Asian Economics. 54 (C). pp. 22-38. https://doi.org/10.1016/j.asieco.2017.12.001.

- 2021. A New Index of Globalisation: Measuring Impacts of Integration on Economic Growth and Income Inequality. The World Economy. 44 (2). pp. 409-443. https://doi.org/10.1111/twec.12998. 


\section{About the Asia-Pacific Regional Cooperation and Integration Index}

The Asia-Pacific Regional Cooperation and Integration Index (ARCII) is a broad-based, multidimensional measure of regional integration. It was initially developed in 2017 and its methodology and applications gradually expanded (Huh and Park 2017a; 2018b; Park and Claveria 2018; Huh and Park 2021). The composite index measures progress on a set of relevant dimensions of regional integration, and identifies strengths and weaknesses within regional, subregional, and national contexts (Asian Development Bank [ADB] 2021). This chapter discusses the framework and methodology used to construct the index and presents a guide on the interpretation of the indicators to allow for a deeper understanding of ARCII.

\section{Evolution of the ARCII Framework}

\section{Baseline Structure of the Index}

In 2017, Huh and Park conceptualized and implemented a six-dimensional framework to construct a composite index that measures different aspects of regional integration. ${ }^{1}$ The main objective of producing the metric was to help countries better gauge the level of regional integration. The ARCII indexes first presented by Huh and Park (2017) are referred to in this report as the baseline index.

The ARCII baseline embodies six socioeconomic dimensions that are fundamental to regional integration: (i) trade and investment integration, (ii) money and finance integration, (iii) regional value chain, (iv) infrastructure and connectivity, (v) free movement of people, and (vi) institutional and social integration. The index makes use of 26 indicators to measure the different aspects of regional integration across these dimensions to calculate subindexes, then use these subindexes to compile the overall index (Huh and Park 2017a; 2018b). Out of the 26 indicators, 24 are bilateral data expressed as an economy's regional activity relative to its global activity. The ARCII, therefore, uses the most comprehensive bilateral set of available indicators of regional integration. Figure 2.1 illustrates the structure of the baseline index. Huh and Park (2017a) provides a more detailed discussion on the composition and data description. The index covers ADB member economies in Asia, which include 45 developing member economies along with Australia, Japan, and New Zealand, and five other regions: Africa, European Union, Latin America, Middle East, and Northern America. ${ }^{2}$ 
Figure 2.1: Asia-Pacific Regional Cooperation and Integration Index Baseline Framework
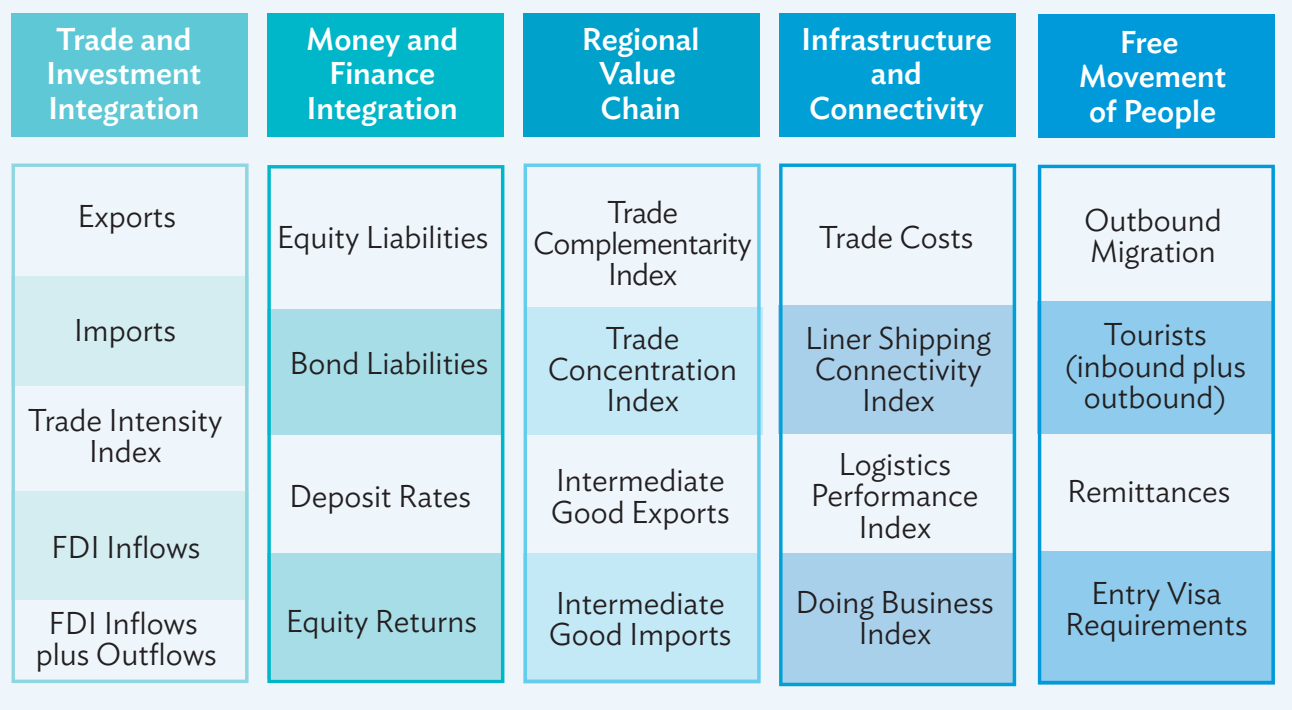

Institutional

and Social

Chain

Connectivity
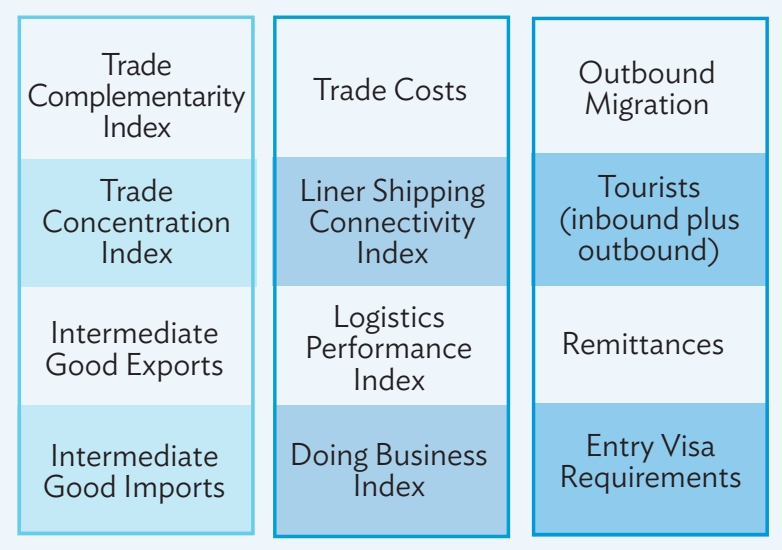

Integration

Intermediate Good Exports

Intermediate Good Imports

\begin{tabular}{|c|}
\hline Free Trade \\
Agreements \\
Signed \\
Embassy \\
Presence \\
Bilateral \\
Investment \\
Treaties Signed \\
Double Taxation \\
Treaties Signed \\
Cultural \\
Proximity \\
\hline
\end{tabular}

$\mathrm{FDI}=$ foreign direct investment

Source: Asian Development Bank.

\section{Motivation for the Enhanced Framework}

The uncertain global economic environment highlights the importance of monitoring regional dynamics and interdependence. ${ }^{3}$ Amid difficult conditions, the nature of regional integration is also rapidly changing (ADB 2019a). The digital technologies that are defining new forms of connectivity, including e-commerce, have made regional integration more complex and challenging to measure. The sharing of regional technology and collaboration in research and development increasingly drive innovation. And environmental cooperation is evolving through the inclusion of provisions in trade and investment agreements or trade in environmental goods.

As the channels of regional cooperation and integration evolve and expand, its impact needs to be reassessed continuously. Developing better regional cooperation and development measures allows researchers and policy makers to weigh the costs and benefits of integration-oriented policies in greater detail (De Lombaerde and Saucedo Acosta 2017; OECD 2019). ${ }^{4}$ In this light, the baseline ARCII framework has been enhanced to draw in an expanded range of factors involved in regional integration. Improvements include two new dimensions that measure the contributions of digital connectivity and environmental cooperation to the index and adding new indicators to existing dimensions. The main purpose of enhancing the ARCII framework is to improve the availability, quality, and consistency of data, and to ensure that the enhanced ARCII index adequately captures the role and mechanisms of regional cooperation and integration. These enhancements offer a comprehensive approach to track developments, particularly progress that is relevant ADB's Strategy 2030 and operational priorities (Box 2.1). The new framework builds on the baseline index to provide a more updated and accurate metric of regional integration.

This section is largely based on the highlights of the ARCIl inception workshop held in April 2020 (ADB 2020c).

Similar efforts to develop new approaches measuring progress in regional cooperation and integration include, among others, UNECA Africa Regional Integration Index (UNECA 2016; 2019), UNESCAP Digital and Sustainable Regional Integration Index (UNESCAP 2020), the European Bank for Reconstruction and Development regional integration monitoring system (Chirmiciu 2020), and DOC Institute Eurasia index (Gharleghi 2019). 


\section{Box 2.1: ADB's Strategy 2030 Operational Plan for Regional Cooperation and Integration and Asia-Pacific Regional Cooperation and Integration Index}

The Strategy 2030 of the Asian Development Bank (ADB) recognizes regional cooperation and integration as one of seven operational priorities, given its potential to promote growth, narrow development gaps, and increase productivity and employment. Three operational priorities guide ADB's approach to fostering OP7-as regional cooperation and integration is designated in the strategy. These are to promote: (i) greater and higher-quality connectivity between economies, (ii) expanded global and regional trade and investment opportunities, and (iii) increased and diversified regional public goods.

\section{Strategic Operational Priorities of Strategy 2030 Regional Cooperation and Integration and ARCII}

\section{OPERATIONAL APPROACHES}

- Multimodal transport and infrastructure connectivity

- Soft infrastructure for crossborder connectivity

- Renewable energy and sustainable transport
- Soft infrastructure for implementation of trade and investment agreements

- Economic corridors

- Regional financial cooperation
- Regional climate change mitigation and adaptation

- Environment and sustainable tourism

- Regional education and health services

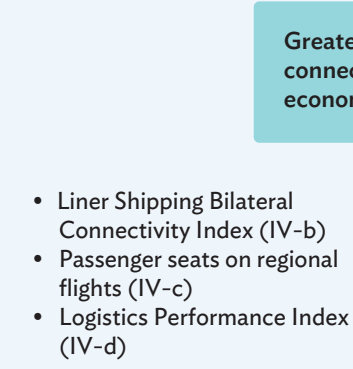

Greater and higher connectivity among conomies
Global and Regional Opportunities Expanded
- IEAs ratified (VIII-b)

- FTAs signed (VI-a)

- BITs signed (VI-b)

- DTTs signed (VI-c)

- IGO membership (VI-d)

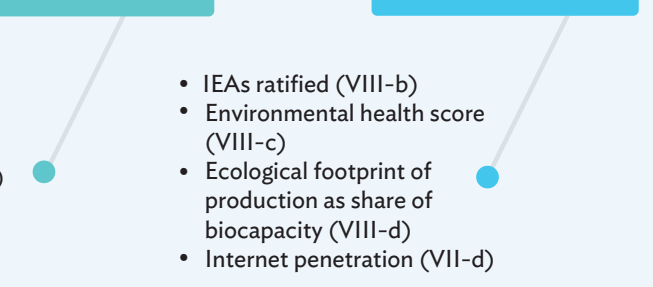

ARCII INDICATORS

ARCII = Asia-Pacific Regional Cooperation and Integration Index, BIT = bilateral investment treaty, DTT = double taxation treaty, FTA = free trade agreement, IEA = international environmental agreement, IGO = intergovernment organization.

Note: For a full list of indicators in the enhanced ARCII framework, refer to Table 2.1.

Source: Asian Development Bank.

Supporting ADB's operational work is a long-term objective of the enhanced framework of the Asia-Pacific Regional Cooperation and Integration Index (ARCII). Refinements to the index aim at offering a comprehensive approach to tracking progress on specific OP7 priorities. The new dimension on technology and digital connectivity could, for example, inform the use of soft infrastructure to improve cross-border connectivity (strategic operational priority 1), while multimodal transport can draw on better international flight metrics. Indicators reflecting participation in free trade agreements, investment and taxation treaties, and intergovernment initiatives can assist operational approaches on soft infrastructure (strategic operational priority 2). Indicators on the state of environment and membership of environmental agreements can complement initiatives to increase and diversify regional public goods (strategic operational priority 3 ). 


\section{Box 2.1 continued}

The ARCII is also among 10 key indicators of regional development progress in ADB's corporate results framework. While ADB uses a set of internationally comparable indicators, it is clear that no external framework, including the Sustainable Development Goal (SDG) framework, can fully reflect the goals of this operational priority. A customized version of the ARCII addresses this by reporting in the bank's annual Development Effectiveness Review. Proposed methodological innovations to the index also seek to improve its precision in measuring progress for small, developing countries (Chapter 4). Expanded economy coverage, new indicators, and the option of customizing to fit stakeholders' circumstances, aim to add to the index's utility and keep it aligned with ADB's overall strategy.

A broader ADB effort to measure progress in regional cooperation and integration is under way. ADB regional departments and subregional programs are also striving to improve their regional cooperation and integration metrics. Recent actions include:

- The Greater Mekong Subregion Statistical Database, established in 2017, has enriched data availability and comparability. This has involved improving data quality, working with national statistical offices to improve data consistency, strengthen database management, and institutionalize mechanisms for data production and dissemination. The Statistics in the Greater Mekong Subregion report presents subregional and sectoral data (e.g., on education, energy).

- The Pacific region faces challenges that limit the comparability of standard indicators. The enhanced ARCII framework, with its feature for index customization, can offer an opportunity to create a tailored metric to help the Pacific regional department track regional cooperation and integration in pertinent areas such as tourism, education, and fisheries.

- The Central Asia Regional Economic Cooperation Institute developed the CAREC Regional Integration Index (CRII) to monitor initiatives and shape policies in the subregion. Latest index estimates signal moderate progress in regional integration over the past 15 years. The Institute also publishes an annual report, the Corridor Performance Measurement and Monitoring (CPMM), which contains rich data on trade facilitation and trade costs.

- The South Asia Subregional Economic Cooperation program uses operational indicators (e.g., contract awards and disbursements) and applies a sectoral approach to measure regional cooperation and integration progress (e.g., transport, trade facilitation, energy).

Moving forward, the index aims to provide operationally relevant analysis of the impact of regional integration on development outcomes and inform policy and initiatives. The option to customize the index-along with capacity building among ADB's developing member countries-complements work on knowledge products and efforts to promote collaboration with external partners.

\section{References:}

Asian Development Bank. 2019. ADB Corporate Results Framework, 2019-2024. Manila. https://www.adb.org/sites/default/files/ institutional-document/504656/policy-paper-adb-results-framework-2019-2024-circulation-22-august.pdf.

- 2019. Strategy 2030 Operational Plan for Priority 7: Fostering Regional Cooperation and Integration, 2019-2024. https://doi. org/10.22617/SPR200023.

2020. New Approaches to Measuring and Assessing Regional Cooperation and Integration: Workshop Highlights. https://dx.doi. org/10.22617/TCS200310-2.

_. 2021. 2020 Development Effectiveness Review. Manila. http://dx.doi.org/10.22617/SGP210129-2.

Source: Asian Development Bank. 


\section{Major Enhancements to the Framework}

The baseline index structure was strengthened to accommodate new approaches to the measurement of regional cooperation and integration ( $\mathrm{RCl}$ ) in Asia. The six-dimensional baseline framework is further improved with the addition of two new dimensions: (i) technology and digital connectivity, and (ii) environmental cooperation, and reclassifying certain dimensions (such as combining people and social integration and having a separate dimension for institutional arrangements). To ensure that the ARCII dimensions adequately capture the underlying regional cooperation and integration dynamics, new indicators were also incorporated into existing dimensions. The enhanced system includes 41 indicators, and each dimension has either five or six indicators.

Updating the framework with new relevant indicators permits a better understanding of the role of technology and the environment in promoting a region's interconnectedness. The technology and digital connectivity dimension naturally respond to the growing role of digital technologies in economic activity, which had not been fully captured in other dimensions. It also aims to reflect regional progress in research and technological exchange. To further improve the index, the environmental cooperation dimension provides a basis for assessing performance in the context of regional cooperation by including information on trade in environmental goods, environmental agreements, ecological footprint, and environmental health scores (Figure 2.2).

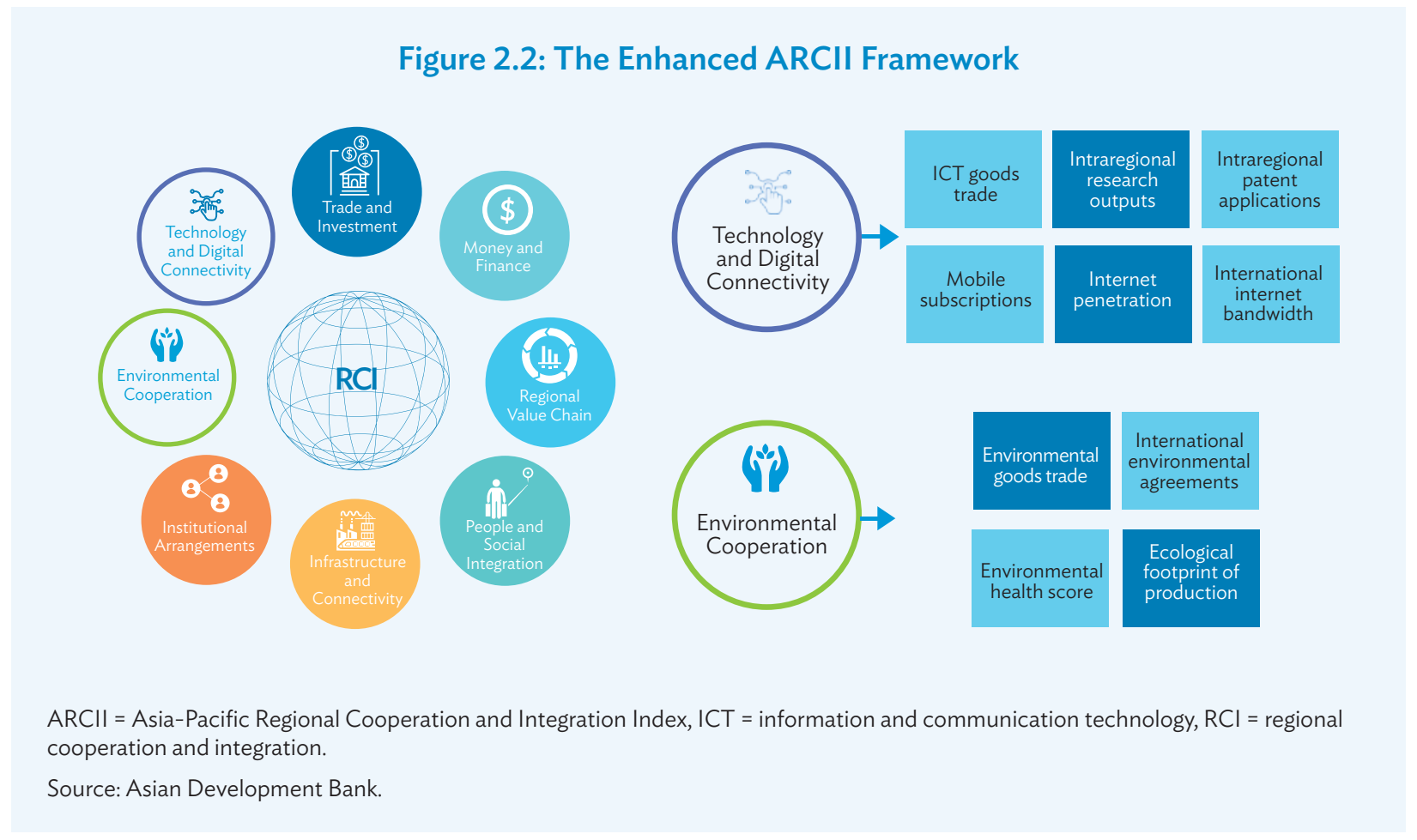

The new indicators added to existing dimensions help ensure that ARCII dimensions adequately capture underlying processes of regional cooperation and integration (Figure 2.3). Five changes stand out:

- The money and finance integration dimension now includes the Chinn-Ito Index (II-d), a widely used national indicator that measures capital account openness. Likewise, this dimension also now accounts for the effect of exchange rate stability (II-e) on regional integration as quantified by co-movements of exchange rates relative to the United States (US) dollar. 
- The regional value chain dimension incorporates a new indicator that measures the value-added contributed by regional trading partners (III-e) relative to contributions by all trading partners. With this indicator, the index can better gauge the performance and role of supply chains in regional integration.

- The infrastructure and connectivity dimension contains new information with the addition of an international flight passenger capacity (IV-c) indicator that reflects the role of air transport connectivity in allowing greater access to the regional and global economy.

- The people and social integration dimension, formerly classified as the free movement of people dimension in the baseline framework, now captures the contribution of exchanges in cultural goods (V-e) and trademark applications $(\mathbf{V}-\mathbf{f})$ to the process of regional integration.

- The institutional arrangements dimension, formerly categorized as the institutional and social integration dimension, incorporates an economy's membership in international intergovernment organizations (VI-d) to estimate how participation in global institutions affects regional integration efforts.

Figure 2.3: New Indicators Added to the ARCII Dimensions

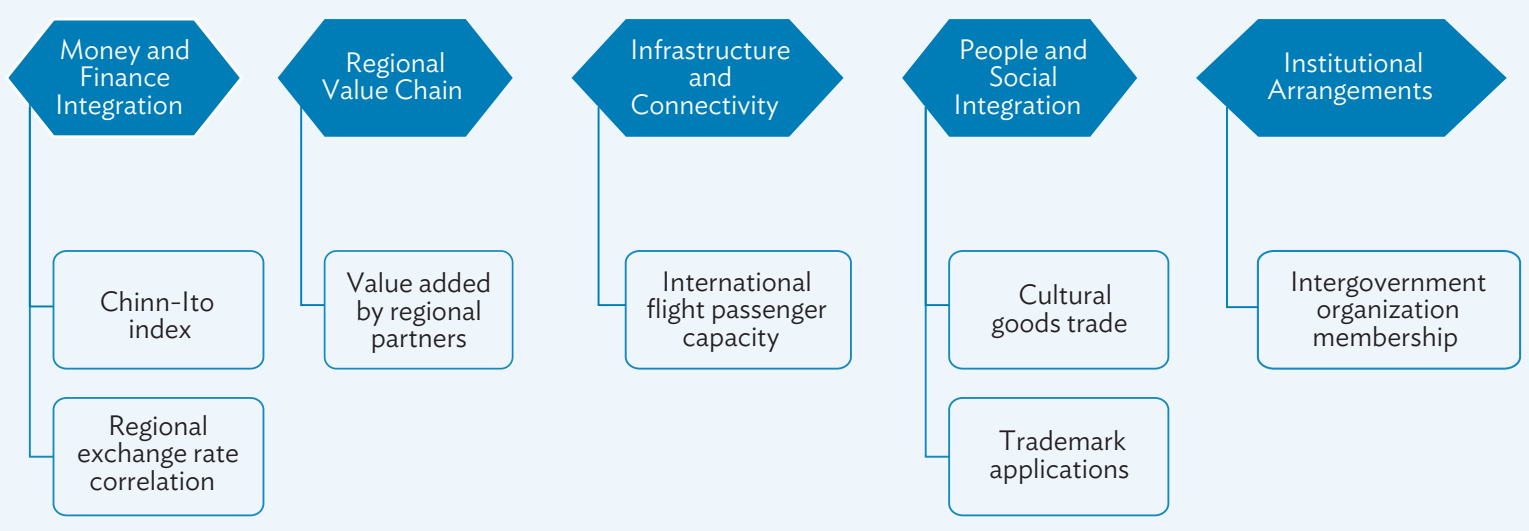

ARCII = Asia-Pacific Regional Cooperation and Integration Index .

Source: Asian Development Bank.

In parallel to the inclusion of new dimensions and indicators, data updates on the baseline indicators were also carried out. As an annual exercise, ADB updates the index whenever new information or data sources become available to ensure the integration of recent trends for indicators in each dimension. More specifically, data source and economy coverage were improved for several indicators in the trade and investment and regional value chain dimensions. The list below describes these changes:

- Available trade data for the Cook Islands from the United Nations Conference on Trade and Development (UNCTAD) database were used to improve economy coverage for the indicators on exports (I-a), imports (I-b), and trade intensity index (I-c).

- For the regional value chain dimension, the trade complementarity (III-a) and trade concentration index were updated. Previously, these were readily available from UNCTAD (Huh and Park 2018). However, the series was discontinued in 2013 for the complementarity index, and in 2014 for the concentration index. To update the series, these indexes were computed using data from the United Nations Commodity Trade Statistics Database (UN Comtrade) Database (three-digit product classification) following the 
formula used by UNCTAD. Trade complementarity is computed as the sum of the absolute value of the difference between the import category shares and the export shares of the economies under study, divided by two. Meanwhile, trade concentration is estimated as the Herfindahl-Hirschman Index (HHI) product concentration index for exports. This is derived as the sum of squared product shares in economy i's exports to economy $j$.

\section{A Closer Look at the Enhanced ARCII Dimensions and Indicators}

The enhanced framework consists of eight dimensions with 41 indicators. Table 2.1 enumerates all indicators included for each dimension, along with the source of data. The following section describes the sources and indicators of the enhanced ARCII framework, underscoring the importance of each indicator for the framework, presenting regional and global trends on the underlying data sources for each indicator, and a user-friendly description of the estimation and interpretation of the indicators. The purpose of this section is to offer a more in-depth insight of the enhanced ARCII framework and underlying data before presenting the main results of the ARCII (Chapter 3). This section provides a detailed discussion of current trends relating to regional cooperation and integration using raw data collected from their respective sources, as well as brief explanations of the general trends of the computed indicators prior to normalization.

Table 2.1: Dimensions and Indicators in the Enhanced ARCII Framework

\begin{tabular}{|c|c|c|c|}
\hline \multicolumn{2}{|l|}{ Dimension } & Indicator & Source of Raw Data \\
\hline \multirow[t]{5}{*}{$\begin{array}{l}\text { I. Trade and } \\
\text { Investment } \\
\text { Integration (5) }\end{array}$} & $\mathrm{I}-\mathrm{a}$ & $\begin{array}{l}\text { Proportion of intraregional goods exports to total } \\
\text { goods exports }\end{array}$ & $\begin{array}{l}\text { Direction of Trade, } \\
\text { International Monetary } \\
\text { Fund (IMF) }\end{array}$ \\
\hline & $\mathrm{I}-\mathrm{b}$ & $\begin{array}{l}\text { Proportion of intraregional goods imports to total } \\
\text { goods imports }\end{array}$ & Direction of Trade, IMF \\
\hline & $\mathrm{I}-\mathrm{C}$ & Intraregional trade intensity index & Direction of Trade, IMF \\
\hline & $\mathrm{I}-\mathrm{d}$ & $\begin{array}{l}\text { Proportion of intraregional foreign direct investment (FDI) } \\
\text { inflows to total FDI inflows }\end{array}$ & $\begin{array}{l}\text { Greenfield FDI: FDI } \\
\text { Markets; Mergers and } \\
\text { acquisitions (MT\$A) FDI: } \\
\text { Zephyr }\end{array}$ \\
\hline & I-e & $\begin{array}{l}\text { Proportion of intraregional FDI inflows plus outflows to } \\
\text { total FDI inflows plus outflows }\end{array}$ & $\begin{array}{l}\text { Greenfield FDI: FDI Markets; } \\
\text { Mergers and acquisitions } \\
\text { (MT\$A) FDI: Zephyr }\end{array}$ \\
\hline \multirow{5}{*}{$\begin{array}{l}\text { II. Money and } \\
\text { Finance } \\
\text { Integration (5) }\end{array}$} & $\mathrm{II}-\mathrm{a}$ & $\begin{array}{l}\text { Proportion of intraregional cross-border equity liabilities } \\
\text { to total cross-border equity liabilities }\end{array}$ & $\begin{array}{l}\text { Coordinated Portfolio } \\
\text { Investment Survey, IMF }\end{array}$ \\
\hline & $\mathrm{II}-\mathrm{b}$ & $\begin{array}{l}\text { Proportion of intraregional cross-border bond liabilities to } \\
\text { total cross-border bond liabilities }\end{array}$ & $\begin{array}{l}\text { Coordinated Portfolio } \\
\text { Investment Survey, IMF }\end{array}$ \\
\hline & $\|-c$ & $\begin{array}{l}\text { Pair-wise dispersion of deposit rates, averaged regionally } \\
\text { relative to the global average }\end{array}$ & $\begin{array}{l}\text { ADB using data from CEIC } \\
\text { Data and Haver Analytics }\end{array}$ \\
\hline & $I I-d^{*}$ & Capital account openness: Chinn-Ito Index (de jure) & $\begin{array}{l}\text { http://web.pdx.edu/ ito/ } \\
\text { chinn-ito_website.htm }\end{array}$ \\
\hline & II-e & $\begin{array}{l}\text { Correlations of exchange rates relative to the US dollar, } \\
\text { averaged regionally minus those averaged globally }\end{array}$ & $\begin{array}{l}\text { ADB using data from CEIC } \\
\text { Data and Haver Analytics }\end{array}$ \\
\hline $\begin{array}{l}\text { III. Regional Value } \\
\text { Chain (5) }\end{array}$ & $\mathrm{III}-\mathrm{a}$ & $\begin{array}{l}\text { Ratio between the averaged trade complementarity index } \\
\text { over regional trading partners and the averaged trade } \\
\text { complementarity index over all trading partners }\end{array}$ & UN Comtrade \\
\hline
\end{tabular}


Table 2.1 continued

\begin{tabular}{|c|c|c|c|}
\hline \multicolumn{2}{|l|}{ Dimension } & Indicator & Source of Raw Data \\
\hline & III-b & $\begin{array}{l}\text { Ratio between the averaged trade concentration index } \\
\text { over regional trading partners and the averaged trade } \\
\text { concentration index over all trading partners }\end{array}$ & UN Comtrade \\
\hline & III-C & $\begin{array}{l}\text { Proportion of intraregional intermediate goods exports to } \\
\text { total intraregional goods exports }\end{array}$ & UN Comtrade \\
\hline & III-d & $\begin{array}{l}\text { Proportion of intraregional intermediate goods imports to } \\
\text { total intraregional goods imports }\end{array}$ & UN Comtrade \\
\hline & III-e & $\begin{array}{l}\text { Ratio between the sum of the value-added contributed } \\
\text { by regional trading partners and that contributed by all } \\
\text { trading partners }\end{array}$ & $\begin{array}{l}\text { UNCTAD-Eora or } \\
\text { ADB-MRIOT }\end{array}$ \\
\hline \multirow[t]{5}{*}{$\begin{array}{l}\text { IV. Infrastructure } \\
\text { and Connectivity (5) }\end{array}$} & IV-a & $\begin{array}{l}\text { Ratio between the averaged trade cost over regional } \\
\text { trading partners and the averaged trade cost over all } \\
\text { trading partners }\end{array}$ & World Bank/UNESCAP \\
\hline & IV-b & $\begin{array}{l}\text { Ratio between the averaged liner shipping connectivity } \\
\text { index over regional trading partners and the averaged liner } \\
\text { shipping connectivity index over all trading partners }\end{array}$ & UNCTAD \\
\hline & IV-c & $\begin{array}{l}\text { Proportion of passenger seats sold on regional flights } \\
\text { relative to those sold on all international flights }\end{array}$ & ICAO \\
\hline & $I V-d^{*}$ & Logistics Performance index (overall) & World Bank \\
\hline & $I V-e^{*}$ & Doing Business Index (overall) & World Bank \\
\hline \multirow[t]{6}{*}{$\begin{array}{l}\text { V. People and Social } \\
\text { Integration (6) }\end{array}$} & $\mathrm{V}-\mathrm{a}$ & $\begin{array}{l}\text { Proportion of intraregional outbound migration to total } \\
\text { outbound migration }\end{array}$ & $\begin{array}{l}\text { United Nations Population } \\
\text { Division }\end{array}$ \\
\hline & $\mathrm{V}-\mathrm{b}$ & $\begin{array}{l}\text { Ratio of intraregional tourists to total tourists (inbound } \\
\text { plus outbound) }\end{array}$ & $\begin{array}{l}\text { World Trade Organization } \\
\text { (WTO) }\end{array}$ \\
\hline & $\mathrm{V}-\mathrm{c}$ & $\begin{array}{l}\text { Ratio of intraregional remittances to total remittances } \\
\text { (outbound) }\end{array}$ & World Bank \\
\hline & $V-d$ & $\begin{array}{l}\text { Cultural proximity with other economies in the region } \\
\text { relative to that with all other economies }\end{array}$ & $\begin{array}{l}\text { Centre d'Etudes } \\
\text { Prospectives et } \\
\text { d'Informations } \\
\text { Internationales (CEPII) }\end{array}$ \\
\hline & V-e & $\begin{array}{l}\text { Ratio of intraregional cultural goods trade (exports plus } \\
\text { imports) to total cultural goods trade }\end{array}$ & UNCTAD, UN Comtrade \\
\hline & $V-f$ & $\begin{array}{l}\text { Ratio of trademark applications made with intraregional } \\
\text { residents to trademark applications made with all } \\
\text { foreign residents }\end{array}$ & $\begin{array}{l}\text { World Intellectual Property } \\
\text { Organization, WDI }\end{array}$ \\
\hline \multirow[t]{5}{*}{$\begin{array}{l}\text { VI. Institutional } \\
\text { Arrangements (5) }\end{array}$} & VI-a & $\begin{array}{l}\text { Proportion of intraregional economies that have signed } \\
\text { free trade agreements with }\end{array}$ & $\begin{array}{l}\text { Design of Trade Agreements } \\
\text { (DESTA) }\end{array}$ \\
\hline & VI-b & $\begin{array}{l}\text { Proportion of intraregional economies that have signed } \\
\text { bilateral investment treaties with }\end{array}$ & UNCTAD, DESTA \\
\hline & $\mathrm{VI}-\mathrm{c}$ & $\begin{array}{l}\text { Proportion of intraregional economies that have signed } \\
\text { double taxation treaties with }\end{array}$ & UNCTAD \\
\hline & $V I-d^{*}$ & $\begin{array}{l}\text { Number of international intergovernment organizations in } \\
\text { which an economy is a member }\end{array}$ & The CIA World Factbook \\
\hline & VI-e & $\begin{array}{l}\text { Proportion of intraregional economies that have } \\
\text { an embassy }\end{array}$ & $\begin{array}{l}\text { Huh (2020) based on } \\
\text { The Europa World Year Book }\end{array}$ \\
\hline
\end{tabular}


Table 2.1 continued

\begin{tabular}{|c|c|c|c|}
\hline \multicolumn{2}{|l|}{ Dimension } & Indicator & Source of Raw Data \\
\hline \multirow{6}{*}{$\begin{array}{l}\text { VII. Technology } \\
\text { and Digital } \\
\text { Connectivity (6) }\end{array}$} & VII-a & $\begin{array}{l}\text { Proportion of intraregional ICT goods trade (exports plus } \\
\text { imports) to total ICT goods trade }\end{array}$ & UNCTAD, UN Comtrade \\
\hline & VII-b & $\begin{array}{l}\text { Proportion of research outputs with intraregional } \\
\text { collaborators relative to research outputs with all } \\
\text { international collaborators }\end{array}$ & $\begin{array}{l}\text { Huh (2020), based on Web } \\
\text { of Science data }\end{array}$ \\
\hline & VII-c & $\begin{array}{l}\text { Proportion of patent applications made with intraregional } \\
\text { residents to patent applications made with all } \\
\text { foreign residents }\end{array}$ & $\begin{array}{l}\text { World Intellectual Property } \\
\text { Organization, WDI }\end{array}$ \\
\hline & VII- $d^{*}$ & Proportion of persons using the internet & $\begin{array}{l}\text { International } \\
\text { Telecommunication Union }\end{array}$ \\
\hline & VII-e* & Proportion of mobile subscriptions per 100 persons & $\begin{array}{l}\text { International } \\
\text { Telecommunication Union }\end{array}$ \\
\hline & VII-f* & International internet bandwidth & ITU/TeleGeography \\
\hline \multirow[t]{4}{*}{$\begin{array}{l}\text { VIII. Environmental } \\
\text { Cooperation (4) }\end{array}$} & VIII-a & $\begin{array}{l}\text { Proportion of intraregional environmental goods trade } \\
\text { (exports plus imports) to total intraregional goods trade }\end{array}$ & UN Comtrade \\
\hline & VIII-b* & $\begin{array}{l}\text { Number of international environmental } \\
\text { agreements ratified }\end{array}$ & The CIA World Factbook \\
\hline & VIII-c* & Environmental health score & $\begin{array}{l}\text { Yale Environmental } \\
\text { Performance Index }\end{array}$ \\
\hline & VIII-d* & $\begin{array}{l}\text { Ecological footprint of production as a share } \\
\text { of biocapacity }\end{array}$ & Global Footprint Network \\
\hline
\end{tabular}

ARCII = Asia-Pacific Regional Cooperation and Integration Index, ICAO = International Civil Aviation Organization, UNCTAD = United Nations Conference on Trade and Development, UNESCAP = United Nations Economic and Social Commission for Asia and the Pacific, UN Comtrade = United Nations Commodity Trade Statistics Database, US = United States, WDI = World Development Indicators.

Notes: Highlighted rows in green indicate new indicators and dimensions included in the enhanced ARCII framework. Indicators marked with an asterisk are national-level indicators.

Source: Asian Development Bank.

\section{Dimension I: Trade and Investment Integration}

Rising uncertainties in the global economic and trade policy environment highlight the need to strengthen regional trade and investment linkages. Deeper integration in trade and investment could be achieved through trade facilitation measures such as reducing tariffs and duties, minimizing import restraints and customs requirements, and developing cross-border infrastructure (ADB 2009), combined with implementing regional laws and regulations that give preferential treatment to contracting parties (Pangestu and Armstrong 2018).

Regional integration in trade and investment promotes freer flow of goods, labor, and capital, which in turn, increases trade in goods as well as investment among regional trading partners. The ARCII reflects the level of regional integration in this dimension by including five indicators that capture the intensity of regional goods trade (i.e., exports, imports) and foreign direct investment. All indicators in this dimension are derived from bilateral data sets, with complete data from 2006 to 2018. 


\section{Trade in Goods}

\section{Indicators}

I-a: Proportion of intraregional goods exports to total goods exports

I-b: Proportion of intraregional goods imports to total goods imports

I-c: Intraregional trade intensity index

Asia's intraregional share in goods has grown over time, from approximately 40\% in 1980 to 57\% in 2019 (Figure 2.4). This trend in trade in goods demonstrates deeper integration of economic activities in the region. Building on classic international trade theory, trade in goods is viewed as a substitute for mobility of factors of production, which could result into equalization of factor prices (i.e., wage rates, rent of capital) (Mussa 2000). Concomitantly, trade in goods could also manifest increasing regional integration efforts, which are often brought about by regional trade agreements-with fewer barriers to trade in favor of regional members, intraregional trade in goods is expected to increase.

In the ARCII, information on trade in goods was utilized to build three indicators that serve as a metric to measure regional integration in the trade and investment dimension. The first two indicators: I-a (proportion of intraregional goods exports to total goods exports) and I-b (proportion of intraregional goods imports to total goods imports), intends to measure the intensity of regional trade in goods. Based on the trends from indicators $\mathrm{I}-\mathrm{a}$ and I-b, imports and exports of goods tend to be highest in Europe. This is followed by Asia, whose regional trade in goods accounts for more than half of its total trade in goods. Within Asia's subregions, Oceania and the Pacific have the highest proportion of regional trade for exports and imports, respectively.

Figure 2.4: Intra and Extraregional Goods Trade-Asia and the Pacific (\$ billion)

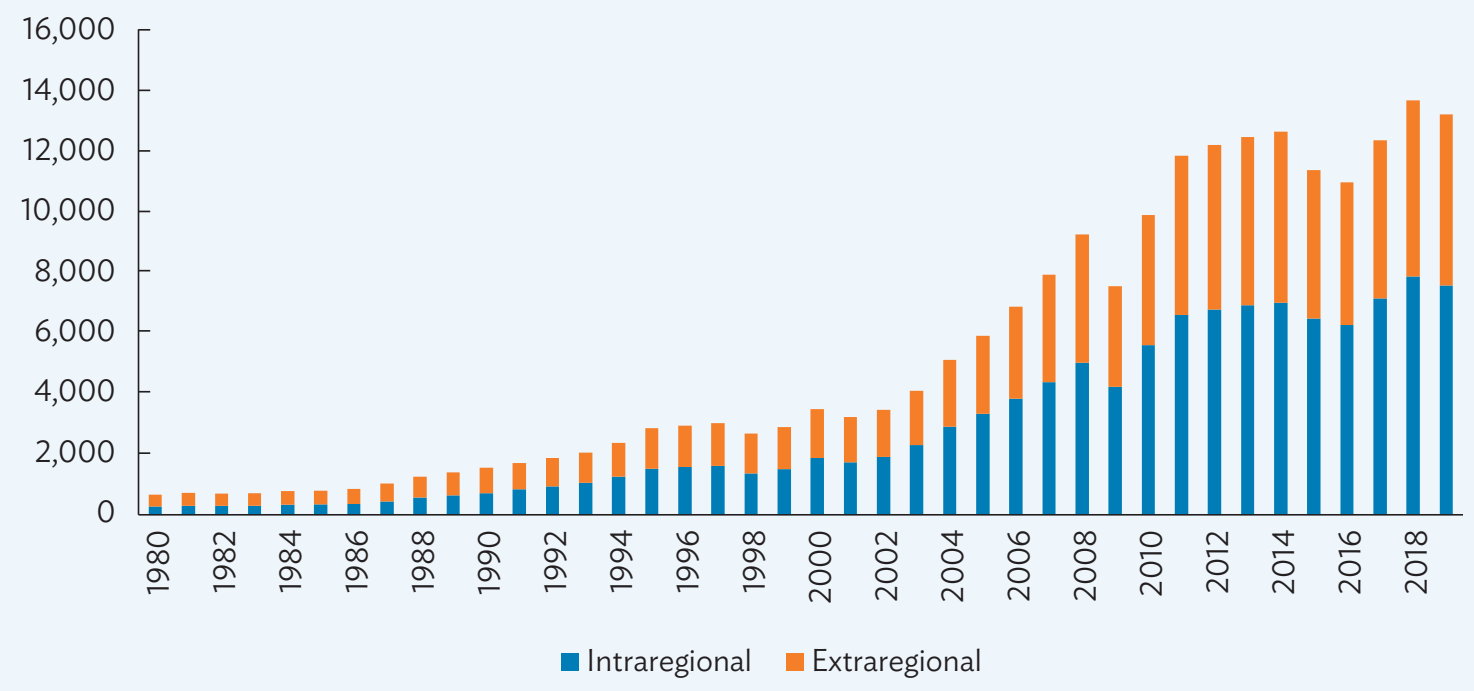

Source: Asian Development Bank calculations using data from the International Monetary Fund. Direction of Trade Statistics. http://data.imf.org/DOT (accessed May 2021). 
Figure 2.5: Intraregional Goods Trade, 2018

(\% of total trade)

(a) By region

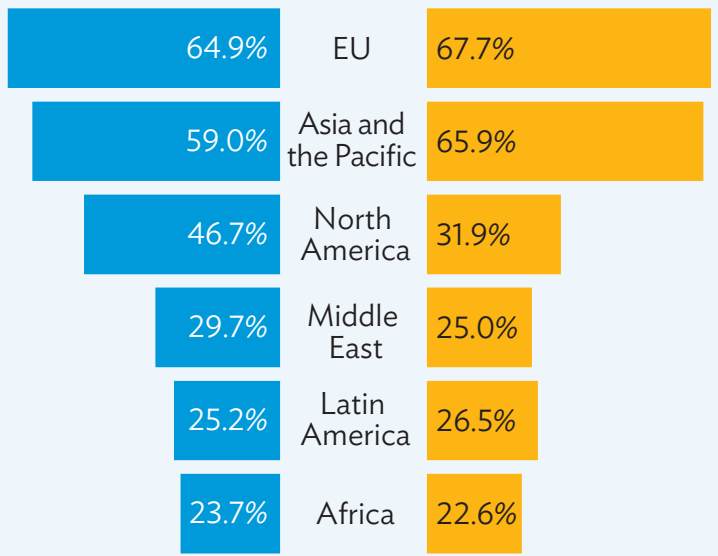

(b) By subregion

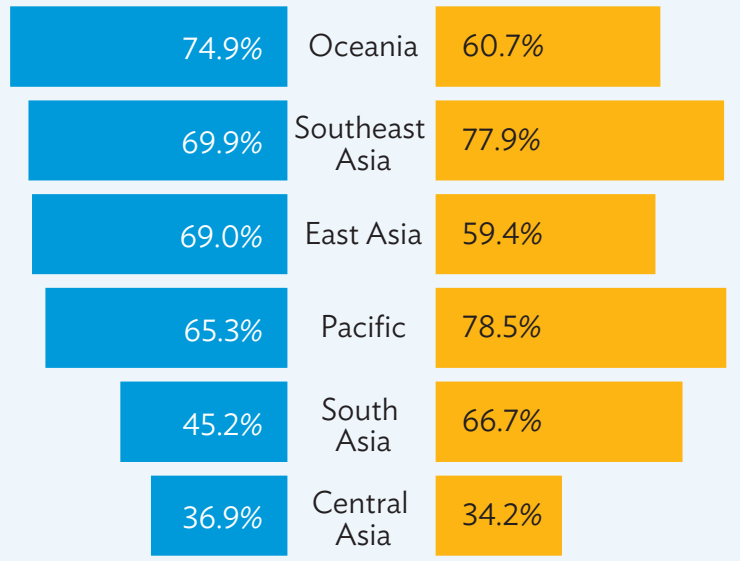

- Exports Imports

$\mathrm{EU}=$ European Union

Source: Asian Development Bank calculations using data from International Monetary Fund. Direction of Trade Statistics. http://data. imf.org/DOT (accessed August 2020).

Figure 2.6: Intraregional Trade Intensity, 2018

(average)

(a) By region

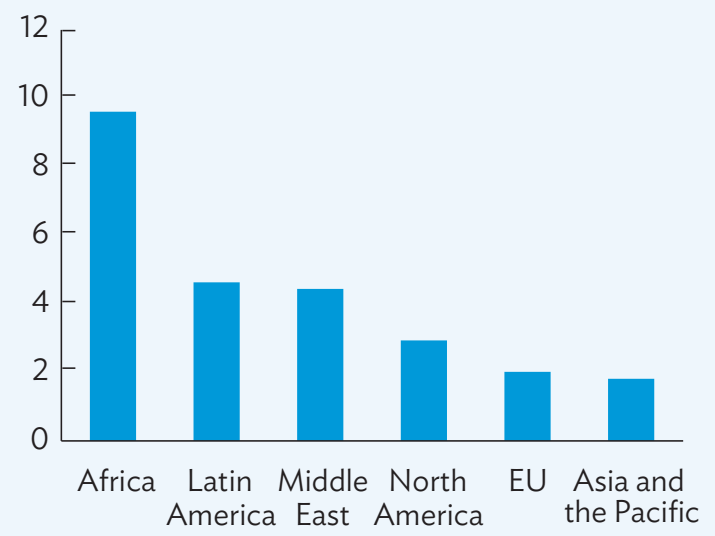

(b) By subregion

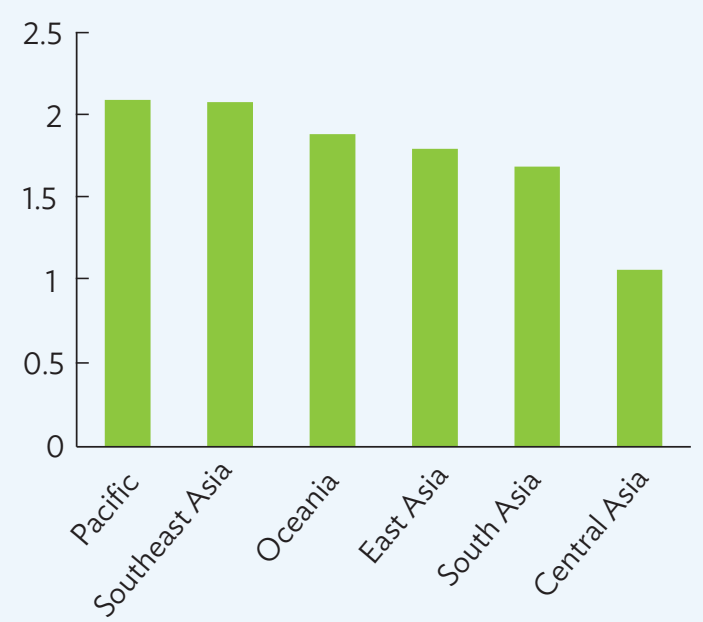

EU = European Union.

Source: Asian Development Bank calculations using data from International Monetary Fund. Direction of Trade Statistics. http://data. imf.org/DOT (accessed August 2020). 
The third indicator, which is indicator I-c (intraregional trade intensity index), determines whether economies trade more with their regional counterparts than the world on average. A higher value for indicators I-a, I-b, and I-c indicates a higher "intensity" of trade within a region. Trends from indicator I-c reveal Africa's high trade intensity, which is more than double that of other regions (Figure 2.6, panel a). On the other hand, Asia falls behind other regions in this indicator, which may be driven by Central Asia's low index estimate (Figure 2.6, panel b).

\section{Foreign Direct Investment}

\section{Indicators}

I-d: Proportion of intraregional FDI inflows to total FDI inflows

I-e: Proportion of intraregional FDI inflows plus outflows to total FDI inflows plus outflows

Foreign direct investment (FDI) refers to the category of international investment that reflects the objective of a resident entity in one economy obtaining a lasting interest in an enterprise resident in another economy. FDI plays an important role in Asian economies, as the region is a key destination of global FDI inflows. Except for Europe, global FDI inflows to Asia have been consistently larger compared to other regions (Figure 2.7, panel a) from 2003 to 2018. Within Asia, East Asia followed by Southeast Asia are the top destinations (Figure 2.7, panel a). Regional integration may affect FDI flows through different channels: (i) opening sectors to investment and aligning policies for investor treatment, and (ii) rationalization of production facilities by transnational corporations within a specific region, which in turn, allows countries to benefit from lower costs of intraregional trade (UNCTAD 2013).

Figure 2.7: Distribution of Foreign Direct Investment Inflows (\$ billion)
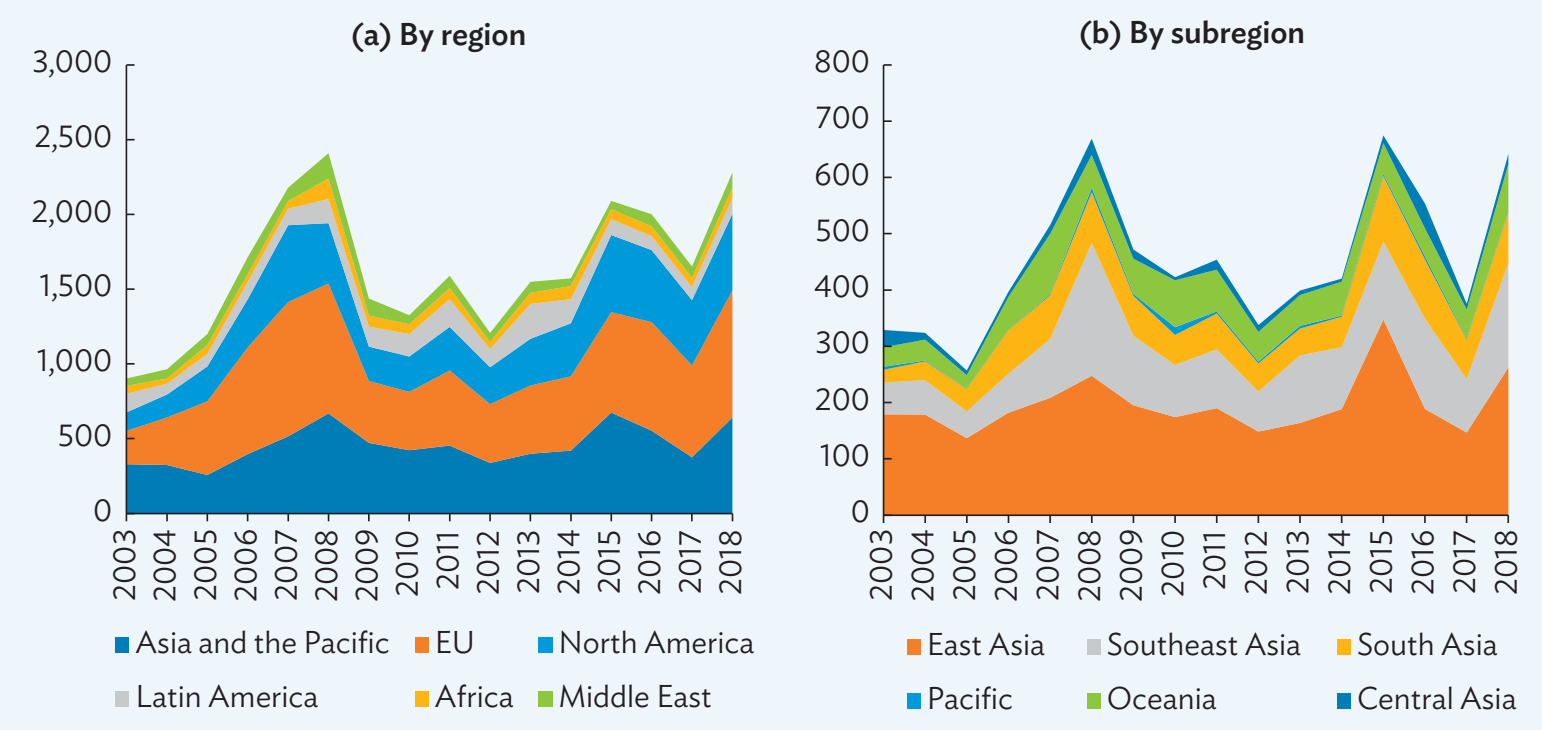

$\mathrm{EU}=$ European Union

Sources: Asian Development Bank calculations using data from Bureau van Dijk. Zephyr M\&A Database; and Financial Times. fDi Markets (both accessed November 2020). 
Figure 2.8: Intraregional Foreign Direct Investment, 2018

(\% of total FDI inflows plus outflows)

(a) By region

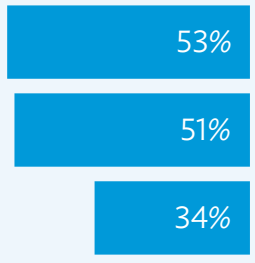

$$
\text { EU }
$$

Asia and the Pacific

34\% Middle East

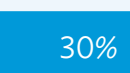

$30 \%$

$17 \%$

$11 \%$
North

America

Latin

America

Africa

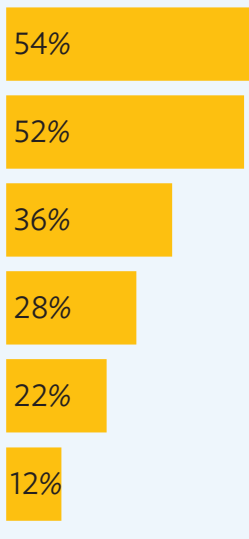

- Inflows (b) By subregion

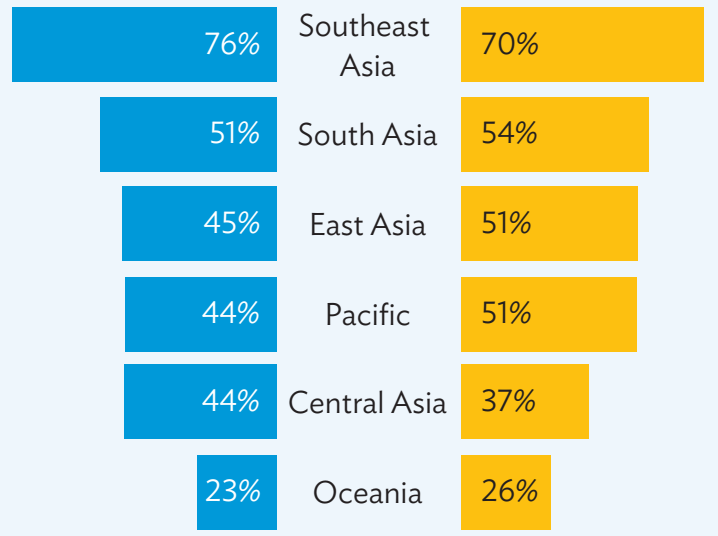

$\mathrm{EU}=$ European Union

Sources: Asian Development Bank calculations using data from Bureau van Dijk. Zephyr M\&A Database; and Financial Times. fDi Markets (both accessed November 2020).

In the ARCII, the FDI is measured by indicators I-d (ratio of intraregional FDI inflows to total FDI inflows), and I-e (ratio of intraregional FDI inflows plus outflows to total FDI inflows plus outflows). A higher share indicates a higher degree of regional investment integration. Trend from both indicators I-d and I-e show that the intensity of intraregional investment is highest in Europe, which is followed closely by Asia in 2018 (Figure 2.8, panel a). Within Asia's subregions, intraregional investment is most prominent in Southeast Asia, with more of its investments sourced from regional partners than from outside the region (Figure 2.8, panel b).

\section{Dimension II: Money and Finance Integration}

The global financial crisis in 2008-2009 exposed the risks and interconnectedness of the international financial system. In a landscape wherein money and finance are rapidly globalized, worsening conditions of global financial markets may have adverse implications on the availability of domestic funding, potentially dampening corporation profits and consequently impacting broader economic activity (Devereux et al. 2011). Regional financial integration can help mitigate this issue by providing an alternative financial resource that could be tapped when the global financial market is unavailable (ADB 2020b).

Deeper monetary and financial integration is exhibited by greater co-capital movements and financial synchronization within the region (United Nations Economic and Social Commission for Asia and the Pacific [UNESCAP] 2020). The ARCII measures the level of regional integration in this dimension by including four indicators. For this dimension, annual rates are computed as the average of daily rates. Data for bond, lending, and money market rates and for stock market returns are sourced from Bloomberg. Except for the Chinn-Ito Index, all indicators in this dimension are bilateral and available from 2006 to 2017; hence, missing data do not need to be imputed. 


\section{Cross-Border Liabilities: Equities and Bonds}

\section{Indicators}

II-a: Proportion of intraregional cross-border equity liabilities to total cross-border equity liabilities II-b: Proportion of intraregional cross-border bond liabilities to total cross-border bond liabilities

Cross-border financing includes financial arrangements between countries such as foreign loans and repatriable financial assets. Greater activity in cross-border financing reflects deeper financial integration, as it promotes bilateral financing activities, which could increase regional financial transactions.

To account for cross-border financing, the ARCII includes two indicators that contain information on cross-border equity (II-a) and bond (II-b) liabilities. A more reliable measure than liabilities would presumably be crossborder holdings of equities and bonds as the holder (creditor) generally knows the origin of securities held, whereas the issuer (debtor) may not know the residency of the holder. However, only 13 of 48 Asian economies report cross-border holdings of equities and bonds. In its Coordinated Portfolio Investment Survey (CPIS) database, the International Monetary Fund (IMF) reports cross-border liabilities for all countries (database participators as well as non-participators) using asset data reported by participants. ${ }^{5}$ This bilateral liability data, available for 40 Asian economies for equities and 39 economies for bonds, were used to construct the indicators.

Figure 2.9: Intraregional Cross-Border Equity and Bond Liabilities, 2018 (\% of total cross-border equity, bonds)

(a) By region

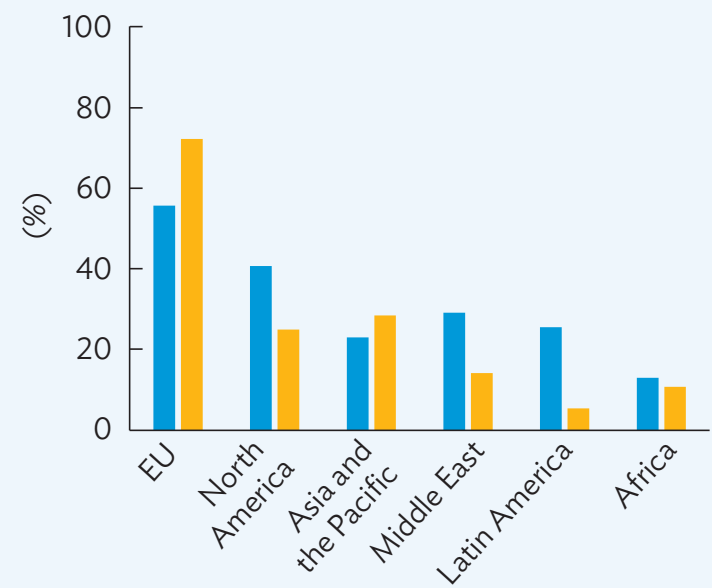

(b) By subregion

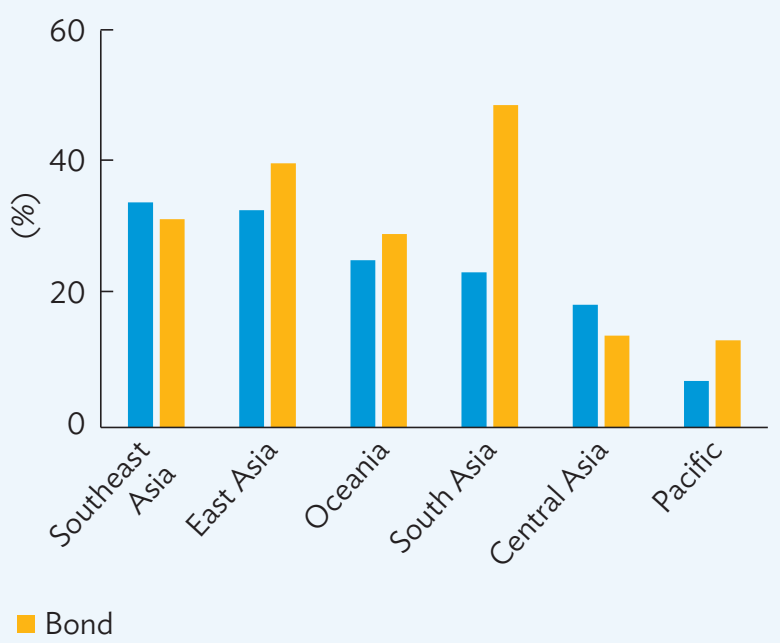

EU = European Union.

Source: Asian Development Bank calculations using data from International Monetary Fund. Coordinated Portfolio Investment Survey. http://cpis.imf.org (accessed August 2020). 
Trends from indicators II-a and II-b show that in 2018, Europe has the highest value of cross-border equity and bond liabilities sourced within the region. Europe is followed by Asia for equity liabilities, while for bond liabilities, it is followed by Latin America. Within Asia, South Asia tends to lead in terms of the intensity of intraregional bond liabilities, while Southeast Asia is at the top for equity liabilities.

\section{Deposit Rates}

\section{Indicators}

II-c: Pair-wise dispersion of deposit rates averaged regionally relative to the global average

Deposit rates pertain to the interest rates paid by financial institutions or banks to depositors. Huge variations in deposit rates across countries may imply fragmentation of financial services markets (Brosens 2017). Therefore, to achieve greater financial integration, synchronization in deposit rate movements is needed.

The indicator (II-c) used in the ARCII to measure this behavior was computed by taking the average of the intraregional and global pair-wise dispersion of deposit rates and dividing it by the global dispersion. A lower coefficient indicates a higher degree of convergence rates in the markets. Indicator II-c shows that Europe has the highest level of convergence among regions, as shown by the substantially low and falling dispersion in its deposit rates since 2006 (Figure 2.10, panel a). On the other hand, convergence in deposit rates is relatively lower in Asia. Trends within its subregions tend to be similar in most years, except for the noticeable spike in 2018 and 2019 experienced by all subregions except South Asia and Central Asia (Figure 2.10, panel b).

Figure 2.10: Pair-wise Dispersion of Deposit Rates

(regional over global)

(a) By region

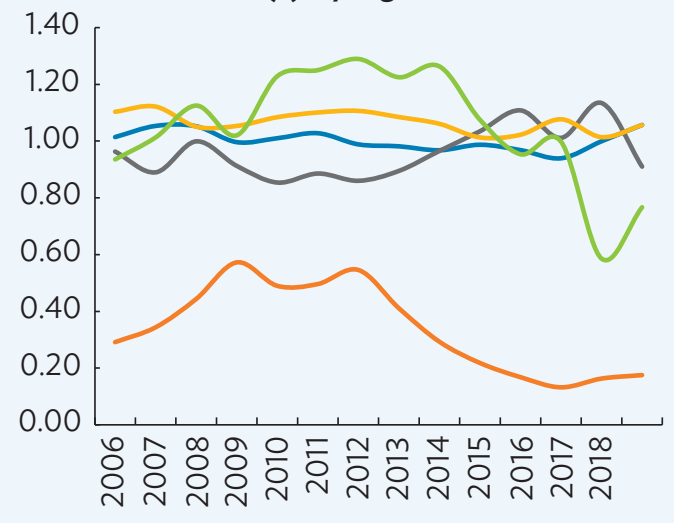

(b) By subregion

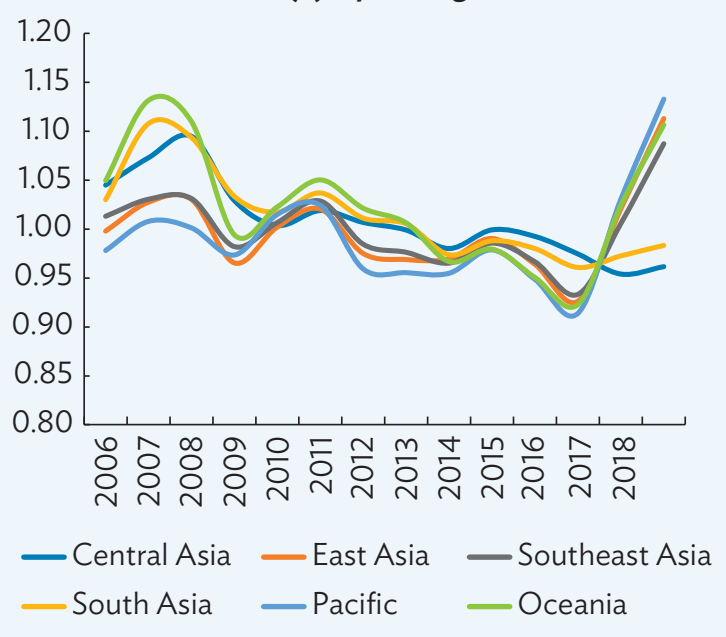

$\mathrm{EU}=$ European Union.

Source: Asian Development Bank calculations using data from CEIC Data and Haver Analytics. 


\section{Capital Account Openness}

\section{Indicators}

II-d: Capital account openness: Chinn-Ito Index (de jure)

Capital account openness creates a conducive environment for regional integration as it lifts administrative and legal restrictions on capital movements (Carmignani and Chowdhury 2008). Consequently, this could assist in increasing the flows of domestic and foreign investment. In the ARCII, the Chinn-Ito Index, measured at the national level, is used as a proxy for capital account openness and is added in the money and finance integration dimension. The index is based on the binary dummy variables that codify the tabulation of restrictions on cross-border financial transactions reported in the IMF's Annual Report on Exchange Arrangements and Exchange Restrictions (AREAER) (Chinn and Ito 2006). A higher value of the index signifies a more liberalized financial market, and in turn higher financial integration.

In 2018, the Chinn-Ito Index (II-d) shows that among regions, North America and Europe have the highest degree of capital account openness (Figure 2.11, panel a). On the other end, Africa and Asia's capital account openness are among the lowest. Within Asia, Oceania and East Asia have the highest indexes, while the rest of the subregions tend to be conservative, as demonstrated by their low index estimates (Figure 2.11, panel b).

Figure 2.11: Capital Account Openness: Chinn-Ito Index, 2018

(a) By region

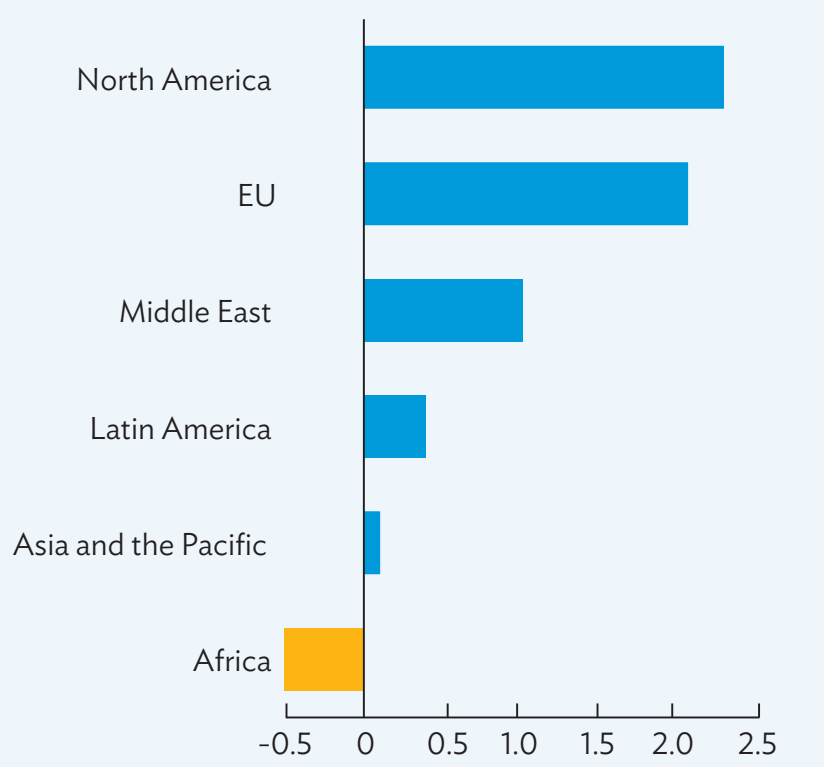

(b) By subregion

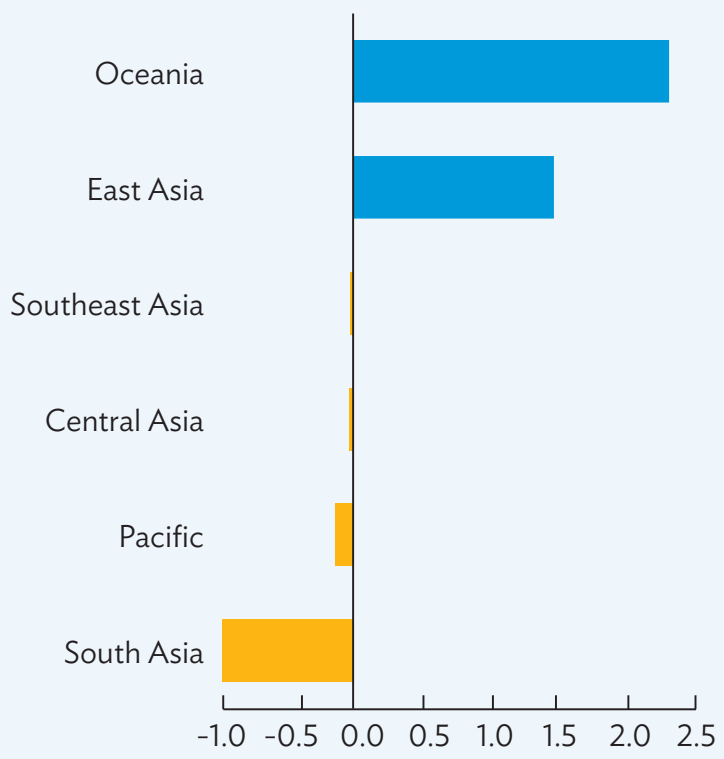

$\mathrm{EU}=$ European Union.

Source: Asian Development Bank calculations using data from Chinn-Ito Index. http://web.pdx.edu/ ito/Chinn-Ito_website.htm (accessed August 2020). 


\section{Exchange Rate Correlation}

\section{Indicators}

II-e: Correlations of exchange rates relative to the US dollar, averaged regionally minus those averaged globally

In reference to the European experience, regional financial arrangement for financial cooperation entails stabilization of the bilateral exchange rate system (Park 2002). As such, a stable exchange rate between currencies has been one of the criteria for convergence in establishing European monetary integration (Kang, Wang, and Yoon 2002). Exchange rates moving in a similar pattern is important as it allows the prices of goods and services between countries to become stable, which has implications on trade. Alternatively, when exchange rates between economies move in tandem, this may also mean that their dynamics is driven by the same economic fundamentals (Castrén and Mazzotta 2005).

The ARCII considers exchange rate co-movements as a measure of financial and monetary integration. In the construction of indicator II-e (correlations of exchange rates relative to the US dollar, averaged regionally minus those averaged globally), pair-wise correlations within a region were measured against the world. ${ }^{6} \mathrm{~A}$ higher value for this indicator suggests higher degree of monetary and financial integration. Trends from indicator II-e shows that intraregional correlation of exchange rates relative to all economies in the world is highest in Europe in 2006 and 2018 (Figure 2.12, panel a). In the case of Asia, only a marginal difference between regional and global correlations of exchange rates is observed in the same period. Within Asian subregions, exchange rate synchronization appears to have strengthened since 2006, considering that most subregions had higher intraregional correlations than worldwide correlations in 2018 (Figure 2.12, panel b).

Figure 2.12: Exchange Rate Correlation

$$
\text { (regional minus global) }
$$

(a) By region

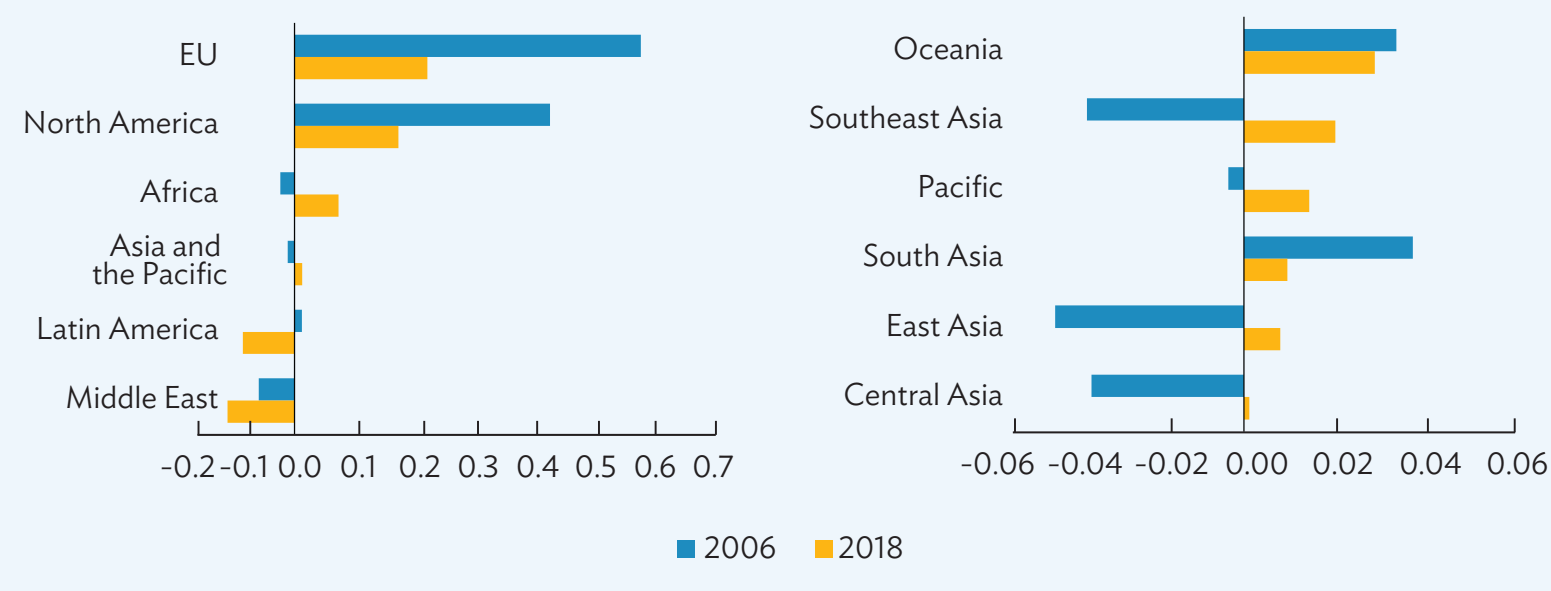

$\mathrm{EU}=$ European Union.

Source: Asian Development Bank calculations using data from Bloomberg, CEIC Data, and Haver Analytics.

This indicator must be interpreted with caution as some regional groups are more prone to use pegged exchange rate regimes. For instance, in the Pacific, eight out of the 14 economies use the currency of another economy (e.g., Australia, New Zealand, and the US), while the other four maintain pegs with a basket of currencies. 


\section{Dimension III: Regional Value Chain}

Regional value chains (RVCs) are regarded as production systems, from input provision to commercialization, that reach beyond national borders and complementary activities within a region to be realized. RVCs offer opportunities for countries within a region to move up the value chains to boost their competitiveness and produce and export higher value-added products (UNCTAD 2018). As such, high levels of innovation, greater efficiency, and increased productivity are often ascribed to RVC participation.

Engagement in RVCs entails deeper integration to facilitate coordination and harmonization among countries in the region on their common industrial interests (UNESCAP 2020). The ARCII captures integration in the RVC dimension by including four indicators with information on trade complementarity, trade concentration, and intermediate goods trade.

\section{Trade Complementarity}

\section{Indicators}

III-a: Ratio between the averaged trade complementarity index over regional trading partners and the averaged trade complementarity index over all trading partners

Trade complementarity measures the degree to which the export pattern of one country matches the import pattern of another, therefore providing valuable information on prospects for intraregional trade (World Bank n.d.). Higher degree of trade complementarity suggests favorable climate for a successful trade agreement, while changes in trade complementarity over time may offer insights on whether trade profiles are becoming more compatible (UNESCAP n.d.).

Figure 2.13: Average Trade Complementarity Index, 2018
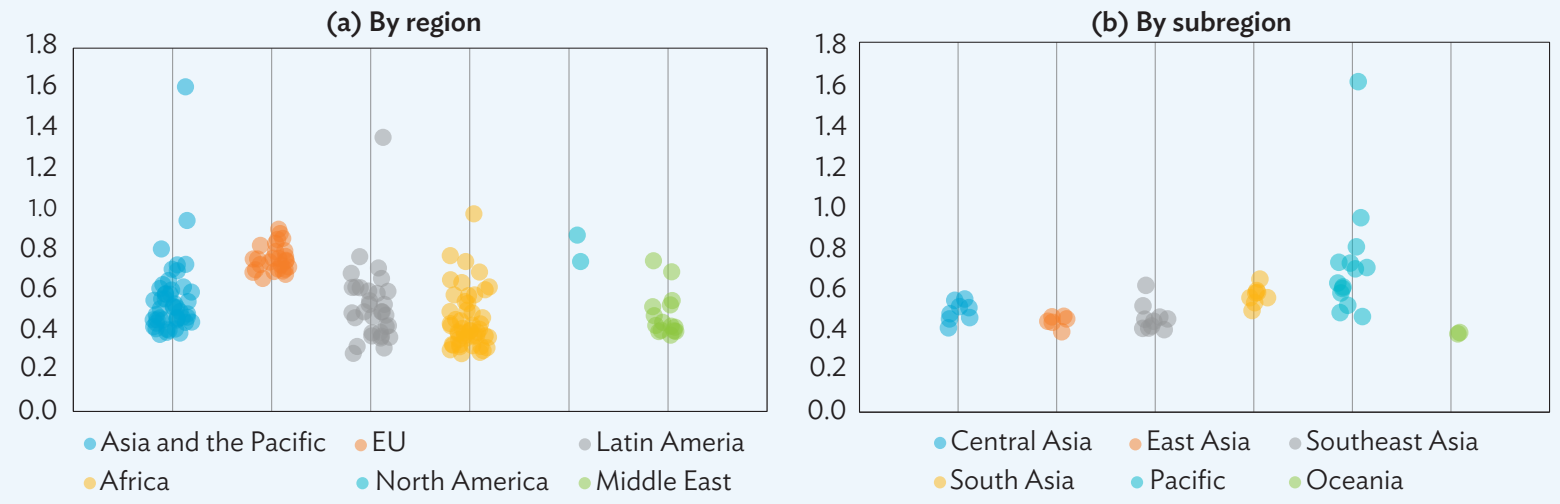

$\mathrm{EU}=$ European Union.

Source: Asian Development Bank calculations using data from United Nations Commodity Trade Statistics Database. https://comtrade.un.org (accessed August 2020). 
In the ARCII, an index for trade complementarity is generated that ranges between 0 (lowest) to 100 (highest). It is computed as the sum of the absolute value of the difference between the import category shares and the export shares of economies under study, divided by two. Following the computation of the index, indicator III-a (ratio between the averaged trade complementarity index over regional trading partners and the averaged trade complementarity index over all trading partners) is created. The higher the indicator value, the higher the complementarity among regional partners.

Trends from indicator III-a shows that Europe has the highest level of trade complementary within its region (Figure 2.13, panel a). Asia follows closely, yet indexes within Asian economies tend to be more dispersed, mainly due to the variation observed in Pacific countries (Figure 2.13, panel b).

\section{Trade Concentration}

\section{Indicators}

III-b: Ratio between the averaged trade concentration index over regional trading partners and the averaged trade concentration index over all trading partners

Trade concentration gauges the degree to which a country's trade (exports or imports) is concentrated in a limited number of products or trading partners. In other words, this measures product or market diversification. One of the basic measures used to estimate trade concentration is the Herfindahl-Hirschman Index (HHI). High concentrations are sometimes interpreted as an indication of vulnerability to economic changes in a small number of product or markets (UNESCAP n.d.-b).

The ARCII utilizes the $\mathrm{HHI}$ to construct indicator III-b (ratio between the averaged trade concentration index over regional trading partners and the averaged trade concentration index over all trading partners). ${ }^{7} \mathrm{~A}$ lower indicator III-b value means a higher level of diversification of products in an economy with its regional partners, relative to all its trading partners.

Trends from indicator III-b show the huge variation in regional trade concentration across all regions (Figure 2.14). On average, however, Latin America and Asia were found to have the highest indexes. With the Asian subregions, Southeast Asia followed by Oceania had the highest level of regional trade concentration.

In particular, product concentration of imports is considered in building indicator III-b. Product classification is at the three-digit level of the Standard International Trade Classification Revision 3. 


\section{Intermediate Goods Trade}

\section{Indicators}

III-c: Proportion of intraregional intermediate goods exports to total intraregional goods exports

III-d: Proportion of intraregional intermediate goods imports to total intraregional goods imports

The emergence of production linkages has altered the structure of international trade, which is manifested by the increase in the value of regional intermediate goods trade or network between countries (Nguyen and $\mathrm{Wu}$ 2020). Intermediate goods are inputs used to produce other goods. Trade in intermediate goods is specifically developed in the context of production fragmentation and vertical specialization, such as the division of labor internationally. In the sphere of regional integration, intermediate goods could be used to measure the degree of integration of a country or industry in the world economy, using the amount of trade in parts and components, together with the international or regional fragmentation of production (UNCTAD and WTO 2012).

In the ARCII, III-c (proportion of intraregional intermediate goods exports to total intraregional goods exports) and III-d (proportion of intraregional intermediate goods imports to total intraregional goods imports). Trends from indicators $\mathrm{III-C}$ and $\mathrm{III-d}$ show that intraregional intermediate goods exports and imports constitute to approximately half of total intraregional goods exports and imports, on average, across all regions.

Trends from indicator III-c shows that among regions, that Asia has the highest level of intraregional in intermediate exports (Figure 2.15). Asia's intraregional intermediate imports are also high, but to a lesser extent. A closer look at the subregions reveals that East Asia leads in both intraregional exports and imports, while the Pacific lags its counterparts.

Figure 2.14: Trade Concentration Index, 2018

$$
\text { (regional over global) }
$$

(a) By region

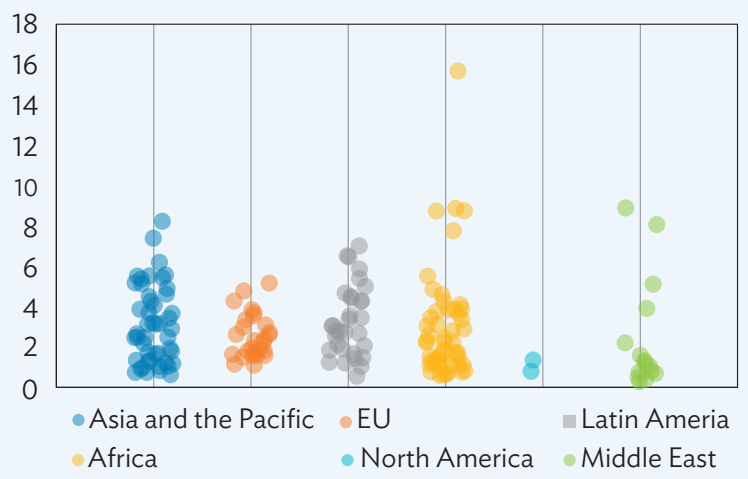

(b) By subregion

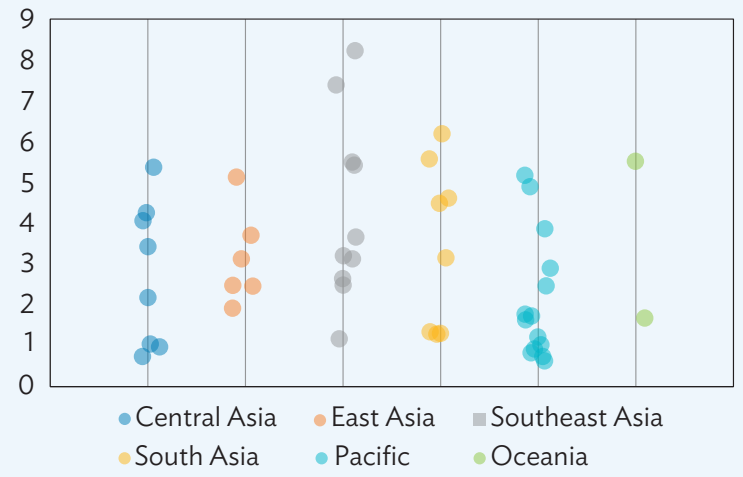

$\mathrm{EU}=$ European Union.

Source: Asian Development Bank calculations using data from United Nations Commodity Trade Statistics Database. https://comtrade.un.org (accessed August 2020). 
Figure 2.15: Intraregional Intermediate Goods Trade, 2018

(\% of total intraregional goods exports, imports)

(a) By region
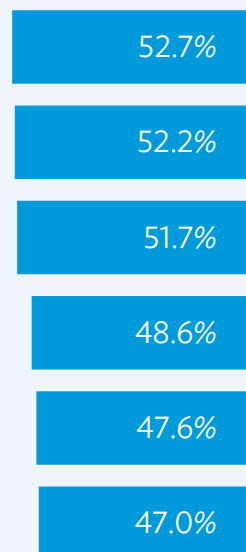

\begin{abstract}
Asia and the Pacific
\end{abstract}

Africa

$$
\text { North }
$$

America

EU

Latin America
Middle East

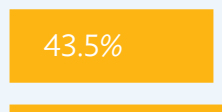

\section{$51.6 \%$}

$53.8 \%$

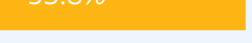

$46.8 \%$

$48.6 \%$

$47.6 \%$ (b) By subregion

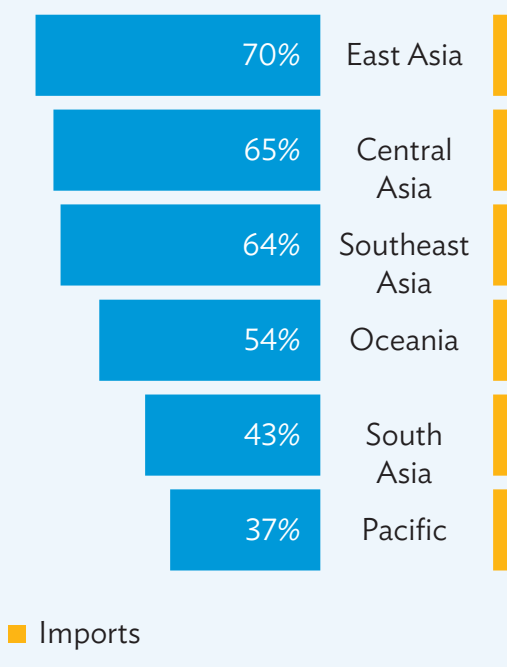

$59 \%$

$52 \%$

$51 \%$

$30 \%$

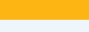

$52 \%$

$25 \%$

Exports Imports

EU = European Union.

Source: Asian Development Bank calculations using data from United Nations Commodity Trade Statistics Database. https://comtrade.un.org (accessed August 2020).

\section{Value-added Contributions}

\section{Indicators}

III-e: Ratio between the sum of the value-added contributed by regional trading partners and that contributed by all trading partners

Aside from an increase in the value of intermediate goods, greater participation in RVCs could also be captured by an increase in the foreign value-added contribution in a country's final output. More often, neighboring countries or countries in the same region are the ones responsible where the foreign value-added in another country's final output is increased (Castillo 2016).

The ARCII uses the economy-to-economy data on value-added contributions from the UNCTAD-Eora Global Value Chain (GVC) database. Using these data, indicator III-e (ratio between the sum of the value-added contributed by regional trading partners and that contributed by all trading partners) is computed to capture the extent of RVC participation among economies. A higher value suggests higher level of RVC participation and regional integration. 
Figure 2.16: Value-Added Contributions

(regional over global)

(a) By region

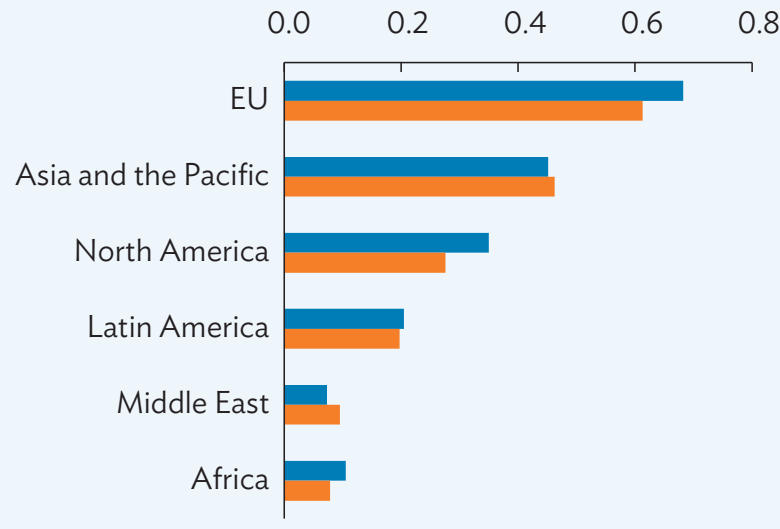

2006 (b) By subregion

$\begin{array}{llllllll}0.0 & 0.1 & 0.2 & 0.3 & 0.4 & 0.5 & 0.6 & 0.7\end{array}$

$\mathrm{EU}=$ European Union.

Source: Asian Development Bank calculations using data from Casella et al. (2019); and United Nations Conference on Trade and Development-Eora Global Value Chain Database. https://worldmrio.com/unctadgvc/ (accessed August 2020).

While the Eora database provides a broader coverage of key global value chain indicators, it may be less accurate than other measures of global value chain activity, including ADB's Multi-Regional Input-Output Tables (ADB MRIOT). For instance, the Eora database bases the structure of small countries from other countries, instead of utilizing country-specific national accounts (Mercer-Blackman, Xiang, and Khan 2021). On the other hand, the ADB MRIOT derives values mainly from national accounts and supply use tables, which is more apt for computing trade indicators. In the future, and as the regional coverage of ADB MRIOT improves, the value-added estimator will be based on ADB estimates.

Trends from indicator III-e show that European countries have the highest RVC participation for both 2006 and 2018 (Figure 2.16). Europe is followed by Asia, which experienced a slight increase in this indicator. Within the subregion, Southeast Asia leads. A marginal improvement in the performance of most subregions in this indicator of RVC participation is also observed.

\section{Dimension IV: Infrastructure and Connectivity}

Cross-border infrastructure connectivity is another catalyst for regional cooperation and integration (Roland-Holst 2009). Better roads, efficient transport systems, and improved cross-border trade policies boost regional economic activity (ADB 2019b; El-Anis 2021; Hanson, Owusu, and Puplampu 2015) and enable sustained economic growth. The index attempts through this dimension to capture the important role of infrastructure in regional integration by including four indicators on trade costs, transport connectivity, international flight passenger capacity, and logistics performance and business regulations. ${ }^{8}$

Data from the CAREC Corridor Performance Measurement Monitoring (CPMM) report were also considered for inclusion in the enhanced framework (ADB 2020a). The CPMM contains granular information on costs for border crossings (e.g. time and payment costs) for 11 countries that participated, namely: Afghanistan, Azerbaijan, the People's Republic of China, Georgia, Kazakhstan, the Kyrgyz Republic, Mongolia, Pakistan, Tajikistan, Turkmenistan, and Uzbekistan. While ARCII indicators generally require global coverage, the CPMM data might be considered for a customized index in this subregion. Chapter 3 has more details on index customization. 
Higher trade costs among regional trading partners correspond to lower regional integration, whereas better shipping connectivity, improved trade logistics performance, and higher Doing Business rankings all help boost it. With these indicators, the index can identify which aspects of infrastructure and connectivity contribute the most to improving regional integration and which ones need further improvement to achieve more gains.

\section{Trade Costs}

\section{Indicators}

IV-a: Ratio between the averaged trade cost over regional trading partners and the averaged trade cost overall trading partners

Greater trade costs discourage exporters and importers from frequently engaging with its trade partners. In 2018, Africa was recorded to have the highest ad-valorem trade cost for all three sectors namely agriculture, manufacturing, and total goods trade (Figure 2.17). The numbers suggest that, on average, total goods trade to and from Africa entails additional costs equivalent to about $328 \%$ of the value of goods. Excessive ad-valorem trade costs serve as an additional trade barrier that prohibits countries in the Africa region to achieve its full potential as a global trading partner. As a consequence, the region continues to be weakly integrated both globally and regionally (Steenkamp, Grater, and Viviers 2016). Europe enjoys the benefits of stronger regional integration partly due to having lower trade costs. A similar situation is evident in Asia, where heterogeneity in trade costs among subregions is apparent. The Pacific islands endure high trade costs, while East Asian economies face the lowest. Goods in the agriculture sector consistently incur high trade costs, which point to inefficiencies in infrastructure and logistics, among other factors. Targeted investments for developing trade corridors could lower these costs substantially and bring about welfare gains (Porteous 2019; Kim and Mariano 2020).

Bilateral trade cost data from United Nations Economic and Social Commission for Asia and the Pacific (UNESCAP)-World Bank is used to compute for the ratio between the average trade cost to regional trading partners and the average trade cost over all trading partners (indicator IV-a). ${ }^{9}$ The database includes all costs related to trading goods between international partners relative to the costs of trading goods domestically (i.e., intranationally). This database measures costs involved in both the export and import of goods between countries. A higher indicator value implies that, on average, it is more costly to trade with regional partners than other trading partners; which corresponds to lower regional integration.

The ratio of intraregional average trade costs relative to world average trade costs has declined slightly from 2006 to 2018 for most regions except North America and Africa (Figure 2.18). For the subregions of ADB, Central Asia and East Asia were able to reduce intraregional average trade costs relative to world trade costs. This can partly be due to projects such as the Belt and Road Initiative where Central and West Asian countries and the People's Republic of China (PRC) benefit from economic corridors that provide better connectivity and reduce trade costs (Ruta et al. 2018). However, countries in South Asia and the Pacific contended with higher intraregional trade costs in 2018 than in 2006. However, South Asia and islands in the Pacific had to deal with higher intraregional trade costs in 2018 than in 2006. In the case of the Pacific, the high trade costs could have been driven in large part by the remoteness and small size of their economies.

A more detailed discussion on the UNESCAP-World Bank Trade Cost Database is outlined in this explanatory note https:/www.unescap.org/sites/ default/d8files/Trade\%20Cost\%20Database\%20-\%20User\%20note.pdf. 
Figure 2.17: Ad-Valorem Trade Cost by Sector, 2018

\section{(a) By region}

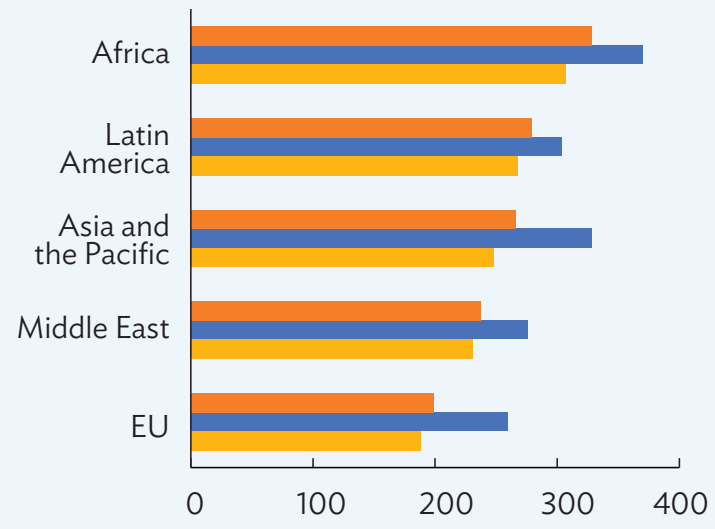

(\%)

\section{(b) By subregion}

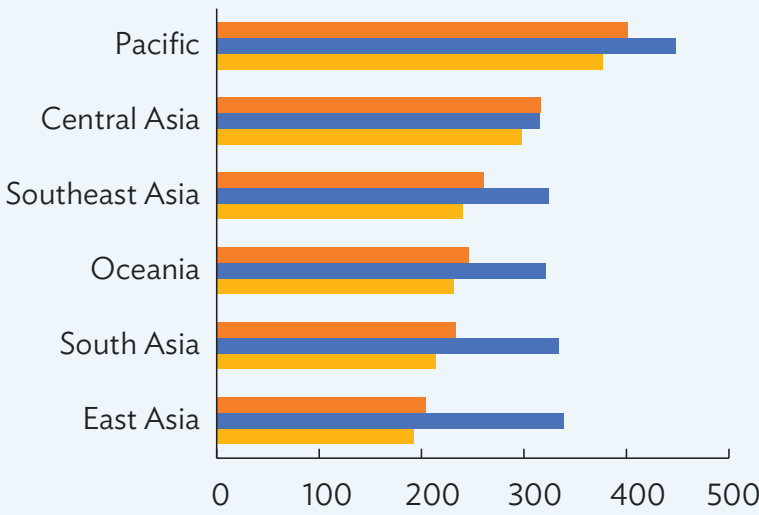

- Total Goods agriculture $\quad$ Manufacturing

$\mathrm{EU}=$ European Union

Source: Asian Development Bank calculations using data from United Nations Economic and Social Commission for Asia and the Pacific (UNESCAP)-World Bank Trade Cost Database. https://www.unescap.org/resources/escap-world-bank-trade-cost-database (accessed August 2020).

Figure 2.18: Change in the Intraregional to World Average Trade Cost Ratio, 2006 versus 2018

$(\%)$

\section{(a) By region}

North America

Africa

Middle East

Asia and the Pacific

EU

$-3.1$

Latin America -5.2

\section{(b) By subregion}

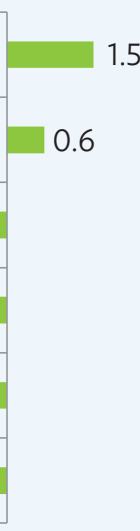

1.2

South Asia

Pacific

0.8

$\mathrm{EU}=$ European Union.

Source: Asian Development Bank calculations using data from United Nations Economic and Social Commission for Asia and the Pacific (UNESCAP)-World Bank Trade Cost Database. https://www.unescap.org/resources/escap-world-bank-trade-cost-database (accessed August 2020). 


\section{Liner Shipping Connectivity}

\section{Indicators}

IV-b: Ratio between the averaged liner shipping bilateral connectivity index (LSBCI) over regional trading partners and the averaged LSBCl over all trading partners

Maritime connectivity is significant for global trade, given that 90 percent of the world's trade is shipped by sea (Fugazza 2019). Establishing strong links with trade partners by improving ease of shipping, increasing the number of direct and indirect connections, and using larger ship vessels is a crucial part of a country's regional and global integration efforts. ${ }^{10}$ Seamless transport from improved connection contributes to lowering trade costs, increasing exports, providing better access to other markets and promoting economic growth (Fugazza and Hoffmann 2017; International Transport Forum 2019).

The ARCII framework uses annual UNCTAD data on the liner shipping bilateral connectivity index (LSBCI) to measure an economy pair's extent of integration to global liner shipping networks. A high LSBCl score reflects stronger connectivity, which in turn could translate to increased participation in global trade (UNCTAD, Division on Technology and Logistics 2020). ${ }^{11}$ In 2018, North America received the highest score for shipping connectivity relative to other regions in the world, while Africa fared poorly (Figure 2.19, panel a). For Asia, the top 10 routes are mostly going to and from East Asia and Southeast Asia, with the PRC showing strong connections with economies in Asia and Europe (Table 2.2). The PRC-Republic of Korea connection has notably been the best-connected economy pair since 2016 (Fugazza 2019 ).

Table 2.2: Top 10 Liner Shipping Bilateral Connectivity Index Scores for Asia and the Pacific Routes, 2018

\begin{tabular}{lc} 
Route & $\mathrm{LSBCl}$ \\
\hline PRC-Republic of Korea & 0.84 \\
Singapore-Malaysia & 0.82 \\
PRC-Singapore & 0.80 \\
\hline PRC-Hong Kong, China & 0.77 \\
PRC-Malaysia & 0.76 \\
Republic of Korea-Singapore & 0.74 \\
Republic of Korea-Malaysia & 0.71 \\
PRC-United Kingdom & 0.71 \\
PRC-Spain & 0.70 \\
PRC-France & 0.70 \\
\hline
\end{tabular}

$\mathrm{LSBCl}=$ liner shipping bilateral connectivity index, PRC = People's Republic of China.

Note: Bilateral routes reflect scores on connectivity between economy $A$ and economy $B$, and vice versa (i.e., the index score for the route from the Republic of Korea to the PRC is the same for the route from the PRC to the Republic of Korea).

Source: Asian Development Bank calculations using data from UN Conference on Trade and Development. UNCTADSTAT. https://unctadstat.unctad.org/ (accessed August 2020).

- The Liner Shipping Bilateral Connectivity Index (LSBCI) is based on five components. For each economy pair, the index is based on the number of transshipments required, number of common direct connections, number of common connections by economy pair with one transshipment, the scale of competition on services connecting the economy pair, and the size of the largest ship on the weakest route connecting the economy pair. The index is normalized to take on values between 0 and 1 (UNCTAD, Division on Technology and Logistics 2020).

11 The framework acknowledges that this indicator is mostly relevant for economies that have direct maritime access and may not be highly relevant for landlocked countries such as those located in Central Asia. 
The ARCII indicator is computed as a ratio between the averaged $\mathrm{LSBCl}$ over regional trading partners and the averaged $\mathrm{LSBCl}$ over all trading partners. A higher ratio value is positively related to regional integration, which reflects a higher ARCII estimate. Average regional ratios show that shipping connectivity has generally improved for most regions except for North America and Africa. Maritime connectivity in Asia has remained relatively unchanged, but has shown improvements for the Pacific islands (Figure 2.19, panel b).

\section{Figure 2.19: Average Liner Shipping Bilateral Connectivity Index-} Intraregional to World Ratio

(a) By region

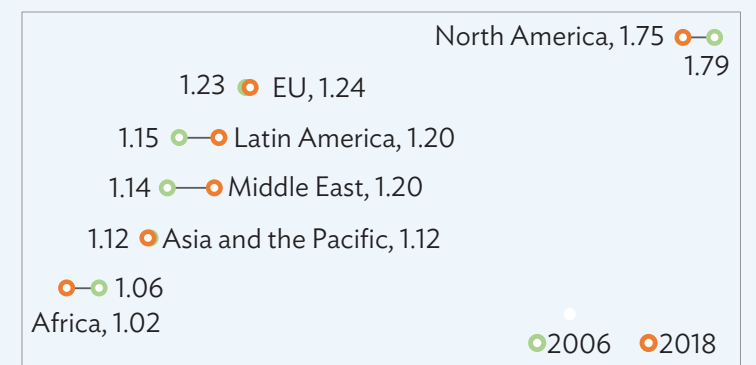

(b) By subregion

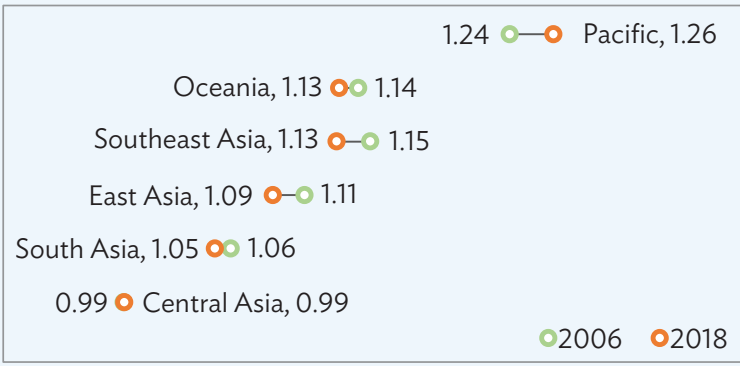

$\mathrm{EU}=$ European Union.

Source: Asian Development Bank calculations using data from UN Conference on Trade and Development. UNCTADSTAT. https://unctadstat.unctad.org/ (accessed August 2020).

\section{International Flight Passenger Capacity}

\section{Indicators}

IV-c: Proportion of passenger seats sold on regional flights relative to those sold on all international flights

Another crucial mode of transport that promotes connectivity and infrastructure development between countries is air transportation. The optimal use of air navigation services is expected to contribute to greater market access and sustainable tourism that leads to economic growth (International Civil Aviation Organization n.d.). More recently, air transport capacity has grown and allowed for more quantities of high-value freight, boosting its important role in global logistics (Rodrigue 2020). In a similar manner, passenger traffic has also swiftly increased, even outperforming growth in the broader global economy. This is evident for areas near air hubs, but also spreads across the economy as a result of better air accessibility (Bowen and Rodrigue 2020).

International flight passenger capacity helps account for the role of air transport connectivity in promoting access to the global economy. The ARCII framework uses bilateral city-level data on passenger capacity for international flights from the International Civil Aviation Organization. In 2018, regional flights for Europe and Asia comprised a large, steady share of international flights which reflect better connectivity and mobility within these regions. Meanwhile, economies within the Asia subregions exhibit high levels of intraregional flight connectivity, except for landlocked economies in Central Asia and South Asia. 
The ARCII framework includes an indicator that measures the number of passenger seats sold on regional flights as a share to those sold on international flights (IV-c). ${ }^{12}$ This ratio allows the index to account for changes in passenger traffic in intraregional flights over time compared to passengers in international flights. Table 2.3 shows that in most regions, the ratio has decreased. This could possibly imply two trends: (i) there are less passengers flying to economies within the region, or (ii) more flight passengers are traveling to international destinations than intraregional ones. A higher indicator value corresponds to greater regional integration-and a higher ARCII estimate.

Table 2.3: Proportion of Passenger Seats Sold on Intraregional Flights (\% of seats on international flights)

(a) By region

\begin{tabular}{lcc}
\hline Region & 2006 & 2018 \\
\hline EU & 78.4 & 74.8 \\
\hline Asia and the Pacific & 68.0 & 65.3 \\
\hline Africa & 60.9 & 57.9 \\
\hline Middle East & 44.7 & 54.6 \\
\hline Latin America & 51.8 & 46.2 \\
North America & 38.0 & 27.7 \\
\hline
\end{tabular}

$\mathrm{EU}=$ European Union.

Note: Highlighted cells in orange (green) reflects a decrease (an increase) in the indicator relative to its 2006 value.

Source: Asian Development Bank calculations using data from the International Civil Aviation Organization. Passenger Traffic, By City Pair (Historical Years Data) 1995-2018.

\section{Logistics Performance Index}

\section{Indicators}

(b) By subregion

\begin{tabular}{|l|r|r|}
\hline Subregion & 2006 & 2018 \\
\hline Southeast Asia & 89.8 & 89.1 \\
\hline Pacific & 84.7 & 80.8 \\
\hline East Asia & 75.3 & 78.8 \\
\hline Oceania & 87.2 & 74.3 \\
\hline South Asia & 50.8 & 44.0 \\
\hline Central Asia & 18.6 & 17.0 \\
\hline
\end{tabular}


challenges related to the customs process and trade-related infrastructure. Addressing these will help them make progress in regional initiatives and attain regional agendas (Guerrero, Lucenti, and Galarza 2009; Takele 2019). In Asia, while the shipment delivery time component received a high score, the low scores for customs and trade and transport infrastructure component indicate which areas need reforms. Intuitively, a higher LPI score translates to greater integration for the infrastructure and connectivity dimension and the overall ARCII.

Figure 2.20: Logistics Performance Index, 2018

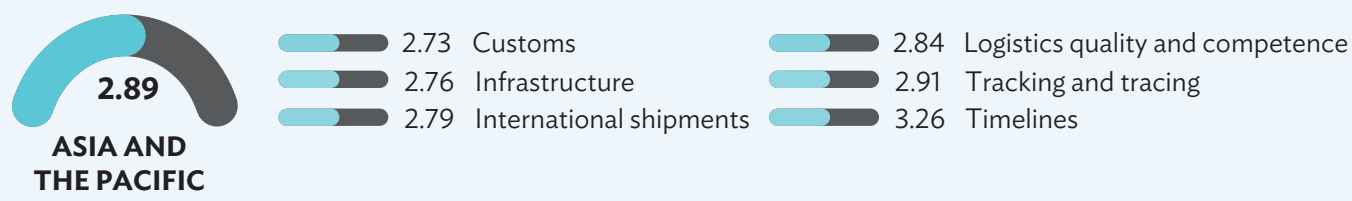

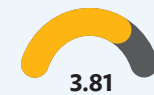

NORTH AMERICA

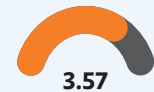

EU

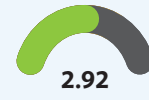

MIDDLE EAST

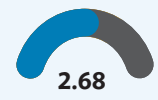

LATIN AMERICA

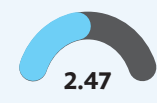

AFRICA

$\mathrm{EU}=$ European Union

Source: Asian Development Bank calculations using data from World Bank. Logistics Performance Index 2018. https://lpi.worldbank. org/ (accessed July 2020).

\section{Doing Business Index}

\section{Indicators}

IV-d: Doing Business Index (overall)

Regulatory reforms create an environment conducive for businesses to start and thrive. It also promotes competition by eliminating barriers to entry. A common metric of regulatory performance in the literature is the Doing Business index. The index scores show there is a steady convergence between developing and developed countries, and those that perform better benefit from more entrepreneurial activity and transparency (World Bank 2020).

The Doing Business index is a national-level indicator of regulatory performance. The score ranges from 0 (worst) to 100 (best).${ }^{14} \mathrm{~A}$ country with a high ease of doing business ranking has a conducive regulatory environment for starting and operating a local firm. In the ARCII framework, a high Doing Business index score translates to greater regional integration.

Recent scores show that regulations in place for countries in North America and Europe help provide an efficient space to do business, while Latin America and Africa lag in some of these areas (Figure 2.21). The use of electronic systems for processes such as business incorporation, tax filing, and property transfers is a common feature among countries that

The Doing Business index rankings are determined by sorting the aggregate scores on the following 10 topics: (i) starting a business, (ii) dealing with construction permits, (iii) obtaining an electricity connection, (iv) registering property, (v) getting access to credit, (vi) protecting minority investors, (vii) paying taxes, (viii) trading across borders, (ix) enforcing contracts, and ( $\mathrm{x}$ ) resolving insolvency (World Bank 2020). 
have performed well in promoting ease of doing business (World Bank 2020). In Asia, while the average Doing Business score in 2020 was 66.3, three out of the top five overall world rankings were from East Asia, with scores of more than 80.

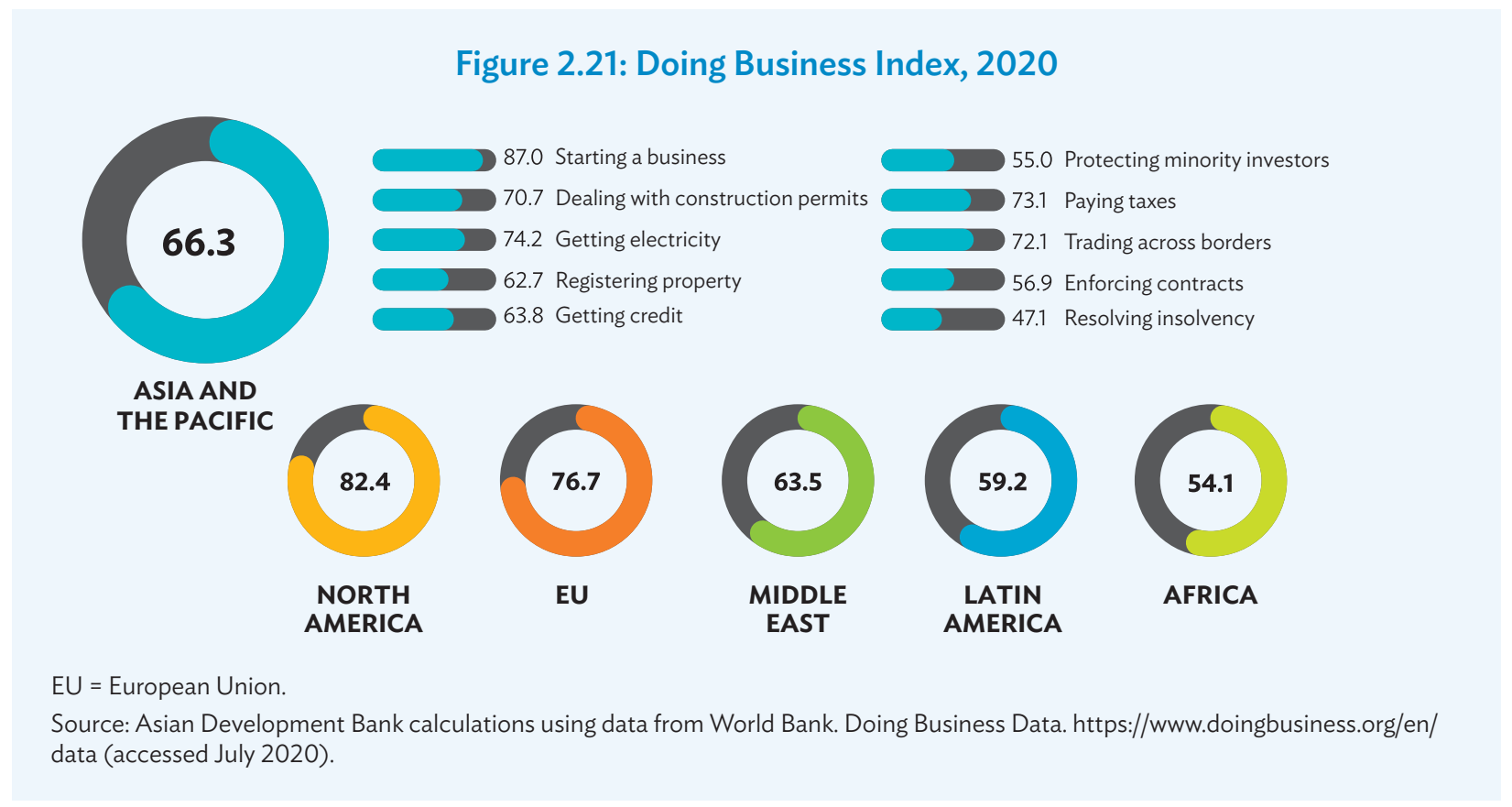

\section{Dimension V: People and Social Integration}

Apart from free flow of goods and services, regional cooperation and integration also entails relaxing restrictions to movement of people. A region that allows its people to freely migrate and travel between countries can promote regional growth through increased labor mobility, tourism revenues, and remittance flows from overseas migrant workers.

Strategies that lessen constraints to the movement of skilled workers help address asymmetries in regional labor markets, making it more efficient (Nonnenmacher 2017). Better policies also contribute to the reallocation of human capital to countries and sectors that are most in need. The ARCII accounts for this aspect of regional cooperation and integration by including variables on outbound migration, tourist numbers, remittances, and entry visa requirements. Higher values for these indicators translate to greater levels of regional integration.

\section{Outbound Migration}

\section{Indicators}

V-a: Proportion of intraregional outbound migration to total outbound migration

An important element of economic integration is international migration (Kikkawa Takenaka, Gaspar, and Park 2019). Significant advancements in increased mobility within a region can be measured by changes in the stock of international migrants. Outbound migration trends in 2019 show that international migrants in Asia mostly relocated 
to economies within Asia, the Middle East, Europe, and North America (Figure 2.22). North America also had international migrants coming from Latin America and Europe. This trend is consistent with the flow of migrants to countries where jobs and other economic opportunities are numerous (Kikkawa Takenaka, Gaspar, and Park 2019).

The ARCII uses bilateral data on international migrant stock from the United Nations to compute the proportion of intraregional outbound migration to total outbound migration. International migrants are defined as those part of the foreign-born population. For instance, for the PRC, an increase in this indicator implies that more foreign citizens in the PRC are migrating to other economies within Asia than they are to countries outside the region. ${ }^{15}$ Increases in the value of the indicator are indicative of stronger regional integration, and contribute to raising the ARCII estimate.

The ratio of intraregional to total outbound migration in Asia has declined slightly, which could signal more migration to countries outside the region rather than within (Figure 2.23, panel a). However, the opposite is true for East Asia where the number of migrants relocating within rather than outside the subregion has increased (Figure 2.23, panel b).

Figure 2.22: Outbound Migration Map, 2019

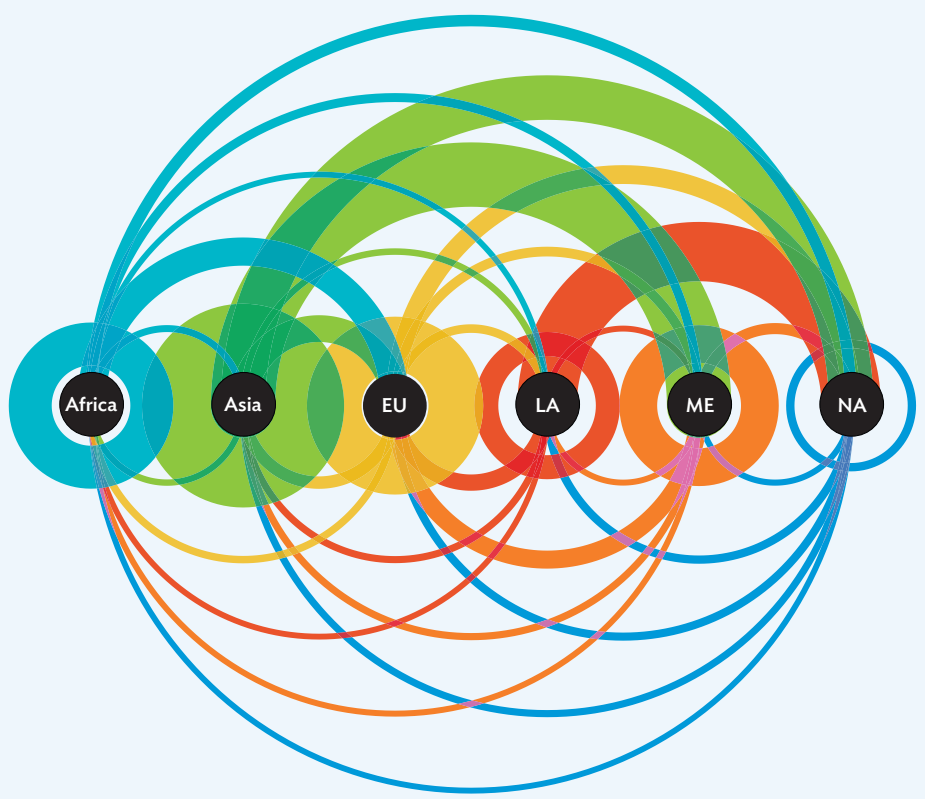

EU = European Union, LA = Latin America, ME = Middle East, NA = North America.

Note: Each region is represented by a unique color (e.g., blue for Africa, green for Asia). The map reflects bilateral information on the stock of migrants as illustrated by the thickness of the lines going from one region to another. For instance, the thick green line originating from Asia and going to North America reflects the volume of migrants. Asia refers to Asia and the Pacific.

Source: Asian Development Bank calculations using data from United Nations Department of Economic and Social Affairs, Population Division. International Migration. https://www.un.org/en/development/desa/population/migration/data/index.asp (accessed June 2020).

15 In 2018, the PRC had more than 5.3 million outbound international migrants, which is the highest among economies in Asia. This is a considerable increase from 2006, when about 4.2 million people migrated. 
Figure 2.23: Intraregional Outbound Migration

(\% of total outbound migration)

(a) By region

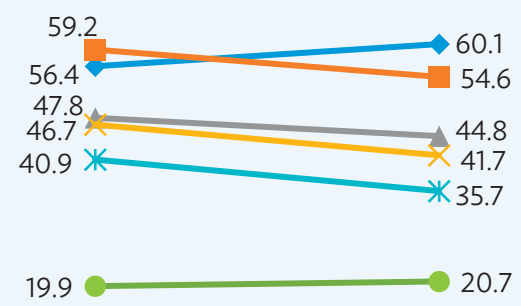

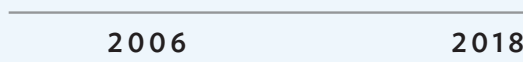

$\longrightarrow$ EU

$\longrightarrow$ Asia and the Pacific

$\because$ North America

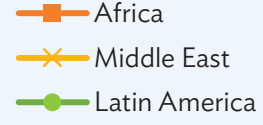

(b) By subregion
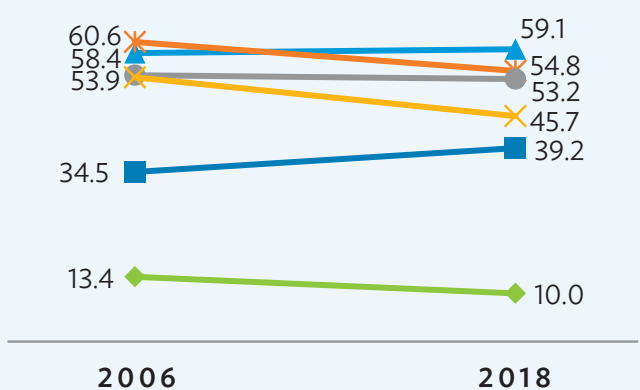

2006

*-Pacific

$\longrightarrow$ Southeast Asia

-Oceania

$\because$ South Asia

$\longrightarrow$ Central Asia

$\mathrm{EU}=$ European Union

Source: Asian Development Bank calculations using data from United Nations Department of Economic and Social Affairs, Population Division. International Migration. https://www.un.org/en/development/desa/population/migration/data/index.asp (accessed June 2020).

\section{Tourists}

\section{Indicators}

V-b: Ratio of intraregional tourists to total tourists (inbound plus outbound)

Tourism has consistently contributed to global economic growth, more so for developing countries (Gwenhure and Odhiambo 2017). The tourism sector helps boost a country's economic output and also provides many employment opportunities. Besides this, the economy also benefits from spillovers to other sectors.

The index accounts for the impact of tourism on regional integration by including a ratio of intraregional to world tourists. An increase in the ratio could mean that the number of tourists traveling within the region is growing faster than that for tourists visiting countries outside the region. This trend is happening in Europe and Asia, where the ratio has slightly increased from 2006 to 2018 (Figure 2.24, panel a). In Central Asia, intraregional tourists increased tremendously, from about 7.9 million in 2006 to 44.3 million in 2018 (Figure 2.24, panel b). Southeast Asian countries have maintained high numbers in intraregional tourism, with sector-specific initiatives such as the Association of Southeast Asian Nations (ASEAN) Tourism Strategic Plan helping to encourage further liberalization of tourism services. 
Figure 2.24: Intraregional Tourists

(\% of total tourists)

(a) By region

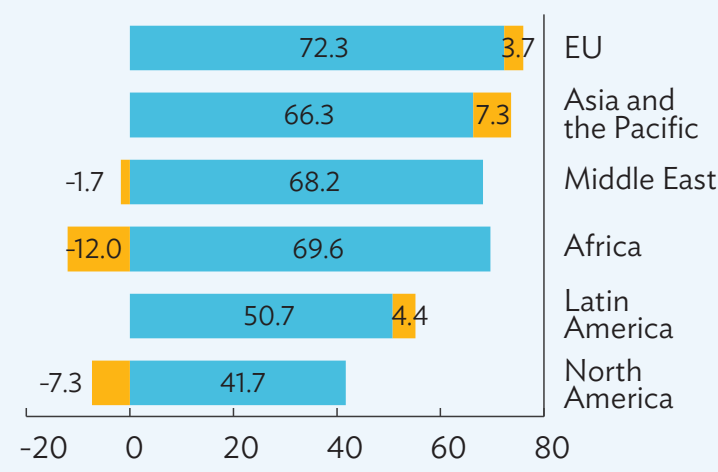

(b) By subregion

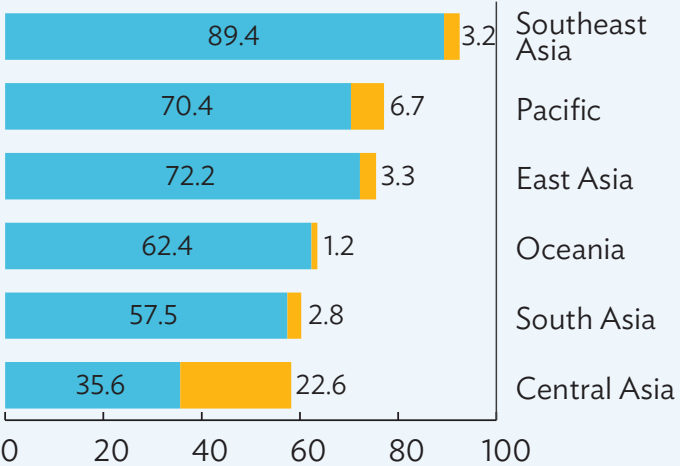

2006 Change from 2006-2018

$\mathrm{EU}=$ European Union

Note: The term "tourists" refer to the sum of inbound plus outbound tourists.

Source: Asian Development Bank calculations using data from the World Trade Organization. Tourism Statistics. https://www.e-unwto. org/toc/unwtotfb/current (accessed June 2020).

\section{Remittances}

\section{Indicators}

V-c: Ratio of intraregional remittances to total remittances

For most developing countries, remittances are a stable source of income for families of overseas workers. At times, remittances also provide a means of external financing to augment available sources of funds. Remittances not only help boost spending and investment, but also contribute to the foreign currency revenue base, all of which helps an economy grow (Kikkawa Takenaka et al. 2020). Increased remittance flows positively impact the economy, particularly for the home country, and heighten regional integration efforts.

The index uses bilateral data on outward remittances from KNOMAD to compute the ratio of intraregional to total remittances $(\mathrm{V}-\mathrm{c})$. A high ratio means a large share of total outward remittances is transferred to economies in the same region as the sender's economy. Through this indicator, the index captures information on the strength of regional linkages, especially the movement of people reflected by the source and destination of remittances. Intraregional outward remittances as a share of total outward remittances is higher in Asia, at about $74 \%$ in 2018 , than in other regions (Figure 2.25, panel a). Recent numbers also show intraregional outward remittances for subregions in Asia have declined, except for Oceania (Figure 2.25, panel b). 
Figure 2.25: Intraregional Outward Remittances

(\% of total outward remittances)

\section{(a) By region}

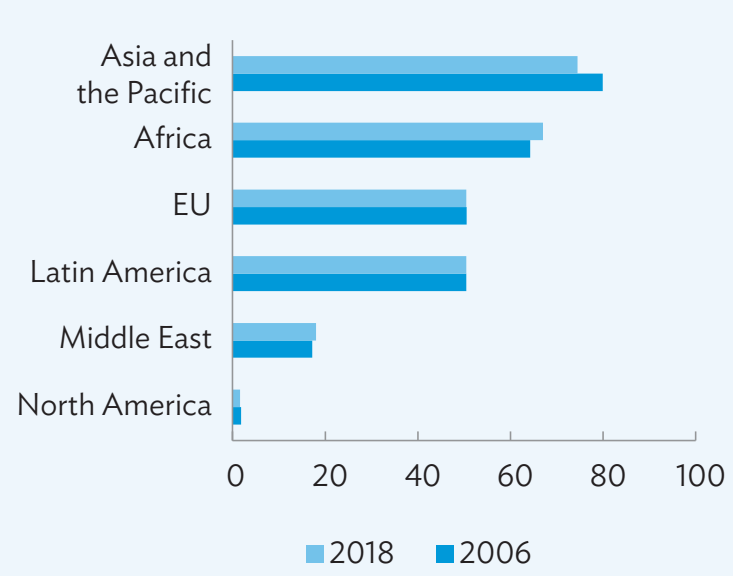

(b) By subregion

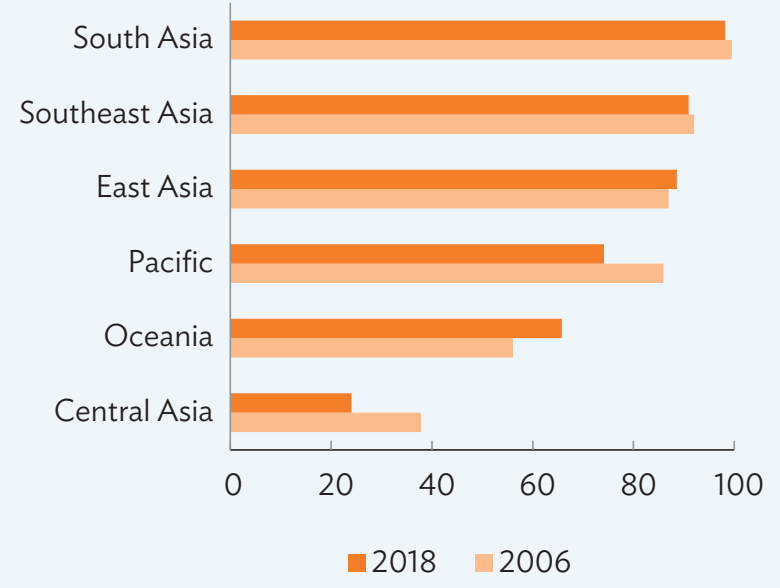

$\mathrm{EU}=$ European Union.

Source: Asian Development Bank calculations using data from the Global Knowledge Partnership on Migration and Development. http://www.knomad.org/data/remittances (accessed April 2020).

\section{Cultural Influences}

\section{Indicators}

V-d: Cultural proximity with interregional economies relative to that with all other economies

$\checkmark$-e: Ratio of intraregional cultural goods trade (exports plus imports) to total cultural goods trade

Shared cultural beliefs and practices matter in strengthening regional integration efforts. United Nations Educational, Scientific and Cultural Organization (UNESCO) highlights the valuable role of culture in smoothing the path to greater integration by maximizing cultural wealth, creativity, and common heritage among countries in a region (UNESCO 2020). By accounting for the role of culture, countries can reinforce better dialogue and gain a deeper social understanding that is helpful in addressing regional interests such as health, security, and the economy. This is particularly apparent in Europe, where identity and culture have had strong influence in shaping its institutions and economy (Tabellini 2010). Within Asia, particularly Southeast Asia, the Association of Southeast Asian Nations (ASEAN) established the ASEAN Strategic Plan for Culture and Arts to help promote intercultural dialogue among member countries (ASEAN 2016).

To capture the dynamics between culture and regional integration, the ARCII framework includes bilateral indicators for cultural proximity (V-d) and cultural goods trade (V-e). 


\section{Cultural proximity}

Raw data from the Centre d'Etudes Prospectives et d'Informations Internationales (CEPII) stipulate eight categories for characterizing cultural proximity between two countries. These are whether they: (i) are contiguous; (ii) share a common official language; (iii) share a language spoken by at least $9 \%$ of their populations; (iv) had a mutual colonizer after 1945; (v) have had a colonial link; (vi) had a colonial relationship after 1945; (vii) currently have a colonial relationship; and (viii) used to be part of the same country. To construct indicator $V$-d, an economy receives one point for an affirmative answer in each of the eight categories. Points are then averaged over all Asian economies and for all economies worldwide. The ratio of these two averages yields the final measure for indicator $\mathrm{V}$-d which is the cultural proximity with other economies in the region relative to all other economies. This variable is time invariant, and so has the same values across all years. ${ }^{16}$

Latin America received the highest value for this indicator since the region is known for its strong culture and traditions; followed by Europe, as evident from the significant role of cultural institutions and shared practices in its integration (Figure 2.26, panel a). Within Asia, countries in East Asia are closest in culture, while those in the Pacific islands show few commonalities (Figure 2.26, panel b). As in the definition of the variable, geography and colonial relationships both play a large role in the computation.

Figure 2.26: Cultural Proximity

(intraregional versus global)

(a) By region

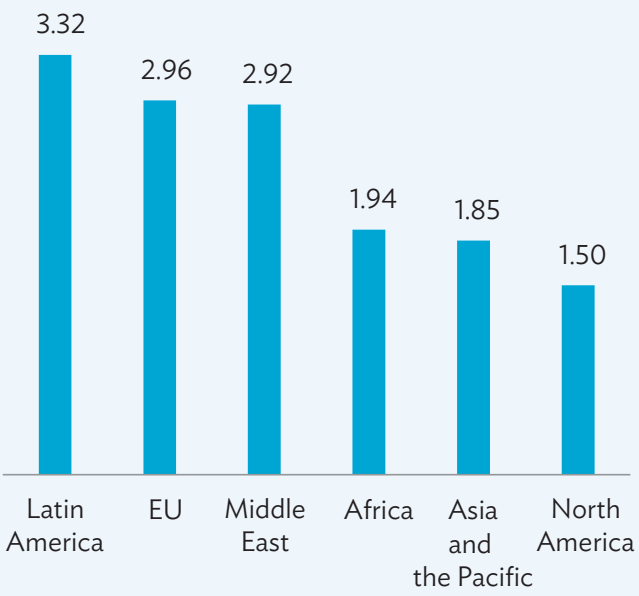

(b) By subregion

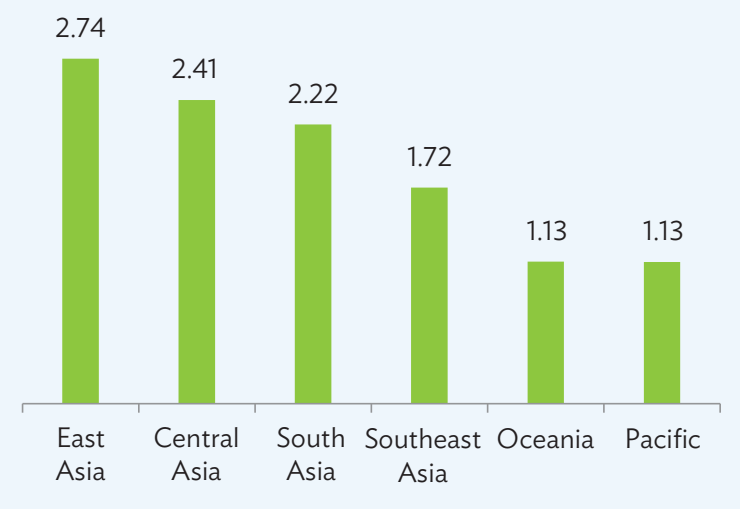

$\mathrm{EU}=$ European Union

Source: Asian Development Bank calculations using data from Centre d'Etudes Prospectives et d'Informations Internationales (the French Research Center in the International Economics). GeoDist Database. http://www.cepii.fr/cepii/en/bdd_modele/bdd.asp (accessed November 2019).

\section{Cultural goods trade}

Another aspect of the cultural perspective of regional integration involves the trade in cultural goods (V-e). The high volume of cultural goods traded in Asia suggests strong social integration within the region. Cultural 
goods were defined following the UNESCO classification/commodity list, on which items such as antiques, musical instruments, recorded media, visual arts, and jewelry are included. Trade in cultural goods among Asian economies steadily increased from 2006 to 2018 (Figure 2.27, panel a), with Oceania and Southeast Asia having the highest share of intraregional trade among countries within their subregions (Figure 2.27, panel b).

\section{Figure 2.27: Intraregional Cultural Goods Trade}

(\% of total cultural goods trade)

(a) By region

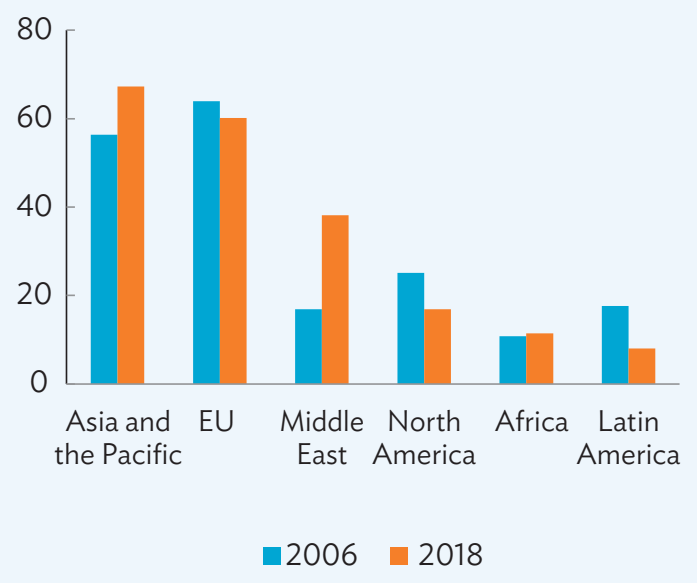

(b) By subregion

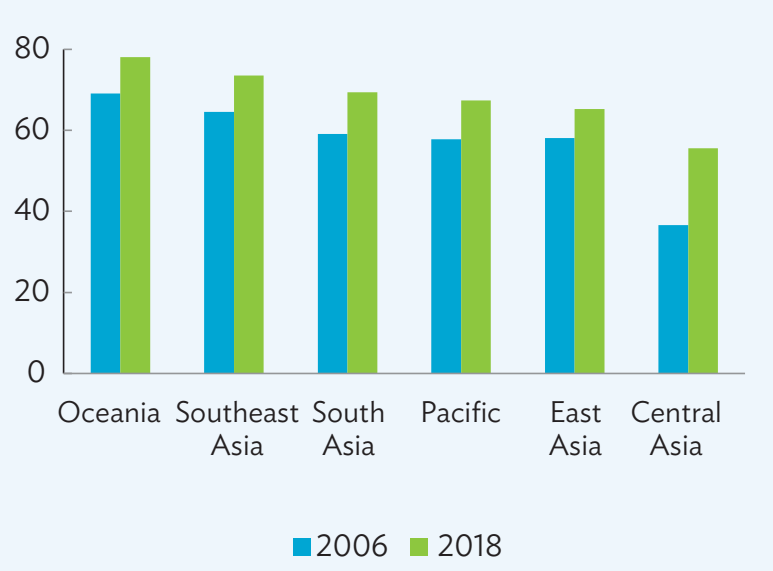

$\mathrm{EU}=$ European Union.

Note: Cultural goods were defined following the United Nations Educational, Scientific and Cultural Organization (UNESCO) classification/commodity list, on which items such as antiques, musical instruments, recorded media, visual arts, and jewelry are included. Source: Asian Development Bank calculation using data from United Nations Commodity Trade Statistics Database. https://comtrade. un.org (accessed August 2020).

\section{Trademark Applications}

\section{Indicators}

V-f: Ratio of trademark applications made with intraregional residents to trademark applications made with all foreign residents

Trademarks are a form of intellectual property protection that plays an important role in the economy. Firms are able to differentiate their goods and services with competitors through means of branding and establishing image value among consumers (World Intellectual Property Organization 2013). In the context of people and social integration, intraregional trademark applications depict the level of innovation between countries within the region. Since trademarks somewhat reflect consumer preferences in the types of products, services, and innovation they value, this indicator reveals commonalities among regional countries. 
Bilateral data on trademark applications were downloaded from the World Intellectual Property Organization website. Intraregional trademark applications are defined as those submitted by applicants whose country is in the same region as the filing office. The indicator used in the ARCII framework is the ratio of trademark applications made with intraregional residents to trademark applications made with all foreign residents $(\mathbf{V}-\mathbf{f})$. Trends show that Europe has had numerous trademark applications within the region, followed by Latin America. In Asia, about $63 \%$ of total trademark applications were filed with intraregional economies in 2018 (Figure 2.28, panel a). The joint efforts of the national intellectual property offices of ASEAN member countries to establish a regional trademark system in particular have bolstered intraregional trademark applications for Southeast Asia (Figure 2.28, panel b).

Figure 2.28: Intraregional Trademark Applications (\% of total applications)

(a) By region

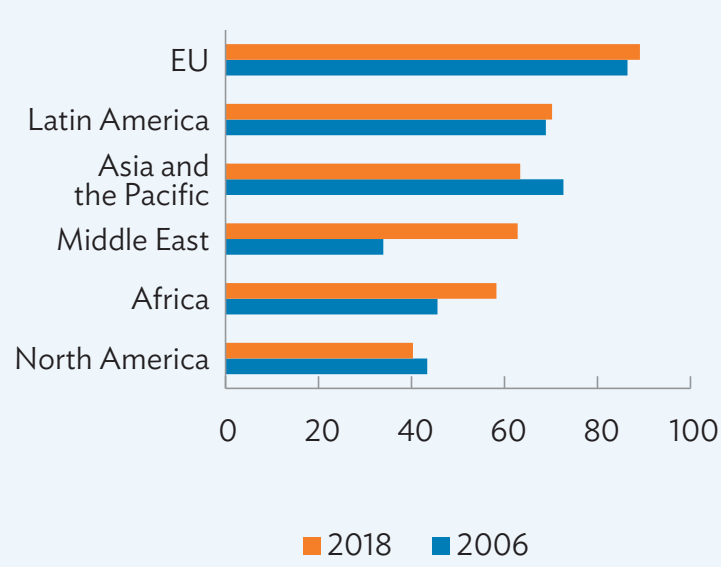

(b) By subregion

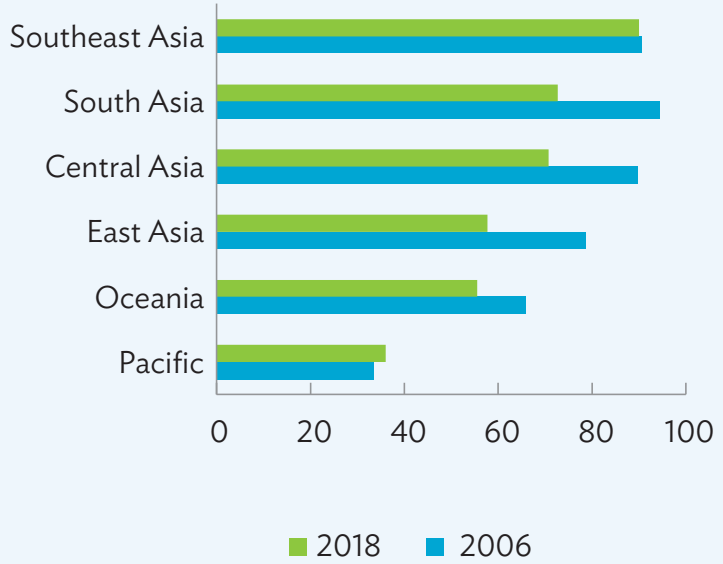

$\mathrm{EU}=$ European Union.

Source: Asian Development Bank calculations using data from World Intellectual Property Organization. WIPO IP Statistics Data Center. https://www3.wipo.int/ipstats/ (accessed May 2020).

\section{Dimension VI: Institutional Arrangements}

In the context of regional integration, a country's institutions influence the sphere of politics and affect economic policies and outcomes (Banerjee and lyer 2005). Stable and inclusive institutions are needed to establish state capacity, and in turn, properly enforce contracts and policies (Besley and Persson 2009).

The ARCII framework reflects the role of strong and good institutions on regional integration by including indicators that measure the participation of economies to international agreements (VI-a, VI-b, VI-c), membership in intergovernment organizations (VI-d), and embassy presence (VI-e). 


\section{Participation in International Agreements}

\section{Indicators}

VI-a: Proportion of intraregional economies that have signed free trade agreements (FTA) with

VI-b: Proportion of intraregional economies that have signed bilateral investment treaties with

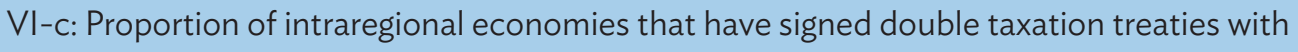

Strengthening ties with regional and global partners involves participation in international institutions and agreements that are well-recognized and followed by other countries. Global organizations such as the World Trade Organization formalized partnerships and strengthened trade systems among countries through mechanisms such as free trade agreements. Other organizations and countries followed suit, extending these mutual agreements to also cover investment and taxation matters. As in any agreement, there are benefits gained and costs incurred by participating countries. These benefits include freer trade and investment flows, and well-established double taxation policies. To reflect how these kinds of arrangements impact regional integration efforts, the ARCII includes bilateral indicators related to free trade agreements ( $\mathrm{VI}-\mathbf{a})$, bilateral investment treaties (VI-b), and double taxation treaties ( VI-c).

\section{Free trade agreements signed}

Free trade agreements have proliferated over the years. With only 19 signed in 1990, the number increased to 292 by January 2019. The rationale behind participating in free trade agreement is to promote trade by eliminating tariffs on goods and services exchanged among member signatories (Athukorala 2020). Modern trade agreements also cover other aspects such as regulatory standards, health and safety rules, and environmental protection, among many others (Rodrik 2018).

The indicator on free trade agreements ( $\mathrm{VI}-\mathrm{a})$ is computed using bilateral data from the Design of Trade Agreements (DESTA) database. It is calculated as a ratio of the number of partner economies in the region with which an economy has signed free trade agreements relative to the total number of economies in the region. As expected, indicators for both Europe and North America have a high value since all countries within those regions had signed free trade agreements with each other by 2018; Asia follows closely with about 95.5\% (Figure 2.29, panel a). Meanwhile, only a few countries in Central Asia and the Pacific have signed mutual agreements (Figure 2.29, panel b).

\section{Bilateral investment treaties signed}

Bilateral investment treaties (BIT) are legal instruments used to govern the circumstances of investment, such as its scope, treatments received by foreign investors, and dispute settlement and compensation mechanisms. Their number has increased significantly over the past 2 decades, and today nearly 3,000 BITs have been signed globally, one-third by economies in Asia. The role of BITs goes beyond increasing bilateral FDI flows and extends to improving the overall institutional framework for investment. For this, their design and structure becomes an important area of investment policy (ADB 2021b). Among many areas, BITs can inform about the degree of control maintained by the state over foreign investment, the level of discrimination between domestic and foreign investors or the quality of investor-state dispute mechanisms (ADB 2021a).

The indicator on bilateral investment treaties (indicator VI-b) is computed using bilateral data from the UNCTAD and Design of Trade Agreements (DESTA) database. It is calculated as a ratio of the number of partner economies in the region that an economy has signed bilateral investment treaties with relative to the total number of economies in the region. North America had a perfect score which implies that Canada and the US have signed mutual BITs, 
Figure 2.29: Free Trade Agreements Signed with Intraregional Economies, 2018

(\% of total economies in the region)

(a) By region

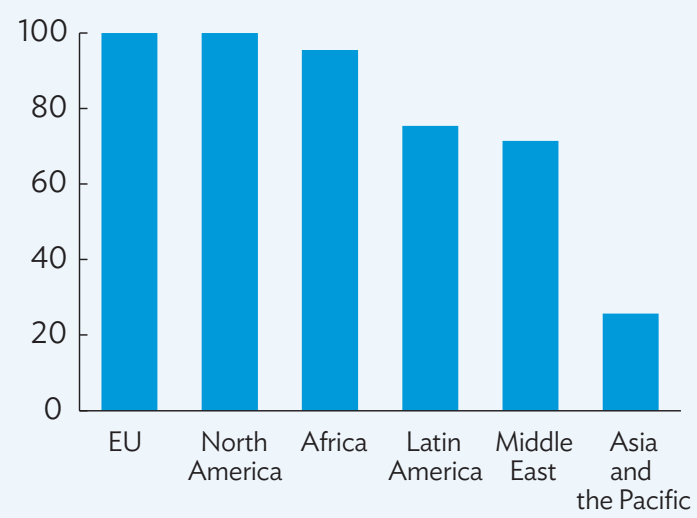

(b) By subregion

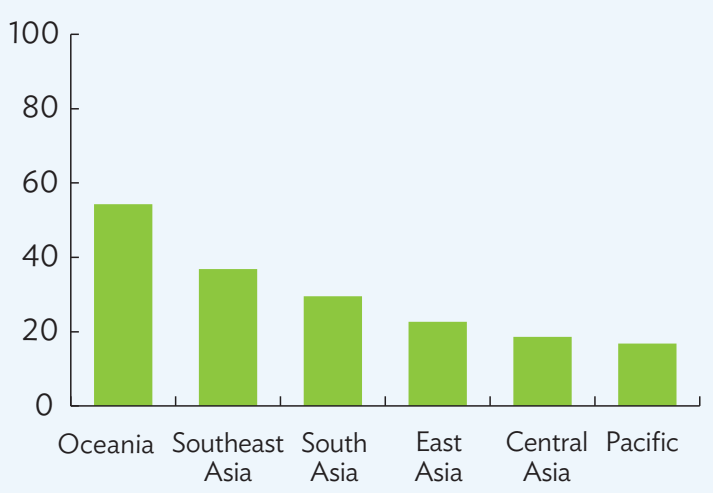

$\mathrm{EU}=$ European Union.

Source: Asian Development Bank calculations using data from A. Dür, L. Baccini, and M. Elsig. 2014. The Design of International Trade Agreements: Introducing a New Database. The Review of International Organizations. 9 (3). pp. 353-375.

while Asia recorded a smaller share of economies that have mutual BITs in the region at 17\% last 2018 (Figure 2.30, panel a). Despite this, all subregions in Asia have recorded a slight increase from its 2006 values, except for the Pacific islands, which indicate that the number of signed BITs has increased over time (Figure 2.30, panel b).

\section{Double taxation treaties signed}

In 2018, the PRC had the greatest number of intraregional double taxation treaties signed in Asia. It had signed agreements with 28 out of 47 other economies in Asia.

North America and Europe are more highly integrated than other regions in their institutional arrangements for double taxation treaties (Figure 2.31, panel a). The same is observed for subregions in Asia, where East Asia leads and is followed by Southeast Asia (Figure 2.31, panel b). A value equal to one for this indicator implies that all countries within a region have signed double taxation treaties with each other (e.g., North America). The closer the indicator is to one, the greater the number of intraregional double taxation treaties signed. There has been an increase in this indicator for most subregions in Asia over the 2006-2018 period.

\section{Membership in Intergovernment Organizations}

\section{Indicators}

VI-d: Number of international intergovernment organizations in which an economy is a member

Enhanced intergovernmental dialogue helps establish strong regional resilience against future financial crises and assist in finding mechanisms to manage regional public goods in areas such as health, environment, 
Figure 2.30: Bilateral Investment Treaties Signed with Intraregional Economies

(\% of total economies in the region)

(a) By region

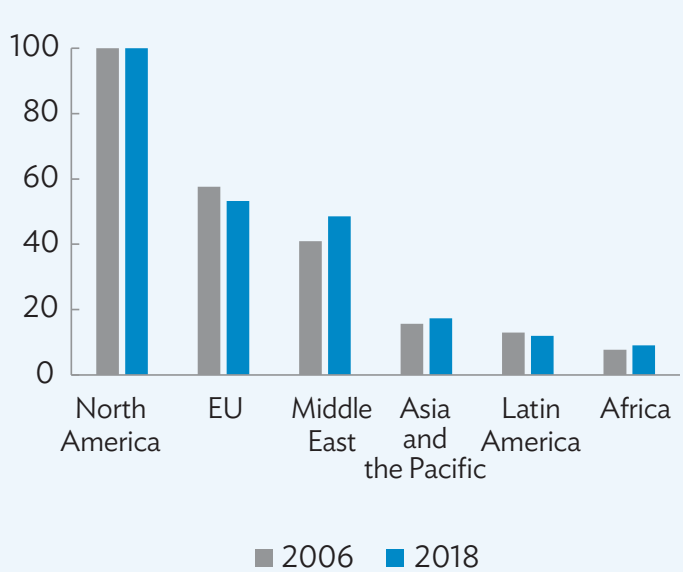

(b) By subregion

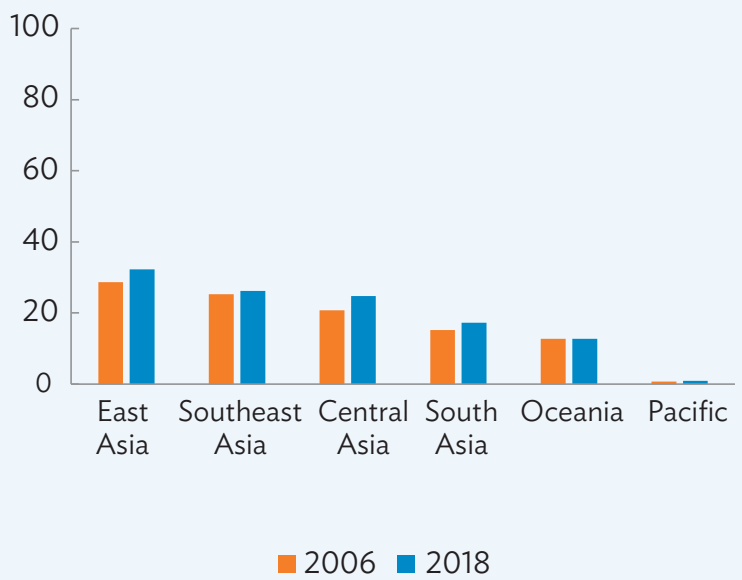

$\mathrm{EU}=$ European Union

Source: Asian Development Bank calculations using data from United Nations Conference on Trade and Development. International Investment Agreements Navigator. https://investmentpolicy.unctad.org/international-investment-agreements/ (accessed June 2020); and A. Dür, L. Baccini, and M. Elsig. 2014. The Design of International Trade Agreements: Introducing a New Database. The Review of International Organizations. 9(3). pp. 353-375.

Figure 2.31: Double Taxation Treaties Signed with Intraregional Economies

(\% of economies in the region)

(a) By region

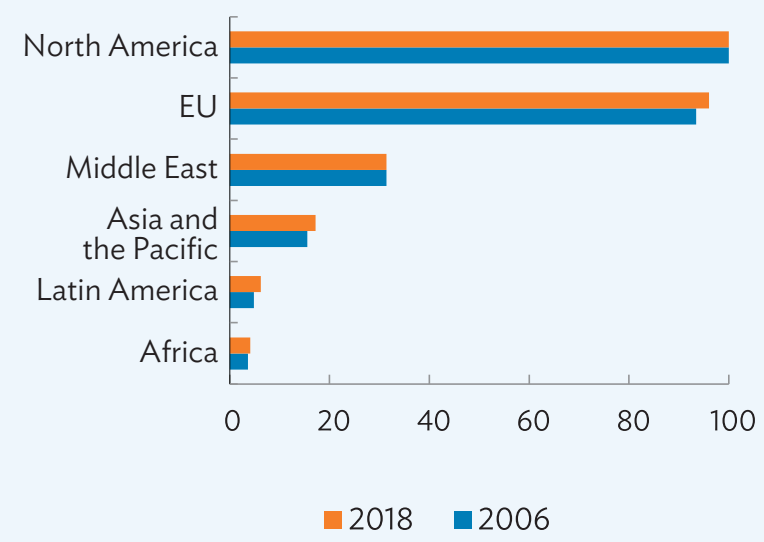

(b) By subregion

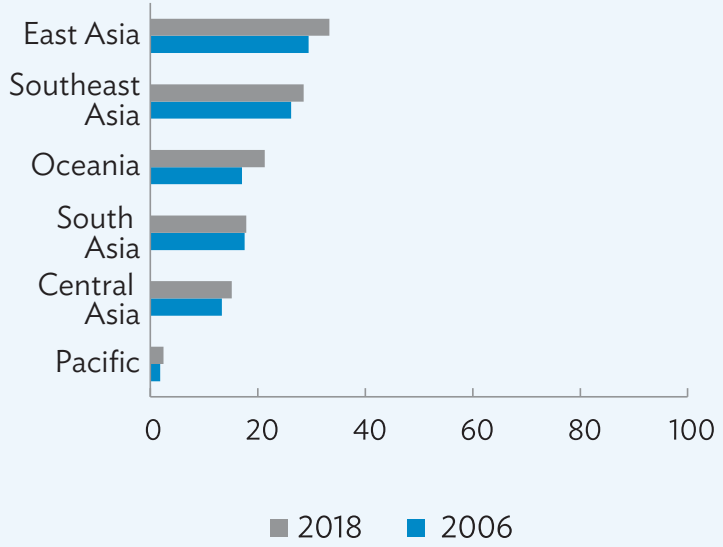

$\mathrm{EU}=$ European Union.

Source: Asian Development Bank calculations using data from the International Bureau of Fiscal Documentation. Tax Treaties Database. https://research.ibfd.org/ (accessed December 2019). 
and safety (Capannelli, Lee, and Petri 2009). Membership in international intergovernment organizations can signal an economy's level of cooperation in the international community. Europe (post-2010) has the highest number of memberships, followed by North America. Among the subregions in Asia, Oceania consistently had the highest number of memberships.

Using data from The CIA World Factbook, this national-level indicator (VI-d) is computed as the number of international intergovernment organizations in which an economy is a member. All regions recorded an increase in membership. The biggest surge from 2006 to 2018 is seen in Europe (Figure 2.32, panel a). In Asia, all subregions improved their membership of intergovernment organizations from 2006 to 2018, with Oceania leading the increase (Figure 2.32, panel b). These higher numbers correspond to stronger integration for this dimension and for the overall index.

Figure 2.32: Number of Intergovernment Organizations Memberships (average by nations)

(a) By region

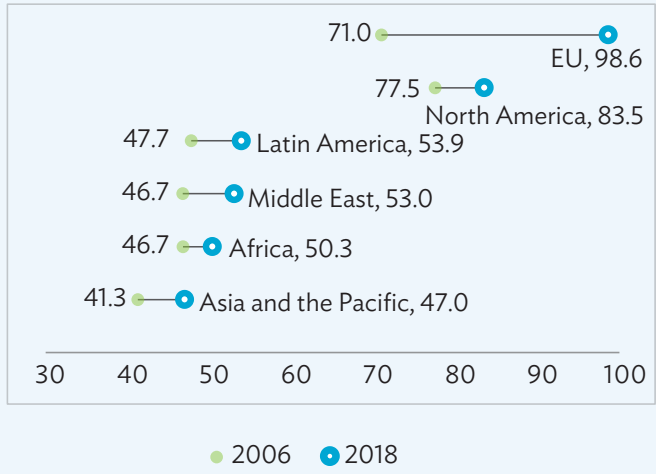

(b) By subregion

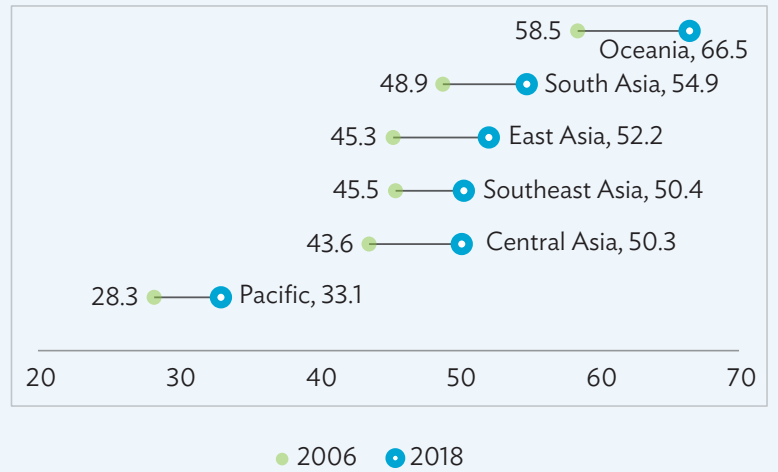

$\mathrm{EU}=$ European Union

Source: Asian Development Bank calculations using data from the United States Central Intelligence Agency. The CIA World Factbook. https://www.cia.gov/the-world-factbook/ (accessed August 2020).

\section{Embassy Presence}

\section{Indicators}

VI-e: Proportion of intraregional economies that have an embassy

Embassies play an important role in establishing international relations and strengthening diplomacy. The benefits of embassy presence to the regional economy are numerous. For instance, embassies assist in managing linkages between two countries and identify areas for mutual cooperation such as participation in bilateral or multilateral agreements. 
Using bilateral data from The Europa World Year Book, the indicator is computed as a ratio of partner economies in the region that have an embassy, relative to the total number of economies in the region. A higher share corresponds to stronger regional integration in the institutional arrangement dimension. North America has the highest share, while Africa and Asia have the lowest (Figure 2.33, panel a). This reflects that embassy presence in economies within Asia is still relatively sparse. In particular, the Pacific islands only have $10 \%$ embassy presence in the subregion, while Oceania has around 54\% (Figure 2.33, panel b).

Figure 2.33: Embassy Presence in Intraregional Economies (\% of economies in the region)

(a) By region

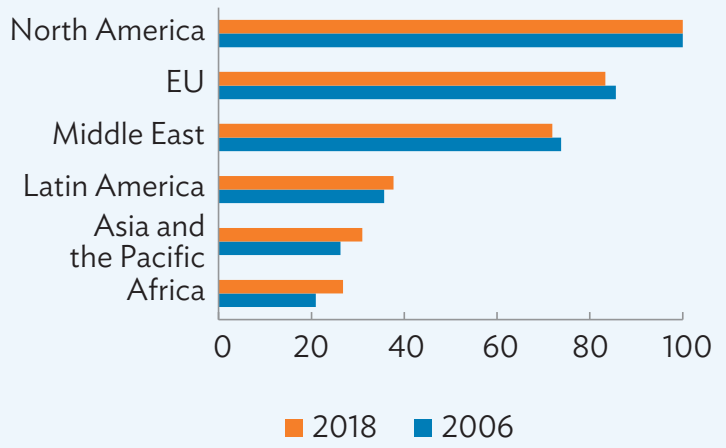

$\mathrm{EU}=$ European Union.

Source: Huh (2020) based on the Europa Publications, ed. 2020. The Europa World Year Book 2020. 61st ed. Routledge. (b) By subregion

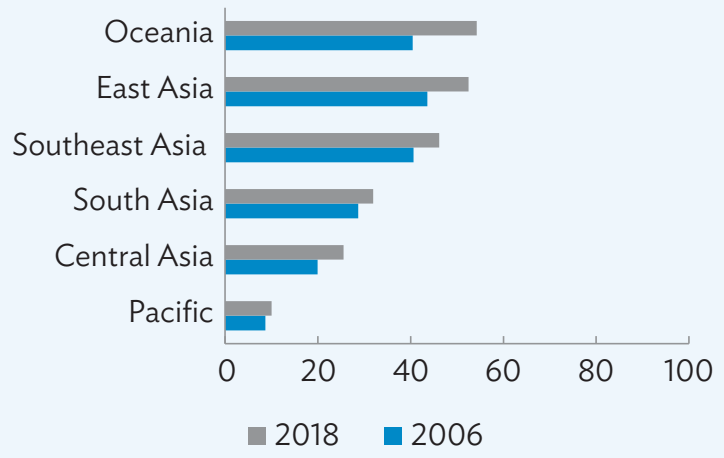

\section{Dimension VII: Technology and Digital Connectivity}

The digital technologies now determining new forms of connectivity have significant impacts on regional integration. ${ }^{17}$ Trends in indicators of technological sharing and digital connectivity show that Asia is increasingly integrated through these channels. The technology and digital dimension naturally responds to the growing role of digital technologies in economic activity, which other dimensions had not fully captured. It also aims to reflect regional progress in research and technological exchange.

This dimension consists of six indicators: four bilateral (VII-a, VII-b, VII-c, VII-f) and two national (VII-d, VII-e) in nature. All are interpreted similarly, where a higher value corresponds to greater levels of regional integration and a higher ARCII estimate.

The discussion for this dimension and its corresponding indicators is largely based on the sixth chapter of the Asian Economic Integration Report 2021. 


\section{Information and Communication Technology (ICT) Goods Trade}

\section{Indicators}

VII-a: Proportion of intraregional ICT goods trade (exports plus imports) to total ICT goods trade

Asia's production networks reflect high regional integration in ICT goods trade. The share of intraregional to total ICT goods trade show that Asia performs better than Europe (Figure 2.34, panel a). Within Asia, the share of intraregional ICT goods is growing, with most subregions having more than a $70 \%$ share. Oceania leads in the trade of ICT goods within its subregion, whereas Central Asian countries tend not to perform as well as the rest of the region (Figure 2.34, panel b).

Figure 2.34: Information and Communication Technology Intraregional Goods Trade (\% of total ICT goods trade)

\section{(a) By region}

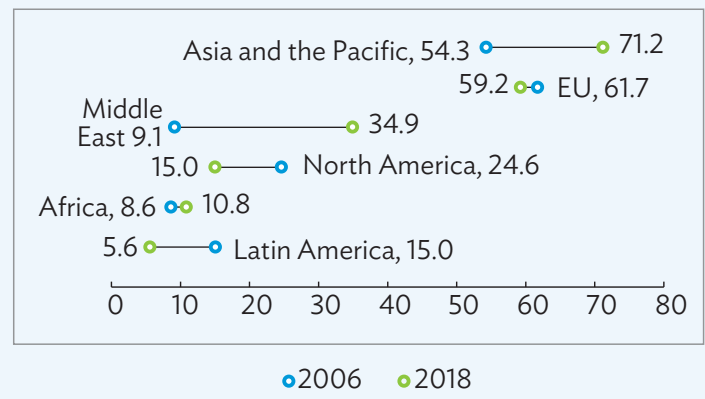

(b) By subregion

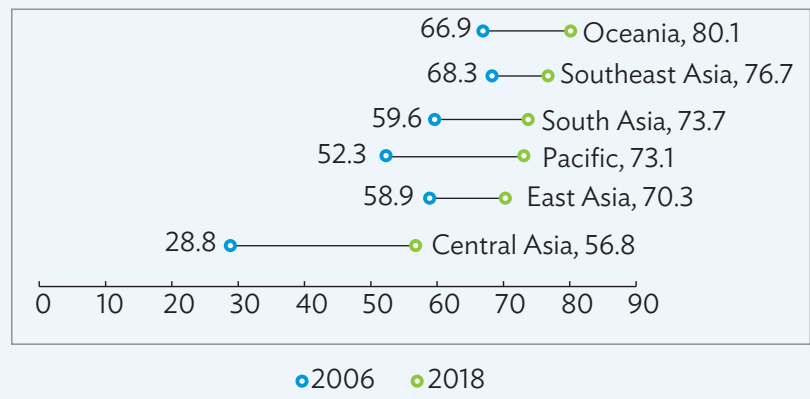

$\mathrm{EU}=$ European Union, ICT = information and communication technology.

Source: Asian Development Bank calculations using data from United Nations Commodity Trade Statistics Database. https://comtrade. un.org (accessed August 2020).

\section{Technology and Knowledge Collaboration}

\section{Indicators}

VII-b: Ratio of research outputs with intraregional collaborators relative to research outputs with all international collaborators

VII-c: Ratio of patent applications made with intraregional residents to patent applications made with all foreign residents 


\section{Research outputs}

Asian economies have improved their regional collaboration through research outputs. Research collaboration and innovation among regional partners can have beneficial effects (Guerrero Bote et al. 2013). Intraregional research is defined as research outputs produced with intraregional collaborators considering the author's affiliation rather than nationality.

Indicators on technology transfer through research (VII-b) in Asia show a steady increasing trend since 2006 (Figure 2.35, panel a), with the Pacific and Southeast Asia having the highest share of research outputs produced with intraregional collaborators relative to its total, followed by South Asia and Central Asia. Meanwhile, research collaboration among regional peers is lower in Oceania and in East Asia, which is explained by higher extraregional research collaboration in these subregions (Figure 2.35, panel b).

Figure 2.35: Research Outputs with Intraregional Collaboration

(\% of total international collaboration)

(a) By region

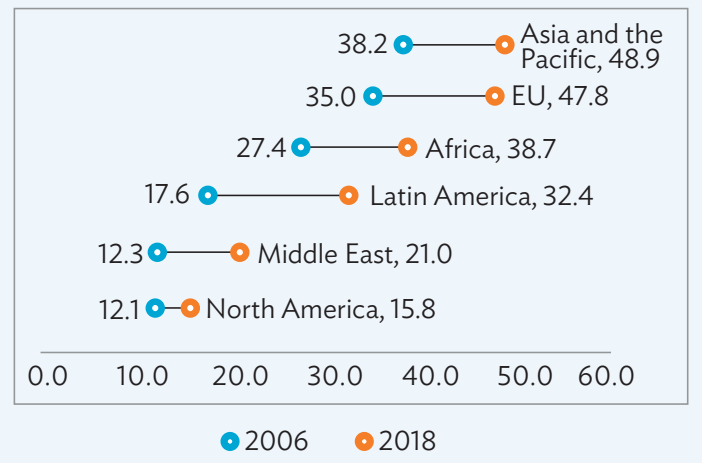

(b) By subregion

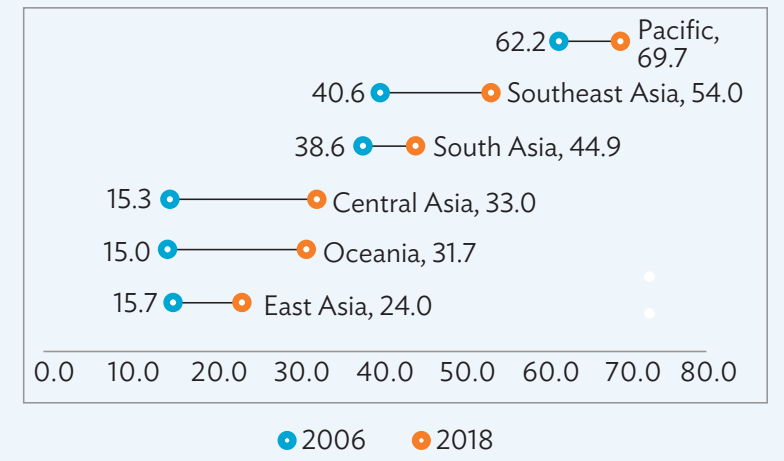

$\mathrm{EU}=$ European Union.

Source: Huh (2020) based on Web of Science data.

Individual economy performance also suggests large heterogeneity in research outputs across Asia. The PRC and Australia have encouraged collaboration among local researchers within Asia, with the PRC producing an average of more than 27,000 research outputs, and Australia more than 17,000, from 2015 to 2018. Other economies in Asia (e.g., India, Japan, the Republic of Korea, Singapore) have also enlarged the pool of intraregional research outputs (Figure 2.36). ${ }^{18}$

\section{Patent applications}

Patterns of registration of patent applications can reflect synergies for research production and innovation at the regional level applications. Intraregional patent applications in Asia have been consistently high, with clear gaps among subregions. Using data from the World Intellectual Property Organization, the ARCII indicator is computed as the number of patent applications made with intraregional residents relative to patent applications made by all foreign residents. A higher share corresponds to stronger regional integration.

\footnotetext{
For instance, a publication produced by an Asian researcher affiliated with a US institution counts in favor of the United States. Meanwhile, if an Asian researcher based in the United States coauthored a paper with a researcher in Canada, this counts as an intraregional research output for the North America region. The equivalent ARCII indicator is computed as a ratio between the number of research outputs with intraregional collaborators relative to research outputs with all international collaborators.
} 
Figure 2.36: Number of Intraregional Research Outputs in Asia and the Pacific

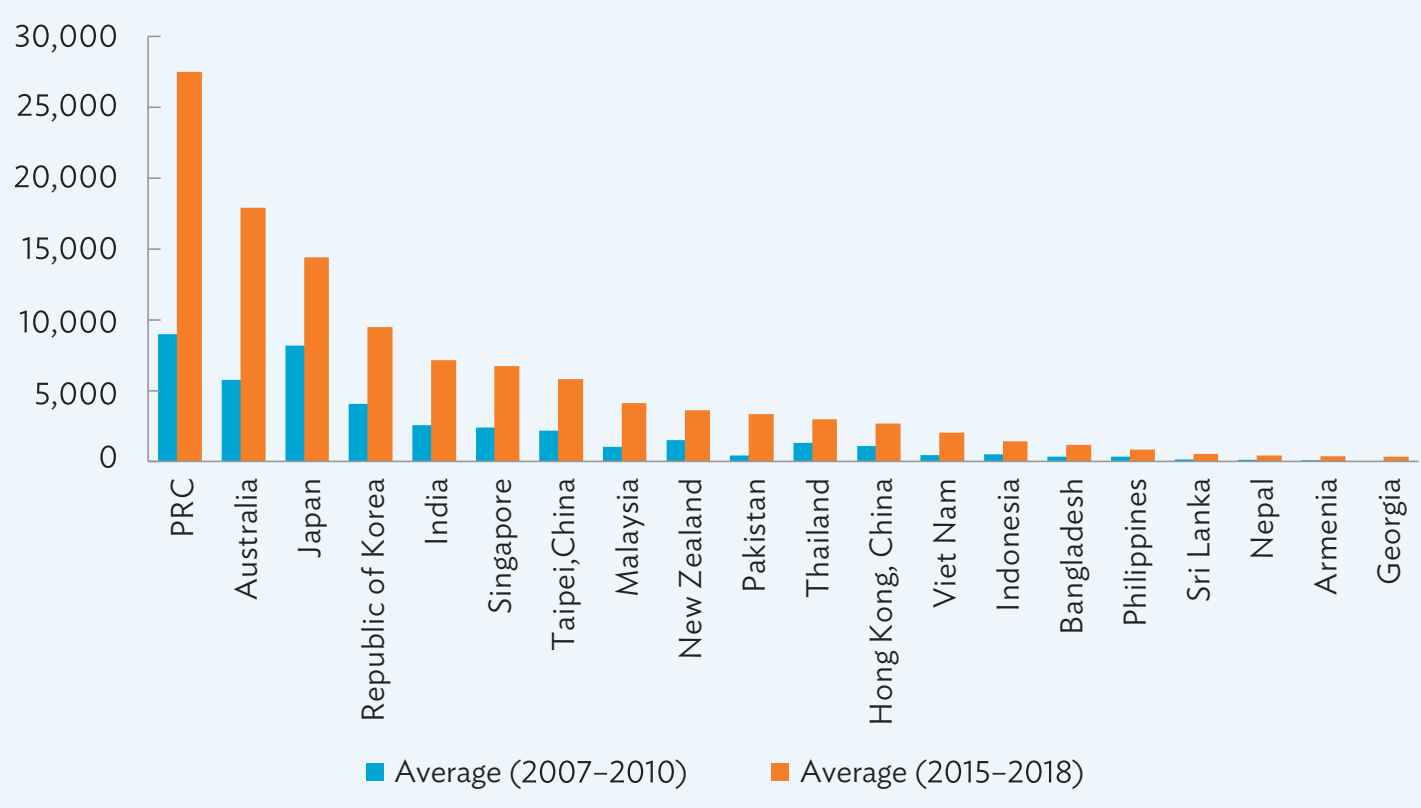

PRC = People's Republic of China.

Note: Refer to research outputs from the Science Citation Index Expanded collection, with all languages, and all research output included. Source: Huh (2020) based on Web of Science data.

Global trends show that Europe's share gradually declined from 28\% in 2006 to 17\% in 2018. Meanwhile, Asia maintained its share within the $60 \%$ to $80 \%$ range over the same period (Figure 2.38, panel a). East Asia filed the largest number of intraregional patent applications relative to its total, with Southeast Asia's share catching up in recent years (Figure 2.38, panel b). The top three economies in the region are all from East Asia, led by the PRC, which recorded about 1.4 million filings in 2018 (Figure 2.37).

\section{Internet and Mobile Connectivity}

\section{Indicators}

VII-d: Proportion of persons using the internet

VII-e: Proportion of mobile subscriptions per 100 persons

VII-f: International internet bandwidth

\section{Internet penetration}

Digital connectivity in Asia has increased, with rising internet penetration, but large subregional gaps persist. Greater access to online resources through internet connectivity allows consumers, businesses, and governments to gain wider and better access to goods and services beyond geographic borders. Overall, global trends in internet penetration show a steady increase over the last decade, with significant gaps among regions. However, looking at 
Figure 2.37: Number of Intraregional Patent Applications in Selected Asia and the Pacific Economies

('000)

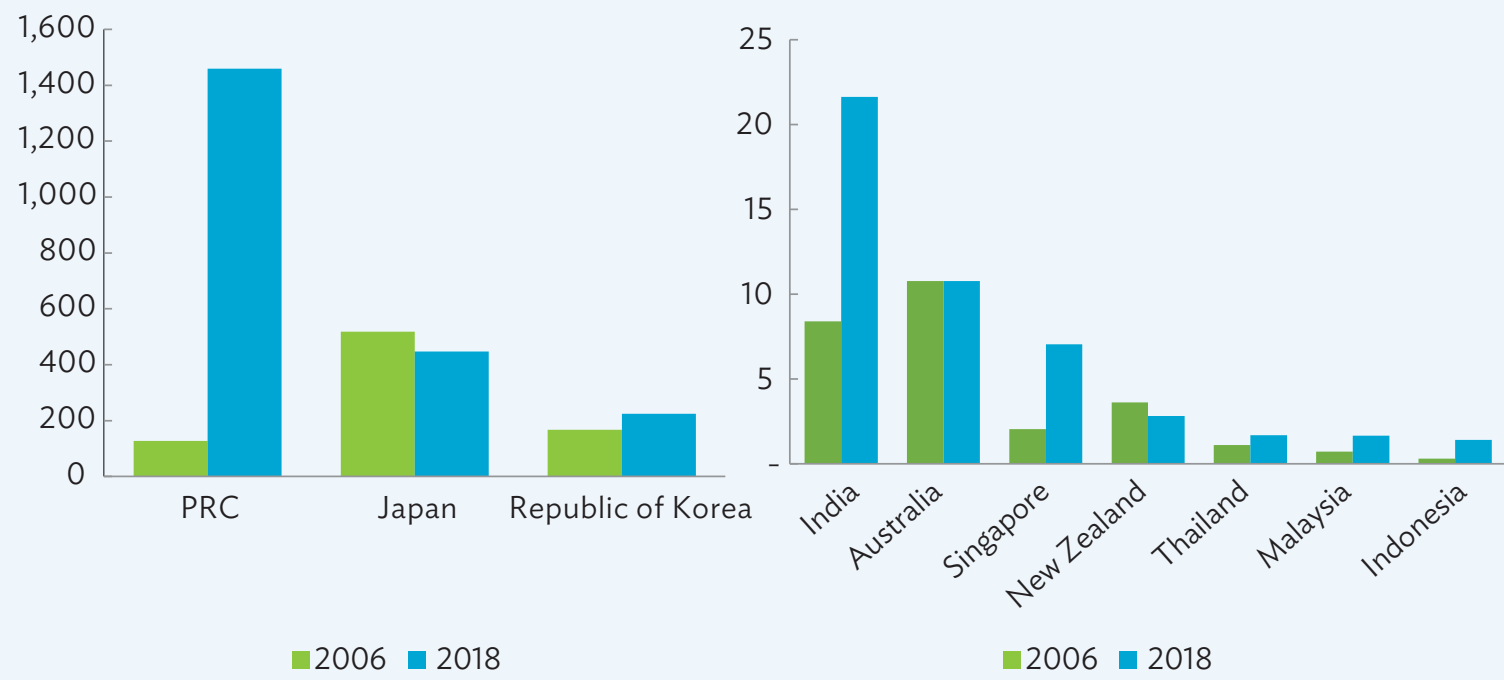

PRC $=$ People's Republic of China.

Source: Asian Development Bank calculations using data from World Intellectual Property Organization (WIPO). WIPO IP Statistics Data Center. https://www3.wipo.int/ipstats/ (accessed May 2020).

Figure 2.38: Intraregional Patent Applications

(\% of total patent filings by all foreign residents)

(a) By region

100

80

60

40

20

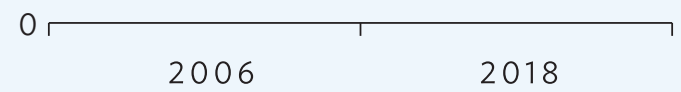

- Asia and the
$\times$ Middle East
$\times \quad$ EU

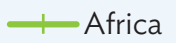

- North America

$x \mathrm{EU}$ (b) By subregion

100

80

60

40

20
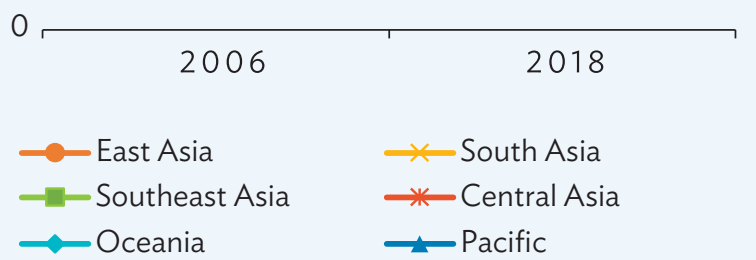

$\mathrm{EU}=$ European Union.

Source: Asian Development Bank calculations using data from World Intellectual Property Organization. WIPO IP Statistics Data Center. https://www3.wipo.int/ipstats/ (accessed May 2020). 
the proportion of the population using the internet, Asia lags behind most regions. More than half of the populations of North America, Europe, and the Middle East had access to the internet by 2013, whereas Asia reached the same level only in 2018 (Figure 2.39, panel a).

Within Asia, progress on digital connectivity varies across economies, with a significant improvement over the past decade (Figure 2.39, panel b). While economies like Australia; Hong Kong, China; Japan; the Republic of Korea; and New Zealand have an average internet penetration rate of more than $85 \%$, the Pacific developing member countries-including Kiribati, Papua New Guinea, and Solomon Islands-continue to struggle, with fewer than 15\% of their populations having internet access (Figure 2.40).

Figure 2.39: Internet Penetration

$$
\text { (\% of population) }
$$

(a) By region

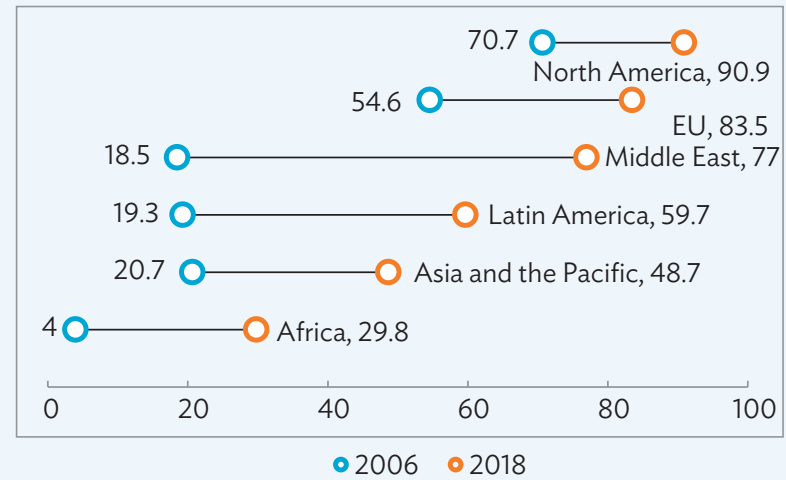

(b) By subregion

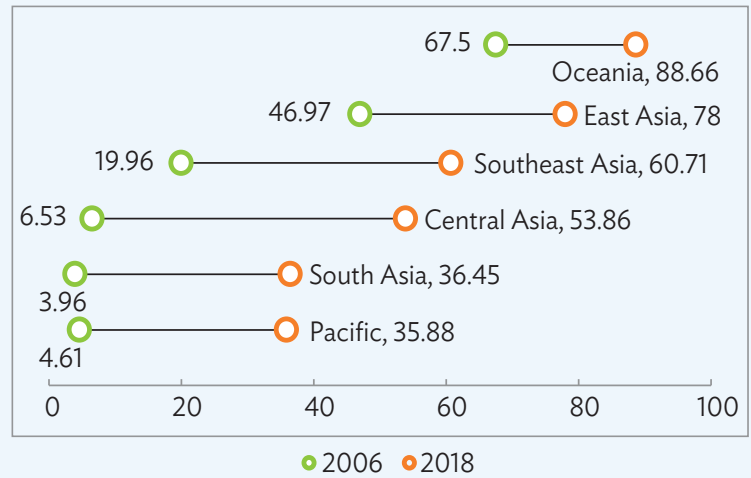

$\mathrm{EU}=$ European Union

Source: Asian Development Bank calculations using data from International Telecommunication Union. Statistics. https:/www.itu.int/en/ ITU-D/Statistics/Pages/stat (accessed February 2020).

\section{Mobile subscriptions}

Another indicator of regional connectivity is the number of mobile subscriptions in a country. The International Telecommunication Union provide this data annually. Mobile phone usage has become a common means of communication. In recent years, this technology and internet usage have been the main drivers of economic growth in developing countries (Bahrini and Qaffas 2019). Besides creating about $\$ 1.1$ trillion of economic value in 2018 for the global mobile ecosystem, mobile technologies have helped enterprises conduct business - through e-commerce, for example (GSM Association 2019). They have also generated spillover effects to other industries through higher output and more employment opportunities.

There is a clear growing global trend in mobile phone usage. All regions had more mobile subscribers in 2018 than in 2006, with Asia and Africa recording the biggest jump (Figure 2.41, panel a). For Asian mobile users, East Asia had the most mobile subscriptions - from 77 mobile subscription per 100 users in 2006 to 152 in 2018. This means some people have more than one mobile subscription (Figure 2.41, panel b). 
Figure 2.40: Internet Penetration for Selected Asia and Pacific Economies

(\% of population)

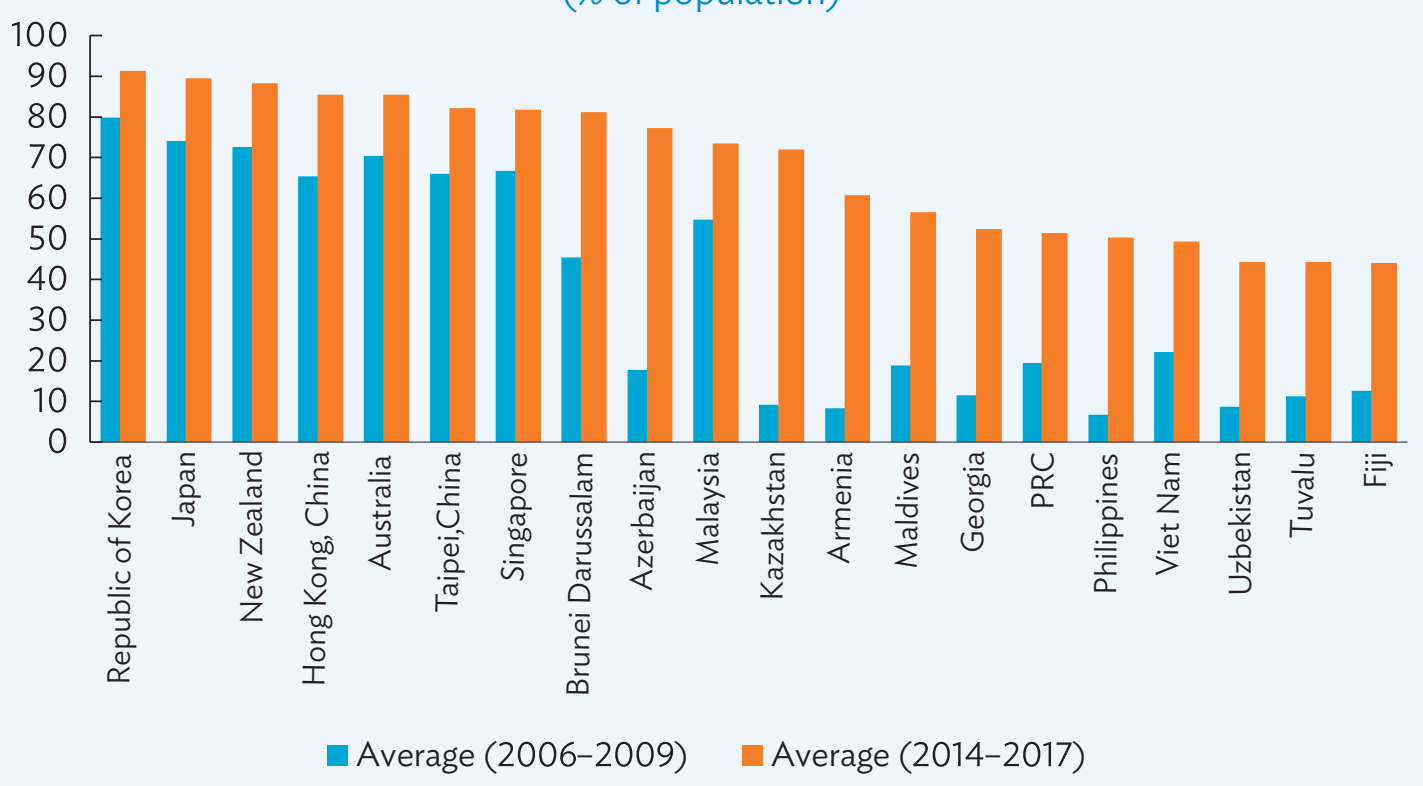

PRC $=$ People's Republic of China.

Source: Asian Development Bank calculations using data from International Telecommunication Union. Statistics. https://www.itu.int/en/ ITU-D/Statistics/Pages/stat (accessed February 2020).

Figure 2.41: Mobile Subscriptions

(per 100 persons)

(a) By region

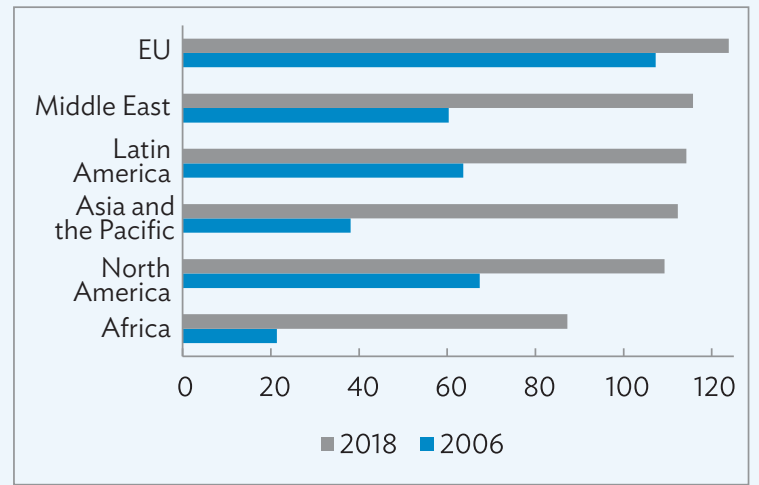

$\mathrm{EU}=$ European Union.

Source: Asian Development Bank calculations using data from International Telecommunication Union. Statistics. https://www.itu.int/en/ ITU-D/Statistics/Pages/stat (accessed February 2020).

\section{International internet bandwidth}

The framework uses national-level data on internet bandwidth per user from International Telecommunication Union to construct indicator VII-f (international internet bandwidth) due to its wider economy and year coverage. To complement this and better understand the bilateral flow of bandwidth among economies and 
regions, the index also uses valuable information from the TeleGeography Global Internet Geography (GIG) report. The GIG report contains dyadic data on internet bandwidth traffic. Internet bandwidth capacity is defined as the amount of data transmitted in the public internet, which includes general internet traffic through e-mail, webpages, video streaming, voice over internet protocol (VOIP) calls, and corporate internet protocol virtual private network (IP VPN) traffic over a given period. The values in Table 2.4 present the internet bandwidth capacity measured in gigabytes per second (Gbps) within Asia (intraregional) and across other regions (interregional).

Asia's bilateral internet bandwidth performs better regionally than with the rest of the world, particularly intraregional internet bandwidth capacity (Table 2.4). The share of bandwidth to North America dropped from 49\% in 2010 to just shy of $25 \%$ in 2019. A possible explanation could be the growing efforts of key content providers such as Google and Facebook in augmenting their proprietary bandwidth across the Pacific to connect their data centers and to push their content closer to end users (TeleGeography 2019). As a result, Asian carriers have little incentive to operate a high-capacity link to North America.

Table 2.4: International Internet Bandwidth by Regional Routes

\begin{tabular}{|c|c|c|c|c|c|}
\hline \multirow[b]{2}{*}{ Origin } & \multirow[b]{2}{*}{ Destination } & \multicolumn{2}{|c|}{ Gbps } & \multicolumn{2}{|c|}{ Share to Total (\%) } \\
\hline & & 2010 & 2019 & 2010 & 2019 \\
\hline Asia and the Pacific & Asia and the Pacific & 1,776 & 58,019 & 37.8 & 54.0 \\
\hline Asia and the Pacific & US and Canada & 2,314 & 26,729 & 49.2 & 24.9 \\
\hline Asia and the Pacific & EU & 499 & 20,150 & 10.6 & 18.7 \\
\hline Asia and the Pacific & Middle East & 81 & 2,480 & 1.7 & 2.3 \\
\hline Asia and the Pacific & Africa & 32 & 112 & 0.7 & 0.1 \\
\hline Asia and the Pacific & Latin America & 0 & 0 & 0.0 & 0.0 \\
\hline
\end{tabular}

$\mathrm{EU}=$ European Union, Gbps = gigabyte per second, US = United States.

Notes: Values refer to the internet bandwidth connected across international borders as of 30 June 2020. The order of region pairs does not imply directionality. Domestic routes are excluded. Regional totals may differ from the sum of connected regions due to rounding.

Source: Asian Development Bank calculations using data from Telegeography. Global Internet Geography (accessed June 2020).

Crucially, the significant share of international internet bandwidth capacity within Asia reflects high internet traffic among Asian economies and shows that digital connectivity is well-established within the region (Figure 2.42, panel a). In particular, South Asia experienced the highest surge in intraregional bandwidth traffic, which could be because the outsourcing industry for economies like India is booming (Figure 2.42, panel b). Internet traffic between Indonesia and Singapore rose from 2.4 Gbps in 2006 to 7,041.6 Gbps in 2019 (Table 2.5).

\section{Dimension VIII: Environmental Cooperation}

While remarkable success has been observed in international trade throughout the past decades, this has led to an unprecedented increase in consumption (OECD 2013). At the same time, environmental concerns are on the rise, from the increase in global temperatures to water and air pollution across neighboring countries, along with a range of other issues that have adverse implications for economic growth and overall well-being.

Tackling environmental degradation necessitates cooperation that goes beyond national borders. This can be done as regional cooperation and integration can help identify and harness inherent synergies between existing and emerging opportunities for collaboration on environmental protection (Duggal 2020). 
Figure 2.42: Intraregional Internet Bandwidth

(\% of total internet bandwidth traffic)

(a) By region

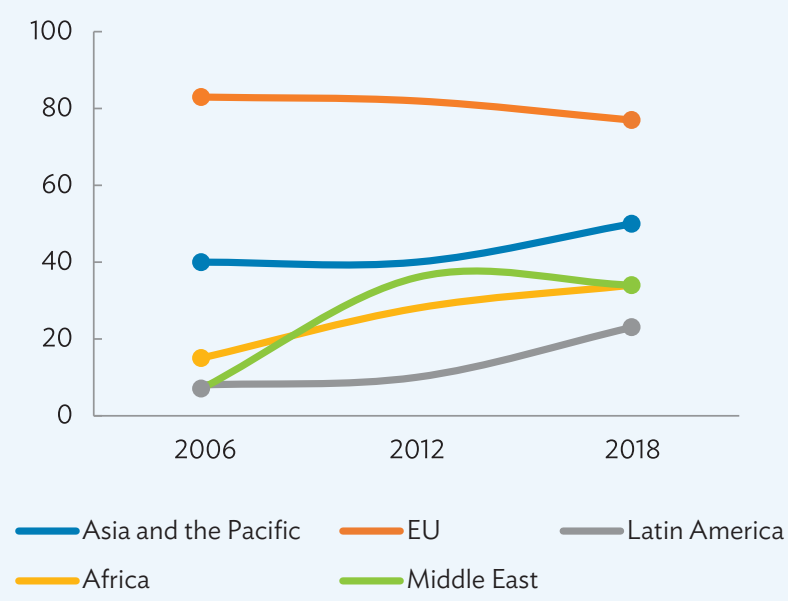

(b) By subregion

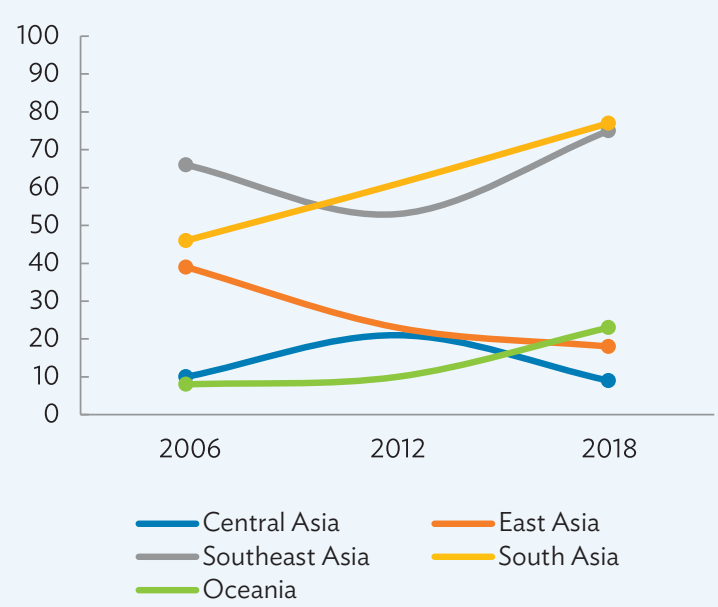

$\mathrm{EU}=$ European Union.

Note: Values refer to the average internet bandwidth with economies belonging to the same region/subregion/subregional program, expressed as ratio to the average internet bandwidth with all economies worldwide.

Source: Asian Development Bank calculations using data from TeleGeography. Global Internet Geography (accessed June 2020).

Table 2.5: International Internet Bandwidth Traffic for Selected Asia and the Pacific Economies (in Mbps)

\begin{tabular}{llrrr} 
Origin & \multicolumn{1}{c}{ Destination } & 2006 & 2012 & \multicolumn{1}{c}{2019} \\
\hline Indonesia & Singapore & 2,437 & 159,406 & $7,041,643$ \\
\hline India & Singapore & 6,153 & 241,969 & $5,537,849$ \\
\hline People's Republic of China & Singapore & 14,337 & 373,804 & $5,069,763$ \\
\hline People's Republic of China & Viet Nam & 3,265 & 194,729 & $5,069,000$ \\
\hline People's Republic of China & Japan & 51,489 & 745,156 & $4,800,856$ \\
\hline Singapore & Thailand & 417 & 87,223 & $4,313,075$ \\
\hline Malaysia & Thailand & 90 & 21,272 & $2,600,000$ \\
\hline Singapore & Viet Nam & 977 & 32,443 & $2,351,000$ \\
\hline Malaysia & Singapore & 4,377 & 154,524 & $2,316,755$ \\
\hline Japan & Singapore & 10,427 & 265,912 & $2,297,443$ \\
\hline People's Republic of China & Taipei,China & 38,033 & 323,234 & $2,011,201$ \\
\hline People's Republic of China & Republic of Korea & 26,212 & 267,608 & $1,382,555$ \\
\hline People's Republic of China & Malaysia & 2,782 & 99,546 & $1,176,155$ \\
\hline Japan & Republic of Korea & 32,174 & 174,042 & $1,095,266$ \\
\hline Australia & New Zealand & 2,862 & 43,193 & $1,022,864$ \\
\hline M & & & & \\
\hline
\end{tabular}

Mbps = megabyte per second.

Notes: Values refer to the internet bandwidth connected across international borders as of 30 June 2019. The order of region pairs does not imply directionality. Domestic routes are excluded. Regional totals may differ from the sum of connected regions due to rounding.

Source: Asian Development Bank calculations using data from TeleGeography. Global Internet Geography (accessed June 2020). 
In this manner, economies have a path to achieving environmentally sustainable economic growth. The ARCII aims to measure the extent of regional environmental cooperation using four indicators, containing information on trade in environmental goods, international environmental agreements, the ecological footprint of production, and details that generate an environmental health score. As the framework evolves, other indicators, particularly those providing bilateral information on environmental linkages, will be gradually integrated into this dimension.

\section{Environmental Goods Trade}

\section{Indicators}

VIII-a: Proportion of intraregional environmental goods trade (exports plus imports) to total intraregional goods trade

Given global awareness of climate change, regional and global initatives for reducing greenhouse gas emissions and limiting global warming have been heightened in recent decades. One of the significant efforts utilized by economies is the elimination of customs duties on environmental goods in order to make their trade more affordable and promote their use (UNEP 2017). Environmental goods pertain to commodities which help attain environmental and climate protection, such as generating clean and renewable energy, improving energy efficiency, and controlling air pollution (WTO n.d.).

In the ARCII, indicator VIII-a (Ratio of intraregional environmental goods trade to total goods trade) is incorporated to ascertain whether regional trade measures targeting environmental goods are working, and if such initiatives have led demand for environmental goods among regional partners to increase. In building this indicator, the itemized list of environmental goods from Asia-Pacific Economic Cooperation was utilized.

Figure 2.43: Intraregional Environmental Goods Trade (\% intraregional goods trade)

(a) By region

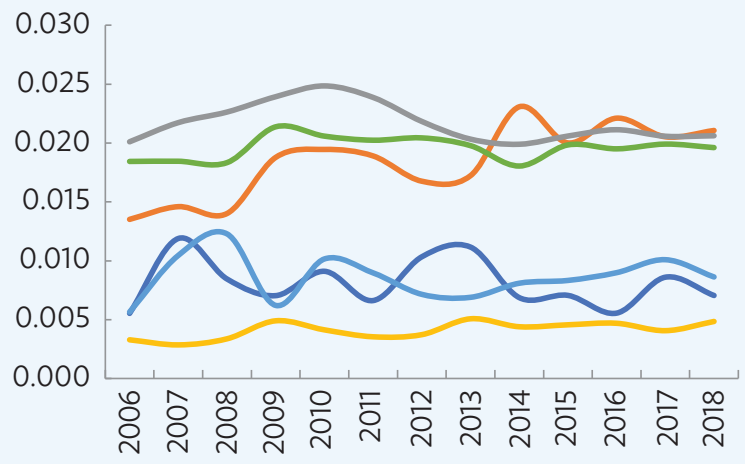

(b) By subregion

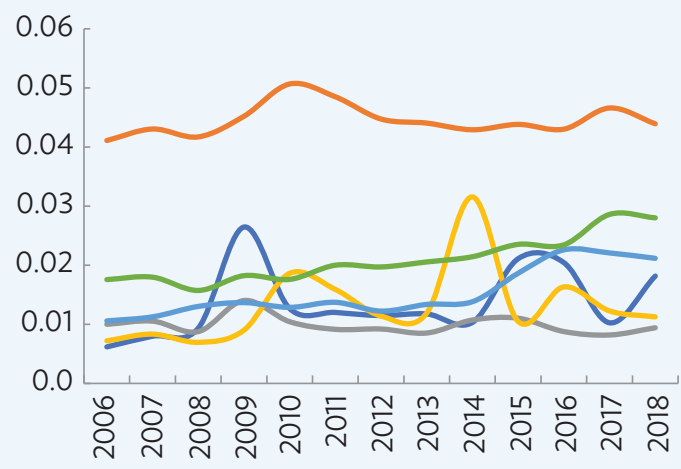

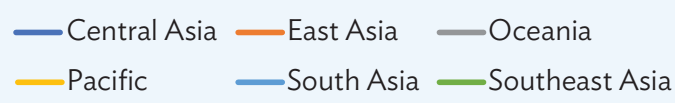

$\mathrm{EU}=$ European Union.

Source: Asian Development Bank calculations using data from United Nations Commodity Trade Database. https://comtrade.un.org (accessed August 2020). 
The list contains 54 products at the Harmonized Standard (HS) six-digit levels, including among other products solar panels, wind turbines, and bamboo flooring (APEC n.d.).

The 2018 trend for indicator VIII-a shows high volumes of intraregional environmental goods trade in EU and Asia (Figure 2.43). Between 2006 and 2018, the share of intraregional trade of environmental goods in Asia increased notably. Within the region, East Asia has the highest volume of intraregional environmental goods trade, while the trend in Southeast Asia has gradually increased since 2006.

\section{International Environmental Agreements Ratified}

\section{Indicators}

VIII-b: Number of international environmental agreements ratified

International environmental agreements (IEAs) are treaties that regulate or manage human impact on the environment. They are important as they enable economies to cooperate in addressing pressing environmental concerns that transcend national boundaries or are global in nature. Arguments in favor of IEAs note that such treaties can influence states' cost-benefit analysis by providing important information on the costs of environmental degradation, which may in turn help curb environmental pollution (Vollenweider 2013).

Figure 2.44: Number of International Environmental Agreements Ratified, 2018

(a) By region

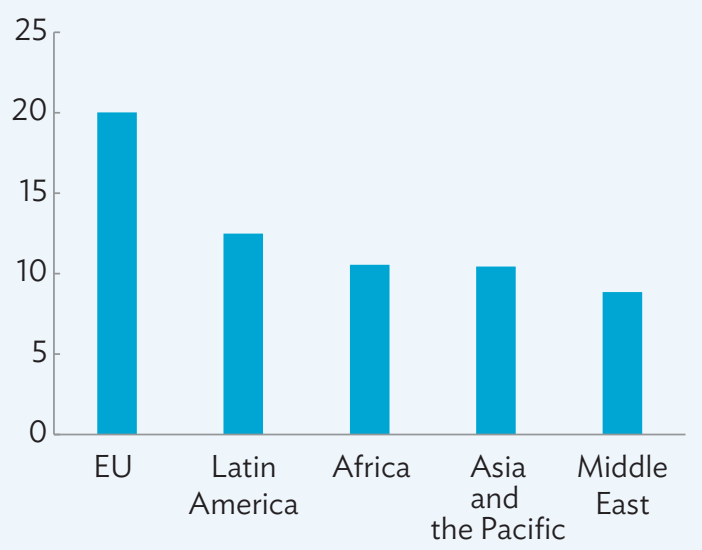

(b) By subregion

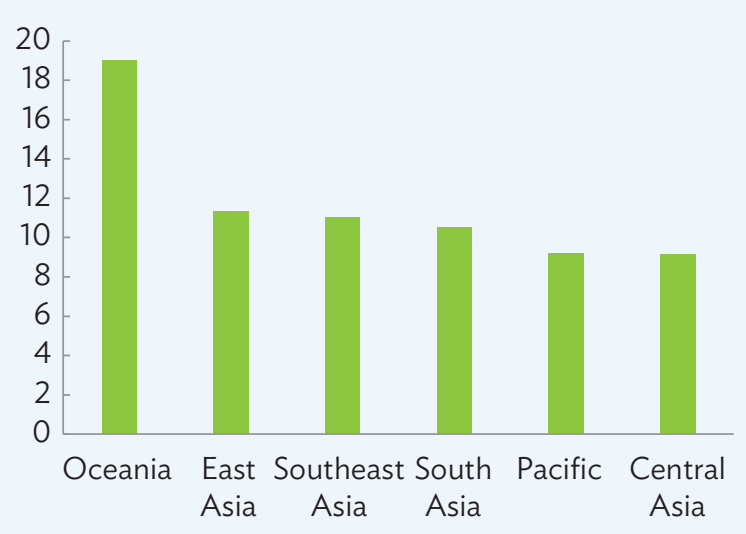

$\mathrm{EU}=$ European Union.

Source: Asian Development Bank calculations from the United States Central Intelligence Agency. The CIA World Factbook. https://www.cia.gov/the-world-factbook/ (accessed August 2020). 
The ARCII includes indicator VIII-b (number of international environmental agreements ratified) to determine whether economies are increasing their engagement in regional or global efforts to tackle environmental issues. A higher value for this indicator means greater environmental cooperation among economies. Trends for this indicator show that among regions, EU has the highest number of ratified IEAs, both for 2006 and 2018 (Figure 2.44). On the other hand, Asia falls behind Latin America, and is almost on par with Africa in terms of performance. Within Asia, Oceania ranks first, and has substantially more IEAs than other subregions.

\section{Ecological Footprint of Production per Capita}

\section{Indicators}

VIII-c: Ecological footprint of production as a share of biocapacity

Under the assumption that economic activity adds greater environmental strain, regional integration would raise environmental pressure, and in a similar vein, the ecological footprint (Altmann 2002). For instance, a study has shown that ecological footprint in consumption tends to be higher in EU countries than in others (Ghita et al. 2018).

Figure 2.45: Ecological Footprint of Production

$$
\text { (\% of biocapacity) }
$$

(a) By region

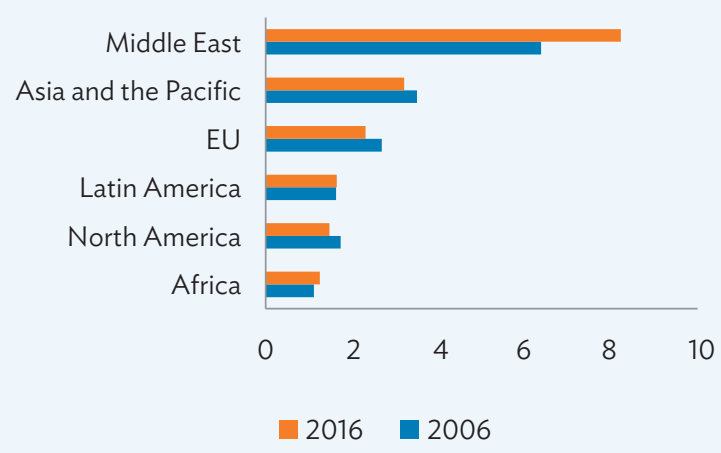

(b) By subregion

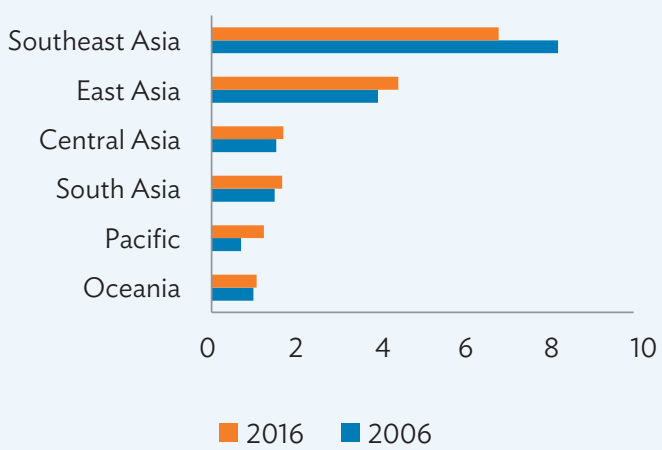

\section{$\mathrm{EU}=$ European Union}

Note: Ecological footprint pertains to a nation's productive footprint, which is the summation of the footprints for all the harvested natural resources and generated wastes within its geographical bounds. Biocapacity pertains to capacity of ecosystems to regenerate the demands of people. A higher ratio (ecological footprint over biocapacity) suggests higher ecological deficit.

Source: Global Footprint Network. National Footprint and Biocapacity Accounts 2021. https://www.footprintnetwork.org/our-work/ ecological-footprint/ (accessed August 2020). 
The ARCII utilizes the data from the Global Footprint Network for indicator VIII-c (ecological footprint of production as a share of biocapacity). The ecological footprint of production is defined as the sum of the footprints for all resources harvested and all of the waste generated within a defined geographical region (Glossary-Global Footprint Network n.d.). On the other hand, biocapacity pertains to ecosystems' capacity to produce biological materials used by people and to absorb waste material generated by human activity, under current management schemes and extraction technologies (Glossary-Global Footprint Network n.d.). A lower value for this indicator is associated with higher environmental cooperation.

As seen in Figure 2.45, panel a, indicator VIII-c has been consistently highest in the Middle East, followed by Asia and Europe. Within Asia, Southeast Asia obtained the highest value for the indicator, and the gap between this subregion and its counterparts is considerably large (Figure 2.45, panel b). However, Southeast Asia marked an improvement in this indicator, as the value decreased from 2006 to 2016. Other subregional groupings experienced a slight increase.

\section{Environmental Health Score}

\section{Indicators}

VIII-d: Environmental health score

The quality of the environment has an impact on people's health and well-being. For instance, environmental pollutants can cause respiratory diseases, heart diseases, and some types of cancer (Brusseau et al. 2019). The World Health Organization noted that in 2012, 23\% of global deaths and 26\% of deaths among children under 5 years of age were attributed to modifiable environmental factors (Prüss-Üstün et al. 2016). In this regard, the importance of environmental risk factors serves as an impetus for coordinated efforts in promoting more healthy environments.

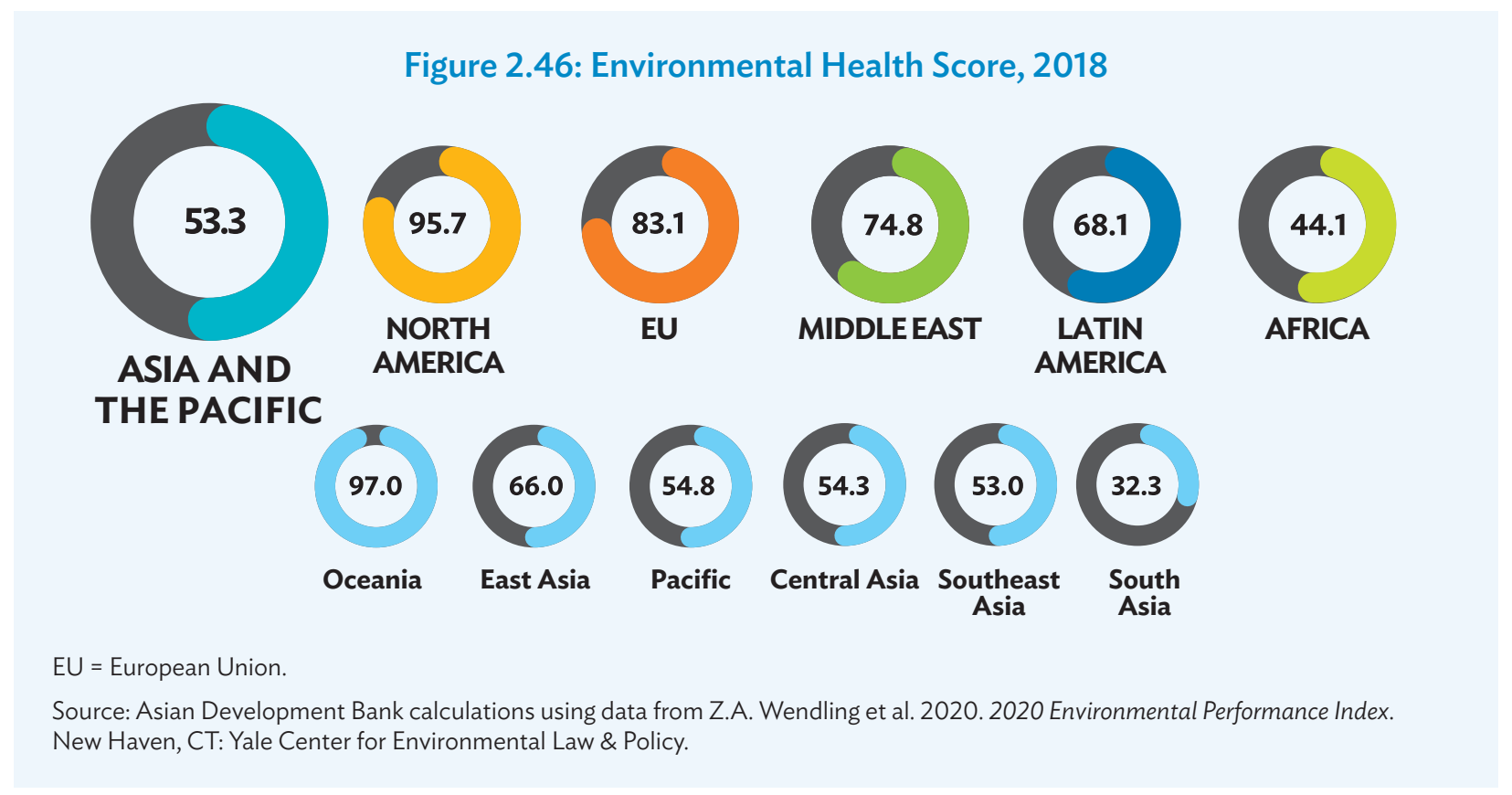


The ARCII includes indicator VIII-d (Environmental Health Score) as a measure in the Environmental Cooperation dimension. The score is a subcomponent of the Environmental Performance Index (EPI) developed by Yale Center for Environmental Law and Policy. Indicator VIII-e gauges how economies fare in protecting their citizens from environmental health risks, and considers four issue categories: air quality, sanitation and drinking water, heavy metals, and waste management. The value for this indicator ranges from 0 (lowest) to 100 (highest). A higher value would suggest that economies are hitting their environmental policy targets to promote environmental health, and therefore higher environmental cooperation.

Trends from indicator VIII-d show that Europe and North America have the highest scores across regions in 2018 (Figure 2.46). Asia and Africa, on the other hand, report lower scores. Among the Asian subregions, Oceania ranks first with an average score of 97.1. South Asia falls behind its neighbors, with an average environmental health score of 32.3.

\section{Methodology Overview}

The process of constructing the index involves data collection, imputation of missing data, normalization through panel min-max scaling, and weighting and aggregation using a two-step panel principal component analysis (PCA) procedure (Huh and Park 2018b). The steps are illustrated in Figure 2.47 and are further elaborated in Appendix $1 .^{19}$

The first step is to collect the historical data for all economies to be used in computing the indicators. The data are updated annually to ensure the latest information is used to generate the index. To fill in data gaps, various imputation methods are implemented: linear interpolation, averaging, regression imputation, and substitution by closest available observation. ${ }^{20}$

As measurement units differ across indicators, normalization is required prior to aggregation to achieve commensurability. Panel min-max normalization involves normalizing indicators based on all sample years and all economies at hand. It is suitable for comparing progress across different economies through the years. However, whenever new data points become available, all indicators need to be normalized again using the new panel. A new data set could change the minimum and maximum values for some indicators, and hence the value of the transformed indicators and resulting composite index. To maintain comparability between existing and new data, the composite index needs to be recalculated using the updated data set (OECD and Joint Research Centre - European Commission 2008). Panel normalization is said to induce a "nonseparability" between years in a sample: a change in the data from 1 year can induce a change in ranking from another year (Lockwood 2004).

In computing the enhanced ARCII estimates, panel min-max worldwide normalization of the 41 indicators is employed to maintain the time consistency of the index. One of the drawbacks of min-max scaling is that extreme values can distort the distribution of normalized values. This can also understate or overstate the resulting composite index. A noticeable difference between the enhanced versus the baseline is the normalization of indicators, which is determined by the nature of comparison or analysis being made on the ARCII results.

Weighting and aggregation of data are intended to improve comparability by utilizing all information at hand. The most important source of incomparability is said to be the systemic statistical properties of the index components that affect weighting (UNCTAD 2007). PCA remains the main statistical tool to obtain the weights utilized for

\footnotetext{
A more detailed discussion of constructing the index, including the imputation methods, normalization procedure, and panel PCA methodology used for the baseline ARCII framework is available in Park and Claveria (2018).

20 A more detailed explanation of the various imputation methods is presented in Huh and Park (2018).
} 
Figure 2.47: Flowchart of ARCII Construction

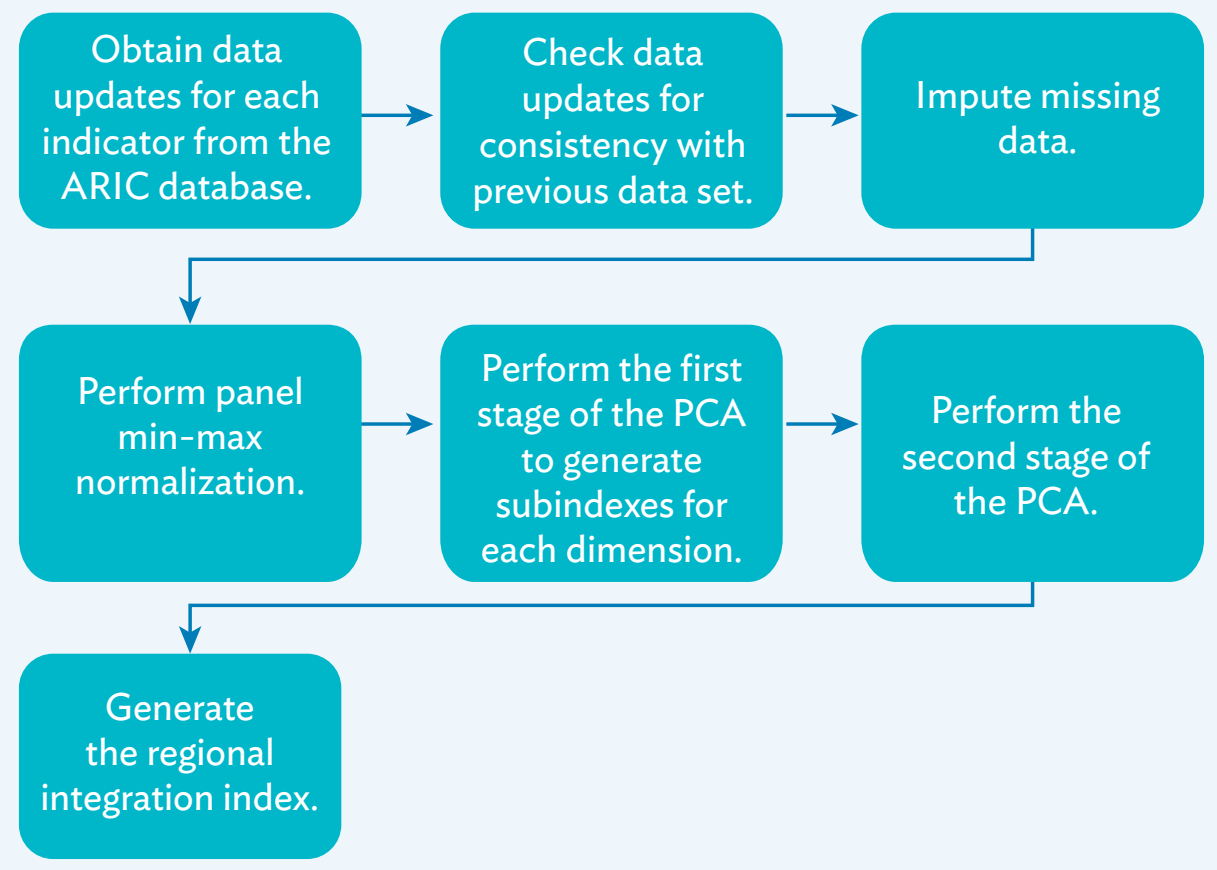

ARCII = Asia-Pacific Regional Cooperation and Integration Index, ARIC = Asia Regional Integration Center, PCA = principal component analysis. Source: Asian Development Bank.

compiling the ARCII. A two-stage panel PCA estimation is carried out to obtain time-consistent weights for aggregation. Before that, the indicators are normalized based on all regions together (i.e., worldwide normalization). In the first stage, panel PCA is applied to each of the dimensions independently, and the implied weights assigned to the indicators are used for constructing a set of dimensional composite indexes. In the second stage, panel PCA is applied again to weigh the dimensional indexes to produce an overall index, which is the ARCII. The two-stage PCA is implemented separately for each region to account for the different features and characteristic of the region in the computation of the index.

All results in the first-stage PCA are invariant to whether the framework is the baseline or enhanced, because each dimension is treated separately when applying PCA. However, the results change in the second stage. This is because the baseline framework has six dimensions, while the enhanced ARCII framework has eight dimensions. The overall index changes since the total weight of one, which was initially allocated into six dimensions in the baseline ARCII, is now allotted to eight dimensions.

Table 2.6 presents the number of principal components that were chosen to calculate the dimensional composite indexes. The number of principal components included differs across dimensions except for North America, where all indicators are equal-weighted as there are only two member countries in the region (Canada and the US). In the case of Europe, the indicators in dimension VI (institutional arrangements) are equal-weighted because most countries have the same value, i.e., perfect indexes across all member countries. This is because Europe has established plurilateral agreements among its members with respect to free trade agreements and bilateral investment treaties. 
Table 2.6: Principal Component Analysis for Aggregation

\begin{tabular}{lcccccc} 
Dimensions & $\begin{array}{c}\text { Asia and } \\
\text { the Pacific }\end{array}$ & EU & $\begin{array}{c}\text { Latin } \\
\text { America }\end{array}$ & Africa & $\begin{array}{c}\text { North } \\
\text { America }\end{array}$ & $\begin{array}{c}\text { Middle } \\
\text { East }\end{array}$ \\
\hline I. Trade and Investment Integration & 2 & 2 & 2 & 2 & Equal & 2 \\
\hline II. Money and Finance Integration & 3 & 3 & 3 & 3 & Equal & 3 \\
\hline III. Regional Value Chain & 3 & 2 & 2 & 3 & Equal & 3 \\
\hline IV. Infrastructure and Connectivity & 2 & 2 & 3 & 2 & Equal & 2 \\
\hline V. People and Social Integration & 2 & 3 & 2 & 3 & Equal & 2 \\
VI. Institutional Arrangements & 1 & Equal & 2 & 2 & Equal & 2 \\
\hline VII. Technology and Digital Connectivity & 3 & 2 & 3 & 3 & Equal & 2 \\
VIII. Environmental Cooperation & 2 & 2 & 2 & 2 & Equal & 2 \\
\hline
\end{tabular}

$\mathrm{EU}=$ European Union

Source: Asian Development Bank calculations.

Three principal components were chosen for combining the eight-dimensional composites into the overall ARCII across the regions (except for North America, where equal weighting applies). The same set of weights were used for the regional and global normalization cases.

The 48 Asian economies covered in this study are classified by subregion (number of economies in parentheses): ${ }^{21}$

- Central Asia (8): Armenia, Azerbaijan, Georgia, Kazakhstan, the Kyrgyz Republic, Tajikistan, Turkmenistan, Uzbekistan

- East Asia (6): the People's Republic of China; Hong Kong, China; Japan; the Republic of Korea; Mongolia; Taipei,China

- Southeast Asia (10): Brunei Darussalam, Cambodia, Indonesia, the Lao People's Democratic Republic (Lao PDR), Malaysia, Myanmar, the Philippines, Singapore, Thailand, Viet Nam

- South Asia (8): Afghanistan, Bangladesh, Bhutan, India, Maldives, Nepal, Pakistan, Sri Lanka

- The Pacific (14): the Cook Islands, Fiji, Kiribati, Marshall Islands, Federated States of Micronesia, Nauru, Palau, Papua New Guinea, Samoa, Solomon Islands, Timor-Leste, ${ }^{22}$ Tonga, Tuvalu, Vanuatu

- Oceania (2): Australia, New Zealand

\section{Interpretation}

In general, bilateral data was used to compile ratios of intraregional activity to total activity. However, there are a few exceptions-indicators IV-c Logistics Performance Index, IV-d Doing Business Index, VI-d international intergovernment organization membership, VII-d internet penetration rate, VII-e mobile subscriptions per 100 persons, VII-f international internet bandwidth, VIII-b number of international environmental agreements ratified, VIII-c environmental health score, and VIII-d ecological footprint of production as share of biocapacitywhich are based on national rather than bilateral data.

The groupings are based on ADB's Asian Economic Integration Report: https://aric.adb.org/aeir.

Timor-Leste is classified as a Pacific developing member country in the 2006-2018 enhanced ARCIl estimates to be consistent with the baseline estimates done since 2017. For the next round of updating, Timor-Leste will be included in Southeast Asia in keeping with ADB's current classification. 
An indicator with a higher value corresponds to deeper integration for that particular dimension, which translates to a higher ARCII estimate. However, the following three indicators are interpreted inversely:

- II-c: A higher value for this indicator implies that the pair-wise dispersion of deposit rates are larger and spread apart, which translates to weaker integration.

- III-b: The trade concentration index measures the concentration of economies' exports and imports among products. It is generally thought that if two economies produce diversified products, regional integration would lead to more benefits, as they can complement each other in trade. Under this premise, higher values in the concentration index are associated with lower regional integration (Huh and Park 2018).

- IV-a: Higher trade costs make it more expensive to trade with regional partners, which denotes lower regional integration levels.

This chapter has shown steps in the development of ARCII since its inception in 2017 to provide a broad-based measure of efforts to create and intensify economic ties within the region across a range of dimensions. With its six-dimensional structure, the baseline framework incorporates different aspects of regional integration as it aims to determine the progress and performance of Asia, through time and compared to other regions.

As the channels of regional cooperation and integration continue to evolve, the index structure has been strengthened to accommodate new approaches to the measurement of regional cooperation and integration in Asia. Improvements to the baseline ARCII framework draw in an expanded range of factors involved in regional integration, with two new dimensions measuring the contributions of digital connectivity and environmental cooperation to the index and new indicators added to existing dimensions.

The next chapter presents the estimates and key findings of the enhanced ARCII framework, provides a closer look at the trends in dimensional indexes, and discusses regional integration by economy income groups. 


\section{References}

Altmann, J. 2002. Integration of Environmental Aspects in Regional and Inter-Regional Trade Agreements. Research report 29714 205. Berlin: Federal Environmental Agency. https:/www.umweltbundesamt.de/sites/ default/files/medien/publikation/long/2177.pdf.

Asia-Pacific Economic Cooperation. n.d. ANNEX C-APEC List of Environmental Goods. ANNEX C-APEC List of Environmental Goods. Accessed 14 June 2021. https://www.apec.org/Meeting-Papers/LeadersDeclarations/2012/2012_aelm/2012_aelm_annexC.

Asian Development Bank (ADB), ed. 2009. Study on Intraregional Trade and Investment in South Asia. Manila.

- 2019a. Accelerating Regional Cooperation and Integration in Asia and the Pacific: 2017 Conference Highlights. https://doi.org/10.22617/TCS190209-2.

_ 2019b. Asia Pacific Trade Facilitation Report 2019: Bridging Trade Finance Gaps through Technology. https://doi. org/10.22617/SPR190433-2.

- 2020a. CAREC Corridor Performance Measurement and Monitoring: Annual Report 2019. https://doi. org/10.22617/TCS200205-2.

-2020b. Financial Integration and Macrofinancial Linkages in Asia: Crises, Responses, and Policy Considerations. https://doi.org/10.22617/TCS200287-2.

—. 2020a. New Approaches to Measuring and Assessing Regional Cooperation and Integration: Workshop Highlights. https://dx.doi.org/10.22617/ TCS200310-2.

_.2021a. ADB International Investment Agreement Tool Kit: A Comparative Analysis. Manila: Asian Development Bank. https://doi.org/10.22617/TCS210171-2.

_. 2021. Asian Economic Integration Report 2021: Making Digital Platform Works for Asia and the Pacific. Manila. https://doi.org/10.22617/TCS210048-2.

Association of Southeast Asian Nations. 2016. ASEAN Strategic Plan for Culture and Arts 2016-2025. Jakarta. 10 October. https://asean.org/?static_post=asean-strategic-plan-culture-arts-2016-2025.

Athukorala, P. 2020. Free Trade Agreements in the World Trade System: Substance and Semantics. Foreign Trade Review. 55 (1). pp. 13-20. https://doi.org/10.1177/0015732519886771.

Bahrini, R., and A. Qaffas. 2019. Impact of Information and Communication Technology on Economic Growth: Evidence from Developing Countries. Economies. 7 (1). p. 21. https://doi.org/10.3390/economies7010021.

Banerjee, A., and L. lyer. 2005. History, Institutions, and Economic Performance: The Legacy of Colonial Land Tenure Systems in India. The American Economic Review. 95 (4). pp. 1190-1213.

Besley, T., and T. Persson. 2009. The Origins of State Capacity: Property Rights, Taxation, and Politics. American Economic Review. 99 (4). pp. 1218-1244. https://doi.org/10.1257/aer.99.4.1218. 
Bowen, J., and J. P. Rodrigue. 2020. Air Transport. In J. P. Rodrigue. The Geography of Transport Systems. Fifth Edition, 456. New York: Routledge. https://transportgeography.org/contents/chapter5/air-transport/.

Brosens, T. 2017. Financial Integration in the Eurozone Should Not Be a Tough Sell. VoxEU.Org (blog). 24 May. https://voxeu.org/article/financial-integration-eurozone-should-not-be-tough-sell.

Brusseau, M. L. et al. 2019. Environmental Impacts on Human Health and Well-Being. In M. L. Brusseau et al., eds. Environmental and Pollution Science. pp. 477-499. London: Academic Press. https://doi.org/10.1016/B978-012-814719-1.00026-4.

Capannelli, G., J.W. Lee, and P. Petri. 2009. Developing Indicators for Regional Economic Integration and Cooperation. ADB Working Paper Series on Regional Economic Integration. No. 33. (September): 56. Manila: ADB.

Carmignani, F. and A. Chowdhury. 2008. Does Financial Openness Promote Economic Integration? In B. Guha Khasnobis and G. Mavrotas, eds. Financial Development, Institutions, Growth and Poverty Reduction. pp. 141-163. Studies in Development Economics and Policy. London: Palgrave Macmillan UK. https://doi. org/10.1057/9780230594029_7.

Casella, B. et al. 2019. Improving the Analysis of Global Value Chains: The UNCTAD-Eora Database. Transnational Corporations. 26 (3). New York and Geneva: United Nations.

Castillo, J. C. 2016. Regional Value-Added Component in Manufacturing Evidence from Top Exporters and Regions of the World Economy. United Nations Industrial Development Organization, Inclusive and Sustainable Industrial Development Working Paper Series. No. 14. Vienna: UNIDO.

Castrén, O., and S. Mazzotta. 2005. Foreign Exchange Option and Returns Based Correlation Forecasts: Evaluation and Two Applications. ECB Working Paper. No. 447. Frankfurt a. M.: European Central Bank (ECB). http://hdl. handle.net/10419/152881.

Chinn, M. D., and H. Ito. 2006. What Matters for Financial Development? Capital Controls, Institutions, and Interactions. Journal of Development Economics. 81 (1). pp. 163-192.

Chirmiciu, A. 2020. Transition Qualities Measuring Progress in the EBRD Region. Presented at the Virtual Inception Workshop on New Approaches to Measuring and Assessing Regional Cooperation and Integration. 16-17 April. ADB.

De Lombaerde, P. and E. J. Saucedo Acosta, eds. 2017. Indicator-Based Monitoring of Regional Economic Integration. Vol. 13. United Nations University Series on Regionalism. Cham: Springer International Publishing. https://doi. org/10.1007/978-3-319-50860-3.

Devereux, M. B. et al., eds. 2011. The Dynamics of Asian Financial Integration. New York: Routledge. https://www.adb. org/sites/default/files/publication/29087/dynamics-asian-financial-integration.pdf.

Duggal, V. K. 2020. Carbon Market Cooperation to Build a Low-Carbon Future. Future of Regional Cooperation in Asia and the Pacific. Manila: ADB. https://doi.org/10.22617/TCS200336-2.

El-Anis, I. 2021. Transport Infrastructure and Regional Integration in the Middle East. The Muslim World. 111 (1). pp. 27-53. https://doi.org/10.1111/muwo.12371. 
Fugazza, M. 2019. Bilateral Maritime Connectivity since 2006: A Primer Using New Liner Shipping Bilateral Connectivity Index (LSBCl) Calculation. UNCTAD Transport and Trade Facilitation Newsletter. 4 December. https://unctad.org/news/bilateral-maritime-connectivity-2006-primer-using-new-liner-shipping-bilateralconnectivity.

Fugazza, M., and J. Hoffmann. 2017. Liner Shipping Connectivity as Determinant of Trade. Journal of Shipping and Trade. 2 (1). p. 1. https://doi.org/10.1186/s41072-017-0019-5.

Gharleghi, B. 2019. Eurasia Integration Index. https://mpra.ub.uni-muenchen.de/94347/1/MPRA_paper_94347.pdf.

Ghita, S. I. et al. 2018. Perspectives of Ecological Footprint in European Context under the Impact of Information Society and Sustainable Development. Sustainability. 10 (9). pp. 3224. https://doi.org/10.3390/su10093224.

Glossary-Global Footprint Network. https:/www.footprintnetwork.org/resources/glossary/ (accessed 25 May 2021).

Greater Mekong Subregion. Statistical Database. https://www.greatermekong.org/stats/index-static.php (accessed 4 August 2021).

GSM Association. 2019. The Mobile Economy 2019. London: GSM Association. https://data.gsmaintelligence.com/ api-web/v2/research-file-download?id=39256194\&file=2712-250219-ME-Global.pdf.

Guerrero Bote, V. P., C. Olmeda-Gómez, and F. de Moya-Anegón. 2013. Quantifying the Benefits of International Scientific Collaboration. Journal of the American Society for Information Science and Technology. 2. p. 392. https://doi.org/10.1002/asi.22754.

Guerrero, P., K. Lucenti, and S. Galarza S. 2009. Trade Logistic and Regional Integration in Latin America and the Caribbean. IDB Working Paper Series. December. New York: Inter-American Development Bank. https://publications.iadb.org/en/publication/trade-logistic-and-regional-integration-latin-americacaribbean.

Gwenhure, Y., and N. M. Odhiambo. 2017. Tourism and Economic Growth: A Review of International Literature. Tourism Review. 65 (1). pp. 33-44.

Hanson, K. T., F. Y. Owusu, and K. P. Puplampu. 2015. Infrastructure and Capacity Development as a Catalyst for Regionalism and Economic Integration in Africa. Contemporary Regional Development in Africa. 7. pp. 139-158. Farnham, England: Ashgate Publishing Limited. http://lib.dr.iastate.edu/communityplanning_pubs/28.

Huh, H. S. 2020. Memo and Computed Indicators and Estimates Using the Enhanced Asia-Pacific Regional Cooperation and Integration Index Framework (Consultant Report for TA-9763). 4 December.

Huh, H. S., and C. Y. Park. 2017a. Asia-Pacific Regional Integration Index: Construction, Interpretation, and Comparison. ADB Economics Working Paper Series. No. 511. Manila: ADB. https://ideas.repec.org/p/ris/ adbewp/0511.html.

. 2018b. Asia-Pacific Regional Integration Index: Construction, Interpretation, and Comparison. Journal of Asian Economics. 54 (C). pp. 22-38. https://doi.org/10.1016/j.asieco.2017.12.001. 
- 2021. A New Index of Globalisation: Measuring Impacts of Integration on Economic Growth and Income Inequality. The World Economy. 44 (2). pp. 409-443. https://doi.org/10.1111/twec.12998.

International Civil Aviation Organization. Economic Development of Air Transport: Connectivity. https://www. icao.int/sustainability/Pages/Connectivity.aspx (accessed 13 May 2021).

International Transport Forum. 2019. 2019 Summit Ministerial Declaration on Transport Connectivity for Regional Integration. Leipzig, Germany. 23 May. https:/www.itf-oecd.org/2019-summit-ministerial-declarationtransport-connectivity-regional-integration.

Kang, S., Y. Wang, and D. R. Yoon. 2002. Exchange Rate Co-Movements and Business Cycle Synchronization between Japan and Korea. ADBI Research Paper Series. No. 40. Tokyo: Asian Development Bank Institute (ADBI). http://hdl.handle.net/11540/4146.

Kikkawa Takenaka, A., R. Gaspar, and C. Y. Park. 2019. International Migration in Asia and the Pacific: Determinants and Role of Economic Integration. ADB Economics Working Paper Series. No. 592. Manila: ADB. http://dx.doi. org/10.22617/WPS190473-2.

Kikkawa Takenaka A., et al. 2020. COVID-19 Impact on International Migration, Remittances, and Recipient Households in Developing Asia. ADB Briefs. No. 148. Manila: ADB. https://doi.org/10.22617/BRF200219-2.

Kim, K. and P. Mariano. 2020. Trade Impact of Reducing Time and Costs at Borders in the Central Asia Regional Economic Cooperation Region. ADBI Working Paper Series No. 1106. Tokyo: ADBI.

Lockwood, B. 2004. How Robust Is the Kearney/Foreign Policy Globalisation Index? The World Economy. 27 (4). pp. 507-523. https://doi.org/10.1111/j.0378-5920.2004.00611.x.

Mercer-Blackman, V., W. Xiang, and F. Khan. 2021. Understanding FDI Spillovers in the Presence of GVCs. Policy Research Working Paper No. 9645. Washington, DC: World Bank.

Mussa, M. 2000. Factors Driving Global Economic Integration. Presented at Global Opportunities and Challenges, Jackson Hole, Wyoming. 25 August. https://www.imf.org/en/News/Articles/2015/09/28/04/53/sp082500.

Nguyen, S. T. and Y. Wu. 2020. Economic Integration and Network Trade: A Comparison of East Asia and the European Union. Asian Economic Papers. 19 (1). pp. 19-37. https://doi.org/10.1162/asep_a_00751.

Nonnenmacher, S. 2017. Free Movement within the ASEAN. In Migration, Free Movement and Regional Integration. pp. 347-394. Social Sciences Studies Series. Paris: UNESCO Publishing and UNU Institute on Comparative Regional Integration Studies.

Organisation for Economic Co-operation and Development (OECD). 2013. Economic Globalisation: Origins and Consequences. Paris: OECD Publishing.

- 2019. Measuring the Digital Transformation: A Roadmap for the Future. OECD Publishing. https://doi. org/10.1787/9789264311992-en.

OECD and Joint Research Centre-European Commission. 2008. Handbook on Constructing Composite Indicators: Methodology and User Guide. Paris: OECD. https://doi.org/10.1787/9789264043466-en. 
Pangestu, M., and S. Armstrong. 2018. Asian Economic Integration: The State of Play. In S. Armstrong and T. Westland, eds. Asian Economic Integration in an Era of Global Uncertainty. pp. 15-62. ANU Press. http://www.jstor.org/stable/j.ctt20krz01.9.

Park, C. Y., and R. Claveria. 2018. Constructing the Asia-Pacific Regional Cooperation and Integration Index: A Panel Approach. SSRN Electronic Journal. https://doi.org/10.2139/ssrn.3188636.

Park, C. Y. 2002. Prospects for Financial Integration and Exchange Rate Policy Cooperation in East Asia. ADBI Research Paper Series. No. 48. Tokyo: ADBI. http://hdl.handle.net/10419/111138.

Porteous, O. 2019. High Trade Costs and Their Consequences: An Estimated Dynamic Model of African Agricultural Storage and Trade. American Economic Journal: Applied Economics. 11 (4). pp. 327-366. https://doi.org/10.1257/ app.20170442.

Prüss-Üstün, A. et al. 2016. Preventing Disease Through Healthy Environments: A Global Assessment of the Burden of Disease from Environmental Risks. Geneva: World Health Organization.

Rodrigue, J. P. 2020. Transportation Modes, Modal Competition and Modal Shift. In J. P. Rodrigue, ed. The Geography of Transport Systems. p. 456. New York: Routledge. https://transportgeography.org/contents/ chapter5/transportation-modes-modal-competition-modal-shift/.

Rodrik, D. 2018. What Do Trade Agreements Really Do? Journal of Economic Perspectives. 32 (2). pp. 73-90. https://doi.org/10.1257/jep.32.2.73.

Roland-Holst, D. 2009. Infrastructure as a Catalyst for Regional Integration, Growth, and Economic Convergence: Scenario Analysis for Asia. In From Growth to Convergence: Asia's Next Two Decades, edited by Fan Zhai. pp. 108-149. London: Palgrave Macmillan UK. https://doi.org/10.1057/9780230250604_4.

Ruta, M. et al. 2018. How Much Will the Belt and Road Initiative Reduce Trade Costs? World Bank Blogs (blog). 16 October. https://blogs.worldbank.org/trade/how-much-will-belt-and-road-initiative-reduce-trade-costs.

Steenkamp, E., S. Grater, and W. Viviers. 2016. Streamlining South Africa's Export Development Efforts in Sub-Saharan Africa: A Decision Support Model Approach. In R. Teh et al., eds. Trade Costs and Inclusive Growth. Switzerland: World Trade Organization (WTO). https://www.wto.org/english/res_e/booksp_e/tradecosts-incl-growth_chap2_e.pdf.

Tabellini, G. 2010. Culture and Institutions: Economic Development in the Regions of Europe. Journal of European Economic Association. 8 (4). pp. 677-716. https://doi.org/10.1111/j.1542-4774.2010.tb00537.x.

Takele, T. B. 2019. The Relevance of Coordinated Regional Trade Logistics for the Implementation of Regional Free Trade Area of Africa. Journal of Transport and Supply Chain Management. 13 (March). https://doi.org/10.4102/jtscm.v13i0.417.

TeleGeography. 2019. Global Internet Geography Report. https://www.telegeography.com/products/global-internetgeography/analysis/regional-analysis/asia/index.html.

United Nations Conference on Trade and Development (UNCTAD). 2013. Regional Integration and Foreign Direct Investment in Developing and Transition Economies. Geneva. https:/unctad.org/system/files/official-document/ ciimem4d2_en.pdf. 
2018. Identifying and Promoting Regional Value Chains in Leather and Leather Products in Africa. UNCTAD/GDS/ECIDC/2017/6. Geneva. https://unctad.org/system/files/official-document/gdsecidc2017d6 -en.pdf.

UNCTAD, DITC. 2007. Developing Countries in International Trade 2007: Trade and Development Index. United Nations. https://doi.org/10.2139/ssrn.1283665.

UNCTAD, Division on Technology and Logistics. 2020. Data Notes on Liner Shipping Bilateral Connectivity Index, Annual. 17 November. https://unctadstat.unctad.org/wds/TableViewer/summary.aspx.

UNCTAD and WTO. 2012. A Practical Guide to Trade Policy Analysis. UNCTAD and WTO. https://www.wto.org/ english/res_e/publications_e/wto_unctad12_e.pdf.

United Nations Environment Programme (UNEP). 2017. Trade in Environmental Goods. UNEP-UN Environment Programme. 21 November. http://www.unep.org/explore-topics/green-economy/what-we-do/environmentand-trade-hub/trade-environmental-goods.

UNECA (2016). Africa Regional Integration Index Report 2016. Addis Ababa: United Nations Economic Commission for Africa.

UNECA (2019). Making Sense Of Regional Integration Indexes, Addis Ababa: United Nations Economic Commission for Africa.

United Nations Economic and Social Commission for Asia and the Pacific (UNESCAP). 2020. Regional Integration for Sustainable Development in Asia and the Pacific: ESCAP Digital and Sustainable Regional Integration Index and Indicator Framework. Bangkok: UNESCAP. https://www.unescap.org/resources/DigiSRII.

— n.d. Complementarity. https://artnet.unescap.org/APTIAD/Complementarity.pdf.

—. n.d. Sectoral Hirschman. https://artnet.unescap.org/APTIAD/Sectoral\%20Hirschmann.pdf.

United Nations Educational, Scientific and Cultural Organization (UNESCO). 2020. Culture and Education Play a Central Role in the Regional Integration of Central America. UNESCO News. 20 November. https://en.unesco. org/news/culture-and-education-play-central-role-regional-integration-central-america.

Vollenweider, J. 2013. The Effectiveness of International Environmental Agreements. International Environmental Agreements: Politics, Law and Economics. 13 (3). pp. 343-367. https://doi.org/10.1007/s10784-012-9193-y.

World Bank. 2020. Doing Business 2020: Comparing Business Regulation in 190 Economies. Washington, DC. https://doi.org/10.1596/978-1-4648-1440-2.

—. Trade Indicators. World Integrated Trade Solution. https://wits.worldbank.org/wits/wits/witshelp/Content/ Utilities/e1.trade_indicators.htm (accessed 20 May 2021).

World Intellectual Property Organization (WIPO). 2013. The Economics of Trademarks. World Intellectual Property Report 2013: Brand-Reputation and Image in the Global Marketplace. WIPO Economics and Statistics Series. https://www.wipo.int/edocs/pubdocs/en/wipo_pub_944_2013-chapter2.pdf. 
World Trade Organization (WTO). 2010. Environmental Goods Agreement (EGA). https://www.wto.org/english/ tratop_e/envir_e/ega_e.htm (accessed 14 June 2021).

Yeo, A. D., A. Deng, and T. Y. Nadiedjoa. 2020. The Effect of Infrastructure and Logistics Performance on Economic Performance: The Mediation Role of International Trade. Foreign Trade Review. 55 (4). pp. 450-465. https://doi.org/10.1177/0015732520947676. 


\section{Measuring Regional Integration through the Enhanced ARCII Framework}

This chapter turns to the key findings and results of the enhanced Asia-Pacific Regional Cooperation and Integration Index (ARCII) framework. It presents trends in regional integration for each dimension of the framework, with particular focus on the performance of $\mathrm{Asia}^{23}$ and its subregions. Detailed analysis of the ARCII estimates is provided by looking at progress across the eight dimensions of regional cooperation and integration, and the contribution of each of 41 indicators in the dimensional indexes is investigated. As a robustness check, estimates from the eight-dimensional enhanced framework are compared with estimates produced using the six-dimensional baseline framework. The chapter goes on to show the flexibility of the ARCII framework-how it can be customized to cater and adapt to the objectives and needs of a specific region or economy grouping.

\section{Key Findings and Results of the Enhanced ARCII Framework}

ARCII estimates generated in the enhanced framework indicate that regional integration levels in Asia have remained stable over more than a decade. Updated estimates of the overall ARCII for Asia show a balanced trend from 2006, with an estimate of 0.45, to a slightly higher index of 0.48 in 2018 (Figure 3.1). The increase can be attributed to improvements in digital connectivity and progress in trade and investment activity within the region.

Noticeable improvement in the technology and digital connectivity dimension reflects the rapid growth in intraregional internet bandwidth traffic and research collaboration within Asia. Estimates show demand for international bandwidth traffic almost doubling every two years (TeleGeography 2020). In Asia, international bandwidth demand grew at a compounded annual rate of 53\% between 2014 and 2018, the highest among all regions (TeleGeography 2020). This supports the rapid evolution of the digital economy, which is powered largely by digital data exchange and the emergence of digital platforms (United Nations Conference on Trade and Development 2019). This trend has also enabled e-commerce across borders where goods and services can be digitally delivered, digitally ordered, or platform-enabled (Asian Development Bank [ADB] 2021a). The emergence and consolidation of digitally delivered services, which have grown faster in Asia than any other region, has also benefited from improved digital connectivity. Besides this, patent applications and trade in information and communication technology (ICT) goods within the region made significant contributions to index estimates in the digital connectivity dimension. These trends reflect the digital transformation taking place in Asia, where innovation and digital platforms present new business models and economic prospects (ADB 2021a, 2021b).

Asia refers to the 48 ADB members in Asia and the Pacific. It includes Australia, Japan, and New Zealand, in addition to the 45 developing member economies. It does not include Niue due to limited data availability. 
Figure 3.1: Overall ARCII and Dimensional Indexes-Asia and the Pacific

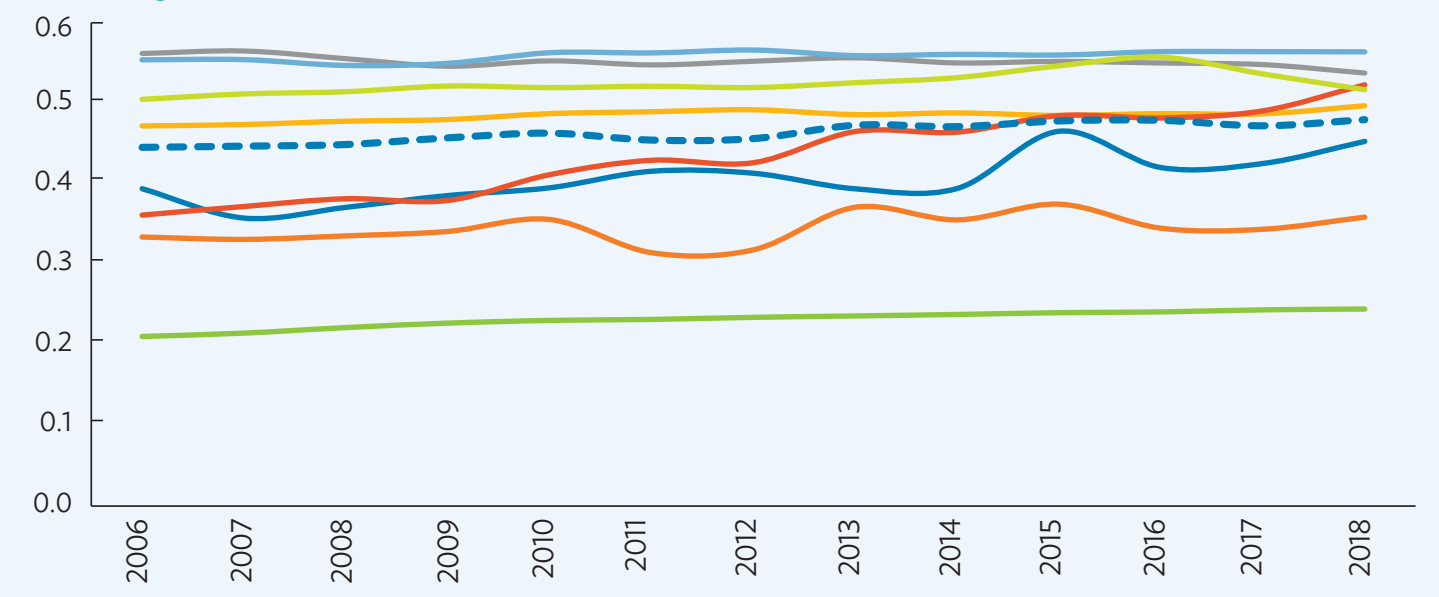

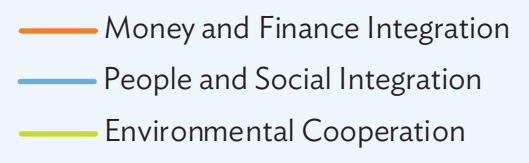
Regional Value Chain Institutional Arrangements - - Overall Index

ARCII = Asia-Pacific Regional Cooperation and Integration Index.

Note: Higher values denote greater regional integration. Worldwide normalization is used for all estimations, where the indicators are normalized using global maximum and minimum values across all regions.

Source: Asian Development Bank. Asia-Pacific Regional Cooperation and Integration Index Database. https://aric.adb.org/database/ arcii (accessed May 2021).

Some progress is also observed in the trade and investment aspect of regional cooperation and integration (Figure 3.1). The dimensional index for this increased by around $7 \%$ from 2017 , of which intraregional goods imports and cross-border investments were large contributors. Intraregional trade is a crucial element of total trade in Asia and is clustered in selected economies and subregions, particularly East Asia and Southeast Asia (United Nations Economic and Social Commission for Asia and the Pacific [UNESCAP] 2018a). The strong intraregional trade patterns have been coupled with policy reforms adopted by 22 economies in Asia to boost liberalization and promote cross-border investments in the region (UNESCAP 2018).

Estimated weights for Asia's ARCII estimates provide valuable information on the drivers of regional integration in the region. ARCll estimates are generated using a principal component analysis (PCA) for each dimension and a second PCA for the overall index. In Asia, the people and social integration dimension has the largest weight (0.14), while the money and finance dimension takes the least weight at 0.09 . The weights also vary among indicators in a specific dimension (Table 3.1). For instance, in the regional value chain dimension, intermediate goods imports (III-d) are assigned the highest weight (0.234) and the trade complementarity index is the lowest (0.137). Notably, the weights assigned to each dimension differ across regions (Appendix Table A2.1). For instance, while the digital connectivity dimension gets the highest weight in Europe, it has the lowest weight in Latin America.

The people and social integration and regional value chain dimensions continue to sustain regional integration in Asia, as seen in their high contributions to the overall ARCII estimate (Figure 3.2). In contrast, money and finance integration remains the weakest aspect of regional integration in Asia, having the lowest weight and contribution among the dimensions. 


\section{Table 3.1: ARCII Dimensions and Indicators, Panel Principal Component Analysis-Derived Weights for Asia and the Pacific}

\begin{tabular}{|c|c|c|}
\hline \multicolumn{2}{|c|}{ Dimensions and Indicators } & Weight \\
\hline \multicolumn{2}{|c|}{ I. Trade and Investment Integration } & 0.133 \\
\hline $\mathrm{I}-\mathrm{a}$ & Proportion of intraregional goods exports to total goods exports & 0.168 \\
\hline $\mathrm{I}-\mathrm{b}$ & Proportion of intraregional goods imports to total goods imports & 0.183 \\
\hline $\mathrm{I}-\mathrm{C}$ & Intraregional trade intensity index & 0.219 \\
\hline I-d & Proportion of intraregional foreign direct investment (FDI) inflows to total FDI inflows & 0.216 \\
\hline I-e & Proportion of intraregional FDI inflows plus outflows to total FDI inflows plus outflows & 0.215 \\
\hline \multicolumn{2}{|c|}{ II. Money and Finance Integration } & 0.091 \\
\hline II-a & Proportion of intraregional cross-border equity liabilities to total cross-border equity liabilities & 0.215 \\
\hline II-b & Proportion of intraregional cross-border bond liabilities to total cross-border bond liabilities & 0.181 \\
\hline $\mathrm{II}-\mathrm{c}$ & Pair-wise dispersion of deposit rates averaged regionally relative to the global average & 0.190 \\
\hline II-d & Capital account openness: Chinn-Ito Index (de jure) & 0.164 \\
\hline II-e & Correlations of exchange rates relative to the US dollar, averaged regionally minus those averaged globally & 0.250 \\
\hline \multicolumn{2}{|c|}{ III. Regional Value Chain } & 0.129 \\
\hline III-a & $\begin{array}{l}\text { Ratio between the averaged trade complementarity index over regional trading partners and the } \\
\text { averaged trade complementarity index over all trading partners }\end{array}$ & 0.137 \\
\hline III-b & $\begin{array}{l}\text { Ratio between the averaged trade concentration index over regional trading partners and the } \\
\text { averaged trade concentration index over all trading partners }\end{array}$ & 0.209 \\
\hline III-c & Proportion of intraregional intermediate goods exports to total intraregional goods exports & 0.217 \\
\hline III-d & Proportion of intraregional intermediate goods imports to total intraregional goods imports & 0.234 \\
\hline III-e & $\begin{array}{l}\text { Ratio between the sum of the value-added contributed by regional trading partners and that } \\
\text { contributed by all trading partners }\end{array}$ & 0.204 \\
\hline \multicolumn{2}{|c|}{ IV. Infrastructure and Connectivity } & 0.135 \\
\hline IV-a & $\begin{array}{l}\text { Ratio between the averaged trade cost over regional trading partners and the averaged trade cost } \\
\text { over all trading partners }\end{array}$ & 0.182 \\
\hline IV-b & $\begin{array}{l}\text { Ratio between the averaged liner shipping connectivity index over regional trading partners and the } \\
\text { averaged liner shipping connectivity index over all trading partners }\end{array}$ & 0.190 \\
\hline IV-c & Proportion of passenger seats sold on regional flights relative to those sold on all international flights & 0.192 \\
\hline IV-d & Logistics Performance index (overall) & 0.220 \\
\hline IV-e & Doing Business Index (overall) & 0.216 \\
\hline \multicolumn{2}{|c|}{ V. People and Social Integration } & 0.136 \\
\hline V-a & Proportion of intraregional outbound migration to total outbound migration & 0.195 \\
\hline$V-b$ & Ratio of intraregional tourists to total tourists (inbound plus outbound) & 0.206 \\
\hline $\mathrm{V}-\mathrm{c}$ & Ratio of intraregional remittances to total remittances & 0.095 \\
\hline$V-d$ & Cultural proximity with other economies in the region relative to that with all other economies & 0.152 \\
\hline $\mathrm{V}$-e & Ratio of intraregional cultural goods trade (exports plus imports) to total cultural goods trade & 0.175 \\
\hline V-f & $\begin{array}{l}\text { Ratio of trademark applications made with intraregional residents to trademark applications made } \\
\text { with all foreign residents }\end{array}$ & 0.177 \\
\hline \multicolumn{2}{|c|}{ VI. Institutional Arrangements } & 0.130 \\
\hline $\mathrm{VI}-\mathrm{a}$ & Proportion of intraregional economies that have signed free trade agreements with & 0.157 \\
\hline VI-b & Proportion of intraregional economies that have signed bilateral investment treaties with & 0.207 \\
\hline
\end{tabular}


Table 3.1 continued

\begin{tabular}{ccc} 
Dimensions and Indicators & Weight \\
VI-c & Proportion of intraregional economies that have signed double taxation treaties with & 0.220 \\
VI-d & Number of international intergovernment organizations in which an economy is a member & 0.200 \\
VI-e & Proportion of intraregional economies that have an embassy & 0.216 \\
VII. Technology and Digital Connectivity & 0.115 \\
VII-a $\quad$ Proportion of intraregional ICT goods trade (exports plus imports) to total ICT goods trade & 0.173 \\
VII-b $\quad \begin{array}{l}\text { Proportion of research outputs with intraregional collaborators relative to research outputs with all } \\
\text { international collaborators }\end{array}$ & 0.170 \\
VII-c $\quad \begin{array}{l}\text { Proportion of patent applications made with intraregional residents to patent applications made with } \\
\text { VII-d } \quad \text { Proportion of persons using the internet }\end{array}$ & 0.195 \\
VII-e & Proportion of mobile subscriptions per 100 persons & 0.164 \\
VII-f & International internet bandwidth & 0.185 \\
VIII. Environmental Cooperation & 0.113 \\
VIII-a $\quad \begin{array}{l}\text { Proportion of intraregional environmental goods trade (exports plus imports) to total intraregional } \\
\text { VIII-b }\end{array} \quad$ Number of international environmental agreements ratified & 0.129 \\
VIII-c & Environmental health score & 0.224 \\
VIII-d & Ecological footprint of production as a share of biocapacity & 0.284 \\
\hline
\end{tabular}

$\mathrm{ARCII}=$ Asia-Pacific Regional Cooperation and Integration Index, ICT = information and communication technology, $\mathrm{PCA}=$ principal component analysis, US = United States.

Source: Asian Development Bank. Asia-Pacific Regional Cooperation and Integration Index Database. https://aric.adb.org/database/arcii (accessed May 2021).

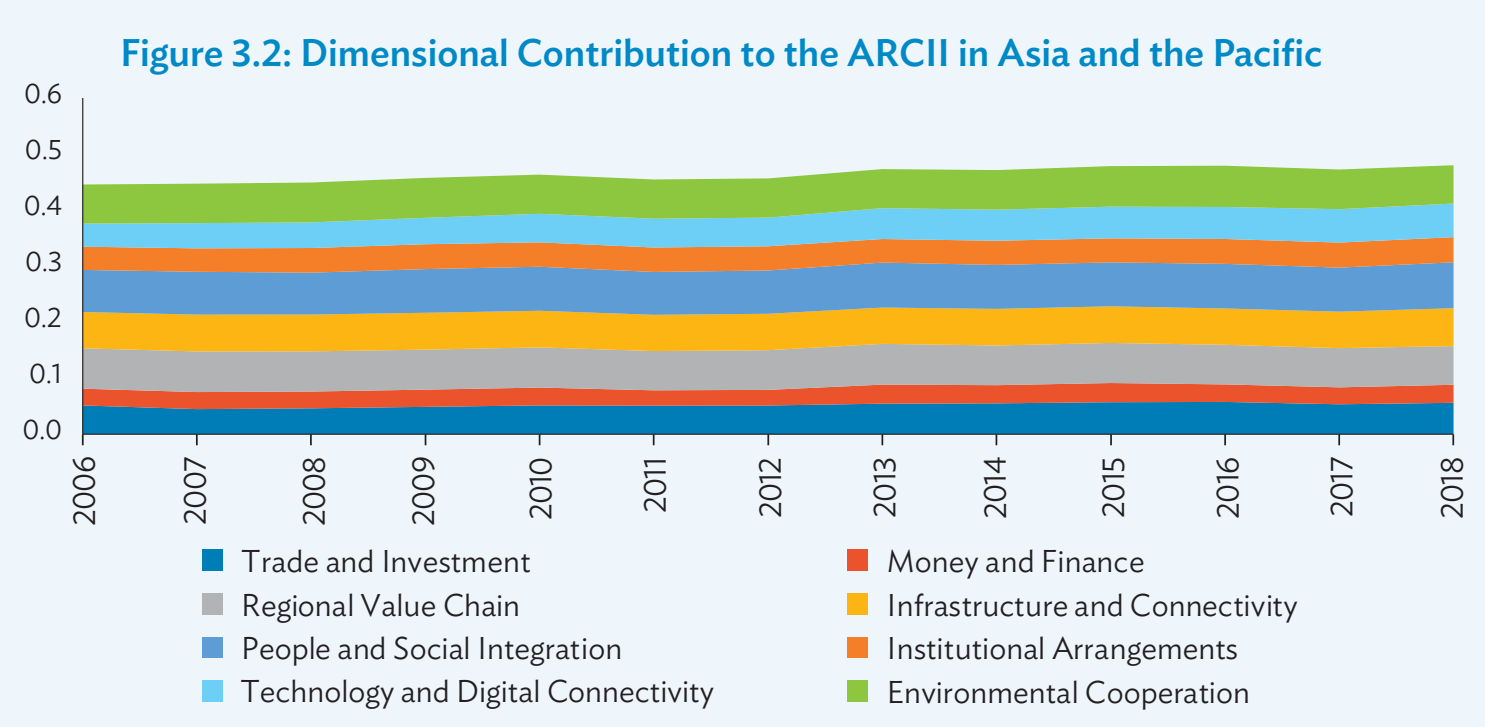

ARCII = Asia-Pacific Regional Cooperation and Integration Index

Note: Dimensional contribution is computed as the weight of the dimension multiplied by the dimensional index.

Source: Asian Development Bank. Asia-Pacific Regional Cooperation and Integration Index Database. https://aric.adb.org/database/ arcii (accessed May 2021). 


\section{Integration Trends by Subregions and Regions}

Within Asian subregions, Southeast Asia, closely followed by East Asia, attains the highest overall index across the whole period (Figure 3.3, panel a). Central Asia and South Asia, although having a low index in comparison with other subregions, saw regional integration trend upward from 2006 to 2018. Asian subregions continued to display wideranging performance across dimensions (Figure 3.3, panel b). For instance, East Asia scored highest in the money and finance, regional value chain, infrastructure and connectivity, and institutional arrangements dimensions.

East Asia's prominence in the regional value chain dimension may be explained by its strong and well-integrated regional production networks in manufacturing. Likewise, East Asia led the region in the newly incorporated dimensions of technology and digital connectivity and environmental cooperation. On the digital front, recent efforts, such as the Regional Knowledge Sharing Initiative, have helped improve East Asia's partnerships in the technology and digital sphere by promoting the sharing of knowledge and experience within the Central Asia Regional Economic Cooperation (CAREC) region. ${ }^{24}$ On the environmental front, the Inner Mongolia Sustainable Cross-Border Development Investment Program has encouraged the use of high-level technology for ecological restoration within East Asia (ADB 2021a).

Southeast Asia outperformed most subregions in trade and investment, the people and social integration dimension, and in technology and digital connectivity. Southeast Asia's performance in trade and investment may be driven by the strong activity with regional partners, considering that about $60 \%$ of its trade was with other economies in Asia. The Association of Southeast Asian Nations (ASEAN) Digital Masterplan envisions Southeast Asia becoming a leading digital community and economic bloc, powered by secure and transformative digital services, technologies and ecosystem (ASEAN 2021).

Finally, South Asia and Central Asia trailed other subregions in most dimensions (Figure 3.3, panel b). However, ongoing initiatives promoting energy trade and enhancing multimodal transport networks in South Asia, such as the construction of a pipeline corridor between Bangladesh and India, are poised to generate direct benefits and spillover effects for countries in the region. South Asian economies have also allotted sizable investments in developing ports and airports to increase capacity (ADB 2019b). For Central Asia, initiatives to boost national and global digital connectivity are being pursued by encouraging CAREC clusters to integrate the use of ICT across operations (ADB 2021a). ${ }^{25}$ Furthermore, broad network coverage at low costs is crucial for sustaining the rise of e-commerce and ultimately improving Central Asia's performance in the digital connectivity dimension. While the ARCII does not cover the Russian Federation and Iran, the construction of a customized index for Eurasia aims to address this and provide a more complete picture for this subregion (page 89 for a discussion of the Eurasian index).

Overall ARCII estimates for subregional initiatives in Asia have remained stable for ASEAN members and in the Greater Mekong Subregion (GMS), while they improved for CAREC and declined slightly for South Asia Subregional Economic Cooperation (SASEC) countries (Figure 3.3, panel c). The extent of regional cooperation and integration in these subregional initiatives varies across the eight dimensions (Figure 3.3, panel d). ASEAN exhibits the highest degree of regional cooperation and integration, which is particularly strong in trade and investment, people and social integration, technology and digital connectivity, and environmental cooperation. Regional integration in the GMS shows a similar path to ASEAN. The subregion is introducing innovations in green financing, and integrating environment, social, and governance principles to promote sustainable trade (ADB 2021a). Meanwhile, improvements in transport linkages with nearby subregions are expected from joint initiatives between SASEC and the Bay of Bengal

24 The CAREC subregion is composed of 11 countries that participated: Afghanistan, Azerbaijan, the People's Republic of China, Georgia, Kazakhstan, the Kyrgyz Republic, Mongolia, Pakistan, Tajikistan, Turkmenistan, and Uzbekistan.

25 The CAREC Regional Integration Index (CRII) produced by the CAREC Institute is based on the framework introduced by Huh and Park (2017) to construct the ARCII. The latest CRII results show progress in CAREC integration, albeit only moderate. Holzhacker, Karymshakov, and Lu (2021). 
Figure 3.3: Overall ARCII and Dimensional Indexes-Asia and the Pacific

(a) Overall ARCII for Subregions

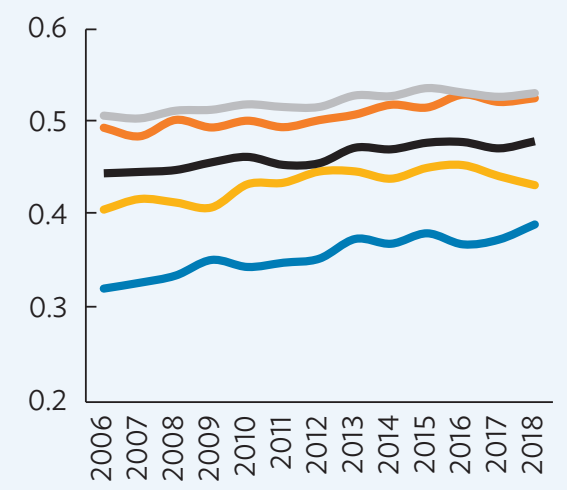

(b) Dimensional Indexes for Subregions, 2018

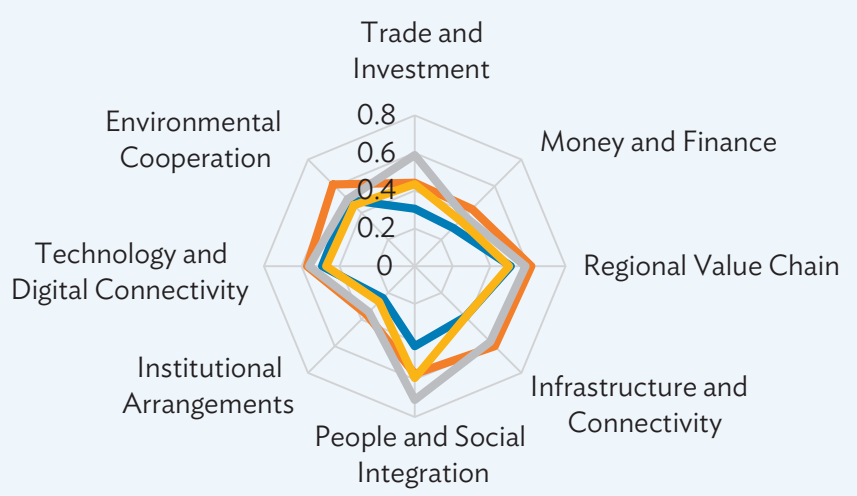

Central Asia $\longrightarrow$ East Asia $\longrightarrow$ Southeast Asia $\longrightarrow$ South Asia and the Pacific

(c) Overall ARCII for Subregional Initiatives

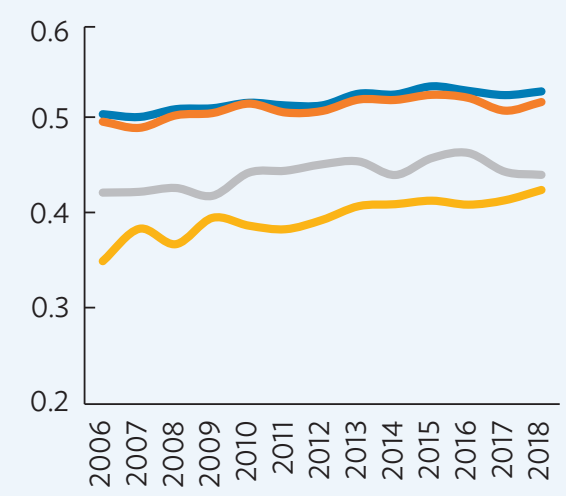

(d) Dimensional Indexes for Subregional Initiatives, 2018

Trade and Investment Integration

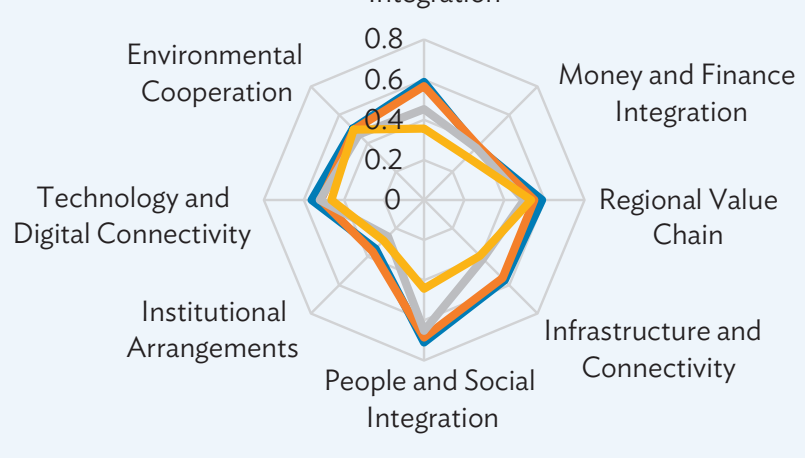

- ASEAN - CAREC GMS - SASEC

ARCII = Asia-Pacific Regional Cooperation and Integration Index, ASEAN = Association of Southeast Asian Nations, CAREC = Central Asia Regional Economic Cooperation, GMS = Greater Mekong Subregion, SASEC = South Asia Subregional Economic Cooperation.

Note: Higher values denote greater regional integration. Worldwide normalization is used for all estimations, where the indicators are normalized using global maximum and minimum values across all regions. In panel $b$, the figure shows the dimensional indexes for subregions in Asia for 2018. For instance, the gray line illustrates that Southeast Asia received the highest index in the trade and investment dimension, and in the people and social integration dimension.

Source: Asian Development Bank. Asia-Pacific Regional Cooperation and Integration Index Database. https://aric.adb.org/database/ arcii (accessed May 2021).

Initiative for Multi-Sectoral Technical and Economic Cooperation. While CAREC seems to be the least regionally integrated initiative, strengthening trade linkages and addressing gaps in physical and digital connectivity remain a priority. Increased investments in ICT and knowledge services are needed to help tackle challenges caused by the wide digital divide and eventually enable CAREC to make stronger digital connections regionally and globally (ADB 2021a). 
Regional integration indexes are also estimated for other regions worldwide. The enhanced ARCII framework includes a new region, the Middle East, in the sample (Box 3.1). Across regional groupings, the European Union (EU) remains the global leader in regional integration from 2006 to 2018 by a long margin (Figure 3.4, panel a). The EU reports a strong institutional and social integration, given its solid economic and monetary union institutions, highly integrated labor markets, and common regional frameworks in the areas of education, research and innovation, security, agriculture, and environmental regulation (European Commission 2019). The regional integration index for Asia is below the EU, but above all other regions.

In Asia, the panel PCA-weights tend to be evenly distributed across all dimensions, except for the money and finance dimension which received a comparably lower weight (Appendix Table A2.1). There is a considerable heterogeneity in the leading dimensions across regions based on the derived weights. People and social integration accounts for the largest weight, irrespective of the regional score, in the regional indexes of Latin America and the Middle East. On the other hand, infrastructure and connectivity received the highest weight for EU and the institutional arrangements dimension the highest weight for Latin America.

Asia's latest dimensional indexes for 2018 on trade and investment, regional value chains, and people and social integration equal those of the EU (Figure 3.4, panel b). These results signal that levels of regional integration in Asia for those three dimensions are the same as in Europe. However, Asia-EU gaps remain in the money and finance dimension, where some convergence has occurred in recent years, and the same is seen with infrastructure and connectivity, institutional arrangements, and environmental cooperation. Importantly, Asia's performance in the new technology and digital connectivity dimension is higher than all other regions. In line with this, Asia had the highest international internet bandwidth demand in 2018 (TeleGeography 2020) and housed 8 of the world's top 15 outsourcing destinations in the provision of cross-border services (Tholons 2018). Most regions outperformed Asia in institutional arrangements, while Africa, and to some extent Latin America, continued to score the lowest in almost all dimensions.

\section{Figure 3.4: Regional Integration Index-Asia and the Pacific versus Other Regions}

(a) Overall ARCII

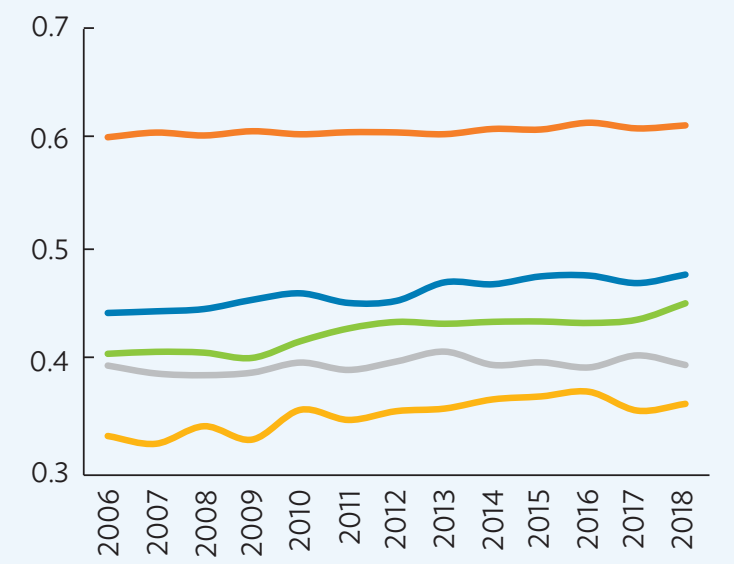

(b) Dimensional Indexes, 2018

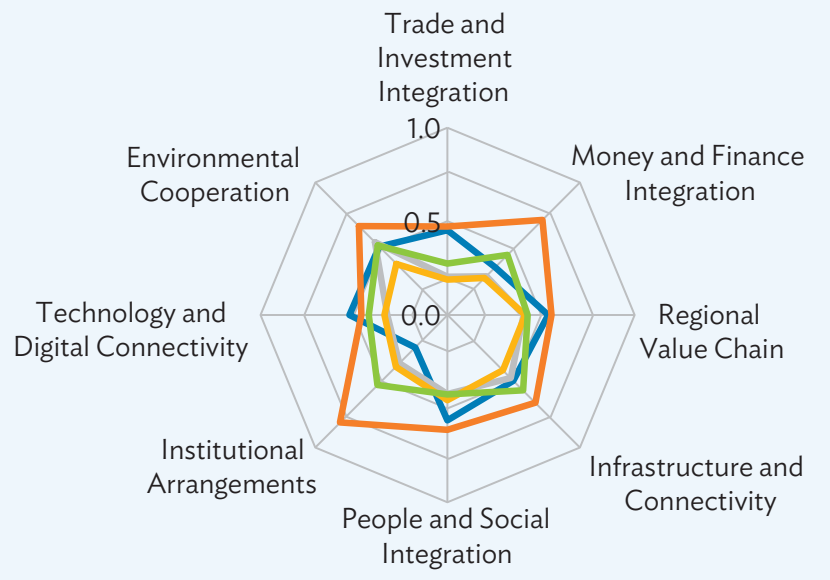

Latin America
Africa
Middle East

ARCII = Asia-Pacific Regional Cooperation and Integration Index, EU = European Union.

Note: Higher values denote greater regional integration. Worldwide normalization is used for all estimations, where the indicators are normalized using global maximum and minimum values across all regions. In panel $b$, the figure shows the dimensional indexes for different regions for 2018.

Source: Asian Development Bank. Asia-Pacific Regional Cooperation and Integration Index Database. https://aric.adb.org/database/ arcii (accessed May 2021). 


\section{Box 3.1: A Glance at ARCII Estimates for the Middle East}

Regional coverage in the enhanced Asia-Pacific Regional Cooperation and Integration Index (ARCII) framework has been expanded from 158 to 173 economies with the inclusion of 15 economies in the Middle East: Bahrain, Islamic Republic of Iran, Iraq, Israel, Jordan, Kuwait, Lebanon, Oman, State of Palestine, Qatar, Saudi Arabia, Syrian Arab Republic, Turkey, United Arab Emirates, and Yemen. Data coverage for most dimensions is high, except for the money and finance dimension of some economies.

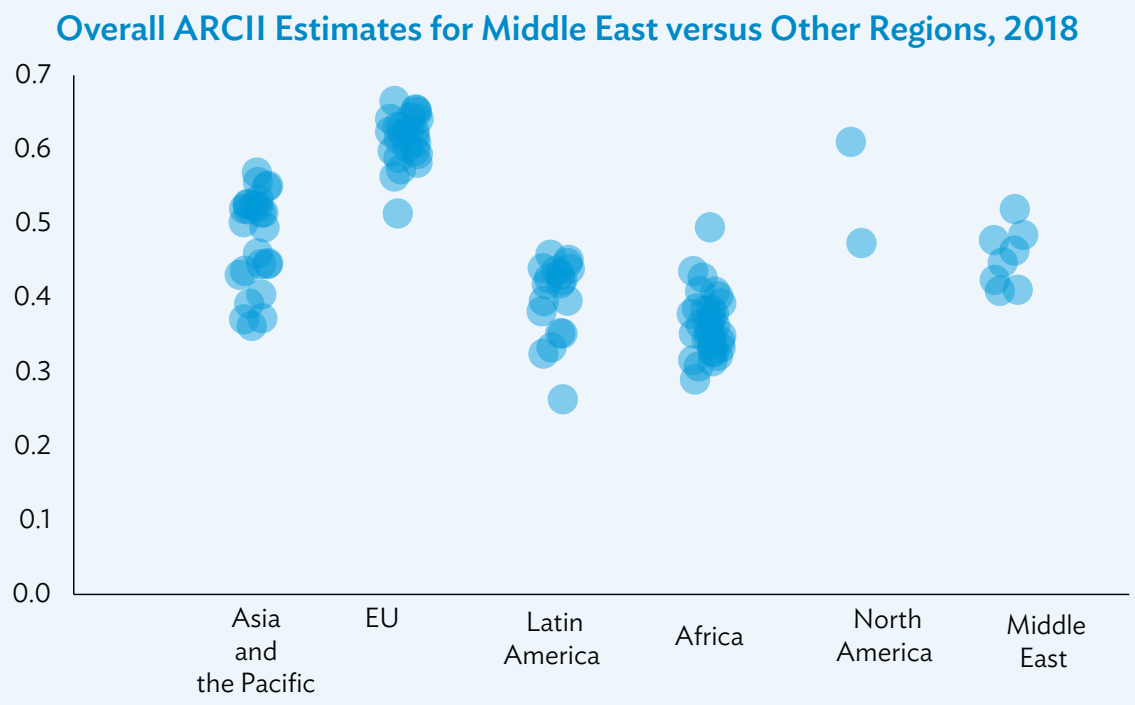

ARCII = Asia-Pacific Regional Cooperation and Integration Index, EU = European Union.

Notes: Higher values denote greater regional integration. Worldwide normalization is used for all estimations, where the indicators are normalized using global maximum and minimum values across all regions.

Source: Asian Development Bank. Asia-Pacific Regional Cooperation and Integration Index Database. https://aric.adb.org/database/ arcii (accessed May 2021).

Results from the enhanced $\mathrm{ARCII}$ framework underscore progress in regional integration in the Middle East region. Results suggest that integration in the institutional arrangements dimension is strong among the Middle East countries, which report the highest indexes in this dimension after Europe. The institutional arrangements dimension comprises indicators on membership in free trade agreements, embassies in the region, bilateral investment treaties, double taxation treaties, and cultural proximity. While indexes are relatively low in the trade and investment, money and finance, and regional value chain dimensions, the Middle East posted high integration levels in the two new dimensions (technology and digital connectivity, environmental cooperation), following the European Union in ranking.

Similar initiatives for Arab countries provide some information on monitoring regional integration efforts. The United Nations Economic and Social Commission for Western Asia (ESCWA) developed the Arab Economic Integration System of Indices as both a diagnostic tool and a policy and communication tool. The framework provides a three-level analysis (country, regional, global) and involves three separate scoreboards, categorized as enablers, policies, and outcomes. Ongoing initiatives by other institutions, such as the Islamic Development Bank (IsDB), should contribute to inform the trends and priorities in regional integration for the Middle East. ${ }^{a}$

a Islamic Development Bank (IsDB). 2019. IsDB Regional Cooperation and Integration Policy: Achieving Sustainable and Inter-dependent Growth through Mutual Cooperation. Jeddah, Saudi Arabia.

Source: Asian Development Bank. 


\section{Main Trends in Dimensional Indexes}

While regional integration trends in Asia remain relatively stable, a closer look at subregional trends provides additional elements on the region's performance. A glance at the eight ARCII dimensions suggests that the most significant gaps among subregions have been seen in the trade and investment, infrastructure and connectivity, and people and social integration dimensions (Figure 3.5). In terms of dispersion, the money and finance dimension is the most volatile among subregions, notably for the Pacific. This could be explained by the unstable nature of the new indicators, specifically the currency exchange rate correlation variable (II-e). Apart from the variable nature of exchange rates between economies, data availability for the Pacific islands is also sparse, particularly on bond liabilities (II-b) and deposit rates (II-c).

Figure 3.5: Enhanced ARCII Dimensional Indexes by Subregion
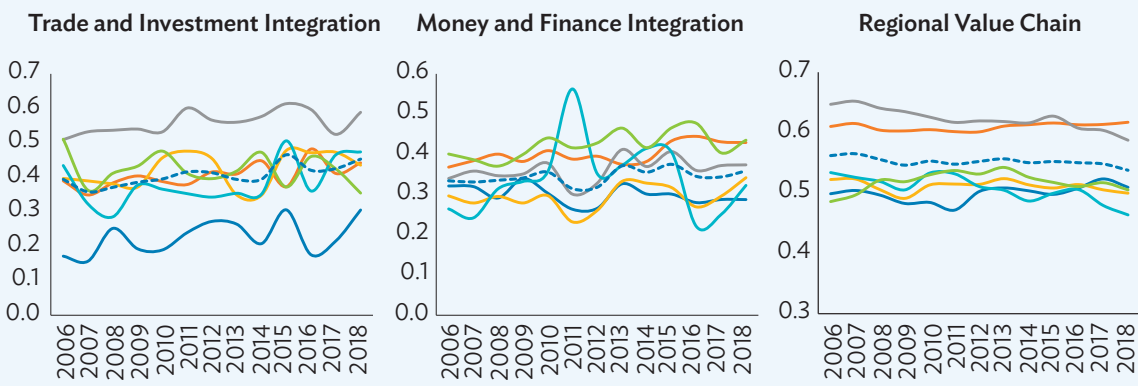

Infrastructure and Connectivity
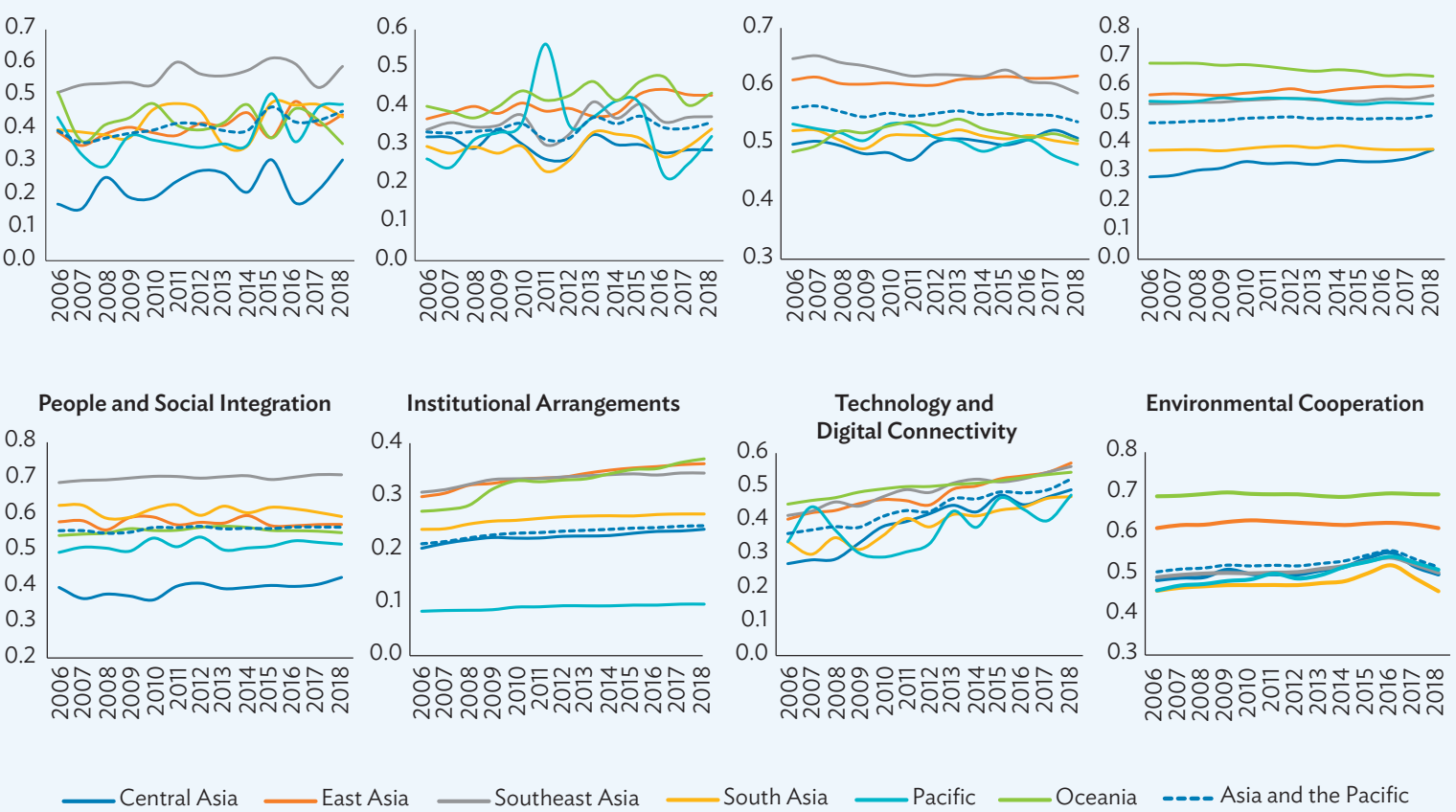

Central Asia _ East Asia

_ Southeast Asia

ia -.-- Asia and the Pacific

ARCII = Asia-Pacific Regional Cooperation and Integration Index.

Notes: Higher values denote greater regional integration. Worldwide normalization is used for all estimations, where the indicators are normalized using global maximum and minimum values across all regions.

Source: Asian Development Bank. Asia-Pacific Regional Cooperation and Integration Index Database. https://aric.adb.org/database/ arcii (accessed May 2021).

The enhanced ARCII aims to emphasize other channels of regional integration besides tangible economic flows between economies. The digital economy has given consumers and business a broader platform to connect instantaneously, and geographical borders no longer limit their modes of interaction. These developments manifest the important role of digitalization in enabling countries to become more integrated. They also call for innovative 
approaches to measuring regional and global linkages to explain the impact of technology and digitalization. ${ }^{26}$ Dimensional indexes in technology and digital connectivity suggest a steadily increasing trend, with Southeast Asia, Oceania, and East Asia performing considerably better than other subregions. The impact of digitalization in Southeast Asia is evident in its increased internet usage, and dynamic ICT trade activity, with economies like Viet Nam and Hong Kong, China having strong ICT goods production capacity. In addition, Oceania and East Asia both exhibit wide internet penetration, numerous mobile subscriptions, and plenty of intraregional research collaboration.

To a great extent, trends in regional integration will be linked to digital trade and digital technology. Globalization's growing reliance on data will allow businesses to tap new markets, and consumers to access new products and services (Van der Marel 2020; 2021). Different mobile payment platforms have also emerged, providing a convenient alternative to traditional financial services for consumers and businesses. Yet, restrictions in digital trade, particularly in digital services, have increased in recent years (Benz, Ferencz, and Nordås 2020). These restrictions are associated, for example, to digital infrastructure, restrictions on telecommunications usage or cross-border data privacy, including storage of personal data. Limited internet access and a paucity of patent applications in the Pacific subregion contribute to its generally low, yet highly variable dimensional index. Convergence in regulatory frameworks for digital trade will undoubtedly become an increasingly important area for Asia's regional cooperation and integration. Efforts to measure digital policy frameworks (UNESCAP 2020) should contribute to regulatory harmonization to support the digital economy.

A regional comparison of dimensional indexes also provides a clearer picture on Asia's regional integration process (Figure 3.6). Trends in the enhanced ARCII dimensional indexes show that trade and investment flows and regional value chain linkages remain high in Asia and comparable to Europe, with performance for other regions considerably lower. In contrast, Asia's performance in money and finance integration, infrastructure connectivity, and institutional arrangements remains below par. Globally, the most dynamic dimension of regional integration is technology and digital connectivity, with most regions having experienced a steady increase since 2006 . Asia has reported the highest indexes in this dimension among all regions since 2012.

In terms of dispersion, the regional value chains and environmental cooperation dimensions are more convergent than other dimensions, whereas institutional arrangements show the largest variance between regions. This can be explained by diversity in policies related to international treaties and participation in global organizations.

Finally, in the newly added environmental cooperation dimension, Asia's status is comparable to most other developing regions, though the gap with Europe and North America is substantial. Environmental cooperation is an increasingly important dimension for regional integration. However, its measurement has been often overlooked due to a lack of reliable bilateral indicators on environmental performance. ${ }^{27}$ The enhanced ARCII accounts for these dynamics through new indicators to measure ecological footprint, environmental health score, international environmental agreements, and trade in environmental goods. The ARCII will continue enriching this dimension with more accurate proxies for regional environmental cooperation.

26 Gröning, de la Rubia, and Straubhaar (2020), for example, address this question by remeasuring the number of international transactions in services and data trade. With this aim, efforts to improve the measurement of the digital economy have emerged in recent years (UNCTAD 2019; OECD, WTO, and IMF 2020; Crisostomo et al. 2021).

27 Indicators are needed that take into account the transnational nature of environmental cooperation. International environmental agreements, for example, have been on the rise to address environmental degradation and climate change and reflect the desire to look at this dimension from a public good perspective. Together with such agreements, trade policies already used to promote environmental policy can provide a proxy for regional environmental cooperation. 
Figure 3.6: Enhanced ARCII Dimensional Indexes by Region
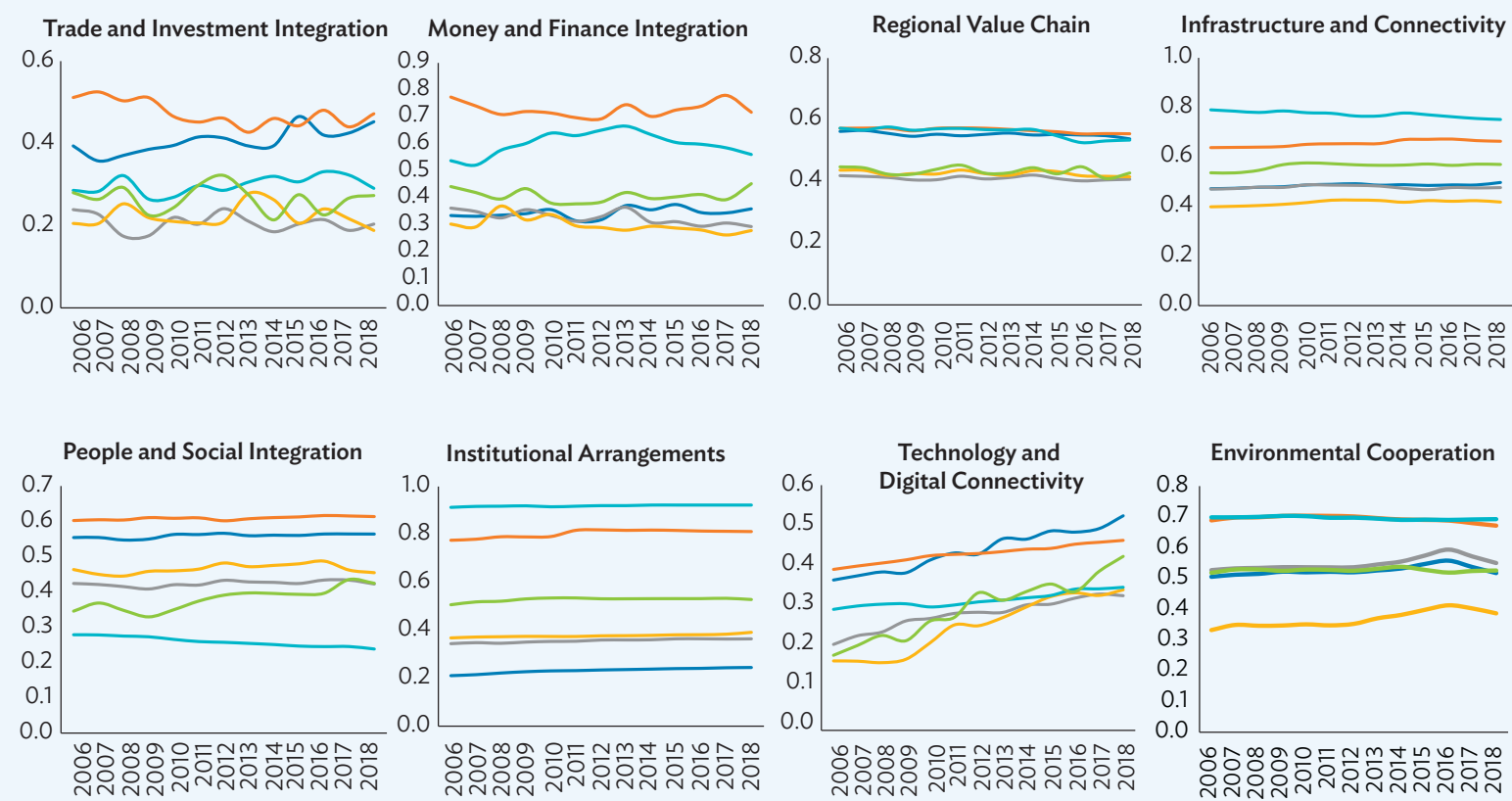

— Asia and the Pacific

-EU L Latin America

- Africa

- North America

— Middle East

ARCII = Asia-Pacific Regional Cooperation and Integration Index, EU = European Union.

Note: Higher values denote greater regional integration. Worldwide normalization is used for all estimations, where the indicators are normalized using global maximum and minimum values across all regions.

Source: Asian Development Bank. Asia-Pacific Regional Cooperation and Integration Index Database. https://aric.adb.org/database/ arcii (accessed May 2021).

\section{Contribution to ARCII Dimensional Indexes by Indicator}

To better assess these regional integration trends, the ARCII methodology permits users to decompose the contribution of each indicator to its dimensional index (Figure 3.7). The contribution is calculated based on indicator $i$ 's weight and the normalized value of indicator $i$ in region $j$, as follows:

$$
\text { Contribution }_{i j}=\left[\text { weight }_{i j}\right] \times\left[\text { normalized index }_{i j}\right] \quad \forall \mathrm{i}=1, \ldots . n
$$

Examining separate contributions provides further information about the main indicators influencing the dimensional indexes in Asia (Figure 3.7). ${ }^{28}$ In the trade and investment dimension, indicators of both trade (I-a, I-b,) and foreign direct investment (I-d, I-e) are driving the dimensional index, with a minor role for the intraregional trade intensity indicator $(\mathbf{I}-\mathbf{c})$. In the case of money and finance, the new exchange rate correlation (II-d) and capital account openness (II-e) indicators drive the dimensional index, which explains some of the differences in the dimensional index in the baseline ARCII framework. For the regional value chains dimensions, 
Figure 3.7: Contribution to Dimensional Indexes by Indicator-Asia and the Pacific
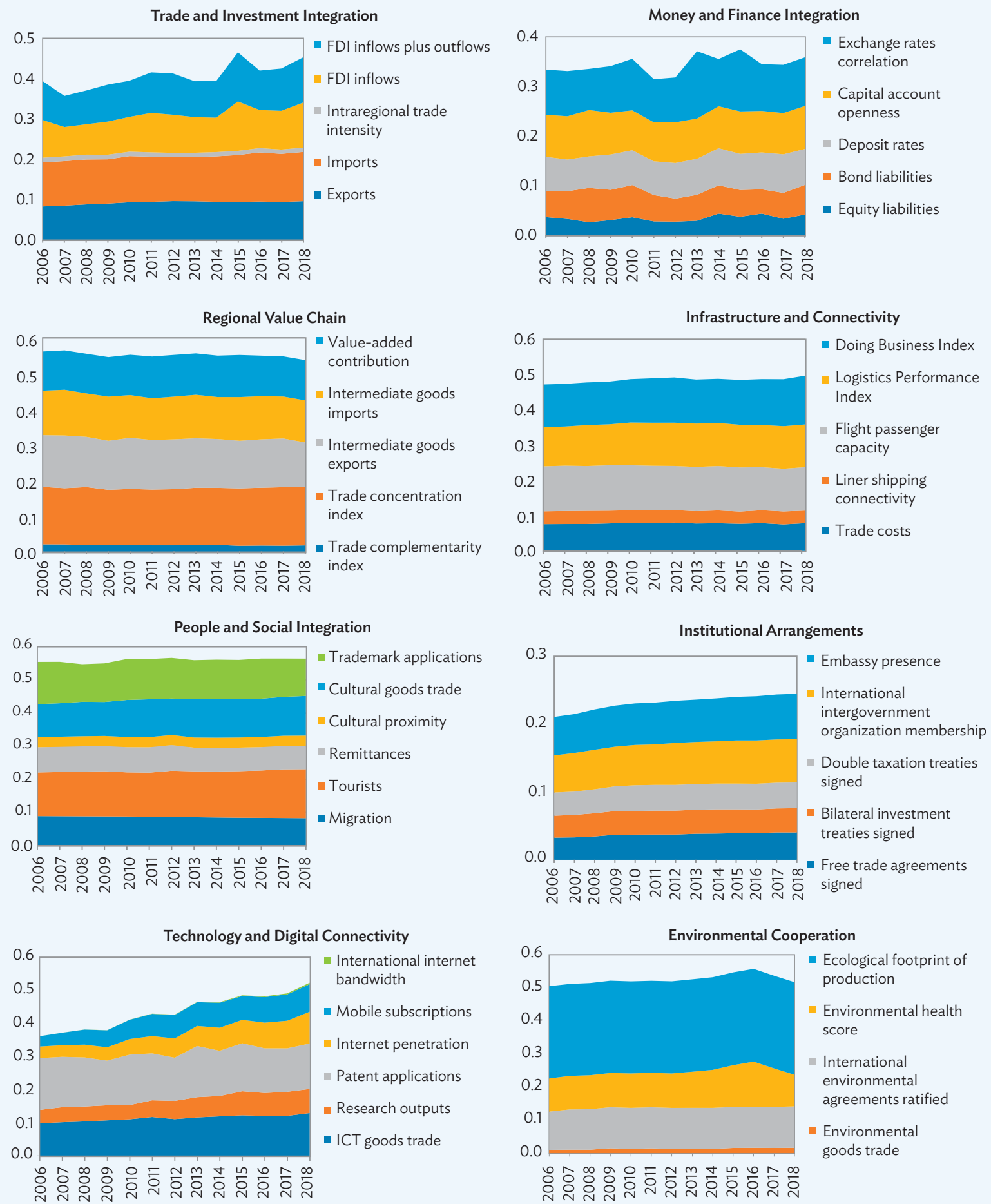

$\mathrm{FDI}=$ foreign direct investment, $I C T=$ information and communication technology.

Note: Indicators titles are simplified to facilitate reading. For a full list and definitions of all indicators, see Table 2.1.

Source: Asian Development Bank. Asia-Pacific Regional Cooperation and Integration Index Database. https://aric.adb.org/database/ arcii (accessed May 2021). 
the trade concentration (III-b) and intermediate goods trade indicators (III-c, III-d) are the most relevant. The contribution of national indicators in the infrastructure and connectivity dimension, the Doing Business (IV-e) and Logistics Performance (IV-d) index-explains about half of the dimensional index. Indexes in the people and social integration dimension are driven by the tourism ( $\mathbf{V}-\mathbf{b})$, trademark applications $(\mathbf{V}-\mathbf{f})$, and cultural goods trade $(\mathrm{V}$-e) indicators. Results in the institutional arrangements dimension are evenly driven by its five indicators, whereas the growing trend in the technology and digital connectivity dimension is driven, unsurprisingly, by increasing internet penetration (VII-d) and mobile subscriptions (VII-e). Finally, results in the environmental cooperation dimension index suggest that the ecological footprint (VIII-d) indicator and international environmental agreements ratified (VIII-b) are major contributors.

Decomposition of individual contributions by indicator also highlights some caveats regarding the use of worldwide normalization in the enhanced ARCII methodology (which also features in Chapter 4). Contributions from a relatively small number of indicators (i.e., intraregional trade intensity, trade complementarity, liner shipping connectivity, cultural proximity, environmental goods trade) are lower because the min-max normalization method is used. The normalized indexes for these indicators may be small because of global extreme values.

\section{Regional Integration by Income Level}

Regional cooperation and integration have been pursued as a development strategy to promote economic growth and to reduce inequality and poverty. From 1990 to 2017, developing countries increased their share of global exports from $16 \%$ to $30 \%$, while poverty plunged from $36 \%$ to $9 \%$ (Engel et al. 2021). The mechanisms through which regional integration impacts on these factors are often attributed to economies of scale, market access, technology and knowledge spillovers which are generated by reduced barriers in trade, finance, or people movement. The effects of regional integration on inequality, for example, are explained by the impact of job creation for low-skilled workers and new economic opportunities for less advantaged groups. In a classical trade framework, countries with abundant low-skill labor supply would benefit from trade liberalization. ${ }^{29}$ More recently, new approaches to understanding the impact of trade shocks on income distribution focus on the gains and losses for different economic and social groups (Engel et al. 2021).

Empirical approaches to measure the effect of regional integration on income inequality or poverty focus on measures of regional cooperation and integration such as participation in trade agreements, shares of intraregional trade, or tariff reductions. Some studies have found a positive impact on growth (DiCaprio, Santos-Paulino, and Soklova 2017; Bong and Premaratne 2018; Mann 2015; Kamau 2010) while others are inconclusive (Vamvakidis 1998; Tumwebaze and ljjo 2015; Te Velde 2011).

Therefore, a glance at the ARCII estimates clustered by economy income is useful to better understand some of the linkages described in the literature. For this analysis, all 173 economies in the enhanced ARCII framework are classified using income groups defined by the World Bank. Based on the distribution of the enhanced ARCll estimates by income group, results suggest that ARCII indexes increase with income per capita (Figure 3.8). High-income economies report considerably higher ARCII indexes, with an average close to 0.6 against 0.4 for other income groups, suggesting a strong link between regional integration and economic development. Upper middle-income, lower middle-income, and low-income economies report ARCII indexes that are near each other. Noticeably, the dispersion among income groups also differs, with high-income economies reporting greater dispersion in relation to the other income groups. The variance in ARCII indexes is also positively correlated with levels of income per capita.

Park and Claveria (2018) provides more detailed literature review of regional cooperation and integration's impact on growth, inequality, and poverty 
Figure 3.8: Distribution of ARCII by Income Group-World, 2018

2006

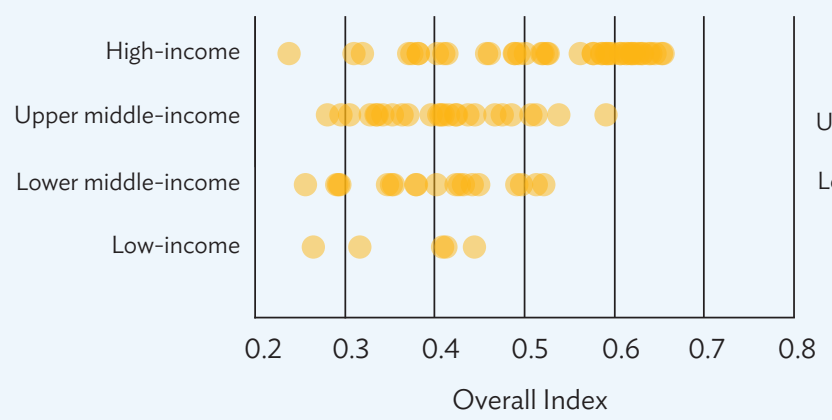

2018

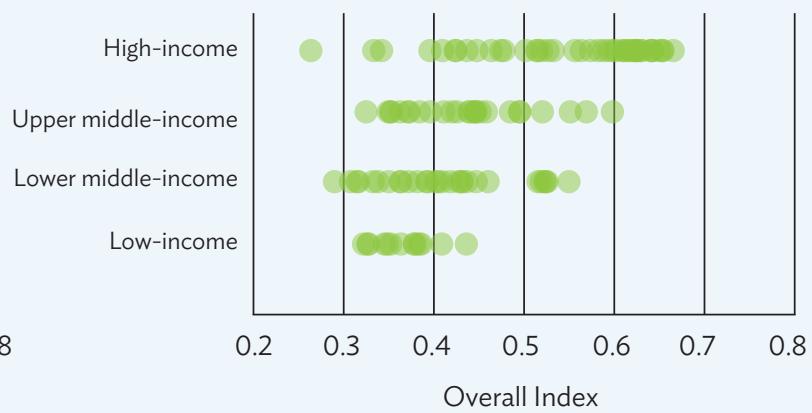

ARCII = Asia-Pacific Regional Cooperation and Integration Index

Note: Higher values denote greater regional integration. Worldwide normalization is used for all estimations, where the indicators are normalized using global maximum and minimum values across all regions. All regions included. Income groupings follow the World Bank classification.

Source: Asian Development Bank (ADB) calculations using data from ADB. Asia-Pacific Regional Cooperation and Integration Index Database. https://aric.adb.org/database/arcii; World Bank. World Development Indicators. https://databank.worldbank.org/source/ world-development-indicators (all accessed May 2020).

The ARCII dimensional indexes by income group also indicate some differences in distribution (Figure 3.9). In particular, the trade and investment dimension shows higher indexes for high-income and lower middle-income countries. Differences among other income groups are also narrower than in other dimensions (e.g., money and finance). In general, dimensional indexes are more positively correlated to income per capita in the case of money and finance, regional value chains, infrastructure and connectivity, institutional arrangements, technology and digital connectivity, and environmental cooperation. Meanwhile, the remaining two dimensions-trade and investment and people and social integration-are less correlated to income.

In terms of variance, dimensional indexes differ considerably among dimensions. Money and finance and institutional arrangements display higher dispersion, while the infrastructure and connectivity and environmental cooperation indexes showed lower dispersion.

\section{Comparison of the Baseline and Enhanced ARCII Estimates}

One way to investigate whether the results of the enhanced ARCII framework are robust is to compare them with the indexes estimated using the baseline structure. However, due to several enhancements in the index structure such as (i) the expansion of ARCII from six to eight dimensions, (ii) the inclusion of additional indicators, and (iii) rearrangement of established dimensions, the results among the two indexes are not fully comparable. Nonetheless, the approach for estimating ARCII allows for some, if not total, comparability between the two indexes. While the composition of the two indexes slightly differs, the main trends in regional and subregional differences are consistent. 


\section{Figure 3.9: Distribution of ARCII Dimensional Indexes by Income Group}
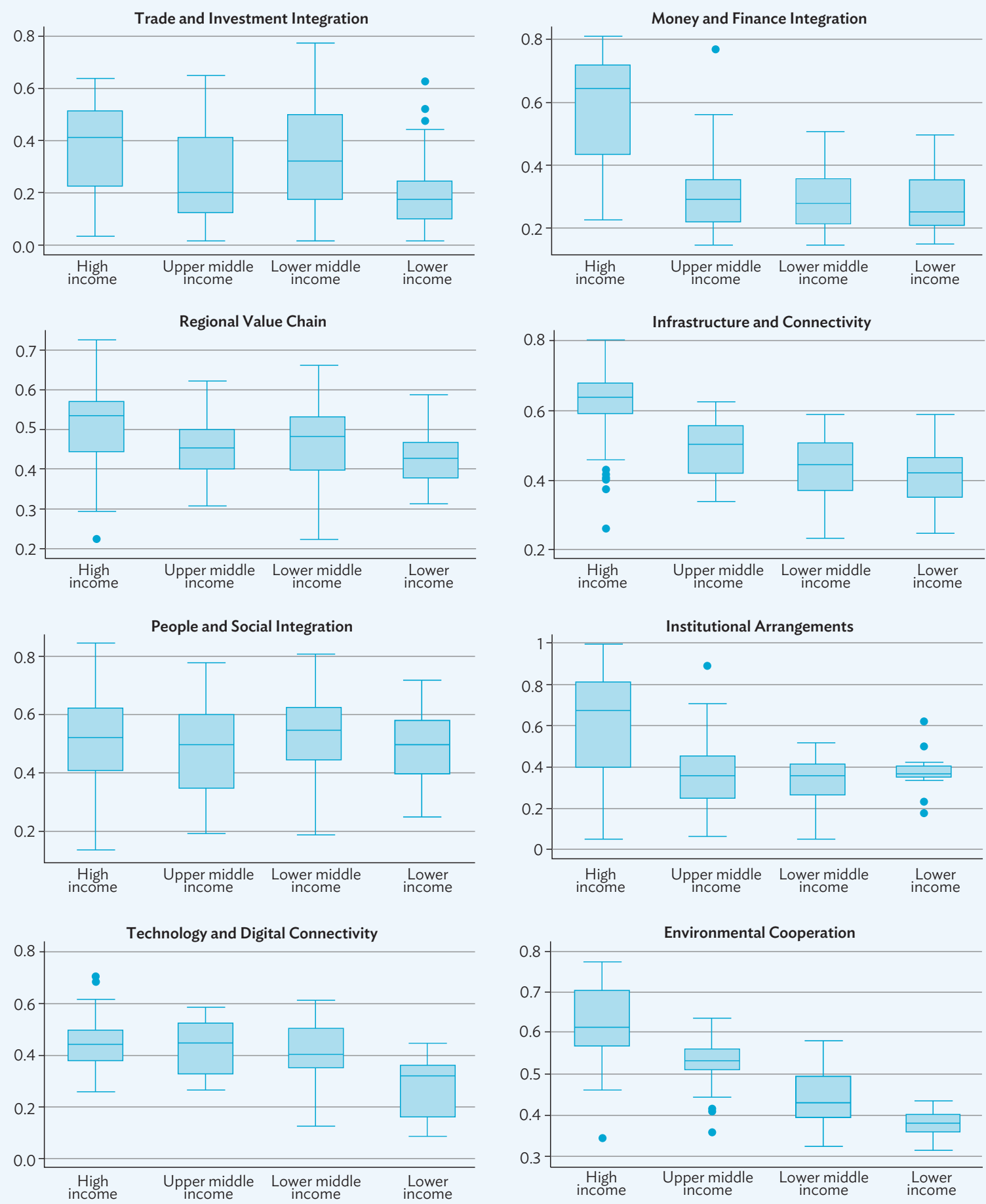

ARCII = Asia-Pacific Regional Cooperation and Integration Index.

Note: Income groupings follow the World Bank classification.

Source: Asian Development Bank. Asia-Pacific Regional Cooperation and Integration Index Database. https://aric.adb.org/database/ arcii (accessed May 2021). 
The ARCII methodology involves two steps, with a PCA applied to each dimension independently, followed by a second PCA estimation to produce an overall index. Importantly, results in the first step are invariant regardless of the number of dimensions in the overall index, because each dimension is treated separately when applying PCA. Although there are some differences in the overall indexes, both the baseline (six-dimension) and enhanced (eight-dimension) indexes describe a similar evolution of integration for the region groups (Figure 3.10).

Figure 3.10: Overall ARCII Estimates: Baseline versus Enhanced Framework

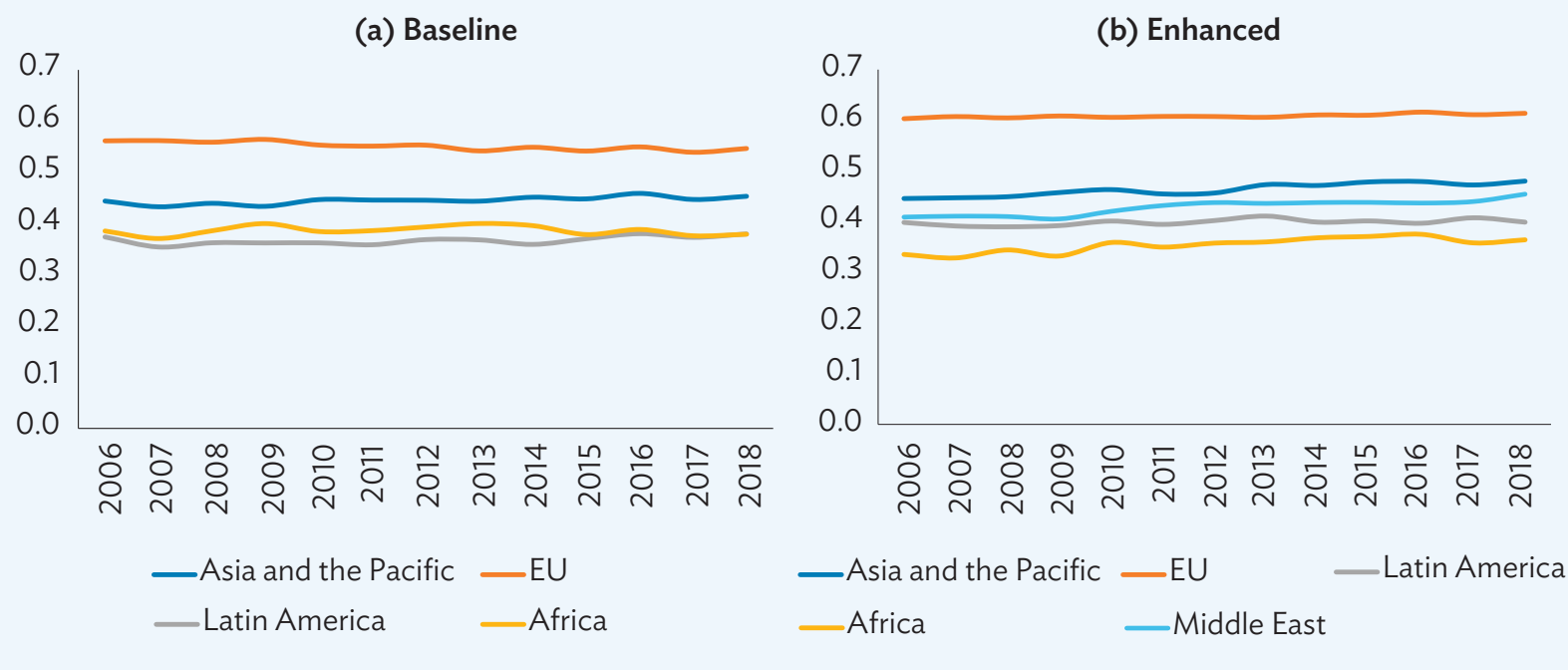

ARCII = Asia-Pacific Regional Cooperation and Integration Index, EU = European Union.

Notes: Higher values denote greater regional integration. Worldwide normalization is used for all estimations, where the indicators are normalized using global maximum and minimum values across all regions.

Source: Asian Development Bank. Asia-Pacific Regional Cooperation and Integration Index Database. https://aric.adb.org/database/ arcii (accessed May 2021).

A comparison of dimensional indexes between the baseline and enhanced index for Asia indicates relatively small changes in certain dimensions (Figure 3.11). Trade and investment indexes fall slightly in the enhanced index, while money and finance dip more significantly in the enhanced index. The differences in estimates and trends for the money and finance dimension can be explained by innovations introduced in that dimension: the removal of an indicator of equity returns and the addition of indicators of capital account openness (II-d) and exchange rate stability (II-e). Indeed, the equity returns indicator had large data gaps especially for countries in the Pacific islands which affected the computation of the dimensional and overall ARCIl estimate. Moreover, the behavior of the new indicators (II-d, II-e) in the enhanced framework was stable between 2017 and 2018, with no notable difference observed. This may have offset the volatility in the same period from other indicators included in the baseline money and finance dimension. The inclusion of two new indicators (II-d and II-e) in the enhanced framework, with better economy and year coverage, should help improve the measurement in this dimension.

Another clear difference between the baseline and enhanced indexes and trends appears for the dimensions of people and social integration and institutional arrangements (Figure 3.11). A key modification of the framework was the reclassification of certain dimensions-i.e., grouping people and social integration together and having a 
Figure 3.11: ARCII Dimensional Indexes for Asia and the Pacific: Baseline versus Enhanced

(a) Baseline

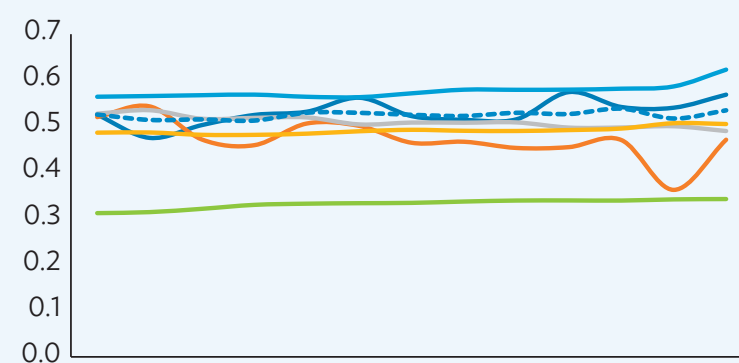

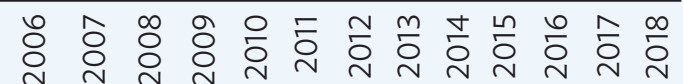

- Trade and Investment

Regional Value Chain

Movement of People

-.-- Overall Index (b) Enhanced

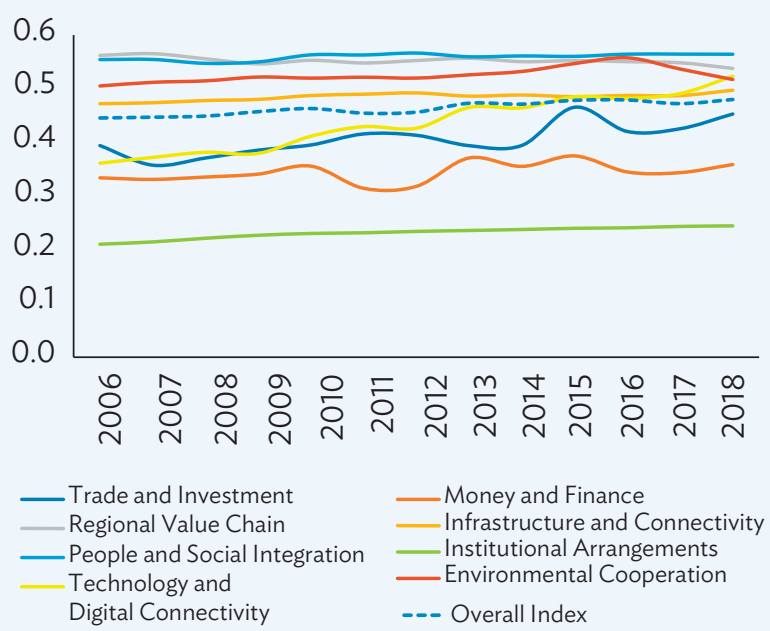

ARCII = Asia-Pacific Regional Cooperation and Integration Index.

Notes: Higher values denote greater regional integration. Worldwide normalization is used for all estimations, where the indicators are normalized using global maximum and minimum values across all regions.

Source: Asian Development Bank. Asia-Pacific Regional Cooperation and Integration Index Database. https://aric.adb.org/database/ arcii (accessed May 2021).

separate dimension for institutional arrangements. This change makes direct comparison of the results with the baseline model inadvisable. ${ }^{30}$

Regional value chains score increases slightly in the enhanced index. This could be due to the inclusion of an indicator on value-added contributions (III-e), while trends in the infrastructure and connectivity and institutional arrangements remain stable.

\section{Index Customization}

The enhanced ARCII framework aims at capturing regional cooperation and integration through two new dimensions. The enhancement also underlines that some dimensions or indicators might be more relevant for users in certain regions or economy groups. Allowing a higher degree of flexibility in the inclusion or exclusion of dimensions and indicators is therefore an objective of the enhanced framework.

In the enhanced framework, the cultural proximity indicator was reclassified under the people and social integration dimension. It had been under the institutional and social integration dimension in the baseline framework. Besides this change, the people and social integration dimension added new indicators on cultural goods trade and trademark applications. On the other hand, the institutional arrangements dimension (formerly classified as institutional and social integration) includes a new indicator on intergovernment organization membership. Table 2.1 has the full list of dimensions and indicators of the enhanced framework. 
The adapted use of the framework, or index customization, is aimed at giving ARCII users and researchers the tools for selecting the dimensions and indicators that are part of the ARCII estimation. Furthermore, given issues on data availability for certain economies, the customized index should allow inclusion of alternative indicators and comparison of regional integration levels with a benchmark.

The six-dimension baseline ARCII or the eight-dimension enhanced ARCII could be used as benchmark. The construction of the ARCII can be adjusted to meet the specific needs of users and to account for data availability in certain economies. When measuring intra-subregional integration indexes (i.e. Pacific islands, East Asia), the same set of weights from Asia could also be applied.

\section{Example: Eurasia Index Customization}

With the objective to provide a tool to monitor and analyze regional cooperation and integration, the ARCII framework and methodology by Park and Claveria (2018) was used to create a regional integration index for the Eurasia region. The Eurasia index was subsequently tailored to include indicators that are more accurate and relevant to the socioeconomic context of the subregion, which comprises nine economies: Armenia, Azerbaijan, Georgia, Kazakhstan, the Kyrgyz Republic, the Russian Federation, Tajikistan, Turkmenistan, and Uzbekistan.

\section{Baseline Eurasia Index}

The baseline Eurasia index is generated through two different methods. First, the Eurasia group was treated as a separate subregion in Asia and its index calculated accordingly. Second, the Eurasian countries were included in a larger group of countries across Asia and the Pacific. In both cases, indicators pertaining to regional cooperation and integration in money and finance were excluded from computations because data on these indicators was lacking for the Eurasian countries. Table 3.2 shows the weights of the remaining five dimensions in the baseline Eurasia index.

Table 3.2: Weights of Dimensions in the ARCII for Eurasia

\begin{tabular}{lcc} 
Dimension & RCl within Eurasia & RCl within Asia and the Pacific \\
Trade and Investment & 0.196 & 0.203 \\
Regional Value Chain & 0.197 & 0.201 \\
Infrastructure and Connectivity & 0.208 & 0.208 \\
Movement of People & 0.197 & 0.199 \\
Institutional and Social Integration & 0.202 & 0.188 \\
Total & 1.000 & 1.000 \\
\hline
\end{tabular}

$\mathrm{ARCII}=$ Asia-Pacific Regional Cooperation and Integration Index, $\mathrm{RCI}=$ regional cooperation and integration.

Source: Asian Development Bank. Asia-Pacific Regional Cooperation and Integration Index Database. https://aric.adb.org/database/arcii (accessed May 2021).

\section{Customized Eurasia Index}

The customized Eurasia index uses an alternative set of indicators to capture the different dimensions of regional integration. Using the six-dimension baseline Eurasia index as a benchmark, several indicators were added or 
replaced in each dimension to better capture the dynamics of regional integration. The selection of additional indicators is determined by data quality, availability of alternative data sources, and other channels of integration not captured in the standard ARCII framework. Based on these considerations, the customized Eurasia index provides alternative indicators for four dimensions, while excluding the money and finance and the infrastructure and connectivity dimensions from the baseline framework (Table 3.3).

It is important to stress that the customized index can be used to make comparisons only within the same subregion and it is not comparable to any other index. More important, use of a customized index also entails some modifications to the methodology and interpretation:

- As some indicators in the baseline may be replaced by indicators from other data sources, and in particular national data sources, the results may highlight data discrepancies with international data sources.

- As the number and type of indicators may vary between the standard and customized index, the retained number of principal components - and, therefore, the weights for each dimension-may differ.

As an example, comparison of the preliminary results from the baseline and customized Eurasia index shows slight variation in trends across the dimensions and the overall index (Figure 3.12). Overall, indexes tend to be lower in the customized index. Meanwhile, for both the baseline and customized Eurasia index, the movement of people dimension and the institutional and social integration dimension tend to be main drivers of regional integration.

The proposed approach to customization allows users to tailor the ARCII framework and include or exclude indicators according to data availability and needs. Future customizations will include the Pacific, where data are not available for several countries.

Table 3.3: Indicators in Eurasia and Customized Eurasia Index

\begin{tabular}{|c|c|c|}
\hline Dimension & Indicator & Data Source(s) \\
\hline \multirow[t]{3}{*}{ 1. Trade } & 1.1 Proportion of intraregional goods exports to total goods exports & \multirow{2}{*}{ DOTS database } \\
\hline & 1.2 Proportion of intraregional goods imports to total goods imports & \\
\hline & 1.3 Ratio of intraregional goods exports and imports to GDP & $\begin{array}{l}\text { DOTS database and the WDI } \\
\text { database }\end{array}$ \\
\hline \multirow[t]{3}{*}{$\begin{array}{l}\text { 2. Regional } \\
\text { Value Chains }\end{array}$} & $\begin{array}{l}\text { 2.1 Proportion of intraregional exports of intermediate goods to total } \\
\text { intraregional exports of goods }\end{array}$ & \multirow{2}{*}{ UN Comtrade } \\
\hline & $\begin{array}{l}\text { 2.2 Proportion of intraregional imports of intermediate goods to total } \\
\text { intraregional imports of goods }\end{array}$ & \\
\hline & $\begin{array}{l}\text { 2.3 Proportion of intraregional exports and imports of intermediate } \\
\text { goods to GDP }\end{array}$ & $\begin{array}{l}\text { UN Comtrade and the WDI } \\
\text { database }\end{array}$ \\
\hline \multirow[t]{3}{*}{$\begin{array}{l}\text { 3. Movement } \\
\text { of People }\end{array}$} & 3.1 Proportion of Eurasian countries that do not require an entry visa & National sources \\
\hline & $\begin{array}{l}\text { 3.2 Ratio of the number of intraregional inbound visitors to the total } \\
\text { number of international visitor arrivals } \\
\text { 3.3 Ratio of the number of intraregional outbound visitors in the total } \\
\text { number of outbound visitor departures }\end{array}$ & $\begin{array}{l}\text { UNWTO's tourism database and } \\
\text { national sources }\end{array}$ \\
\hline & $\begin{array}{l}\text { 3.4 Ratio of the total number of interregional inbound visitor arrivals } \\
\text { and intraregional outbound visitor departures to the population size }\end{array}$ & WDI database \\
\hline
\end{tabular}


Table 3.3 continued

\begin{tabular}{|c|c|c|}
\hline \multirow[t]{3}{*}{ Dimension } & Indicator & Data Source(s) \\
\hline & $\begin{array}{l}\text { 3.5 Ratio of intraregional remittance inflows to total remittance inflows } \\
\text { 3.6 Ratio of intraregional remittance outflows to total remittance } \\
\text { outflows }\end{array}$ & $\begin{array}{l}\text { World Bank's migration and } \\
\text { remittances database and } \\
\text { national sources (central banks) }\end{array}$ \\
\hline & 3.7 Ratio of intraregional remittance inflows and outflows to GDP & $\begin{array}{l}\text { World Bank's migration and } \\
\text { remittances database, national } \\
\text { sources (central banks) and the } \\
\text { WDI database }\end{array}$ \\
\hline \multirow[t]{5}{*}{$\begin{array}{l}\text { 4. Institutional } \\
\text { and Social } \\
\text { Integration }\end{array}$} & $\begin{array}{l}\text { 4.1 Proportion of Eurasian countries with which the country concerned } \\
\text { has signed an RTA } \\
\text { 4.2 Proportion of Eurasian countries with which the country concerned } \\
\text { has signed a customs union and/or a common market agreement }\end{array}$ & $\begin{array}{l}\text { WTO and ADB's databases on } \\
\text { RTAs }\end{array}$ \\
\hline & $\begin{array}{l}4.3 \text { Proportion of Eurasian countries with which the country concerned } \\
\text { has signed a bilateral investment treaty }\end{array}$ & UNCTAD and DESTA \\
\hline & $\begin{array}{l}\text { 4.4 Proportion of Eurasian countries with which the country concerned } \\
\text { has signed a treaty on avoiding double taxation }\end{array}$ & UNCTAD \\
\hline & $\begin{array}{l}\text { 4.5 Proportion of Eurasian countries that have an embassy in the } \\
\text { country concerned }\end{array}$ & $\begin{array}{l}\text { Huh (2020) based on The Europa } \\
\text { World Year Book and national } \\
\text { sources (ministries of foreign affairs) }\end{array}$ \\
\hline & $\begin{array}{l}\text { 4.6 Cultural proximity with other Eurasian countries relative to that } \\
\text { with all other countries }\end{array}$ & CEPII database \\
\hline
\end{tabular}

CEPII = Centre d'Etudes Prospectives et d'Informations Internationales, DESTA = Design of Trade Agreements, DOTS = Direction of Trade Statistics, GDP = gross domestic product, RTA = regional trade agreements, UN = United Nations, UNCTAD = United Nations Conference on Trade and Development, UNWTO = United Nations World Trade Organization, WDI = World Development Indicators.

Note: Highlighted rows in green indicate new indicators and dimensions included in the customized Eurasia index framework.

Source: Asian Development Bank.

Figure 3.12: Comparison of Baseline and Customized Eurasia Index, 2018

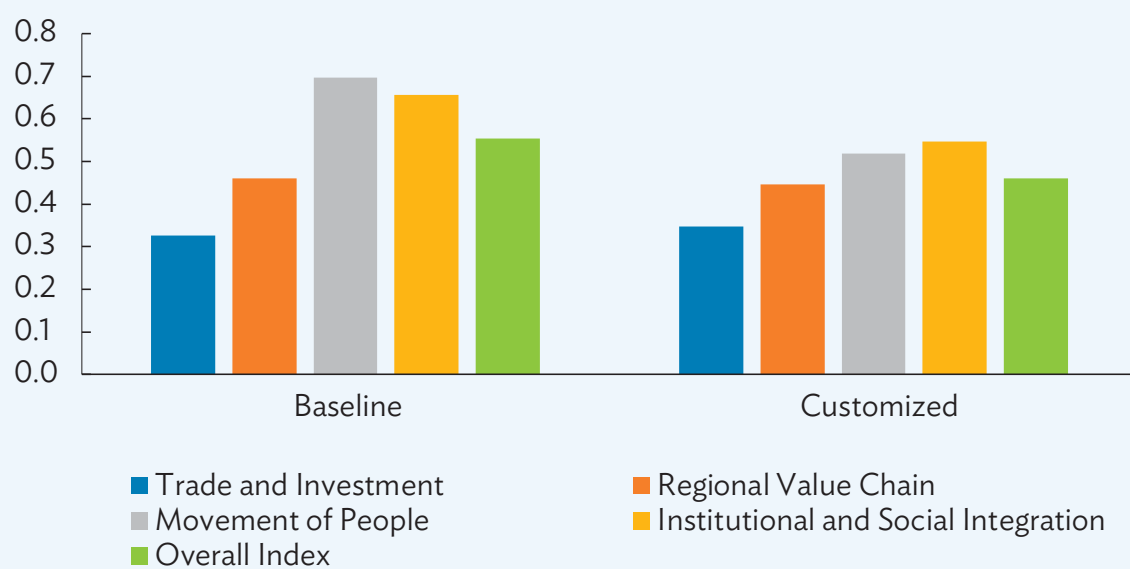

Notes: Higher values denote greater regional integration. Worldwide normalization is used for all estimations, where the indicators are normalized using global maximum and minimum values across all regions.

Source: Asian Development Bank. Asia-Pacific Regional Cooperation and Integration Index Database. https://aric.adb.org/database/ arcii (accessed May 2021). 


\section{Customization by Non-Regional Group: The Example of Asia-Pacific Economic Cooperation}

Other forms of customization include the use of the baseline ARCII estimates for non-regional groups, including by income and by membership to international agreements or organizations. Future applications in this regard include the generation of a regional cooperation and integration index for the Asia-Pacific Economic Cooperation (APEC) economies, as featured in Box 3.2.

\section{Box 3.2: Measuring Regional Integration in Non-Regional Groupings: Asia-Pacific Economic Cooperation}

The ARCII framework can be applied in building a regional integration index for selected economy groupings. For instance, a regional integration index could be built for a regional economic forum such as the Asia-Pacific Economic Cooperation (APEC). The 21 APEC region members are Australia; Brunei Darussalam; Canada; Chile; Hong Kong, China; Indonesia; Japan; Malaysia; Mexico; New Zealand; the People's Republic of China; Papua New Guinea; Peru, the Philippines; the Republic of Korea; the Russian Federation; Singapore; Taipei,China; Thailand; the United States; and Viet Nam.

Building a regional integration index for APEC entails the panel normalization (i.e., min-max rescaling) of indicator values first among APEC economies (regional normalization) and second among APEC and all other economies included in the data set (worldwide normalization). After which, the standard two-stage panel principal component analysis (PCA) approach is applied. Results from this exercise using the six-dimension baseline framework follows.

Panel PCA-derived weights show that the "institution and social integration" dimension has noticeably less weight in APEC than in other regions. The highest dimensional index for APEC across dimensions is received by the "movement of people." Meanwhile, the dimensional indexes suggest that the leading dimension in APEC is the "movement of people" dimension, followed by "infrastructure and connectivity." Compared to other regions, APEC indexes are considerably high across time, with a similar level to the EU from 2013 onwards.

\section{Overall and Dimensional Indexes-APEC Integration Index}

(a) Overall Indexes
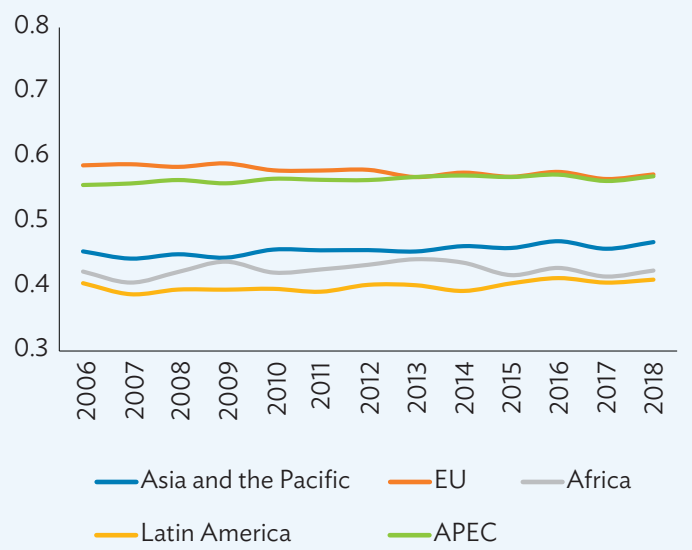

(b) Dimensional Indexes
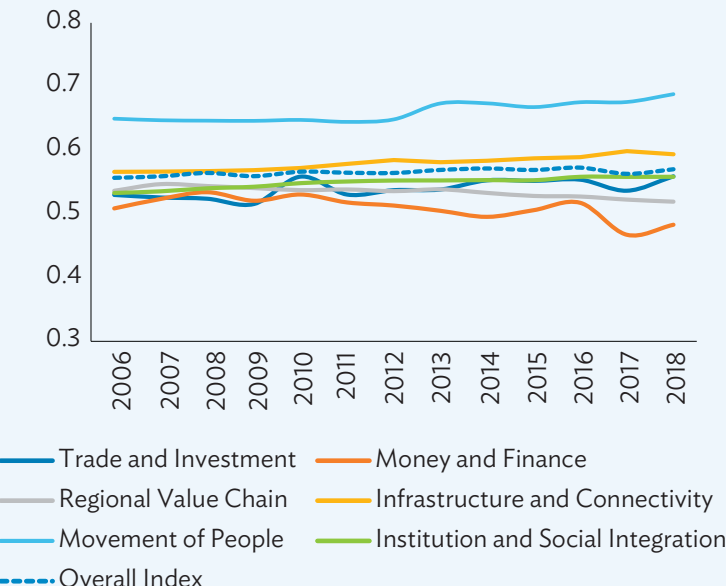

APEC $=$ Asia-Pacific Economic Cooperation, EU = European Union.

Note: Higher values denote greater regional integration. Worldwide normalization is used for all estimations, where the indicators are normalized using global maximum and minimum values across all regions.

Source: Asian Development Bank. Asia-Pacific Regional Cooperation and Integration Index Database. https://aric.adb.org/database/ arcii (accessed May 2021). 
This chapter has described the main results of the enhanced ARCII framework and highlighted the stable regional integration trend for Asia over time. More important, with the inclusion of two new dimensions, the index now reflects how rapid growth of the digital economy and continuous efforts toward environmental collaboration help strengthen integration within Asia and the Pacific. For the money and finance dimension, the incorporation of two new indicators could better inform trends on financial integration. Index customization will allow users to tailor the ARCII framework to their needs, improve the accuracy of underlying data by incorporating other data sources, and develop in-depth dimensional analysis on specific areas of regional integration. The next chapter delves into the possible downsides of ARCII as a measure of regional integration and proposes several solutions on how to address these biases. 


\section{References}

Asian Development Bank (ADB). 2019a. Maritime Cooperation in SASEC. Manila. https://doi.org/10.22617/ SPR190418-2.

- 2019b. Asian Economic Integration Report 2019/2020: Demographic Change, Productivity, and the Role of Technology. Manila. https://doi.org/10.22617/TCS190461-2.

2021a. Asian Economic Integration Report 2021: Making Digital Platform Works for Asia and the Pacific. Manila. https://doi.org/10.22617/TCS210048-2.

2021b. Capturing the Digital Economy: A Proposed Measurement Framework and its Applications (A Special Supplement of Key Indicators for Asia and the Pacific 2021). Manila.

Association of Southeast Asian Nations (ASEAN). 2021. ASEAN Digital Masterplan 2025. Jakarta: ASEAN Secretariat. https://asean.org/storage/ASEAN-Digital-Masterplan-2025.pdf.

Benz, S., J. Ferencz, and H. K. Nordås. 2020. Regulatory Barriers to Trade in Services: A New Database and Composite Indices. The World Economy. 43 (11). pp. 2860-2879. https://doi.org/10.1111/twec.13032.

Bong, A. and G. Premaratne. 2018. Regional Integration and Economic Growth in Southeast Asia. Global Business Review. 19 (6). pp. 1403-1415. https://doi.org/10.1177/0972150918794568.

Crisostomo, M. C., J. M. Guinto, A. G. Juani, A. J. Lumba, J. Mariasingham, C. Torelli, and J. A. Bernabe. 2021. Capturing the Digital Economy: A Proposed Measurement Framework and Its Applications. Unpublished draft. Mandaluyong City, Philippines. https://mrio.adbx.online/?secure-download=392.

DiCaprio, A., A. U. Santos-Paulino, and M. V. Soklova. 2017. Regional Trade Agreements, Integration and Development. United Nations Conference on Trade and Development Research Paper. No. 1. 10 July.

Engel, J. D. Kokas, G. Lopez-Acevedo, and M. Maliszewska. 2021. The Distributional Impacts of Trade: Empirical Innovations, Analytical Tools, and Policy Responses. Trade and Development Series. World Bank, Washington, DC. 19 May. http://hdl.handle.net/10986/35552.

European Commission, Directorate-General for Communication. 2019. The EU in 2018-General Report on the Activities of the European Union. Luxembourg: Publications Office of the European Union: European Union.

Gröning, S., C. de la Rubia, and T. Straubhaar. 2020. On the Remeasurement of International Trade in the Age of Digital Globalisation. In A. Klasen, ed. The Handbook of Global Trade Policy. pp. 47-78. Hoboken, NJ: WileyBlackwell. https://doi.org/10.1002/9781119167402.ch3.

Holzhacker, H., K. Karymshakov, and S. Lu. 2021. CAREC Regional Integration Index: Some Progress, But New Push Required. People's Republic of China: CAREC Institute. https://www.carecinstitute.org/wp-content/ uploads/2021/02/CRII-edited-10-Feb-2021_HK3.pdf.

Islamic Development Bank (IsDB). 2019. IsDB Regional Cooperation and Integration Policy: Achieving Sustainable and Inter-dependent Growth through Mutual Cooperation. Jeddah, Saudi Arabia. 
Kamau, N. T. 2010. The Impact of Regional Integration on Economic Growth: Empirical Evidence from Comesa, Eac and Sadc Trade Blocs. American Journal of Social and Management Sciences 1. pp. 150-163. https://doi. org/10.5251/ajsms.2010.1.2.150.163.

Mann, K. 2015. The EU, a Growth Engine? The Impact of European Integration on Economic Growth in Central Eastern Europe. FIW Working Paper. No. 136. FIW-Research Centre International Economics, Vienna. http://hdl.handle.net/10419/121136.

Organisation for Economic Co-operation and Development, World Trade Organization, and International Monetary Fund. 2020. Handbook on Measuring Digital Trade. Paris: OECD Publishing. https://www.oecd.org/ sdd/its/Handbook-on-Measuring-Digital-Trade-Version-1.pdf.

Park, C. Y. and R. Claveria. 2018. Does Regional Integration Matter for Inclusive Growth? Evidence from the Multidimensional Regional Integration Index. Economics Working Paper Series No. 559. Manila: Asian Development Bank.

Te Velde, D. W. 2011. Regional Integration, Growth and Convergence. Journal of Economic Integration 26 (1). pp. 1-28.

TeleGeography. 2020. The State of the Network. https://www2.telegeography.com/hubfs/assets/Ebooks/state-ofthe-network-2020.pdf.

Tholons. 2018. Tholons Services Globalization Index 2018. Tholons. http://tholons.com/Tholonstop100/ TSGI2018Report.pdf.

Tumwebaze, H. K. and A. T. Ijjo. 2015. Regional Economic Integration and Economic Growth in the COMESA Region, 1980-2010. African Development Review. 27 (1). pp. 67-77. https://doi.org/10.1111/1467-8268.12123.

United Nations Conference on Trade and Development (UNCTAD). 2019. Digital Economy Report 2019: Value Creation and Capture-Implications for Developing Countries. Geneva: United Nations. https://unctad.org/ system/files/official-document/der2019_en.pdf.

United Nations Economic and Social Commission for Asia and the Pacific (UNESCAP). 2018a. Summary of the Asia-Pacific Trade and Investment Report 2018. Bangkok: United Nations.

_. 2018b. Asia-Pacific Trade and Investment Report 2018: Recent Trends and Developments. Bangkok: United Nations.

-2020. Regional Integration for Sustainable Development in Asia and the Pacific: ESCAP Digital and Sustainable Regional Integration Index and Indicator Framework. Bangkok: United Nations Economic and Social Commission for Asia and the Pacific. https://www.unescap.org/sites/default/files/TIID_DigiSRII\%20\%2B.pdf.

Vamvakidis, A. 1998. Regional Integration and Economic Growth. The World Bank Economic Review 12 (2). pp. 251-270.

van der Marel, E. 2020. Globalization Isn't in Decline: It's Changing. European Centre for International Political Economy. August 2020. https://ecipe.org/wp-content/uploads/2020/08/ECl_20_PolicyBrief_06_2020_ LY06.pdf.

—. 2021. Digital-Based Services Globalization and Multilateral Trade Cooperation. Global Policy. 12 (3). pp. 392-398. https://doi.org/10.1111/1758-5899.12941. 


\section{Balancing ARCII Downsides: Sensitivity Analysis and Robustness Checks}

Construction of the Asia-Pacific Regional Cooperation and Integration Index (ARCII) necessarily involves making some underlying assumptions that occasionally can affect the precision of the index and signal the need for further interpretation. Having introduced the index indicators shaped by these assumptions in Chapter 2 and presented how ARCII has been refined since inception and the main results in Chapter 3, this chapter shifts to how possible downsides in the ARCII methodology can be identified and resolved. The main issues related to the ARCII are examined and several alternative approaches to address them are proposed.

Building on bilateral indicators for trade, financial, people movement, digital, institutional flows, and other dimensions, the ARCII has advantages over other methodologies and provides considerably more granular information on the dynamics of regional integration. At the same time, it is important to spell out the existing caveats to the formulation of the index and identify possible downsides that can emerge from the definition of the framework, the methodology, or data quality.

The identified caveats stem from (i) the choice of denominator for the indicators; (ii) the choice of regional or worldwide normalization; (iii) the focus on regionalization measures (i.e., regionalization bias); and (iv) the possible presence of spatial dependence in ARCII estimates. A convenient summary of the discussion for this chapter is outlined in Figure 4.1.

Figure 4.1: Identifying Bias in ARCII Estimation
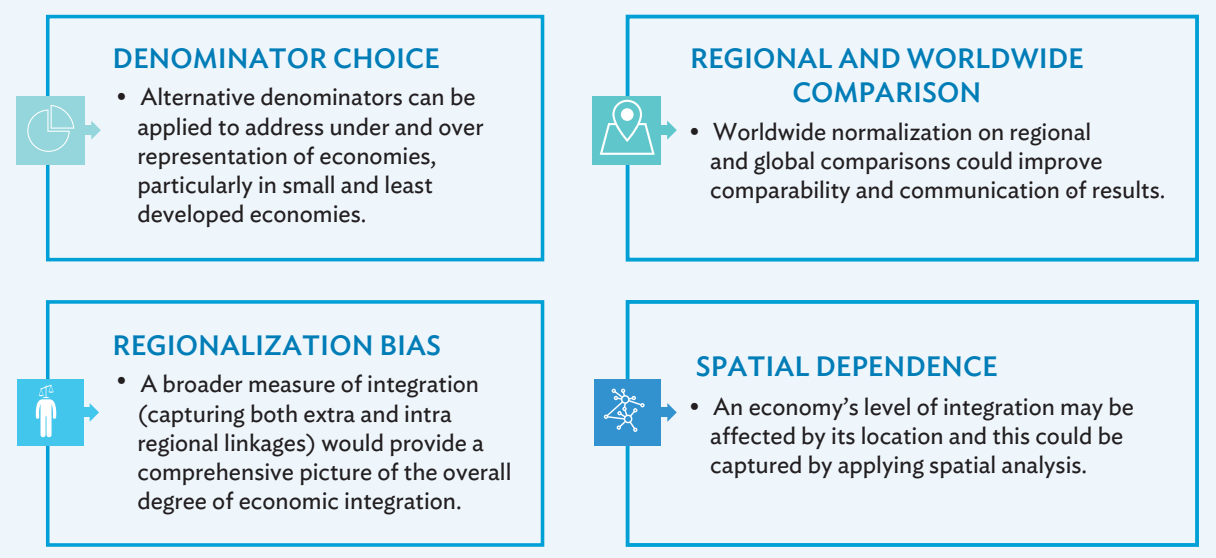

ARCII = Asia-Pacific Regional Cooperation and Integration Index .

Source: Asian Development Bank. 


\section{Denominator Choice in ARCII Indicators}

In delineating the main issues related to the ARCII, several indicators are constructed using bilateral data to compile ratios of intraregional to total activity. This structure is aimed at defining regional integration as an increasing function of regional to global linkages. While conceptually this definition seems appropriate to "define" regional integration, the indicator may tend to underrepresent or overrepresent regional integration levels for certain economies, particularly those with strong regional linkages due to their size, geographical location, or economic structure. For instance, some small island developing states (SIDS) and less developed countries in Asia ${ }^{31}$ report high ARCII or dimensional indexes, indicating a strong degree of regional integration. The Lao People's Democratic Republic (PDR), Myanmar, and Fiji are notable examples (Figure 4.2).

Figure 4.2: Overall ARCII and Dimensional Indexes for Selected Economies, 2018 (Enhanced Framework)

(a) Overall Index

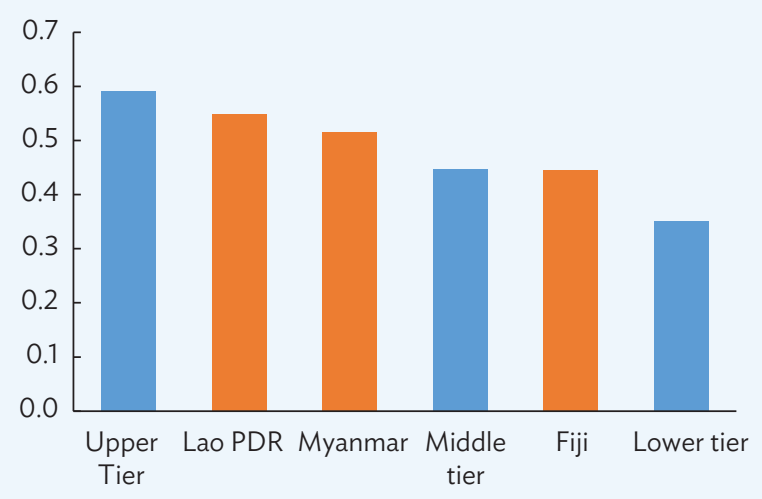

(b) Trade and Investment

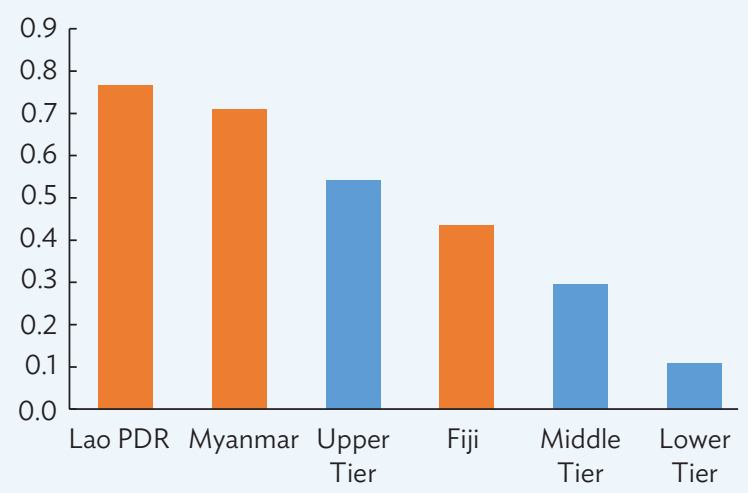

ARCII = Asia-Pacific Regional Cooperation and Integration Index, Lao PDR = Lao People's Democratic Republic.

Note: Upper tier, middle tier, and lower tier indexes were computed by ranking the average of indexes across the 173 economies included in the ARCII framework.

Source: Asian Development Bank. Asia-Pacific Regional Cooperation and Integration Index Database. https://aric.adb.org/database/ arcii (accessed May 2021).

As an example, indicator l-a depicts the proportion of intraregional goods exports to total goods exports. As total goods exports can be defined as the sum of intraregional $\left(E X P^{i n}\right)$ and extraregional $\left(E X P^{e x}\right)$ goods exports, the indicator is described as:

$$
\text { I-a. Share of intraregional to total goods exports }=\frac{\text { EXP }^{\text {in }}}{\operatorname{EXPin}^{\mathbf{n}}+\mathbf{E X P}^{\mathbf{e x}}}
$$

\footnotetext{
Asia refers to the 48 Asia and Pacific members of ADB, which include Japan and Oceania (Australia and New Zealand) in addition to the 45 developing member economies. It does not include Niue due to its limited data coverage.
} 
Small and less developed countries may not have competitive enough export profiles or the required capacity to trade beyond the region. These constraints mean they tend to trade products only within their own region. For small Pacific economies, estimates put intraregional exports at more than $60 \%$ of total exports between 2006 and 2018. As a result, the EXP $P^{e x}$ component in equation (1) would tend to be small and the indicator I-a would tend to converge to a maximum value of 1 . The same logic applies for other indicators when they are deflated by the world total as the standard denominator. Hence, using the world total as a denominator may, in some cases, overestimate the overall and dimensional ARCIl estimates for small and less developed countries.

A possible approach when estimating ARCII indexes for small and less developed economies is to employ an alternative denominator for the type of regional-to-global indicators described above. Figure 4.3 depicts the dimensional indexes of Asia and the Pacific's subregions generated from the eight-dimension model using gross domestic product (GDP) or population as denominator (alternative denominator) for selected indicators. The list of alternative indicators is provided in Appendix 3. Taking indicator I-a as an example, the alternative indicator is estimated as:

$$
\mathrm{I}-\mathrm{a}^{*} \text {. Share of intraregional goods exports to GDP }=\frac{E X P^{i n}}{G D P}
$$

\section{Figure 4.3: Enhanced ARCII Dimensional Scores with Gross Domestic Product or Population as Denominator}

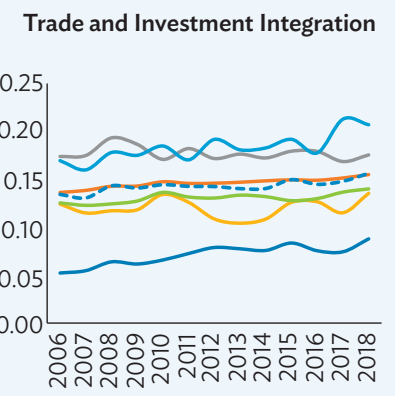

Money and Finance Integration

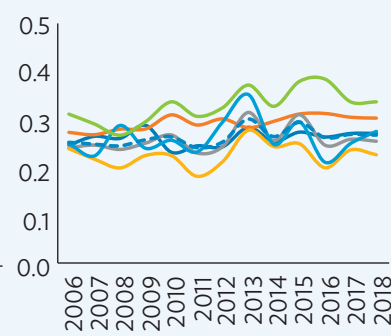

People and Social Integration
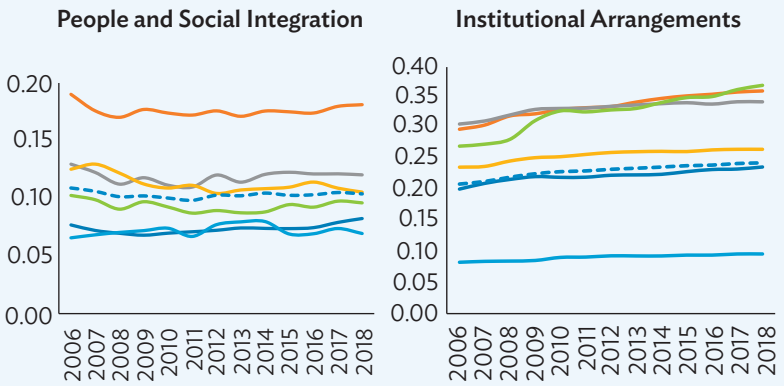

Regional Value Chain
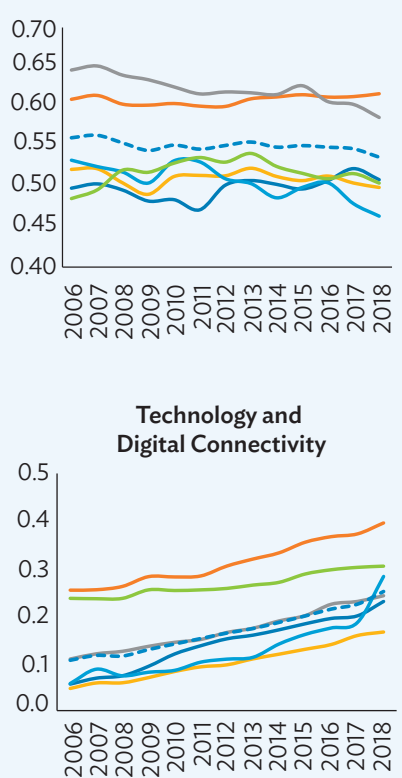

Infrastructure and Connectivity
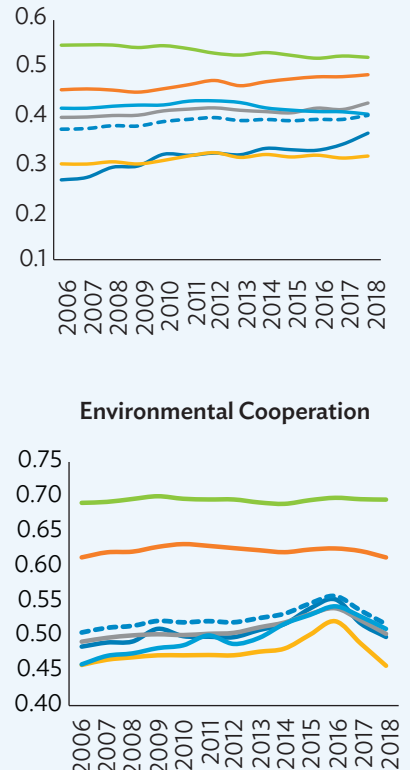

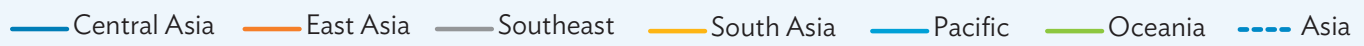

ARCII = Asia-Pacific Regional Cooperation and Integration Index .

Source: Asian Development Bank. Asia-Pacific Regional Cooperation and Integration Index Database. https://aric.adb.org/database/ arcii (accessed May 2021). 
Deflating the indicators by GDP or population (depending on the indicator) makes the dimensional indexes decline significantly in dimensions I, II, IV, V, and VII. The effects are particularly pronounced in dimensions I (Trade and Investment) and $\mathrm{V}$ (People and Social Integration) as the choice of denominator affects most indicators in these dimensions. Indicators in dimensions III (Regional Value Chains) and VI (Institutional Arrangements) are generally less affected. Results in Figure 4.3, using GDP or population as the alternative denominator, can be compared with the original dimensional indexes by subregion presented in Figure 3.5.

The use of indicators with the alternative denominator makes ARCII estimates for small and less developed countries less vulnerable to overestimation. For instance, overall indexes of Cambodia, the Lao PDR, and Myanmar tend to be on the upper end with the standard denominator (Figure 4.4, panel a). However, their indexes range within the middle tier average when the alternative denominator is used (Figure 4.4, panel b).

Figure 4.4: Overall ARCII in Selected Asian Economies, 2018

(a) World Total as Denominator

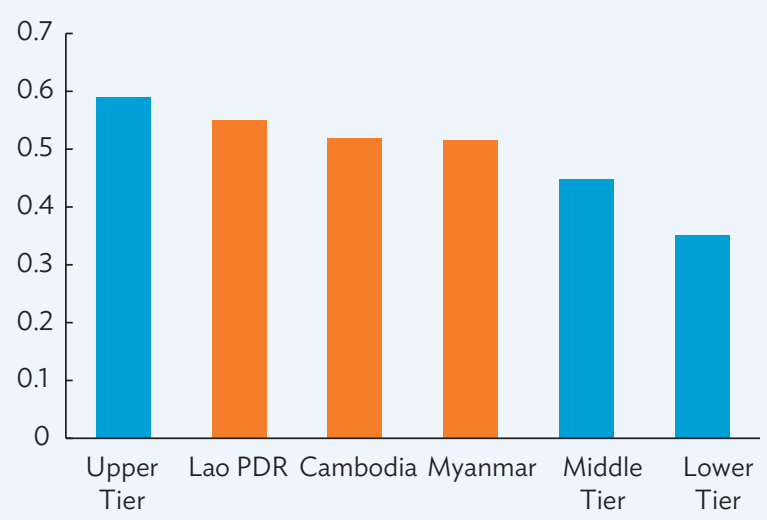

(b) GDP or Population as Denominator

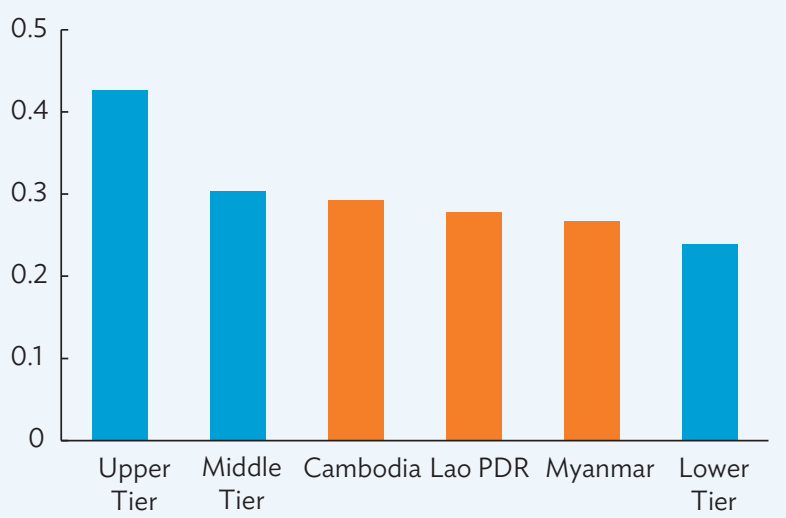

ARCII = Asia-Pacific Regional Cooperation and Integration Index, GDP = gross domestic product, Lao PDR = Lao People's Democratic Republic.

Note: Upper tier, middle tier, and lower tier indexes were computed by getting the average of indexes of the economies in ranked at the top, middle, and bottom across 173 economies included in the ARCII framework.

Sources: Asian Development Bank calculations using data from ADB. Asia-Pacific Regional Cooperation and Integration Index Database. https://aric.adb.org/database/arcii; World Bank. World Development Indicators. https://databank.worldbank.org/source/ world-development-indicators (all accessed May 2020).

Although the alternative denominator partially solves the overestimation problem, it may also have some weaknesses. The original indicator values prior to normalization nicely reside in the range of 0 (minimum integration) to 1 (maximum integration) when the standard denominator is used, while an indicator using GDP or population as denominator would be unbounded. Indeed, as shown in Figure 4.5, indicators using the alternative denominator may have more outliers and a more concentrated distribution. As a result, the denominator used in the min-max normalization procedure in ARCII becomes large, leading to lower indicator values and, consequently, lower ARCII estimates.

Alternative standardization procedures to min-max normalization can be applied instead to indicators with the alternative denominator to account for the presence of extreme values and skewness of the data (Box 4.1). To be consistent with the ARCII baseline model (Huh and Park 2018; Park and Claveria 2018) and to make results comparable, 
Figure 4.5: Distribution for Selected Indicators in ARCII Framework-World, 2018
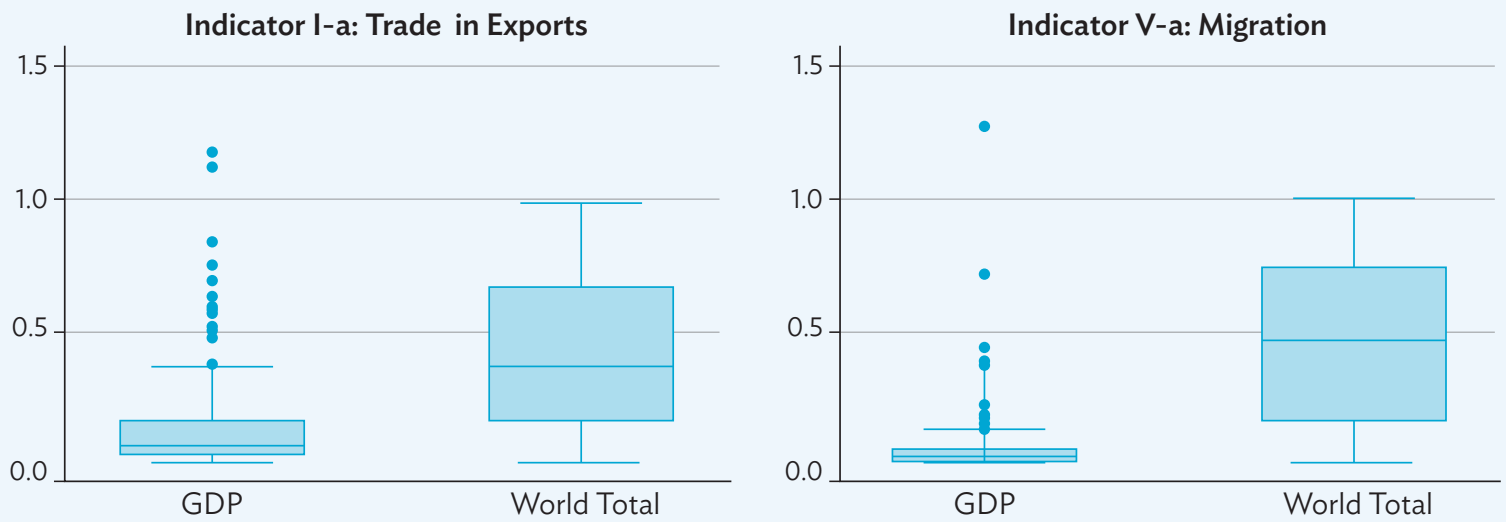

ARCII = Asia-Pacific Regional Cooperation and Integration Index, GDP = gross domestic product.

Note: The graphs present indicator values prior to undergoing normalization.

Source: Asian Development Bank. Asia-Pacific Regional Cooperation and Integration Index Database. https://aric.adb.org/database/ arcii (accessed May 2021).

the conceptual framework of the enhanced ARCII will continue to use the original denominator of world totals. However, robustness checks using the alternative denominator are recommended for small and least developed economies.

In summary, the different procedures indicate some trade-offs in the selection of the denominator and some implications for estimating regional integration indexes. Using the world total as a denominator makes the results comparable and interpretable, with a caveat that indexes for small and least developed economies could be overestimated. GDP or population as a denominator may partially solve these issues, but indicator values tend to be unbounded. Alternative transformation methods, such as the z-score and cube root, could help resolve the skewness of the data and the outliers. Table 4.1 provides a comparison of the advantages and disadvantages of each denominator approach.

\section{Table 4.1: Comparison of Alternative Denominators for ARCII}

\begin{tabular}{|c|c|c|}
\hline Denominator & Advantages & Possible Issues \\
\hline $\begin{array}{l}\text { World total } \\
\frac{E X P^{i n}}{E X P^{i n}+E X P^{e x}}\end{array}$ & $\begin{array}{l}\text { Values nicely reside in the } \\
\text { range of } 0 \text { (minimum) to } \\
1 \text { (maximum). }\end{array}$ & $\begin{array}{l}\text { - High indexes in dimensions I and V. } \\
\text { - Interpretation is not straightforward for some small and least } \\
\text { developed economies. }\end{array}$ \\
\hline $\begin{array}{l}\text { GDP }\left(\frac{E X P^{i n}}{G D P}\right) \text { or } \\
\text { Population }\left(\frac{E X P^{i n}}{P O P}\right)\end{array}$ & $\begin{array}{l}\text { - Less vulnerable to the issue } \\
\text { of small and underdeveloped } \\
\text { economies } \\
\text { - Compatible with global } \\
\text { economic integration index } \\
\text { (GEII). }\end{array}$ & $\begin{array}{l}\text { - Majority of indicators in dimensions I (trade and } \\
\text { investment) and } \mathrm{V} \text { (people and social) will be affected. } \\
\text { - Unbounded values for indicators. } \\
\text { - EXPin increases may make the overall ratio fall, despite no } \\
\text { change in extraregional activity. }\end{array}$ \\
\hline
\end{tabular}

ARCII = Asia-Pacific Regional Cooperation and Integration Index, GDP = gross domestic product.

Source: Asian Development Bank. 


\section{Box 4.1: Treating Extreme Values When Using Alternative Denominator in ARCII Indicators}

Two options are proposed for dealing with the skewness of indicators using the alternative indicator. The most straightforward is to remove the outliers (extreme values) to narrow the spread between the minimum and maximum values. This would lead to a smaller denominator when the standard min-max procedure is applied and would result in higher Asia-Pacific Regional Cooperation and Integration Index (ARCII) estimates. The drawback is that it will ultimately produce fewer observations.

The second option is to apply a functional transformation. Common applications are the log transformation and the z-score normalization, but they may not be appropriate for indicators using gross domestic product (GDP) or population as denominator. For instance, the log transformation would be unable to handle 0 values, which are abundant among indicators. Meanwhile, since the indicator data does not follow a normal distribution, using a z-score transformation could not solve the issue of data skewness. An example of skewness (right-skewed) among indicators using the alternative denominator is presented in the figure below.

\section{Skewness of Selected Indicators with the GDP or Population as the Denominator}

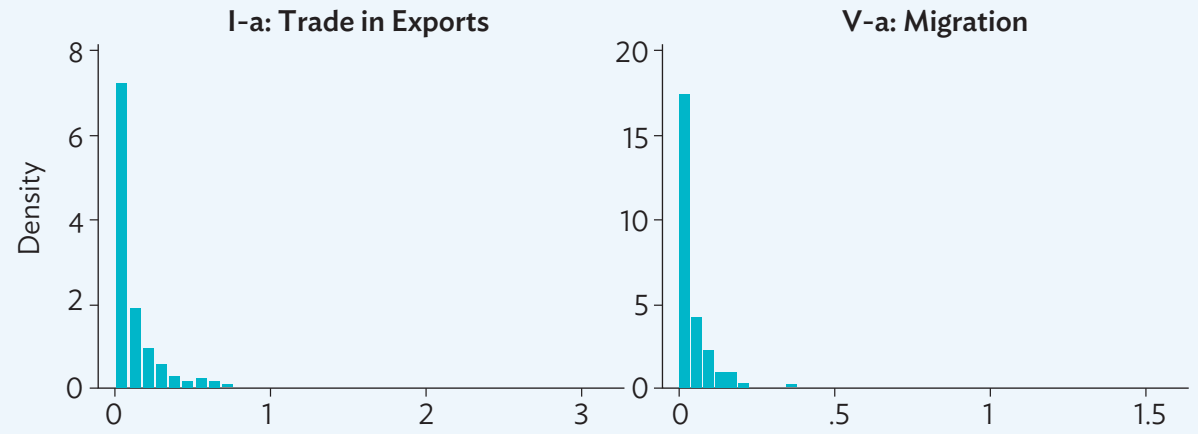

GDP = gross domestic product.

Note: The graphs present indicator values prior to undergoing normalization. The $\mathrm{x}$-axis refers to the indicator values.

Source: Asian Development Bank. Asia-Pacific Regional Cooperation and Integration Index Database. https://aric.adb.org/database/ arcii (accessed May 2021).

A possible transformation to smooth the distribution of skewed indicators is cube root transformation:

$$
X_{C}=X^{1 / 3}
$$

which aims to reduce the right skewness of distribution and can be applied to zero and negative values. A comparison between the different techniques suggests that the cubic root transformation tends to perform better at handling indicator outliers using GDP as denominator.

\section{Comparison of Transformation Procedures on Selected Indicators}

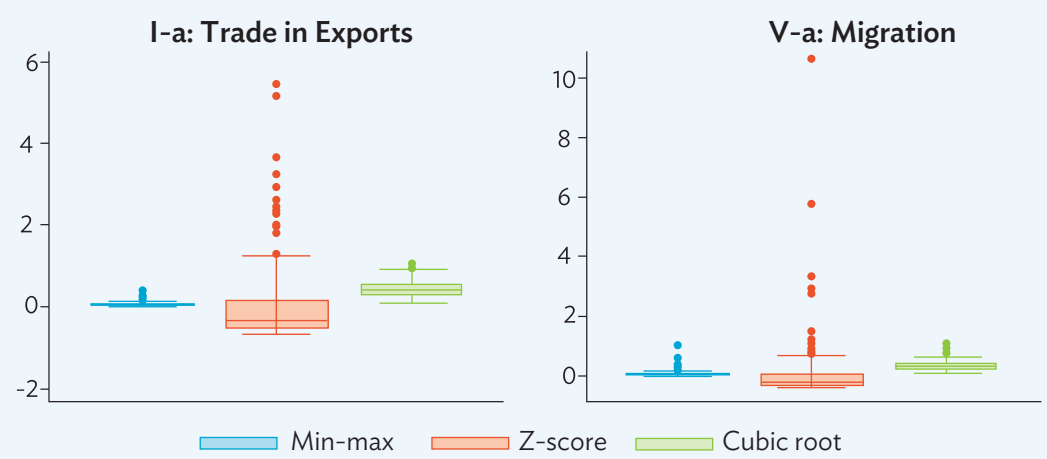

Source: Asian Development Bank. Asia-Pacific Regional Cooperation and Integration Index Database. https://aric.adb.org/database/arcii (accessed May 2021). 


\section{Selection of Regional or Worldwide Normalization}

In the ARCII framework, indexes are normalized using standard min-max procedure. This procedure is carried out before principal component analysis (PCA) and can use either regional sub-samples (regional min-max normalization) or the worldwide sample (worldwide min-max normalization). Regional min-max normalization is a standard approach used to measure member countries' integration level within a region and assess them against set goals. For instance, when comparing regional cooperation and integration performance between economies and subregions within Asia (e.g., Central Asia, East Asia, Oceania, Pacific, South Asia, and Southeast Asia), the ARCII estimates are usually generated using regional normalization.

However, for cross-regional comparisons (e.g., the level of regional cooperation and integration in Asia relative to Europe), regional normalization is not recommended, as regions tend to have different minimum and maximum values. For example, Figure 4.6 shows differences in the minimum and maximum values for each region of four indicators in the Trade and Investment dimension.

Figure 4.6: Distribution on Indicators in Trade and Investment Integration

(a) Trade in exports

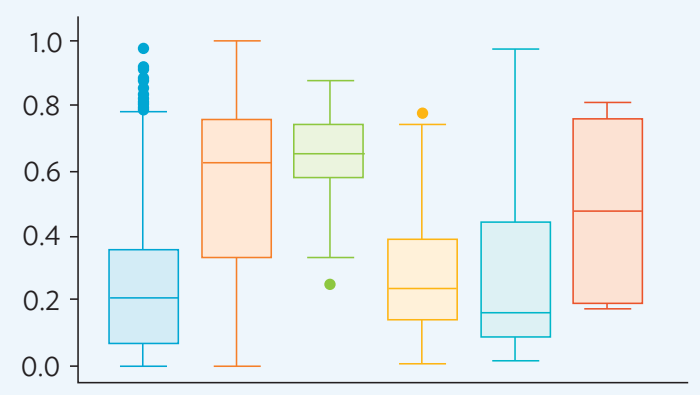

(c) Trade intensity index

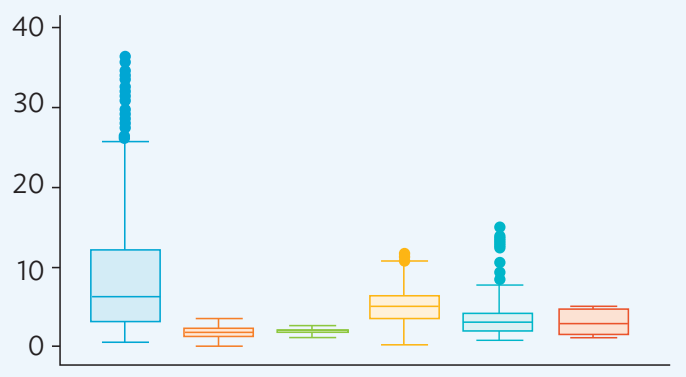

$\square$ Africa $\square$ Asia and the Pacific $\square$ EU (b) Trade in imports

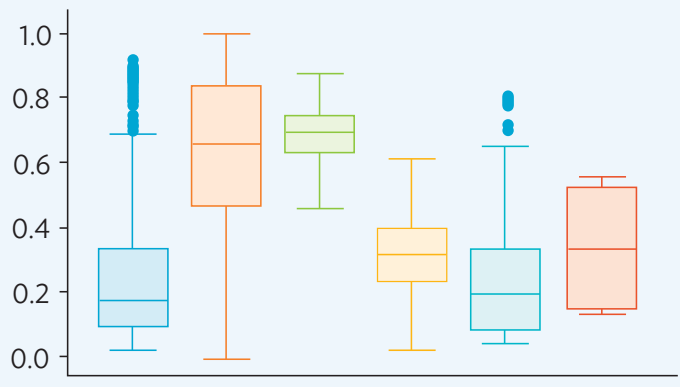

(d) Foreign direct investment inflows

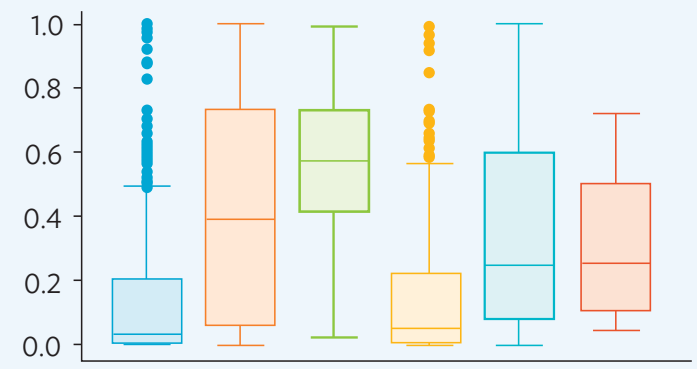

$\square$ Latin America $\square$ Middle East $\square$ United States

$\mathrm{EU}=$ European Union

Note: The graph presents indicator values prior to normalization. The indicators include those which use the world totals as denominator.

Source: Asian Development Bank. Asia-Pacific Regional Cooperation and Integration Index Database. https://aric.adb.org/database/ arcii (accessed May 2021). 
Figure 4.7: ARCII Estimates by Region and Type of Normalization, 2018

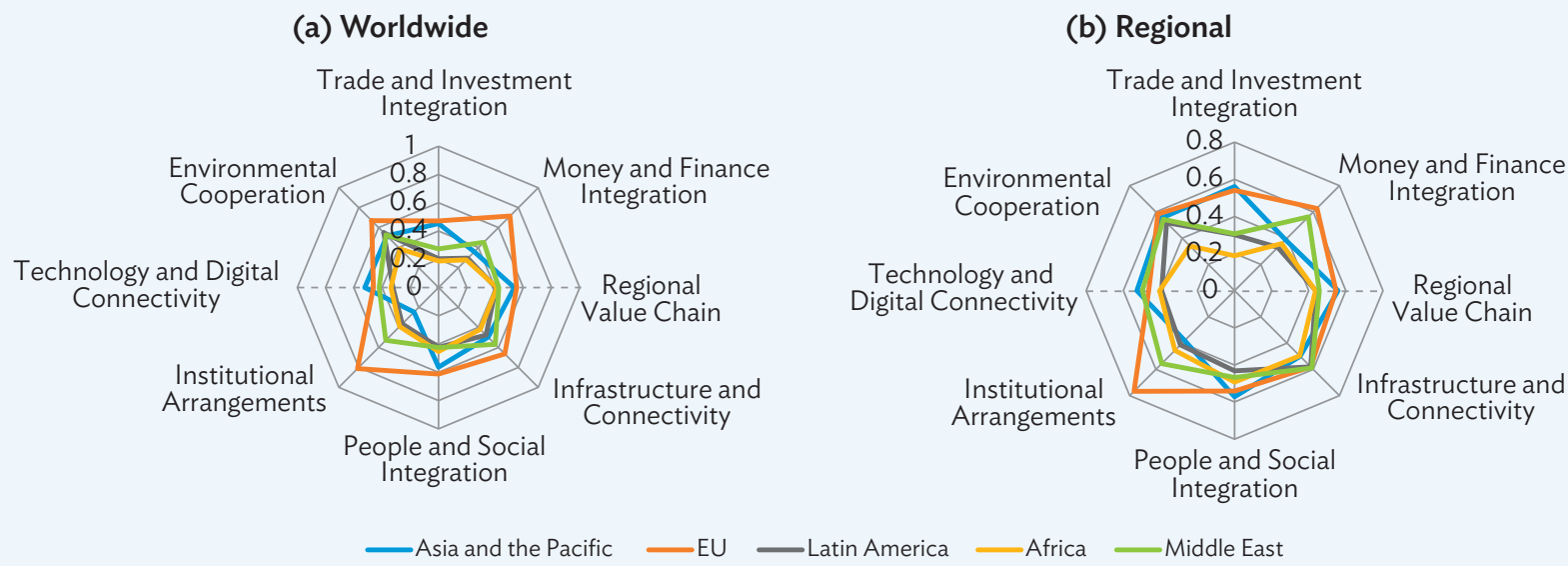

ARCII = Asia-Pacific Regional Cooperation and Integration Index, EU = European Union.

Note: Enhanced framework results using the world totals as the denominator.

Source: Asian Development Bank. Asia-Pacific Regional Cooperation and Integration Index Database. https://aric.adb.org/database/ arcii (accessed May 2021).

To allow direct comparison, an alternative is to normalize indicators based on global maximum and minimum values, also known as worldwide min-max normalization. A direct advantage of this approach is that the indexes can be compared at the same base. Figure 4.7 provides a comparison of interregional dimensional indexes for worldwide and regional normalization and shows that slight differences can be seen.

While ARCII baseline estimates have been presented using regional and worldwide min-max normalization, future ARCIl estimates will only report results using worldwide normalization. There are two main motivations for this. First, while comparison between regions is crucial to the analysis, inconsistencies may be encountered when regional normalization is used, particularly with alternative denominators such as GDP or population. Differences in the normalization by region are possible (with different minimum and maximum values per region) which could be an obstacle to having a common basis for cross-regional comparison. Second, the use of a common normalization method can also facilitate communication of ARCII results.

Notwithstanding these differences, the enhanced ARCII framework maintains a hybrid procedure, applying the PCA-weights derived from regional normalization regardless of whether intraregional or interregional comparisons are made. Use of regional PCA-weights ensures that regional features and characteristics are still considered even when values from worldwide normalization are employed to generate the ARCII (Chapter 2).

\section{Regionalization Bias}

By construction, ARCII focuses on intraregional flows, or intraregional activity, as this is the key dimension behind the concept of regional cooperation and integration. ${ }^{32}$ However, this approach can occasionally overemphasize 
the intraregional component of an economy's external linkages, without taking sufficient consideration of the extraregional linkages economies have outside their region. Some arbitrary parameters, such as an economy's place in a given region or subregion, can significantly impact the measurement of regional integration for certain economies.

Consider a Central Asian economy with strong linkages to the Russian Federation, by definition a non-Asia economy based on ADB's classification. While the ARCIl estimate for this economy captures intraregional linkages with other economies in this subregion, it remains silent on the important linkages it may have with the Russian Federation through trade, investment, finance, movement of people, institutional integration, and other channels. Similarly, consider an East Asian economy with a well-developed, interconnected financial sector. By definition, the dimensional indexes in Money and Finance for this economy will only capture intraregional financial flows, omitting the larger volume of extraregional flows.

These examples suggest that in a broader measure of global integration, which integrates both intraregional and extraregional linkages, it is important to have a comprehensive view of an economy's degree of economic integration. In such framework, regional economic integration remains a building block of global economic integration and the two forms of integration influence each other.

The global economic integration index (GEII) was developed to acknowledge and measure both intraregional and extraregional linkages (Huh and Park 2021). A key difference between the GEII (or globalization) index and other measures of globalization, such as the KOF Index of Globalization (Dreher 2006), is that it can be decomposed into regional and nonregional integration. An intraregional economic integration index (IEII) measures regional linkages, whereas an extraregional economic integration index (EEII) measures nonregional linkages. Based on these subindexes, the globalization index assesses the relative contributions of regional and nonregional integration to an economy's globalization trajectory.

To build the GEII index, Huh and Park (2021) use a subset of 25 indicators largely based on the structure of the baseline ARCII to measure different aspects of economic integration. In contrast to ARCII, the denominator used in some indicators of the GEll is the economy's GDP or population instead of the world total. This facilitates the interpretation of the index and the decomposition between intraregional and extraregional linkages. In addition, the GEII uses z-score normalization (instead of ARCIl's min-max normalization) to reduce the effects of extreme values.

Results from Huh and Park (2021) show that that globalization levels measured by GEll have risen from 2006 to 2014 (Figure 4.8). Noticeable dips are observed between 2008 and 2009, and 2011 and 2012, which may be attributed to the global financial crisis and the eurozone debt crises, respectively. Both intraregional and extraregional economic integration share a pattern similar to that for global economic integration. All indexes also experienced some decline in 2009 and 2012-and they have become more synchronized since 2012. Between the two subcomponents, the extraregional component shows a larger variation than the intraregional component.

A regional comparison of the GEll shows the considerable gap between Asia and the two leading regions in terms of global integration, North America and Europe (Figure 4.9). Similar patterns are observed, irrespective of the type of integration. The levels of intraregional integration in Asia and Latin America are similar. While variations among countries and regions remain, the general picture revealed in the global economic integration index is that countries with high levels of global integration also demonstrate deep intraregional (or simply regional) integration. Indeed, with few exceptions, intraregional links contribute more to global integration than extraregional links. 
Figure 4.8: Economic Integration Indexes

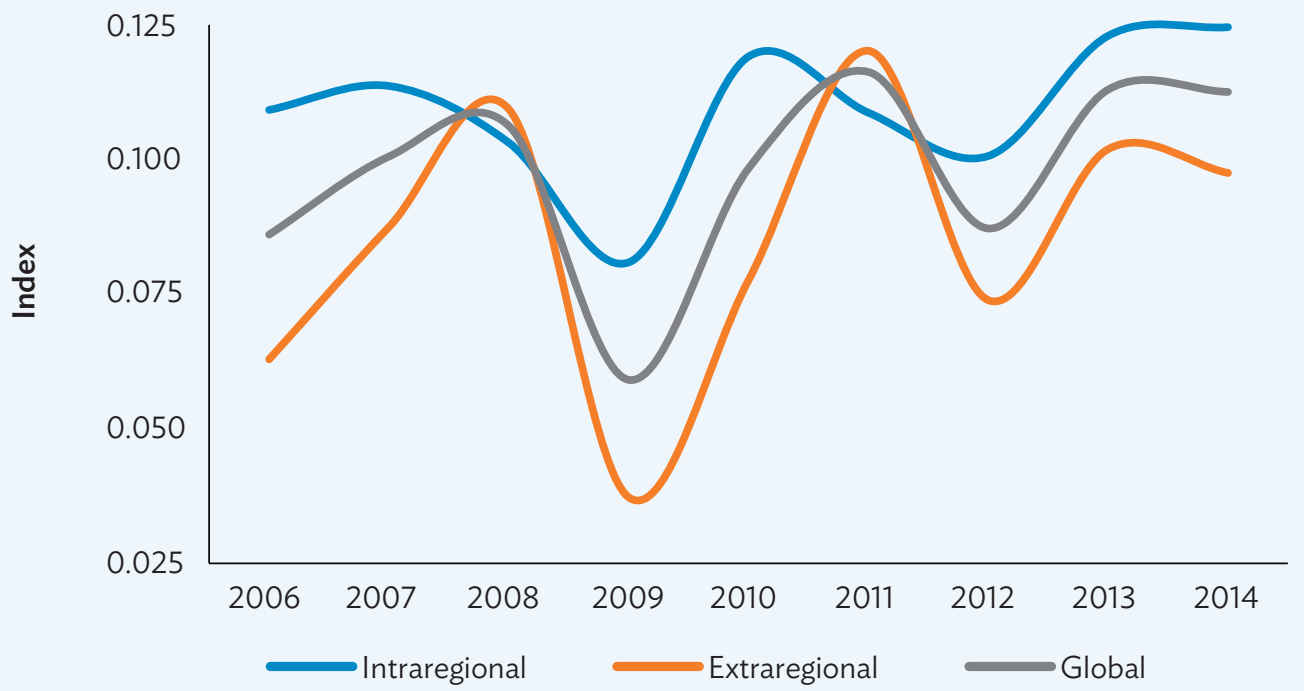

Source: H. S. Huh and C. Y. Park. 2021. A New Index of Globalisation: Measuring Impacts of Integration on Economic Growth and Income Inequality. The World Economy. 44 (2). pp. 409-443. https://doi.org/10.1111/twec.12998.

Figure 4.9: Economic Integration Indexes, by Region

(a) Global

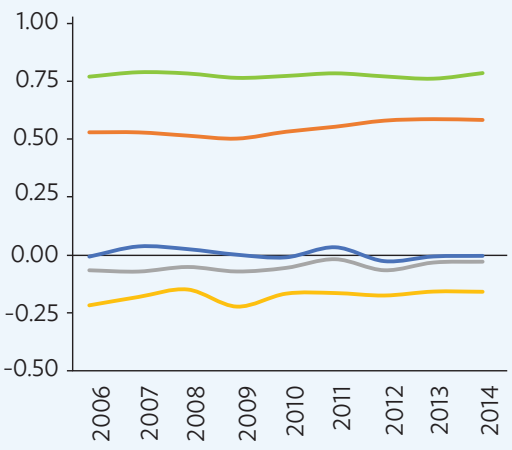

(b) Intraregional

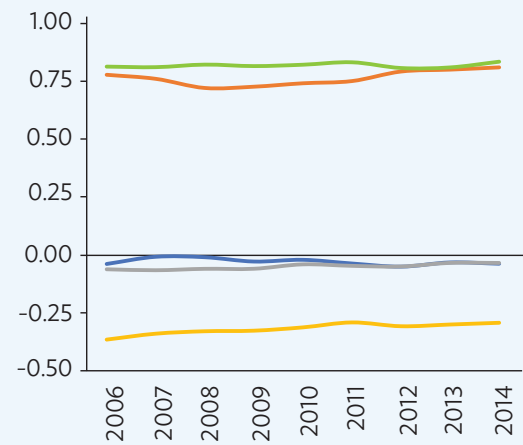

(c) Extraregional

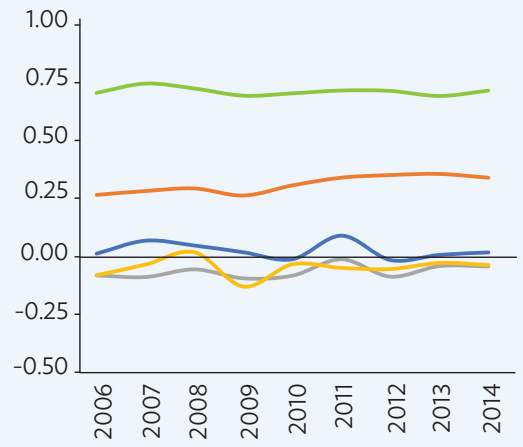

- Asia and the Pacific - EU — Latin America - Africa — North America

$\mathrm{EU}=$ European Union

Source: H. S. Huh and C. Y. Park. 2021. A New Index of Globalisation: Measuring Impacts of Integration on Economic Growth and Income Inequality. The World Economy. 44 (2). pp. 409-443. https://doi.org/10.1111/twec.12998.

A new globalization index building on Huh and Park (2021) will be developed, using as blueprint the structure of the eight-dimension (enhanced) ARCII. The denominator in the new globalization index will cover a sample of 173 economies over the 2006-2018 period of the enhanced ARCII. The new globalization index is intended to provide a more complete synopsis of an economy's full economic integration profile, taking into consideration regional and nonregional channels. 


\section{Spatial Autocorrelation Bias in ARCII Estimates and Correction}

An economy's geographic location can play an important role in its ability to forge linkages with other economies in a region. ${ }^{33}$ For instance, geographically disadvantaged economies are at the low end of the regional integration spectrum. Landlocked economies have no territorial access to the sea, limited border crossings, and transit dependence. Due to their remoteness, landlocked countries are dependent on neighboring transit countries for their external trade and suffer from high transaction costs. Therefore, it comes as no surprise that Central Asia remains the subregion least integrated with Asia. Meanwhile, sea-locked economies face greater risk of marginalization due to their small size, remoteness from large markets, and high vulnerability to economic and natural shocks.

At the same time, an economy's degree of regional integration tends to depend on that of its neighbors. As observed in Figure 4.10, panel a, economies with low ARCII estimates seem to be near one another, and those with high ARCII estimates are clustered in the same manner. ARCII dimensions likewise depict that neighboring economies generally have similar index estimates (Figure 4.10, panels $b$ to g). This suggests that economies might influence their neighbors' integration potential through certain dimensions of regional integration such as trade, investment, and movement of people.

\section{Spatial Dependence: Why Does It Matter?}

Spatial dependence occurs in two different forms (Anselin and Rey 1991a). In one, it affects error terms only and is mostly considered to be a nuisance (in the statistical sense) which needs to be controlled for. Spatial error is indicative of omitted (spatially correlated) covariates that if left unattended would affect inference and render inefficient estimates. This is referred to as a nuisance spatial dependence and is addressed through the spatial error model (SEM). The SEM is appropriate when the concern is to correct for the potentially biasing influence of the spatial autocorrelation due to the use of spatial data, regardless of whether the model of interest is spatial or not (Anselin 2003). The standard equation for the SEM is:

$$
\text { (1) } \begin{aligned}
Y & =X \beta+\xi \\
\xi_{i} & =\lambda W \xi+\mu
\end{aligned}
$$

where $Y$ is a $N x 1$ vector of observations on the dependent variable, $X$ is an $N x K$ matrix of observations on the covariates, $\beta$ is a $K x 1$ vector of regression coefficients, $\xi$ in an $N x 1$ vector of spatially autocorrelated error terms, $W \xi$ is a spatial lag for the errors, $\lambda$ is the autoregressive coefficient, and $\mu$ is another error term.

In its second form, the spatial dependence is given a substantive interpretation, in that a variable of interest at one location is also influenced by values of its neighbors. In cases like this, where the interest is to analyze the nature of spatial spillover and its underlying economic and social processes, the spatial lag model or the spatial autoregressive model (SAR) is deemed appropriate. In the SAR, the influence of unmeasured independent variables while at the same time stipulating the effect of neighboring attribute values is captured through the lagged dependent variable. The SAR model is typically denoted as follows:

$$
\text { (2) } Y=\rho W Y+X \beta+\mu
$$

33 This section builds on and expands presentation in Chapter 7 of the Asian Economic Integration Report 2021: Making Digital Platforms Work for Asia and the Pacific. 
Figure 4.10: Spatial Distribution of the ARCII in Asia and the Pacific, 2018

\section{(a) Overall ARCII}

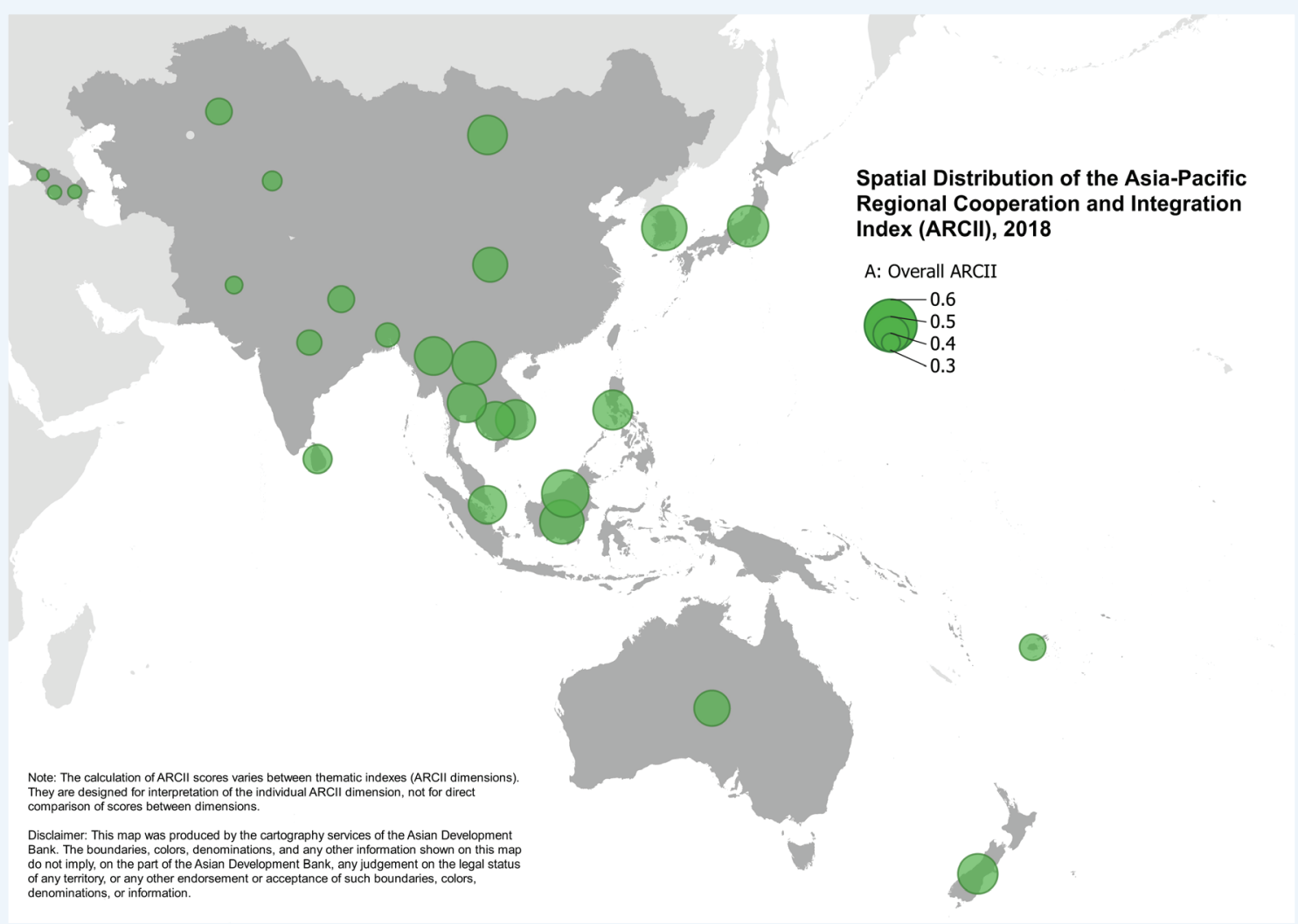

(b) Trade and Investment

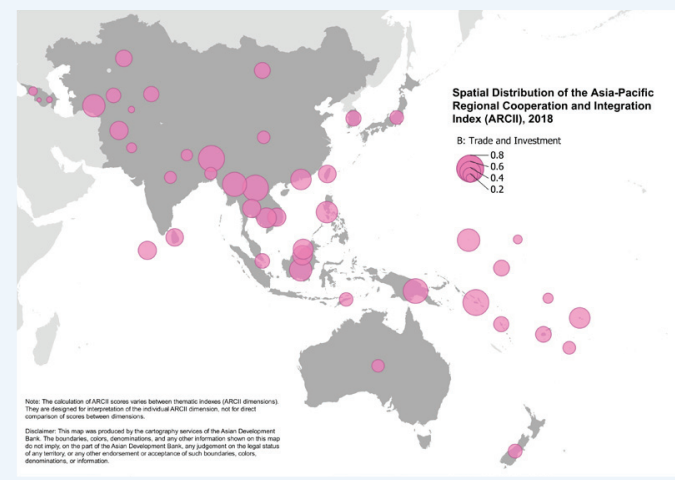

(c) Money and Finance

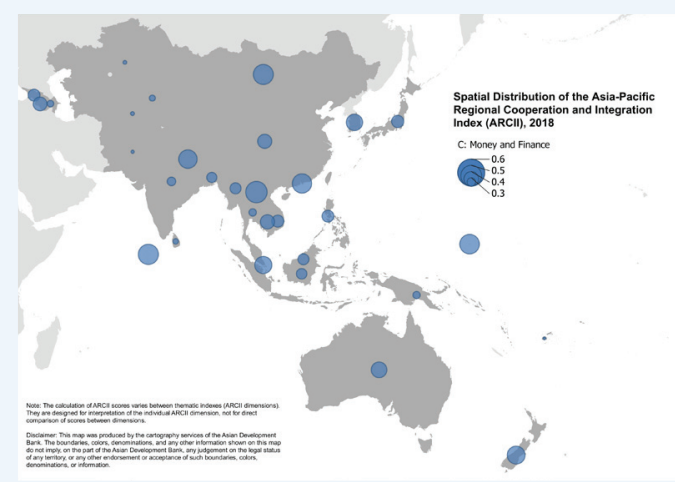


Figure 4.10 continued

Figure 4.10: Spatial Distribution of the ARCII, 2018

(d) Regional Value Chain

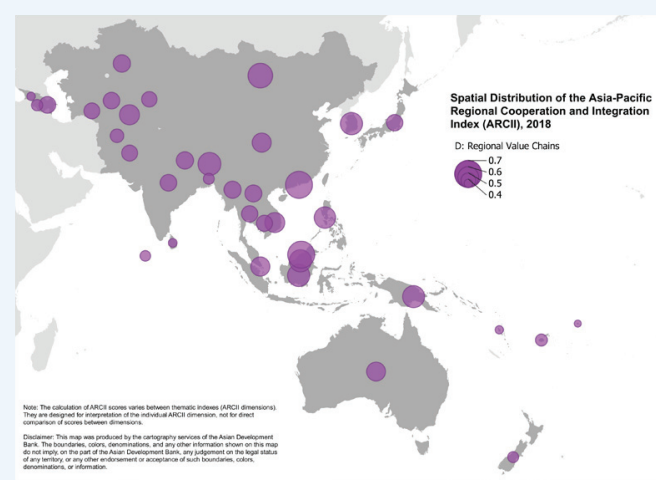

(f) People and Social Integration

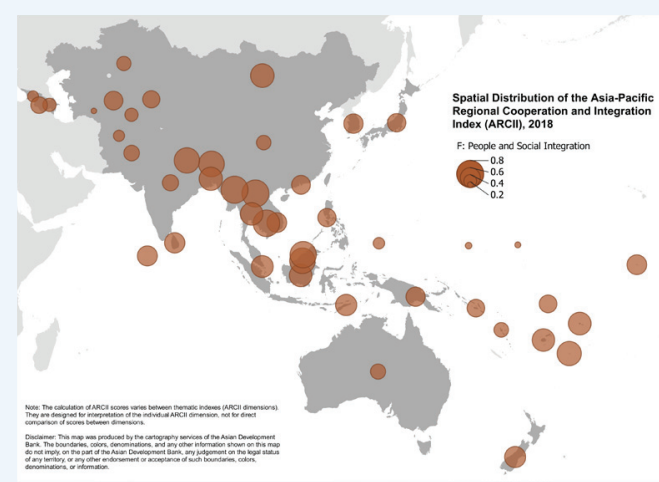

(h) Technology and Digital Connectivity

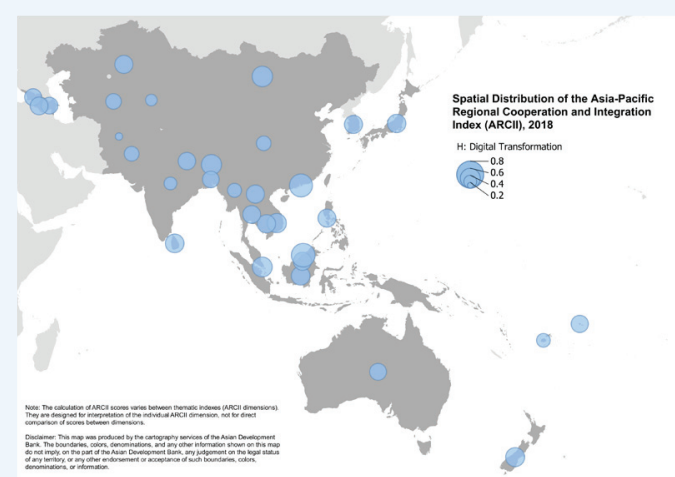

(e) Infrastructure and Connectivity

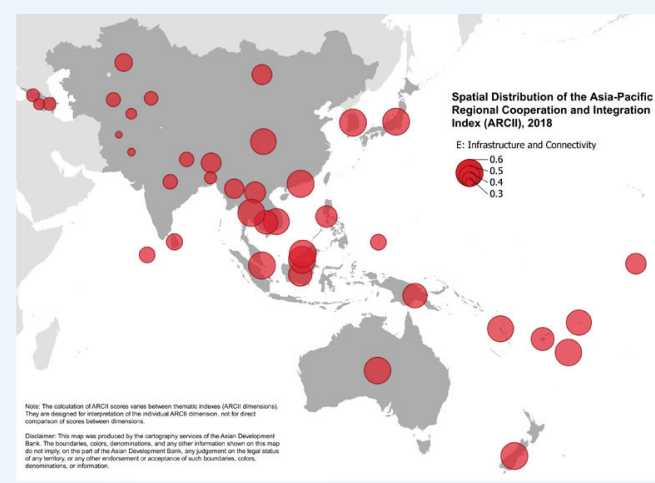

(g) Institutional Arrangements

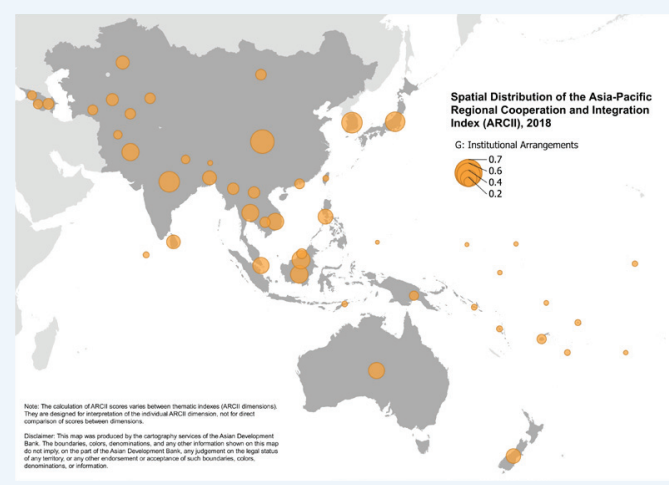

(i) Environmental Cooperation

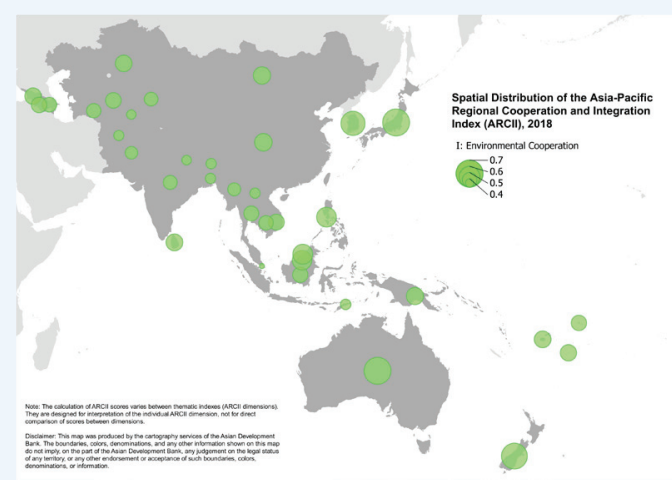

ARCII = Asia-Pacific Regional Cooperation and Integration Index .

Source: Asian Development Bank. Asia-Pacific Regional Cooperation and Integration Index Database. https://aric.adb.org/database/ arcii (accessed May 2021). 
where $\rho$ is a spatial autoregressive coefficient, $\mu$ is a vector of error terms, and the other notation is the same as the previous equation. In contrast to the other time series counterparts of this model, the spatial lag term $W Y$ is correlated with the disturbances, even when the latter are independent identically distributed (iid).

Applying these concepts to regional integration, correcting for spatial autocorrelation would be important to assess the influence that location exerts on regional integration. Concomitantly, accounting for such influence needs to be controlled for, especially when ARCII will be used to analyze the effect of regional integration on other socioeconomic factors such as poverty and inequality. Statistical analysis relies on the assumption that observations are independent of one another. If spatial autocorrelation exists, then this assumption is not met, affecting the validity of hypothesis testing. Ignoring spatial dependence may lead to biased or inefficient estimates on the determinants of regional integration and, alternately, impact of regional integration on other variables. A standard ordinary least squares (OLS) approach may be inappropriate for modelling in such a case, and alternative models such as the SEM and SAR should be considered.

\section{Spatial Weights}

An essential component in spatial analysis is the spatial weights matrix, which imposes a spatial structure on the data set. It is represented by the variable $W$ in equations 1 and 2 from above. There are two basic strategies in creating spatial weights: (1) binary strategies (e.g., fixed distance, $\mathrm{K}$ nearest neighbors, contiguity) where a feature is either a neighbor or not, and (2) weighted strategies (e.g., inverse distance or zone of indifference), where neighboring features have varying influence and weights are calculated to reflect this variation.

Since the spatial weight matrix assigns a structure on the data set used, it is important to select the strategy that best reflects how units interact. In the case of ARCII, an inverse squared distance weight matrix would be more appropriate given that some countries in the region are archipelagic in nature. The inverse squared distance weight matrix $(\mathbb{W})$ is a positive definite, symmetric matrix whose elements $\left(w_{i j}\right)$ measure the degree of spatial connection between unit(economy) $i$ and $j$ and take on a finite and non-negative value. Each $w_{i j}$ is defined as $w_{i j}=w_{i j}^{*} / \sum_{j} w_{i j}^{*}$ and

$$
\left\{\begin{array}{llrl}
w_{i j}^{*}=0 & \text { if } & i=j \\
w_{i j}^{*}=1 / d_{i j}^{2} & \text { if } & d_{i j} \leq D \\
w_{i j}^{*}=0 & \text { if } & d_{i j}>D
\end{array}\right.
$$

where $w_{i j}^{*}$ is an element of the non-standardized spatial weight matrix; $w_{i j}$ is an element of the standardized matrix (WW); $d_{i j}$ is the Euclidean (straight line) distance between countries $i$ and $j$; and $D$ is the minimum distance which ensures that all countries will have at least one neighbor.

\section{Moran's I}

One of the most common methods used to detect spatial autocorrelation is using the global Moran's I test. In this test, patterns are assessed on whether they are clustered, dispersed, or random. In the case of regional integration, a significantly positive (negative) statistic from a global Moran's I test shows clustering of economies with similar (dissimilar) levels of regional integration. 
Moran's I statistic is given as:

$$
\text { Moran's } I=\frac{N}{S_{o}} \sum_{i}^{N} \sum_{j}^{N} \frac{w_{i j}\left(x_{i}-\bar{x}\right)\left(x_{j}-\bar{x}\right)}{\sum_{i=1}^{N}\left(x_{i}-x\right)^{2}} \quad i \neq j, S_{o}=\Sigma_{i} \Sigma_{j} w_{i j}
$$

where $N$ is the number of observations; $x_{i}$ and $x_{j}$ are the indexes for economy $i$ and $j ; \bar{x}$ is the average index; and $S_{o}=\Sigma_{i} \Sigma_{j} w_{i j}$ is a standardization factor that corresponds to the sum of the weights.

However, while the Moran's I test may be the most familiar test on spatial autocorrelation, its functions are limited. While it can pick up a range of misspecification errors (e.g., non-normality and heteroscedasticity), it cannot provide insights for selecting alternative model specifications to the standard OLS.

\section{A Step-by-Step Procedure on Addressing Spatial Autocorrelation in ARCII}

The SEM and SAR serve as alternative models to the standard OLS regression, to account for spatial dependence. Both methods attempt to ensure that the estimates and inference from regression analysis considers spatial autocorrelation. The selection between the two models often depends on the research question, but formal statistical tests are also available to determine the correct model specification.

Figure 4.11 describes the standard procedure for addressing spatial autocorrelation through alternative regression models such as the SEM and SAR. As a first step, the standard OLS regression should be run, followed by the LM test for error dependence (LM-Error) and LM test for a missing spatially lagged dependent variable (LM-Lag). The LM test is based on the residuals of the OLS regression and could be used to distinguish between substantive spatial dependence and spatial dependence as a nuisance (Anselin and Rey 1991b). If neither LM-Error nor LM-Lag test statistics are significant (as shown by a rejection of the null hypothesis), the standard OLS should be used. However, if only one of the LM statistics is significant, then the alternative model which have the significant LM statistic should be applied.

Where both the LM-Error and LM-Lag test statistics are significant, the Robust LM tests (Robust LM-Error and Robust LM-Lag) should be applied. Usually, only one of the test statistics from the Robust LM tests will be significant, or one will be more significant than the other. If both are still found to be highly significant, the model which reflects the largest value for the test statistic should be used.

\section{Results}

Preliminary diagnosis on the presence of autocorrelation in the ARCII, specifically for the Asia and Pacific region, was implemented using the global Moran's I test. The test confirms a strong and highly significant spatial autocorrelation in overall ARCII. This suggests that an economy's location influences its level of regional integration (Figure 4.12). The global Moran's I test statistic was also found to be significant across all dimensions, except for money and finance. Meanwhile, the degree of spatial autocorrelation tends to be moderate for most of the dimensional indexes, with only the infrastructure and connectivity dimension (Moran's I $=0.604$ ) having a comparable level to the overall ARCII (Moran's I = 0.680). 
Figure 4.11: Addressing Spatial Autocorrelation

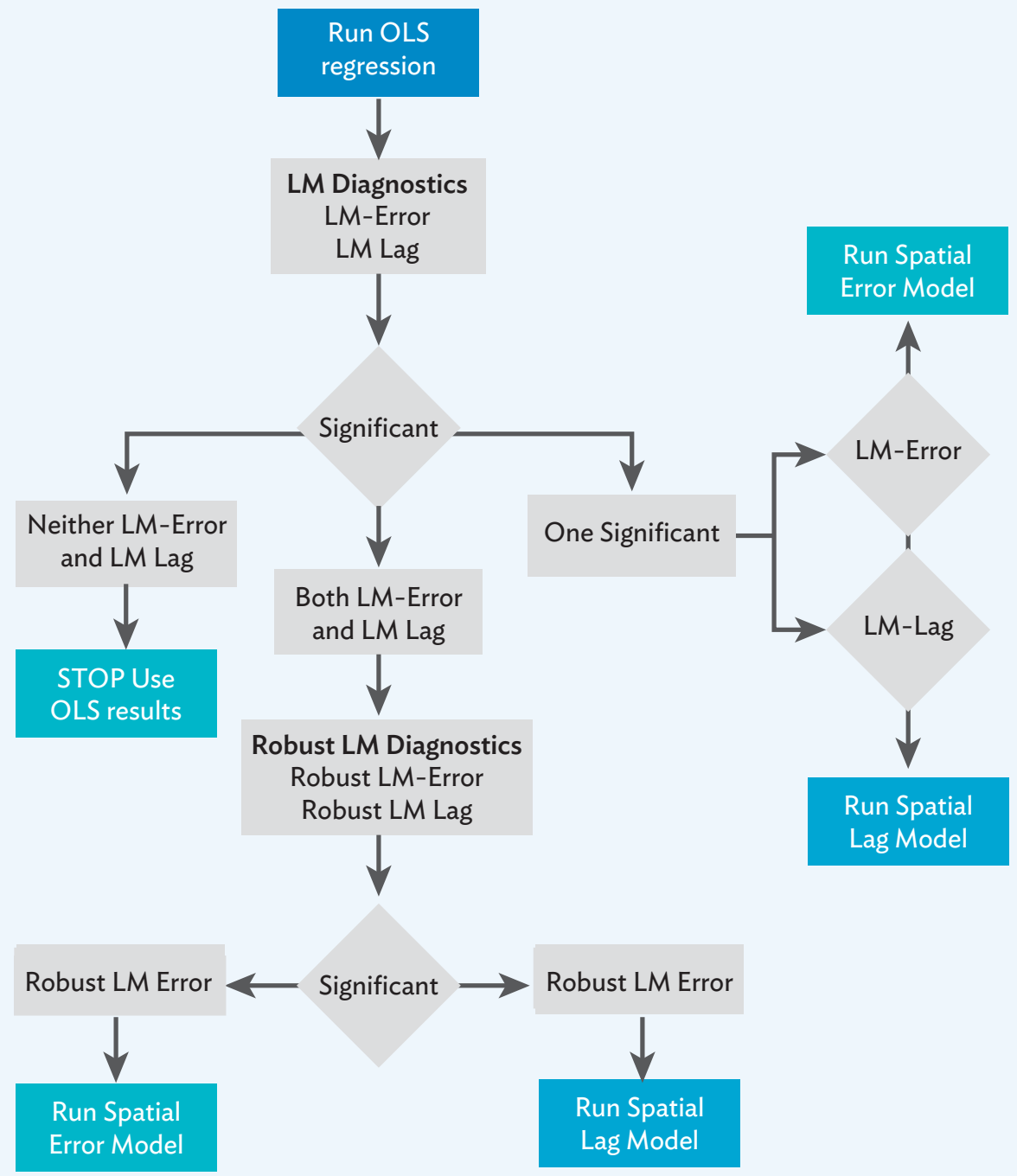

LM = Lagrange Multiplier, OLS = ordinary least squares.

Source: L. Anselin. 2005. Exploring Spatial Data with GeoDa ${ }^{T M}$ : A Workbook. Center for Spatially Integrated Social Science. https://geodacenter.github.io/docs/geodaworkbook.pdf.

The global Moran's I test suggests that spatial autocorrelation in the economies' overall ARCII and dimensional indexes is present. As such, it is imperative to employ further statistical tests to determine the right model specification (e.g., OLS, SEM, SAR) to account for spatial effects. Following the steps illustrated in Figure 4.5, a cross-section OLS regression is first applied to measure the level of regional integration conditional on the logarithm of real GDP, land area, population, and dummy variables on whether an economy is landlocked or sea-locked, using year 2018 data, as follows:

$$
\begin{aligned}
& Y_{i}=\beta_{0}+\beta_{1} \log (\text { Real GDP })_{i}+\beta_{2} \log (\text { Population })_{i}+\beta_{3} \log (\text { Land Area })_{i}+\beta_{4} \text { Land }_{i}+ \\
& \beta_{5} \text { Sea }_{i}+u_{i}(1)
\end{aligned}
$$


Figure 4.12: Results for Global Moran's I Statistic for the ARCII and Dimensional Subindexes

(a) Overall Index

Moran's I: 0.680 (isolates in weights are removed)

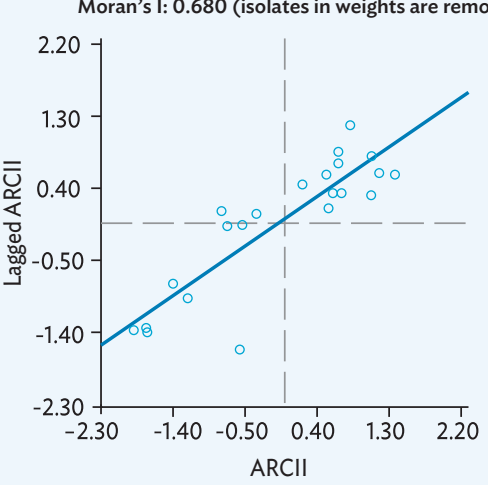

(d) Regional Value Chain

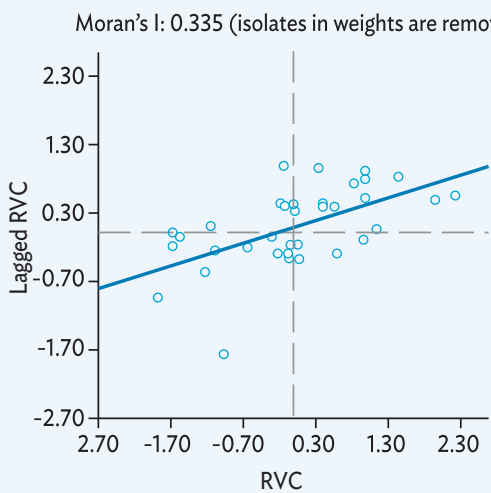

(g) Institutional Arrangements

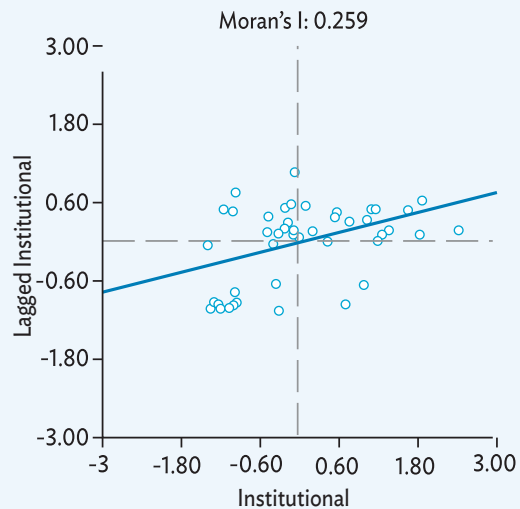

(b) Trade and Investment

Moran's I: 0.111

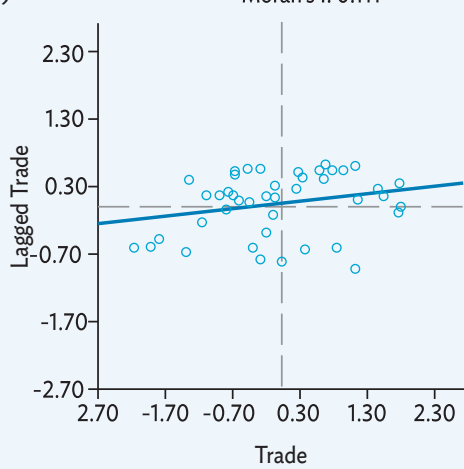

(e) Infrastructure and Connectivity

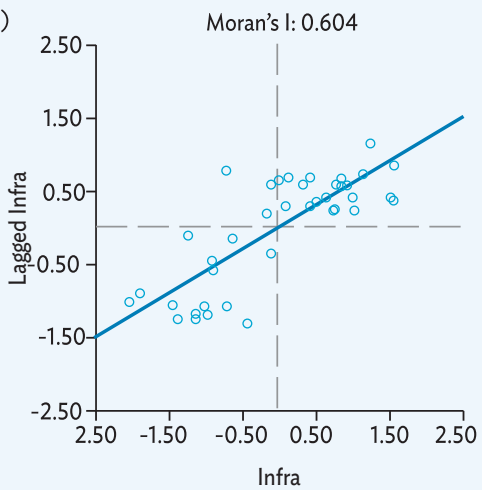

(h) Technology and Digital Connectivity

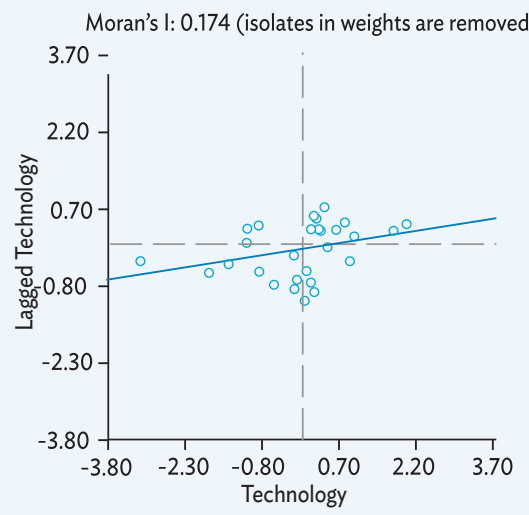

(c) Money and Finance

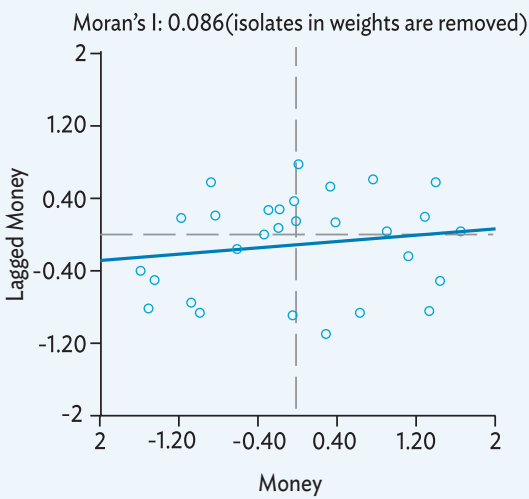

(f) People and Social Integration

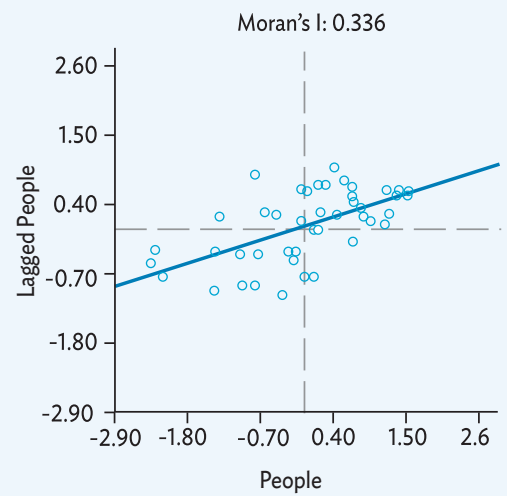

(i) Environmental Cooperation

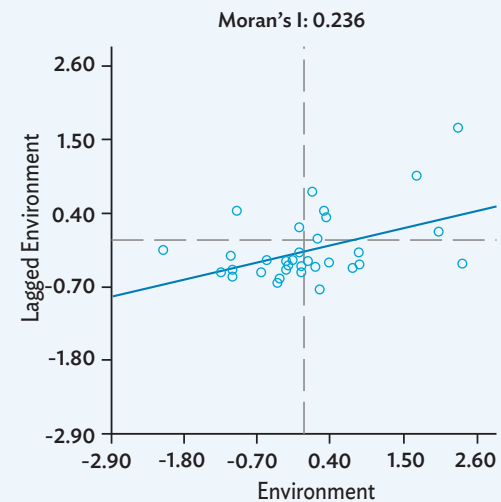

ARCII = Asia-Pacific Regional Cooperation and Integration Index.

Notes: The $y$-axis pertains to the spatially lagged counterparts of the overall and the dimensional indexes in the $x$-axis. The plot reflects a linear fit through the point cloud. The slope of the line is equivalent to the Moran's I.

Source: Asian Development Bank. Asia-Pacific Regional Cooperation and Integration Index Database. https://aric.adb.org/database/ arcii (accessed May 2021). 
where $Y$ is the vector of dependent variables consisting of ARCII and its dimensional indexes; and $u_{i}$ is the error term. The choice of the independent variables is based on Ye and Mikic (2016), which identifies this variable set as the determinants of regional integration in Asia and the Pacific. Other specifications can also be explored.

The final selection on which spatial model to apply was guided by the LM tests (lag and error). Results from LM tests call for the need to use spatial regression models for the overall ARCII estimate (SEM) and the following dimensions: trade and investment integration (SAR), regional value chain (SAR), infrastructure and connectivity (SEM), and people and social integration (SEM) (Table 4.2). For the overall ARCIl estimate and these dimensions, the values of the Akaike Information Criterion (AIC) and the Schwarz Criterion (SC) were also lower in the SAR and SEM models, therefore suggesting both models have better goodness-of-fit than the OLS.

Table 4.2: Ordinary Least Squares Regression and Lagrange Multiplier Tests Results

\begin{tabular}{|c|c|c|c|c|c|c|c|c|c|}
\hline Variable & $\begin{array}{l}\text { Overall } \\
\text { ARCII }\end{array}$ & $\begin{array}{l}\text { Trade and } \\
\text { Investment } \\
\text { Integration }\end{array}$ & $\begin{array}{l}\text { Money and } \\
\text { Finance }\end{array}$ & $\begin{array}{c}\text { Regional } \\
\text { Value Chain }\end{array}$ & $\begin{array}{c}\text { Infrastructure } \\
\text { and } \\
\text { Connectivity }\end{array}$ & $\begin{array}{c}\text { People } \\
\text { and Social } \\
\text { Integration }\end{array}$ & $\begin{array}{l}\text { Institutional } \\
\text { Arrangements }\end{array}$ & $\begin{array}{l}\text { Technology } \\
\text { and Digital } \\
\text { Connectivity }\end{array}$ & $\begin{array}{l}\text { Environmntal } \\
\text { Cooperation }\end{array}$ \\
\hline Log (Real GDP) & 0.013 & -0.03 & 0.01 & 0.02 & $0.05^{* * *}$ & -0.04 & $0.05^{* * *}$ & 0.02 & $0.03^{* *}$ \\
\hline Log (Population) & -0.013 & 0.01 & -0.02 & -0.001 & $-0.06^{* *}$ & 0.02 & 0.007 & $-0.03^{* *}$ & $-0.04^{* * *}$ \\
\hline Log (Land Area) & 0.004 & 0.02 & 0.00 & 0.005 & 0.004 & -0.006 & -0.003 & -0.004 & 0.01 \\
\hline Landlocked & -0.044 & -0.15 & -0.00 & 0.047 & -0.07 & -0.07 & -0.007 & -0.014 & $-0.07^{*}$ \\
\hline Sea-locked & -0.038 & -0.6 & $-0.19^{*}$ & 0.005 & 0.02 & -0.03 & 0.05 & -0.153 & -0.008 \\
\hline Constant & 0.330 & 0.91 & 0.48 & 0.06 & 0.09 & 1.29 & $0.99^{* * *}$ & $0.65^{* * *}$ & 0.33 \\
\hline R-squared & 0.26 & 0.13 & 0.25 & 0.24 & 0.55 & 0.14 & 0.88 & 0.37 & 0.48 \\
\hline $\begin{array}{l}\text { Akaike } \\
\text { Information } \\
\text { Criterion }\end{array}$ & -66.25 & -11.04 & -51.19 & -61.2 & -50.21 & -25.26 & -82.07 & -70.85 & -106.45 \\
\hline $\begin{array}{l}\text { Schwarz } \\
\text { Criterion }\end{array}$ & -58.70 & -3.49 & -43.64 & -53.65 & -42.66 & -17.71 & -74.53 & -63.3 & -96.48 \\
\hline
\end{tabular}

\begin{tabular}{|c|c|c|c|c|c|c|c|c|c|}
\hline \multicolumn{10}{|c|}{ Diagnostic for spatial dependence } \\
\hline LM-lag & $8.93^{* * *}$ & $19.57^{* * *}$ & 0.01 & $5.29^{* *}$ & $7.37^{* * *}$ & 2.75 & 1.76 & 0.91 & 0.11 \\
\hline LM-error & $16.93^{* * *}$ & $12.74^{* * *}$ & 2.70 & 2.4 & $16.55^{* * *}$ & $6.81^{* * *}$ & 0.07 & 0.002 & 0.08 \\
\hline Robust LM-lag & 2.35 & $6.91^{* * *}$ & 1.75 & $3.39^{*}$ & 1.08 & 0.000 & 2.11 & 0.99 & 0.19 \\
\hline Robust LM-error & $10.34^{* * *}$ & 0.09 & $4.44^{* *}$ & 0.5 & $10.27^{* * *}$ & $4.06^{* *}$ & 0.43 & 0.09 & 0.17 \\
\hline
\end{tabular}

ARCII = Asia-Pacific Regional Cooperation and Integration Index, GDP = gross domestic product, LM = Lagrange Multiplier,

OLS $=$ ordinary least squares.

Note: ${ }^{*},{ }^{* *}$, and ${ }^{* * *}$ indicate significance at $10 \%, 5 \%$, and $1 \%$ levels, respectively.

Sources: Asian Development Bank (ADB) calculations using data from ADB. Asia-Pacific Regional Cooperation and Integration Index Database. https://aric.adb.org/database/arcii; World Bank. World Development Indicators. https://databank.worldbank.org/source/worlddevelopmentindicators; Centre d'Études Prospectives et d'Informations Internationales (the French Research Center in International Economics). GeoDist Database. http://www.cepii.fr/CEPII/en/cepii/cepii.asp (all accessed May 2021).

The SAR model used the same set of covariates as the OLS regression, and is therefore specified as follows:

$$
\begin{gathered}
Y_{i}=\rho W Y+\beta_{0}+\beta_{1} \log (\text { Real GDP })_{i}+\beta_{2} \log (\text { Population })_{i}+\beta_{3} \log (\text { Land Area })_{i}+ \\
\beta_{4} \text { Land }_{i}+\beta_{5} \text { Sea }_{i}+\varepsilon_{i}
\end{gathered}
$$


where $W Y$ is the spatial lag of the dependent variable or the weighted average of the values for economy $i$ 's neighbors (with the weights derived from the inverse squared distance weight matrix $W$ ); $\rho$ is the spatial lag parameter; and $\varepsilon_{i}$ is the error term.

Meanwhile, the specification of SEM is given as:

$$
\begin{gathered}
Y_{i}=\beta_{0}+\beta_{1} \log (\text { Real GDP })_{i}+\beta_{2} \log (\text { Population })_{i}+\beta_{3} \log \left(\text { Land Area }_{i}+\beta_{4} \text { Land }_{i}\right. \\
+\beta_{5} \text { Sea }_{i}+\xi_{i} \\
\xi_{i}=\lambda W \xi+u_{i}
\end{gathered}
$$

where $\lambda$ is the spatial error parameter; and $\xi$ and $u$ are the error terms.

The results from the SEM model for the overall ARCII show that the spatially correlated error $(\lambda)$ is highly significant and positively correlated with regional integration (the overall ARCII), as shown in Table 4.3. Real GDP, population, and land area are also found to be strong predictors of regional integration. At the dimensional level, where the SEM or SAR were found to be appropriate, spatially correlated errors $(\lambda)$ and the spatial lag $(\rho)$ were found to be

\begin{tabular}{|c|c|c|c|c|c|c|c|c|c|}
\hline Variable & $\begin{array}{l}\text { Overall } \\
\text { ARCII }\end{array}$ & $\begin{array}{l}\text { Trade and } \\
\text { Investment } \\
\text { Integration }\end{array}$ & $\begin{array}{l}\text { Money and } \\
\text { Finance }\end{array}$ & $\begin{array}{c}\text { Regional } \\
\text { Value Chain }\end{array}$ & $\begin{array}{c}\text { Infrastructure } \\
\text { and } \\
\text { Connectivity }\end{array}$ & $\begin{array}{c}\text { People } \\
\text { and Social } \\
\text { Integration }\end{array}$ & $\begin{array}{l}\text { Institutional } \\
\text { Arrangements }\end{array}$ & $\begin{array}{l}\text { Technology } \\
\text { and Digital } \\
\text { Connectivity }\end{array}$ & $\begin{array}{l}\text { Environmental } \\
\text { Cooperation }\end{array}$ \\
\hline $\begin{array}{l}\text { Log } \\
\text { (Real GDP) }\end{array}$ & $0.02^{* * *}$ & -0.01 & 0.01 & $0.02^{* *}$ & $0.06^{* * *}$ & -0.02 & $0.05^{* * *}$ & 0.02 & $0.03^{* *}$ \\
\hline $\begin{array}{l}\text { Log } \\
\text { (Population) }\end{array}$ & $-0.03^{* * *}$ & $-0.07^{* * *}$ & -0.03 & -0.02 & $-0.07^{* * *}$ & -0.01 & 0.007 & $-0.03^{* *}$ & $-0.04^{* * *}$ \\
\hline $\begin{array}{l}\text { Log } \\
\text { (Land Area) }\end{array}$ & $0.01^{* *}$ & $0.06^{* * *}$ & 0.00 & $0.02^{* *}$ & 0.01 & 0.002 & -0.003 & -0.004 & 0.01 \\
\hline Landlocked & -0.01 & $-0.18^{* *}$ & 0.00 & 0.02 & -0.03 & 0.04 & -0.007 & -0.014 & $-0.07^{*}$ \\
\hline Island & -0.02 & 0.15 & $-0.2^{*}$ & 0.08 & 0.03 & -0.002 & 0.05 & -0.153 & -0.008 \\
\hline $\begin{array}{l}\text { Lag coefficient } \\
\text { (Lambda/Rho) }\end{array}$ & $0.92^{* * *}$ & $0.79^{* * *}$ & & $0.21^{* *}$ & $0.84^{* * *}$ & $0.88^{* * *}$ & & & \\
\hline Constant & $0.38^{* * *}$ & $0.87^{* *}$ & 0.48 & 0.008 & 0.14 & $1.34^{* * *}$ & $0.99^{* * *}$ & $0.65^{* * *}$ & 0.33 \\
\hline R-squared & 0.83 & 0.56 & 0.25 & 0.37 & 0.80 & 0.67 & 0.88 & 0.37 & 0.48 \\
\hline $\begin{array}{l}\text { Akaike } \\
\text { Information } \\
\text { Criterion }\end{array}$ & -99.14 & -23.45 & & -63.99 & -67.39 & -45.01 & & & \\
\hline $\begin{array}{l}\text { Schwarz } \\
\text { Criterion }\end{array}$ & -91.59 & -14.66 & & -55.18 & -59.85 & -37.46 & & & \\
\hline $\begin{array}{l}\text { Estimation } \\
\text { method }\end{array}$ & SEM & SAR & OLS & SAR & SEM & SEM & OLS & OLS & OLS \\
\hline
\end{tabular}

Table 4.3: Regression Results fromOrdinary Least Squares, Spatial Autoregressive Model, and Spatial Error Model

ARCII = Asia-Pacific Regional Cooperation and Integration Index, GDP = gross domestic product, LM = Lagrange Multiplier, OLS $=$ ordinary least squares.

Note: *, ** and ${ }^{* * *}$ indicate significance at $10 \%, 5 \%$, and $1 \%$ levels, respectively.

Sources: Asian Development Bank (ADB) calculations using data from ADB. Asia-Pacific Regional Cooperation and Integration Index Database. https://aric.adb.org/database/arcii; World Bank. World Development Indicators. https://databank.worldbank.org/source/worlddevelopmentindicators; Centre d'Études Prospectives et d'Informations Internationales (the French Research Center in International Economics). GeoDist Database. http://www.cepii.fr/CEPII/en/cepii/cepii.asp (all accessed May 2021). 
significant and have positive relationship with dimensional integration, as represented by the dimensional indexes. The effects of the independent variables, however, tend to vary across these dimensions. Comparisons of the predicted values (from the spatial models) and actual values for the overall ARCII and the dimensional indexes shows slightly lower values for the former, except for the people and social integration dimension (Figure 4.12).

In summary, results from the spatial regression analysis using the SEM and SAR show that for regional cooperation and integration in Asia and the Pacific, location matters. Integrating spatial effects in the regression model also improves the model prediction of regional integration, and produces more definitive results than the simple OLS. Moving forward, the model can be extended to follow a panel specification, where fixed or random effects are controlled for.

This chapter described the main caveats encountered by researchers when using ARCII as a measure of regional integration and laid out in detail the alternative methods to address them. While standard ARCII estimates are robust to analyze the trends and drivers of regional integration, these tools can be complementary, provide nuance to the analysis, and facilitate the interpretation of ARCII results. In developing automatized codes in standard statistical packages, the ARCII team at ADB has a particular eye on simplifying the use of these tools in the future.

Figure 4.13: Comparison of ARCII Estimates, Actual versus Corrected, 2018

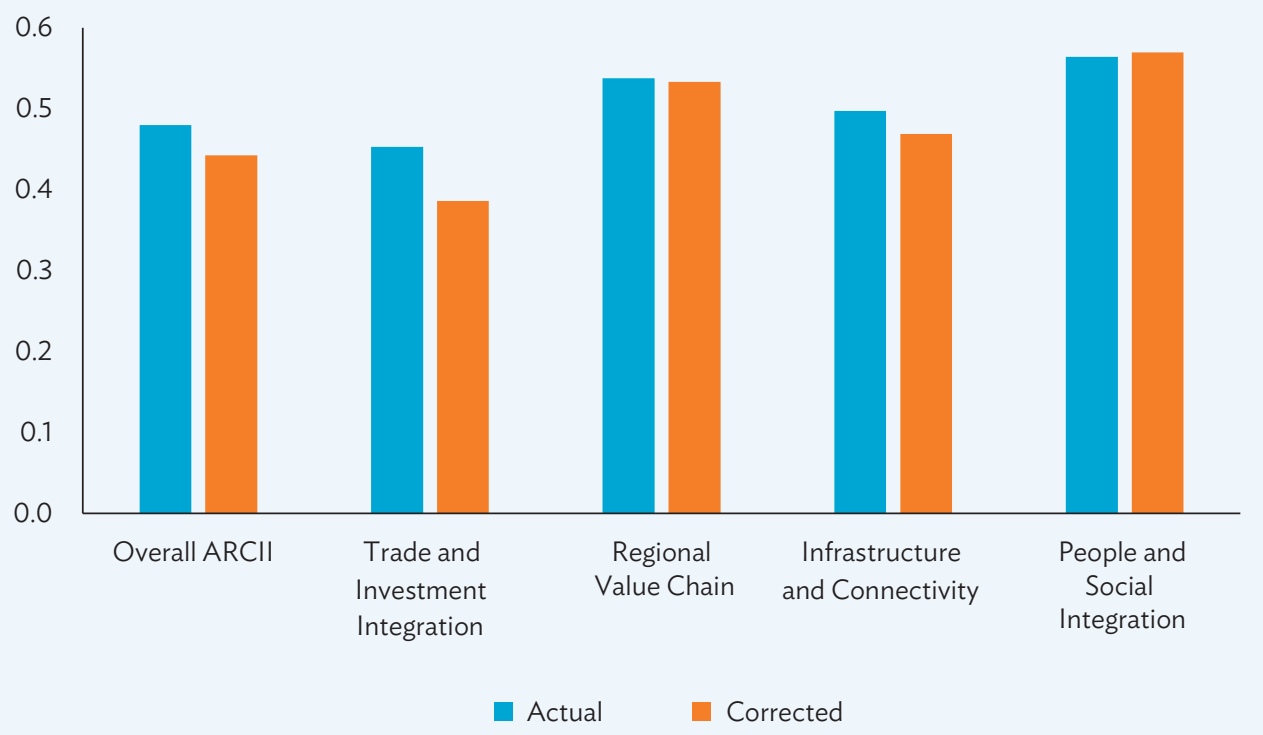

ARCII = Asia-Pacific Regional Cooperation and Integration Index, OLS = ordinary least squares, SAR = spatial autoregressive model, SEM = spatial error model.

Note: Estimates reflected in the graph only display those where the SEM or SAR model was applied. Estimates where the OLS model was used are not reported.

Sources: Asian Development Bank (ADB) calculations using data from ADB. Asia-Pacific Regional Cooperation and Integration Index Database. https://aric.adb.org/database/arcii; World Bank. World Development Indicators. https://databank.worldbank.org/source/ world-development-indicators; Centre d'Études Prospectives et d'Informations Internationales (the French Research Center in International Economics). GeoDist Database. http://www.cepii.fr/CEPII/en/cepii/cepii.asp (all accessed May 2021). 


\section{References}

Asian Development Bank (ADB). 2021. Asian Economic Integration Report 2021: Making Digital Platforms Work for Asia and the Pacific. Manila.

Anselin, L. 2003. Spatial Economics. In B. H. Baltagi, ed. A Companion to Theoretical Econometrics. Malden, MA: Blackwell Publishing Ltd. pp. 310-330. https://doi.org/10.1002/9780470996249.ch15.

Anselin, L. and S. Rey. 1991a. Properties of Tests for Spatial Dependence in Linear Regression Models. Geographical Analysis. 23 (2). pp. 112-131. https://doi.org/10.1111/j.1538-4632.1991.tb00228.x.

—. 1991b. The Performance of Tests for Spatial Dependence in a Linear Regression (91-13). July. https://escholarship.org/uc/item/3cb8891z.

Dreher, A. 2006. Does Globalization Affect Growth? Evidence from a New Index of Globalization. Applied Economics. 38 (10). pp. 1091-1110. https://doi.org/10.1080/00036840500392078.

Huh, H. S. and C. Y. Park. 2018. Asia-Pacific Regional Integration Index: Construction, Interpretation, and Comparison. Journal of Asian Economics 54 (C): pp. 22-38. https://doi.org/10.1016/j.asieco.2017.12.001.

_ 2021. A New Index of Globalisation: Measuring Impacts of Integration on Economic Growth and Income Inequality. The World Economy. 44 (2). pp. 409-443. https://doi.org/10.1111/twec.12998.

Park, C. Y. and R. Claveria. 2018. Constructing the Asia-Pacific Regional Cooperation and Integration Index: A Panel Approach. SSRN Electronic Journal. https://doi.org/10.2139/ssrn.3188636.

Ye, V. and M. Mikic. 2016. The Index of Asia-Pacific Regional Integration Effort. SSRN Scholarly Paper ID 2804903. Rochester, NY: Social Science Research Network. https://doi.org/10.2139/ssrn.2804903. 


\section{Conclusions and Way Forward}

As new economic trends and policy priorities continue to drive Asian economies, the nature and pillars of regional cooperation and integration are also changing. As suggested throughout this report, the digital economy may have a significant impact on Asia's regional integration model. ${ }^{34}$ Digital platforms are gradually taking on a large role in the rise of e-commerce, knowledge sharing, and delivery of cross-border services. Alongside this digital revolution, economies continue to work toward achieving sustainable growth by adapting practices that promote environmental cooperation.

The uncertain global economic environment highlights the importance of monitoring regional dynamics and interdependence. This entails having adequate regional cooperation and integration indicators that can help policy makers gauge progress in economic integration and to assess performance against set goals. As a response, the Asian Development Bank (ADB) produced the Asia-Pacific Regional Cooperation and Integration Index (ARCII) in 2017 to provide a broad-based measure of integration across different socioeconomic dimensions. The first ARCII estimates produced by Huh and Park $(2017,2018)$ and extended by Park and Claveria (2018a) followed the baseline six-dimensional structure discussed in Chapter 2, which uses a comprehensive bilateral set of indicators of regional integration. Similar efforts to construct measures of regional integration have been undertaken by other institutions such as the joint work of the African Union Commission, African Development Bank, United Nations Economic Commission for Africa on the Africa Regional Integration Index, and the Digital and Sustainable Regional Integration Index (DigiSRII) that was recently produced by the United Nations Economic and Social Commission for Asia and the Pacific (UNESCAP).

As the channels of regional cooperation and integration evolve, the ARCII structure has been strengthened to accommodate new metrics of regional cooperation and integration. Developing better metrics allows researchers and policy makers to weigh the costs and benefits of integration-oriented policies in greater detail. Improvements to the baseline ARCII framework draw in an expanded range of the factors involved in regional integration, with two new dimensions measuring the contributions of digital connectivity and environmental cooperation to the index and new indicators added to existing dimensions. The main purpose of enhancing the ARCII framework is to improve the availability, quality, and consistency of data, and to ensure that the enhanced ARCII index adequately captures the role and mechanisms of regional cooperation and integration.

The enhanced ARCII structure comprises of 41 indicators that measure regional integration along eight dimensions: (i) trade and investment, (ii) money and finance, (iii) regional value chains, (iv) infrastructure and connectivity, (v) people and social integration, (vi) institutional arrangements, (vii) technology and digital connectivity, and (viii) environmental cooperation. Updating the framework with new relevant indicators permits a better understanding of the role of technology and the environment in promoting a region's interconnectedness. The technology and digital connectivity dimension naturally responds to the growing role of digital technologies

34 Asia refers to the 48 ADB members in Asia and the Pacific. It includes Australia, Japan, and New Zealand, in addition to the 45 developing member economies. It does not include Niue due to limited data availability. 
in economic activity, which was not fully captured in other dimensions. To further improve the index, the environmental cooperation dimension provides a basis for assessing performance in the context of regional cooperation by including information on trade in environmental goods, environmental agreements, ecological footprints, and environmental health scores.

The results of the enhanced ARCII framework in Chapter 3 show that regional integration trends in Asia remain stable over time. More important, the inclusion of two new dimensions allowed the index to reflect how rapid growth of the digital economy and efforts toward environmental collaboration help strengthen integration within Asia. For the money and finance dimension, the incorporation of indicators on capital account openness (indicator $\mathrm{II}-\mathrm{d}$ ) and exchange rate correlation (indicator II-e) could better inform the financial integration trends. In terms of economy income groups, high-income economies report considerably higher ARCll estimates, suggesting there is a strong link between regional integration and economic development. Upper middle-income, lower middleincome, and low-income economies report ARCll estimates near to each other. Notably, dispersion among income groups also differs, with high-income economies reporting greater dispersion to the other income groups. The variance in ARCIl estimates is also positively correlated with levels of income per capita.

Another significant innovation introduced in the enhanced index is the option for index customization. With this new feature, users can adapt the ARCII framework to their specific economy or regional needs, improve the accuracy of underlying data by incorporating other data sources, and develop in-depth dimensional analysis on specific areas of regional integration. By allowing a higher degree of flexibility in the inclusion or exclusion of dimensions and indicators, users can select which to include in the framework based on factors such as data availability or relevance to the specific needs of a particular economy grouping. Examples of customized indexes have been estimated for Eurasia and the Asia-Pacific Economic Cooperation (APEC) region. The same exercise can be applied to Pacific countries where current data gaps in the money and finance dimension prohibit the index from accurately reflecting the level of financial development in the subregion.

By construction, the estimation of the ARCll involves underlying assumptions that occasionally affect its precision or require further interpretation. Building on bilateral indicators, ARCII has advantages over other methodologies and provides considerably more granular information on the dynamics of regional integration. At the same time, the scope of the current framework has its limitations and produces indexes that come with a few caveats. To address possible bias stemming from the choice of the denominator for the indicators, the framework can consider gross domestic product (GDP) or population as alternatives. This alternate approach makes ARCII estimates less vulnerable to potentially underrepresenting or overrepresenting the regional integration of certain economies, particularly those with strong regional linkages due to size, geographical location, or economic structure. Furthermore, the proposed alternate denominator poses no additional issues when extended to construct a globalization index (Huh and Park 2021). Implementing spatial regression analysis when working with ARCII also helps account for spatial dependence in the estimates and is a better predictor of regional integration than the ordinary least squares estimation.

\section{Possible Extensions and Applications}

The enhanced ARCII framework provides a multidimensional metric of regional integration. Certain aspects of the framework will continue to be improved to boost the data quality, coverage, and scope of the index. The index will benefit from the inclusion of a trade-in-services indicator (e.g., Organisation for Economic Co-operation and Development-World Trade Organization (OECD-WTO) Balanced Trade in Services database or WTO-United Nations Conference on Trade and Development (UNCTAD) services trade data sets provide a good basis) and a more accurate measure of value-added contribution (e.g., ADB Multiregional Input-Output Tables), which will 
be gradually incorporated into the new framework. Likewise, wider data coverage and tailored indicators for island countries in the Pacific subregion, particularly on financial indicators, can contribute to a more precise estimation of the index. There is also scope for further development in research, particularly on extending the ARCII to capture both intraregional and extraregional linkages and using ARCII to evaluate the impact of regional integration on income inequality, inclusive growth, and income convergence.

\section{Expansion to the Globalization Index}

While the ARCII reflects intraregional integration, capturing extraregional and global linkages can provide a more complete assessment and account for some economies (e.g., Russian Federation, Iran) that are not part of the intraregional perspective (ADB 2020). The distinction between intraregional and extraregional drivers that propel global economic integration is particularly important today, especially with the slowing pace of globalization and a broader potential role for regional integration (D'Urbino 2019). However, studies assessing the extent of the relationship between regional economic integration and global economic integration are few and limited.

To address this, the main elements of the ARCII enhanced framework, including the structure, dimensions, economies, and years covered, and the principal component analysis approach, can be adapted in constructing an index that measures an economy's global economic integration level. Following recent work by Huh and Park (2021), the proposed globalization index will also be developed to include 173 economies (previously 158 economies) and to work in parallel with the enhanced ARCII framework. In turn, the newly constructed globalization index will be useful in determining the impact of global integration on economic growth and income inequality, following previous studies by Park and Claveria (2018b), Lang and Tavares (2018), and Huh and Park (2021) on other economic integration indexes. The multidimensional impact of regional cooperation and integration, either as a composite or by specific dimensions, remains relatively unexplored and is a promising area for further analysis. For instance, certain dimensions could be more effective than others in achieving desirable economic goals.

\section{Future Studies on the Impact of Regional Integration and Globalization}

\section{Income Inequality, Inclusive Growth, and Sustainability}

Park and Claveria (2018b) empirically assesses the impact of regional integration on inequality and other development outcomes using an unbalanced panel data set for 156 economies from 2006 to 2016 . The authors' regression analysis used the Gini index as a measure of inequality, a multidimensional index like the ARCII approach, and a set of control variables. Their estimates show that the infrastructure and connectivity dimension has a significant effect on inequality, where improvements in the dimension are associated with reduced income inequality.

While the Gini coefficient is a common measure for income inequality, the data available from the World Development Indicators (WDI) has limited economy coverage. As such, regression results using this variable can only capture about $5 \%$ of the ARCII sample due to missing data, both for the Gini coefficient and some of the control variables (e.g., secondary enrollment, social benefit incidence). This could lead to biased estimates, especially since the Gini index for small and underdeveloped countries is usually unavailable. A feasible approach to address this is to use alternative measures of income inequality with better data coverage. Several other options, such as the Palma ratio, the Atkinson index, or the index developed by Ali and Son (2007) can be applied in future studies involving the ARCII. The Palma index is computed as a ratio between the gross national income share of the richest $10 \%$ and the poorest $40 \%$ of a population (OECD 2016). The data used to compute for the Palma ratio can be collected from the World Inequality Database, which offers wider data coverage than the Gini index. 
On the other hand, the Atkinson index is a welfare-based measure of inequality that reflects the share of total income that a society must forego to gain more equal shares of income between its citizens (United Nations Department of Economic and Social Affairs 2015).

Likewise, income distribution data from the World Inequality Database can be used to create a measure of inclusive growth. This will help assess the importance of regional integration on variables such as economic growth, income inequality, and inclusive growth. Results generated by these proposed studies may help determine whether regionalization and/or globalization can improve desired outcomes. In turn, these findings could contribute to shaping policies, whether at a national, regional, or global scale. Recent studies exploring the link between globalization and inequality find that increased globalization is linked to widening income inequality (Potrafke 2015; Gozgor and Ranjan 2017; Ravallion 2018). Similar studies have been carried out for regional cooperation and integration. The analyses typically involve constructing a measure of regional cooperation and integration or using proxies such as intraregional trade shares or memberships in regional trade agreements, then estimating the impact of regional cooperation and integration on inequality. For instance, Beckfield (2006) uses intraregional trade share as a measure of regional economic integration in Europe, while Bo and Woo (2008) constructs a composite index using principal component analysis. DiCaprio, Santos-Paulino, and Soklova (2017) analyzes the link between regional integration and inequality by developing an index that is based on membership in trade agreements to serve as a proxy for preferential trade access. Results show that regional integration has a positive impact on economic growth and lowers within-income inequality in the countries studied. Detailed analysis of the interaction between regional and global economic integration, and how each can contribute to these outcomes through the enhanced ARCIl framework can be of interest. For instance, if estimates show that both globalization and regionalization reduce income inequality, then this can support the argument for promoting regional integration. However, if globalization worsens income inequality while regional integration improves it, further research may be needed to understand their interaction and trade-offs.

Sustainable growth requires striking a balance between economic development and the environment and considering its transnational nature. While the enhanced framework includes a dimension reflecting regional environmental cooperation, the index can be further refined to assess the trade-offs between regional economic integration and environmental sustainability. Several efforts have been made in this direction (UNESCAP 2020; The Economist Intelligence Unit 2020). Assessing further implications of regional integration for sustainability through the enhanced framework, taking into account impacts on air quality, water pollution, deforestation, and other environmental dimensions will be an important part of ARCII's research agenda.

\section{Income Convergence}

A topic that has received less attention in the regional integration literature is the link between regional integration and income convergence. For instance, the narrative behind integration in the European Union is premised on the thought that deeper economic integration would lead to income convergence; however, Alcidi (2019) explains that this may not always be the case. Venables (1999), for instance, finds heterogeneous effects from free trade agreements (FTAs) depend on the income level of member countries involved; FTAs among low-income countries tend to result in lower income convergence, while agreements between high-income countries lead to convergence. Milanovic (2006) presents evidence of the relatively weak link between economic growth and income convergence, while Schularick and Steger (2010) finds that the correlation between international financial integration and economic growth today is not as strong as in previous periods.

To measure the impact of regional integration on income convergence, the proposed study will deviate from traditional conditional convergence estimation and exploit the concept of "horizontal convergence." In conditional convergence, the coefficient of the initial income level is used to determine the rate at which a certain economy reaches its balanced 
growth path. While horizontal convergence is related to conditional convergence, it is defined differently and pertains to the rate at which a country closes the gap between its per capita income and that of the richest nation in the sample. Harger and Young (2014) notes that there are two main advantages to measuring horizontal convergence. For one, horizontal convergence helps to examine the rate at which a country's standard of living catches up to the highest standard in the sample. Also, it allows identification of the determinants of how fast the gap narrows. This definition of conditional convergence can be extended to measure the rate of convergence not only at the country level, but also at a regional scale, in which comparisons across countries within a region are feasible. This approach is different from the conventional method of comparing outcomes "within countries" only. To address potential endogeneity between convergence and regional integration, the analysis will test different econometric approaches.

\section{Data Envelopment Analysis}

Another feasible research extension involves using ARCII or a globalization index in Data Envelopment Analysis (DEA) to gauge the untapped potentials of regional integration and/or globalization in fostering economic growth, income equality, and income convergence among countries. Naeher (2015) estimates the untapped potential of Asia's regional integration using a different multidimensional regional index. In this approach, a composite index of regional integration outcomes (CRI) is first estimated, comprising three dimensions (trade and investment, monetary and financial integration, and cross-border mobility). The CRI index is used as an output variable in a DEA estimation, while considering as input variables the proxies of two dimensions for regional integration: the quality of cross-border infrastructure (from World Bank's Logistics Performance Index) and institutional arrangements that facilitate private sectors activities (from World Bank's Doing Business). The DEA provides an estimate of Asia's untapped potential for further regional integration, and suggests considerable scope for integration, based on currently available resources (or inputs), for South and Central Asia. Similarly, Naeher and Narayanan (2020) constructs a global production possibility frontier for regional integration outcomes based on two composite indexes. A non-parametric frontier analysis is implemented to rate the regional integration performance of subregions relative to their potential.

In the future, a similar approach can be followed in a DEA setting using the ARCII estimates, a more accurate and comprehensive measure of regional integration, in two ways: first, introducing ARCII as an output variable in relation to a set of proxy measures of the enabling environment for regional integration in each subregion (or input index). Second, using ARCII and dimensional indexes as input variables for explaining the efficiency of development outcomes such as economic growth or income inequality. A non-parametric approach such as DEA can be useful to contextualize the progress in regional integration to the individual conditions and endowments of each economy and contribute to shaping policies related to regional integration.

\section{Knowledge Sharing}

Developing accurate measures of regional integration allow policy makers and researchers to properly monitor and evaluate the progress of individual countries. The enhancements introduced in the ARCII framework reflects the efforts of ADB to revisit these measures. The index acknowledges the pivotal role of digitalization in transforming the nature of regional and global economic integration and the synergies between the environment and regional integration.

Looking forward, the ARCII project will continue implementing knowledge sharing activities and making available all the relevant technical documentation, including its manual, data sets, and software codes. The project will also implement capacity building activities with ADB's developing member countries to promote the use of ARCII as a metric of regional integration, equipping them with the expertise to tailor the ARCII framework and better inform their regional integration strategies. 


\section{References}

Alcidi, C. 2019. Economic Integration and Income Convergence in the EU. Intereconomics 54 (1). pp. 5-11.

Ali, I. and H. H. Son. 2007. Defining and Measuring Inclusive Growth: Application to the Philippines. ERD Working Paper Series No. 98. Manila: Asian Development Bank (ADB).

ADB. 2020. New Approaches to Measuring and Assessing Regional Cooperation and Integration: Workshop Highlights.

Beckfield, J. 2006. European Integration and Income Inequality. American Sociological Review. 71 (6). pp. 964-985.

Bo, C. and Y. P. Woo. 2008. A Composite Index of Economic Integration in the Asia-Pacific Region. United Nations Public Administration Network 27.

DiCaprio, A., A. U. Santos-Paulino, and M. V. Soklova. 2017. Regional Trade Agreements, Integration and Development. United Nations Conference on Trade and Development Research Paper. No. 1. Geneva: UNCTAD.

D’Urbino, L. 2019. Slowbalisation: The Steam Has Gone Out of Globalisation. The Economist. 24 January. https://www.economist.com/leaders/2019/01/24/the-steam-has-gone-out-of-globalisation.

Gozgor, G. and P. Ranjan. 2017. Globalisation, Inequality and Redistribution: Theory and Evidence. The World Economy. 40 (12). pp. 2704-2751.

Harger, K. and A. T. Young. 2014. Globalization and Income Convergence. SSRN Electronic Journal. September.

Huh, H. S. and C. Y. Park. 2017. Asia-Pacific Regional Integration Index: Construction, Interpretation, and Comparison. ADB Economics Working Paper Series No. 511. Manila: Asian Development Bank. https://ideas. repec.org/p/ris/adbewp/0511.html.

- 2018. Asia-Pacific Regional Integration Index: Construction, Interpretation, and Comparison. Journal of Asian Economics. 54 (C). pp. 22-38.

- 2021. A New Index of Globalisation: Measuring Impacts of Integration on Economic Growth and Income Inequality. The World Economy. 44 (2). pp. 409-443.

Lang, V. and M. M. Tavares. 2018. The Distribution of Gains from Globalization. Working Paper 18/54. Washington, DC: International Monetary Fund.

Milanovic, B. 2006. Economic Integration and Income Convergence: Not Such a Strong Link? The Review of Economics and Statistics, 88 (4). pp. 659-670.

Naeher, D. 2015. An Empirical Estimation of Asia's Untapped Regional Integration Potential Using Data Envelopment Analysis. Asian Development Review. 32 (2). pp. 178-195. 
Naeher, D. and R. Narayanan. 2020. Untapped Regional Integration Potential: A Global Frontier Analysis. The Journal of International Trade \& Economic Development. 29 (6). pp. 722-747.

Organisation for Economic Co-operation and Development (OECD). 2016. OECD Factbook 2015-2016. Economic, Environmental and Social Statistics. Paris: OECD Publishing. https://www.oecd-ilibrary.org/content/ publication/factbook-2015-en.

Park, C. Y. and R. Claveria. 2018a. Constructing the Asia-Pacific Regional Cooperation and Integration Index: A Panel Approach. SSRN Electronic Journal.

— 2018b. Does Regional Integration Matter for Inclusive Growth? Evidence from the Multidimensional Regional Integration Index. SSRN Electronic Journal.

Potrafke, N. 2015. The Evidence on Globalisation. The World Economy. 38 (3). pp. 509-552.

Ravallion, M. 2018. Inequality and Globalization: A Review Essay. Journal of Economic Literature. 56 (2). pp. 620-642.

Schularick, M. and T. M. Steger. 2010. Financial Integration, Investment, and Economic Growth: Evidence from Two Eras of Financial Globalization. The Review of Economics and Statistics. 92 (4). pp. 756-768.

The Economist Intelligence Unit. 2020. The Hinrich Foundation Sustainable Trade Index. https://www. hinrichfoundation.com/research/wp/sustainable/sustainable-trade-index-2020/.

United Nations Department of Economic and Social Affairs. 2015. Inequality Measurement. 21 October. https:/www.un.org/en/development/desa/policy/wess/wess_dev_issues/dsp_policy_02.pdf.

United Nations Economic and Social Commission for Asia and the Pacific (UNESCAP). 2020. Regional Integration for Sustainable Development in Asia and the Pacific: ESCAP Digital and Sustainable Regional Integration Index and Indicator Framework. Bangkok: United Nations Economic and Social Commission for Asia and the Pacific.

Venables, A. 1999. Regional Integration Agreements: A Force for Convergence or Divergence? Policy Research Working Papers. Washington, DC: World Bank. 


\section{APPENDIX 1}

\section{Explanatory Note on the ARCII Framework}

This note serves as a comprehensive guide to the construction of the Asia-Pacific Regional Cooperation and Integration Index (ARCII) enhanced framework. The index provides a broad-based measure of regional integration and allows for tracking the progress of regional integration. The ARCII also helps identify strengths and weaknesses across different subregions and different dimensions.

The index is based on 41 indicators that measure aspects of regional integration along eight dimensions: (i) trade and investment integration, (ii) money and finance integration, (iii) regional value chain, (iv) infrastructure and connectivity, (v) people and social integration, (vi) institutional arrangements, (vii) technology and digital connectivity, and (viii) environmental cooperation. This appendix outlines the steps involved in constructing the index.

\section{Methodology}

Building on the methodology of Huh and Park (2017, 2018), the ARCII is compiled using weights obtained from a two-stage principal component analysis (PCA). ${ }^{1}$ In the first stage, the panel PCA apportions a weight to each indicator to construct subindexes for each of the eight dimensions. In the second stage, the PCA is applied again to weigh the subindexes and to compile the overall index. The two-stage PCA is implemented separately for each region to account for their different features and characteristics in the computation of the index.

In Huh and Park (2017, 2018), the first ARCII was based only on 2013 data, partly because other years had limited coverage for some economies. The single-year ARCII was also a reflection of the difficulty of reaching a consensus on the best approach to create time-consistent weights for compiling indicators that may become available or missing over time.

To address this, Park and Claveria (2018) expanded the data coverage to years 2006-2017 and employed panel normalization and panel PCA in building an ARCII that is better able to track the time evolution of the index and identify different drivers of regional integration over time. This approach makes it easier to track progress in regional cooperation and integration in $\mathrm{Asia}^{2}$ and improves the reliability and ease of interpreting the index. The authors also implemented a methodological refinement-the percentile transformation of normalized indicator values - to generate more robust and reliable estimates of ARCII. Finally, to the extent that data availability allows, the construction of ARCII is brought to the subregional level by compiling indicators of activity between economies within each subregion to estimate the degree of intra-subregional integration.

For a full discussion on the construction of the baseline ARCII, please refer to Huh and Park (2018). An earlier 2017 version appeared in the ADB Working Paper Series https://www.adb.org/publications/asia-pacific-regional-integration-index. The ARCII was referred to as Asia-Pacific Regional Integration Index (APRII) in these papers.

2 Asia refers to 48 members of ADB. It includes Australia, Japan, and New Zealand, but does not include Niue due to limited data availability. 


\section{Economies Covered}

The 48 Asian economies covered in this study are classified by subregion (number of economies in parentheses): ${ }^{3}$

- Central Asia (8): Armenia, Azerbaijan, Georgia, Kazakhstan, the Kyrgyz Republic, Tajikistan, Turkmenistan, Uzbekistan

- East Asia (6): the People's Republic of China; Hong Kong, China; Japan; the Republic of Korea; Mongolia; Taipei,China

- Southeast Asia (10): Brunei Darussalam, Cambodia, Indonesia, the Lao People's Democratic Republic (Lao PDR), Malaysia, Myanmar, the Philippines, Singapore, Thailand, Viet Nam

- South Asia (8): Afghanistan, Bangladesh, Bhutan, India, Maldives, Nepal, Pakistan, Sri Lanka

- The Pacific (14): the Cook Islands, Fiji, Kiribati, Marshall Islands, Federated States of Micronesia, Nauru, Palau, Papua New Guinea, Samoa, Solomon Islands, Timor-Leste, ${ }^{4}$ Tonga, Tuvalu, Vanuatu

- Oceania (2): Australia, New Zealand

To allow for comparison with other regions, integration indexes were also built for other regions of the world, utilizing all available information for all the economies and years in the sample period (i.e., 173 economies for 2006-2018) in the data imputation, normalization, and weighting and aggregation. The economies covered in other regions are (number of economies in parentheses):

- European Union (27): Austria, Belgium, Bulgaria, Cyprus, Czech Republic, Denmark, Estonia, Finland, France, Germany, Greece, Hungary, Ireland, Italy, Latvia, Lithuania, Luxembourg, Malta, Netherlands, Poland, Portugal, Romania, Slovak Republic, Slovenia, Spain, Sweden, United Kingdom

- Latin America (32): Antigua and Barbuda, Argentina, Bahamas, Barbados, Belize, Bolivia, Brazil, Chile, Colombia, Costa Rica, Dominica, Dominican Republic, Ecuador, El Salvador, Grenada, Guatemala, Guyana, Haiti, Honduras, Jamaica, Mexico, Nicaragua, Panama, Paraguay, Peru, St. Kitts and Nevis, St. Lucia, St. Vincent and the Grenadines, Suriname, Trinidad and Tobago, Uruguay, Venezuela

- Africa (49): Algeria, Angola, Benin, Botswana, Burkina Faso, Burundi, Cameroon, Cape Verde, Central African Republic, Chad, Comoros, Democratic Republic of the Congo, Republic of the Congo, Cote d'Ivoire, Djibouti, Equatorial Guinea, Eritrea, Ethiopia, Gabon, Gambia, Ghana, Guinea, Guinea-Bissau, Kenya, Lesotho, Liberia, Madagascar, Malawi, Mali, Mauritius, Morocco, Mozambique, Namibia, Niger, Nigeria, Rwanda, Sao Tome and Principe, Senegal, Seychelles, Sierra Leone, South Africa, Sudan, Eswatini (Swaziland), Tanzania, Togo, Tunisia, Uganda, Zambia, Zimbabwe

- North America (2): United States, Canada

- Middle East (15): Bahrain, Islamic Republic of Iran, Iraq, Israel, Jordan, Kuwait, Lebanon, Oman, State of Palestine, Qatar, Saudi Arabia, Syrian Arab Republic, Turkey, United Arab Emirates, Yemen

The groupings are based on ADB's Asian Economic Integration Report: https://aric.adb.org/aeir.

Timor-Leste is classified as a Pacific developing member country in the 2006-2018 enhanced ARCII estimates to be consistent with the baseline estimates done since 2017. For the next round of updating, Timor-Leste will be included in Southeast Asia in keeping with ADB's current classification. 


\section{Constructing the Index}

The process of constructing the index involves data collection, imputation of missing data, normalization through panel min-max scaling, and weighting and aggregation using a two-step panel PCA procedure (Huh and Park 2018). The steps are illustrated in Figure A1. ${ }^{5}$

Figure A1: Flowchart of ARCII Construction

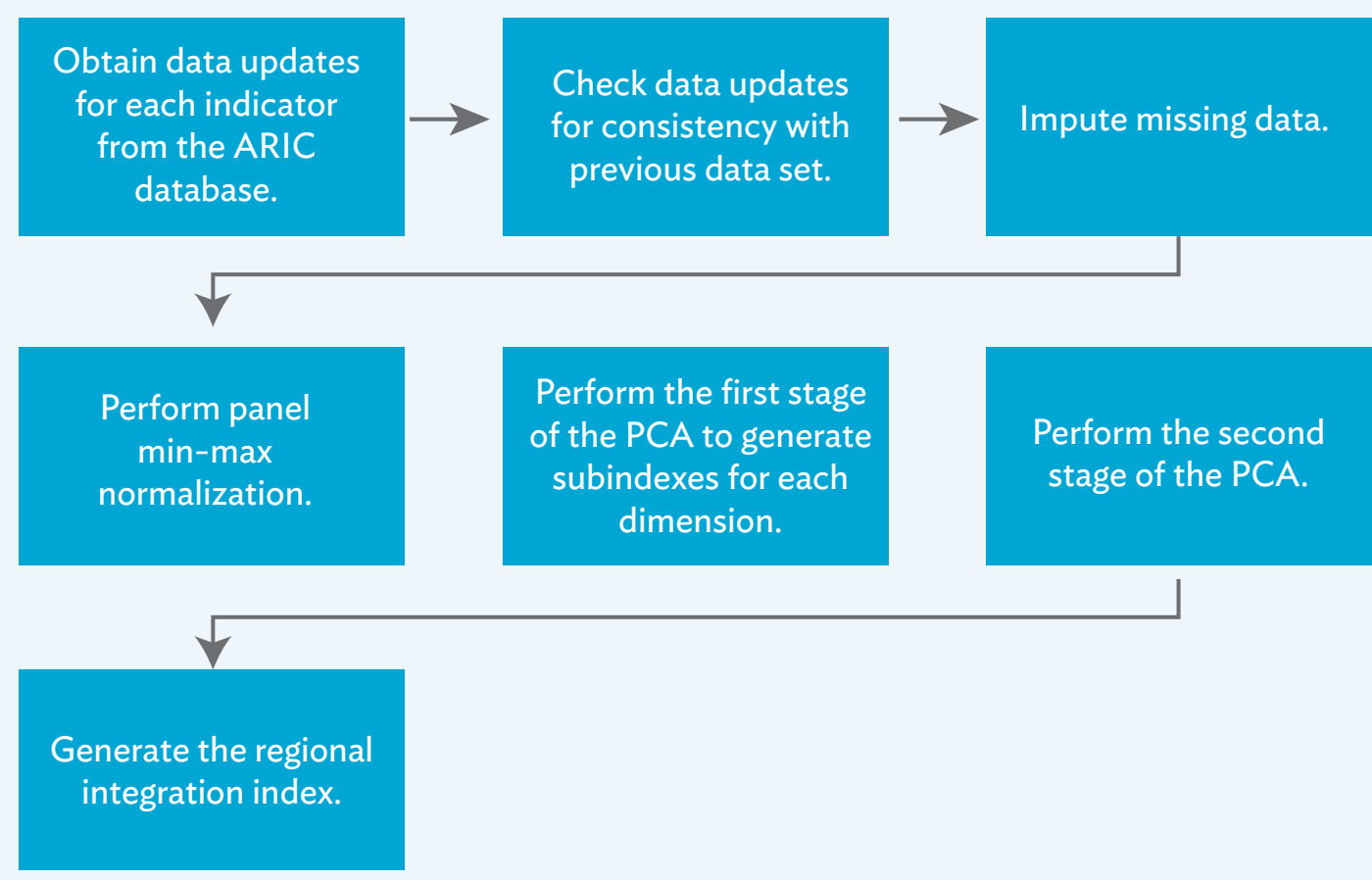

AARCII = Asia-Pacific Regional Cooperation and Integration Index, ARIC = Asia Regional Integration Center, PCA = principal component analysis.

Source: Asian Development Bank.

\section{Steps 1 and 2: Data Collection}

The ARCII has eight dimensions and is composed of the 41 indicators shown in Appendix Table A1.1. The first step in constructing the index is collecting historical data (2006-2018) on these indicators for all 173 economies, of which 48 are from Asia and the Pacific, and the remaining 125 economies from other regions of the world. Once the raw data are collected, the indicators are computed by taking the ratio of the numerator to the denominator as summarized in Table A1.1. For example, indicator I-a is computed annually by dividing intraregional goods exports to total goods exports for each economy.

A more detailed discussion of constructing the index, including the imputation methods, normalization procedure and panel PCA methodology used for the baseline ARCII framework is available in Park and Claveria (2018). 


\section{Step 3: Imputation of Missing Data}

As shown in Table A1.1, data are available for most of the indicators across years. To fill in the data gaps, various imputation methods are implemented: linear interpolation, averaging, regression imputation (Box A1), and substitution by closest available observation (cold-deck imputation).

- An averaging method is implemented to fill in the missing values for indicator IV-b (Liner Shipping Connectivity Index).

- Missing data for indicator V-a (outbound migration) are linearly interpolated using bilateral migration data published every 5 years.

- Meanwhile, instead of linear extrapolation, missing observations at the beginning or end of a series are substituted by the closest observation available. This method is applied to indicator VI-e (embassy). In effect, the last non-missing observation is carried backward (forward) where observations are missing at the beginning (end) of a series. This is similar to the technique adopted by Gygli et al. (2019) in their updated methodology for the KOF Index of Globalization.

- An autoregressive process is used to impute the missing values for indicator VIII-e (ecological footprint).

\section{Box A1: Applying Regression Imputation Method to Address Data Gaps}

The method of regression imputation helped address the data gaps in the ARCII database for the following indicators: IV-a (regional and global average trade cost ratio), IV-d (Logistics Performance Index) and IV-e (Doing Business Index).

Consider first the Logistics Performance Index and the Doing Business Index developed by the World Bank. These measures assess infrastructure levels from different aspects: the Logistics Performance Index examines time and costs associated with logistics processes when transporting goods across borders while the latter primarily examines general business conditions, such as the time and costs for setting up a business, connecting utilities, registration, and so on. The two indexes are strongly related, with a correlation coefficient of $r=0.80$. Given this strong association, a simple regression is used to impute missing data. Estimation results involving regression of each indicator on the other are as follows:

$$
\begin{gathered}
D B I_{j}=3.8216_{(0.32)}+19.8326_{(0.00)} L P I_{j}+\hat{\varepsilon}_{j} \\
L P I_{j}=0.9123_{(0.00)}+0.0322_{(0.00)} D B I_{j}+\hat{\varepsilon}_{j} \\
T C_{j k}=2.4546_{(0.00)}-1.2683_{(0.00)} L S B C I_{j k}-0.1180_{(0.00)} L P I_{j k}+0.2940_{(0.02)} D I S T A N C E_{j k}+\hat{\varepsilon}_{j} \\
R^{2}=0.640 ; A d j-R^{2}=0.637 ; F=229.33[0.00]
\end{gathered}
$$

where the figures in parentheses (squared brackets) are the p-values for the $t(F)$ tests of statistical significance. All estimated coefficients are signed as expected and are statistically significant, with the $p$-values around 0 , except the intercept in the DBI equation. R2, adjusted R2, and F tests yield identical results across equations. The correlation coefficient equals $r=\sqrt{R^{2}}=\sqrt{0.64}=0.80$ and can also be derived from the geometric average of the two coefficient estimates, $r=\sqrt{19.8326 * 0.0322}=0.80$.

ARCII = Asia-Pacific Regional Cooperation and Integration Index

Sources: H. S. Huh and C. Y. Park. 2017. Asia-Pacific Regional Integration Index: Construction, Interpretation, and Comparison. ADB Economics Working Paper Series. No. 511. Manila: Asian Development Bank. https://ideas.repec.org/p/ris/adbewp/0511.html; H. S. Huh and C. Y. Park. 2018. Asia-Pacific Regional Integration Index: Construction, Interpretation, and Comparison. Journal of Asian Economics 54 (C). pp. 22-38. https://doi.org/10.1016/j.asieco.2017.12.001. 


\section{Step 4: Normalization Using Panel Min-Max Scaling}

As measurement units differ across indicators, normalization prior to aggregation is required to achieve commensurability. Panel min-max normalization involves normalizing indicators based on all sample years and all economies at hand. It is suitable for comparing progress across different economies through the years. However, whenever new data points become available, all indicators need to be normalized again using the new panel. A new data set could change the minimum and maximum values for some indicators, and hence the value of the transformed indicators and resulting composite index. To maintain comparability between existing and new data, the composite index needs to be recalculated using the updated data set (OECD and Joint Research CentreEuropean Commission 2008). Panel normalization is said to induce a "nonseparability" between years in a sample: a change in the data from 1 year can induce a change in ranking from another year (Lockwood 2004).

In computing the enhanced ARCII estimates, panel min-max worldwide normalization of the 41 indicators maintains the time consistency of the index. A time element was added to the min-max scaling utilized by Huh and Park $(2017,2018)$. Each individual indicator $x_{q c}^{t}$ of type $q$ for an economy $c$ and time $t$, is transformed into:

$$
I_{t}=\frac{x_{q c}^{t}-\min _{t \in T} \min _{c}\left(x_{q}^{t}\right)}{\max _{t \in T} \max _{c}\left(x_{q}^{t}\right)-\min _{t \in T} \min _{c}\left(x_{q}^{t}\right)}
$$

where the minimum and maximum values for each indicator are calculated across countries and time. The values of $I_{t}$ range from 0 to 1 , with higher values denoting greater integration. For indicators where higher values of the original variable imply lower integration, such as II-c (pair-wise dispersion of deposit rates), III-b (average trade concentration ratio), and IV-a (average trade cost ratio), the transformation is given as:

$$
I_{t}=1-\frac{x_{q c}^{t}-\min _{t \in T} \min _{c}\left(x_{q}^{t}\right)}{\max _{t \in T} \max _{c}\left(x_{q}^{t}\right)-\min _{t \in T} \min _{c}\left(x_{q}^{t}\right)}
$$

The minimum and maximum for each indicator are calculated across countries and time to account for the evolution of the indicators and the resulting composite index. One of the drawbacks of min-max scaling is that extreme values can distort the distribution of normalized values. This can also understate or overstate the resulting composite index.

\section{Steps 5 to 7: Weighting and Aggregation}

Weighting and aggregation of data are intended to improve comparability by utilizing all information at hand. The most important source of incomparability is said to be the systemic statistical properties of the index components that affect weighting (UNCTAD 2007). To avoid this issue, reference weights must be applied to all the years in the sample period. This makes the comparison of the composite index across the years possible.

PCA remains the main statistical tool to obtain the weights utilized for compiling the ARCII. A two-stage panel PCA estimation is carried out to obtain time-consistent weights for aggregation. Before that, the indicators are normalized based on all regions together (i.e., worldwide normalization). Following the notation of Huh and Park $(2017,2018)$, the data vector $X=\left(x_{1}, x_{2}, \ldots, x_{Q}\right)$ becomes a multidimensional data vector $X_{T X Q}=\left(x_{1}^{t}, x_{2}^{t}, \ldots, x_{Q}^{t}\right), t \in T$, where $T$ is the total number of periods and $Q$ is the number of indicators (dimensions). Let $\sum_{Q x Q}$ be the correlation matrix of $X_{T X Q}$. The principal component (PC), $Z_{i}^{t}, i=1,2, \ldots, Q, t \in T$, is defined as 


$$
\begin{aligned}
& Z_{1}^{t}=a_{11} x_{1}^{t}+a_{12} x_{1}^{t}+\cdots+a_{1 Q} x_{1}^{t} \\
& Z_{2}^{t}=a_{21} x_{1}^{t}+a_{22} x_{1}^{t}+\cdots+a_{2 Q} x_{1}^{t} \\
& Z_{Q}^{t}=a_{Q 1} x_{1}^{t}+a_{Q 2} x_{1}^{t}+\cdots+a_{Q Q} x_{1}^{t}
\end{aligned}
$$

Or in matrix form, $Z=A^{\prime} X_{T X Q}$ where $A=\left(a_{1}, a_{2}, \ldots, a_{Q}\right)$. The coefficient matrix $A$ maximizes the variance of $Z=E\left(Z Z^{\prime}\right)=A^{\prime} \sum A$ subject to the following constraints:

$a_{1}^{\prime} a_{1}=a_{2}^{\prime} a_{2}=\cdots=a_{Q}^{\prime} a_{Q}=1$ (unit vector length) and $\operatorname{cov}\left(a_{i}^{\prime} x, a_{j}^{\prime} x\right)=0, i \neq j$ (orthogonality condition)

The solution to the eigenvalue-eigenvector problem resulting from the above-constrained maximization problem is $\lambda_{i}$, which is equal to the variance of $Z$. Moreover, $\lambda_{1}>\lambda_{2}>\cdots>\lambda_{Q}$.

Using the loadings obtained from the panel PCA were used, following the weighting scheme in Huh and Park (2017, 2018). As mentioned, the ARCII is compiled using weights obtained from a two-stage panel PCA. In the first stage, panel PCA apportions a weight to each indicator to construct subindexes for the eight dimensions of regional integration. In the second stage, panel PCA is applied again to weigh the subindexes to compile the overall index. The two-stage PCA is implemented separately for each region so that their different features and characteristics can be accounted for in the computation of the index.

Panel PCA-derived weights are used as reference weights in computing the ARCII for each year of the sample period. Keeping the weights constant over time is useful in analyzing the evolution of the ARCII for each economy and regional or subregional grouping. It also allows a comparison of the composite index across the years.

\section{Data}

In general, bilateral data was used to compile ratios of intraregional activity to total activity. However, there are a few exceptions-indicators IV-c Logistics Performance Index, IV-d Doing Business Index, VI-d international intergovernment organization membership, VII-d internet penetration rate, VII-e mobile subscriptions per 100 persons, VII-f international internet bandwidth, VIII-b number of international environmental agreements ratified, VIII-c environmental health score, and VIII-d ecological footprint of production as share of biocapacity-which are based on national rather than bilateral data. Table A1.1 provides a summary of the source of raw data, year coverage and formulas used to compute for each indicator in the enhanced ARCII framework. For reference, the baseline ARCII framework is summarized in Table A1.2.

An indicator with a higher value corresponds to deeper integration for its dimension, which translates to a higher ARCII estimate. However, the following three indicators are interpreted inversely:

- II-c: A higher value for this indicator implies that the pair-wise dispersion of deposit rates are larger and spread apart, which translates to weaker integration.

- III-b: The trade concentration index measures the concentration of economies' exports and imports among products. It is generally thought that if two economies produce diversified products, regional integration would lead to more benefits, as they can complement each other in trade. Under this premise, higher values in the concentration index are associated with lower regional integration (Huh and Park 2018).

- IV-a: Higher trade costs make it more expensive to trade with regional partners, which denotes lower regional integration levels. 


\section{Table A1.1: Summary of the Enhanced ARCII Framework-Data Sources, Year Coverage, Indicator Formula}

\begin{tabular}{|c|c|c|c|c|c|c|}
\hline Dimension & & Indicator & Source of Raw Data & $\begin{array}{c}\text { Raw Data } \\
\text { Availability }\end{array}$ & Numerator & Denominator \\
\hline \multirow[t]{5}{*}{$\begin{array}{l}\text { I. Trade and } \\
\text { Investment } \\
\text { Integration (5) }\end{array}$} & $\mathrm{I}-\mathrm{a}$ & $\begin{array}{l}\text { Proportion of } \\
\text { intraregional goods } \\
\text { exports to total goods } \\
\text { exports }\end{array}$ & $\begin{array}{l}\text { Direction of Trade, } \\
\text { International } \\
\text { Monetary Fund } \\
\text { (IMF) }\end{array}$ & $\begin{array}{c}2000- \\
2019\end{array}$ & $\begin{array}{l}\text { intraregional } \\
\text { goods exports }\end{array}$ & $\begin{array}{l}\text { Total goods } \\
\text { exports }\end{array}$ \\
\hline & $1-b$ & $\begin{array}{l}\text { Proportion of } \\
\text { intraregional goods } \\
\text { imports to total goods } \\
\text { imports }\end{array}$ & $\begin{array}{l}\text { Direction of Trade, } \\
\text { IMF }\end{array}$ & $\begin{array}{c}2000- \\
2019\end{array}$ & $\begin{array}{l}\text { intraregional } \\
\text { goods imports }\end{array}$ & $\begin{array}{l}\text { Total goods } \\
\text { imports }\end{array}$ \\
\hline & $\mathrm{I}-\mathrm{C}$ & $\begin{array}{l}\text { intraregional trade } \\
\text { intensity index }\end{array}$ & $\begin{array}{l}\text { Direction of Trade, } \\
\text { IMF }\end{array}$ & $\begin{array}{c}2000- \\
2019\end{array}$ & $\begin{array}{l}\text { Share of the } \\
\text { economy's } \\
\text { intraregional trade } \\
\text { to its total trade }\end{array}$ & $\begin{array}{l}\text { Share of the } \\
\text { region's total } \\
\text { trade to world } \\
\text { trade }\end{array}$ \\
\hline & $\mathrm{l}-\mathrm{d}$ & $\begin{array}{l}\text { Proportion of } \\
\text { intraregional foreign } \\
\text { direct investment } \\
\text { (FDI) inflows to total } \\
\text { FDI inflows }\end{array}$ & $\begin{array}{l}\text { Greenfield FDI: FDI } \\
\text { Markets, Mergers } \\
\text { and acquisitions } \\
\text { (M\&A) FDI: Zephyr }\end{array}$ & $\begin{array}{c}2003- \\
2018\end{array}$ & $\begin{array}{l}\text { intraregional FDI } \\
\text { inflows }\end{array}$ & Total FDI inflows \\
\hline & I-e & $\begin{array}{l}\text { Proportion of } \\
\text { intraregional FDI } \\
\text { inflows plus outflows } \\
\text { to total FDI inflows } \\
\text { plus outflows }\end{array}$ & $\begin{array}{l}\text { Greenfield FDI: FDI } \\
\text { Markets, Mergers } \\
\text { and acquisitions } \\
\text { (M\&A) FDI: Zephyr }\end{array}$ & $\begin{array}{c}2003- \\
2018\end{array}$ & $\begin{array}{l}\text { intraregional } \\
\text { FDI inflows plus } \\
\text { outflows }\end{array}$ & $\begin{array}{l}\text { Total FDI inflows } \\
\text { and outflows }\end{array}$ \\
\hline \multirow[t]{5}{*}{$\begin{array}{l}\text { II. Money } \\
\text { and Finance } \\
\text { Integration (5) }\end{array}$} & $I I-a$ & $\begin{array}{l}\text { Proportion of } \\
\text { intraregional cross- } \\
\text { border equity liabilities } \\
\text { to total cross-border } \\
\text { equity liabilities }\end{array}$ & $\begin{array}{l}\text { Coordinated } \\
\text { Portfolio Investment } \\
\text { Survey, IMF }\end{array}$ & $\begin{array}{c}2001- \\
2018\end{array}$ & $\begin{array}{l}\text { intraregional } \\
\text { cross-border } \\
\text { equity liabilities }\end{array}$ & $\begin{array}{l}\text { Total cross- } \\
\text { border equity } \\
\text { liabilities }\end{array}$ \\
\hline & $I I-b$ & $\begin{array}{l}\text { Proportion of } \\
\text { intraregional cross- } \\
\text { border bond liabilities } \\
\text { to total cross-border } \\
\text { bond liabilities }\end{array}$ & $\begin{array}{l}\text { Coordinated } \\
\text { Portfolio Investment } \\
\text { Survey, IMF }\end{array}$ & $\begin{array}{c}2006- \\
2018\end{array}$ & $\begin{array}{l}\text { intraregional } \\
\text { cross-border } \\
\text { bond liabilities }\end{array}$ & $\begin{array}{l}\text { Total cross- } \\
\text { border bond } \\
\text { liabilities }\end{array}$ \\
\hline & $\| \mathrm{I}-\mathrm{c}$ & $\begin{array}{l}\text { Pair-wise dispersion of } \\
\text { deposit rates averaged } \\
\text { regionally relative to } \\
\text { that averaged globally }\end{array}$ & $\begin{array}{l}\text { Asian Development } \\
\text { Bank (ADB) using } \\
\text { various sources }\end{array}$ & $\begin{array}{c}2006- \\
2019\end{array}$ & $\begin{array}{l}\text { Average } \\
\text { intraregional pair- } \\
\text { wise dispersion of } \\
\text { deposit rates }\end{array}$ & $\begin{array}{l}\text { Average pair- } \\
\text { wise dispersion } \\
\text { of deposit rates }\end{array}$ \\
\hline & $I I-d^{*}$ & $\begin{array}{l}\text { Capital account } \\
\text { openness: Chinn-Ito } \\
\text { Index (de jure) }\end{array}$ & $\begin{array}{l}\text { http://web.pdx. } \\
\text { edu/ ito/chinn- } \\
\text { ito_website.htm }\end{array}$ & 1970-2018 & Chinn-Ito Index & $\begin{array}{l}\mathrm{N} / \mathrm{A} \\
(\text { Denominator }=1)\end{array}$ \\
\hline & II-e & $\begin{array}{l}\text { Correlations of } \\
\text { exchange rates relative } \\
\text { to US dollar averaged } \\
\text { regionally minus those } \\
\text { averaged globally }\end{array}$ & $\begin{array}{l}\text { ADB using various } \\
\text { sources }\end{array}$ & $\begin{array}{c}2006- \\
2019\end{array}$ & $\begin{array}{l}\text { Pair-wise } \\
\text { correlations for } \\
\text { monthly exchange } \\
\text { rate in regard } \\
\text { to the US dollar } \\
\text { exchange rate of } \\
\text { all other Asian } \\
\text { economies }\end{array}$ & $\begin{array}{l}\text { Pair-wise } \\
\text { correlations } \\
\text { for monthly } \\
\text { exchange rate in } \\
\text { regard to the US } \\
\text { dollar exchange } \\
\text { rate of all other } \\
\text { economies }\end{array}$ \\
\hline
\end{tabular}


Table A1.1 continued

\begin{tabular}{|c|c|c|c|c|c|c|}
\hline Dimension & & Indicator & Source of Raw Data & $\begin{array}{c}\text { Raw Data } \\
\text { Availability }\end{array}$ & Numerator & Denominator \\
\hline \multirow[t]{5}{*}{$\begin{array}{l}\text { III. Regional Value } \\
\text { Chain (5) }\end{array}$} & $\mathrm{III}-\mathrm{a}$ & $\begin{array}{l}\text { Ratio between the } \\
\text { averaged trade } \\
\text { complementarity } \\
\text { index over regional } \\
\text { trading partners and } \\
\text { the averaged trade } \\
\text { complementarity } \\
\text { index over all trading } \\
\text { partners }\end{array}$ & $\begin{array}{l}\text { United Nations } \\
\text { Conference } \\
\text { on Trade and } \\
\text { Development } \\
\text { (UNCTAD); } \\
\text { UN Comtrade }\end{array}$ & $\begin{array}{c}2006- \\
2019\end{array}$ & $\begin{array}{l}\text { Average trade } \\
\text { complementarity } \\
\text { index over } \\
\text { regional trading } \\
\text { partners }\end{array}$ & $\begin{array}{l}\text { Average trade } \\
\text { complementarity } \\
\text { index over all } \\
\text { trading partners }\end{array}$ \\
\hline & III-b & $\begin{array}{l}\text { Ratio between the } \\
\text { averaged trade } \\
\text { concentration } \\
\text { index over regional } \\
\text { trading partners } \\
\text { and the averaged } \\
\text { trade concentration } \\
\text { index over all trading } \\
\text { partners }\end{array}$ & $\begin{array}{l}\text { UNCTAD; } \\
\text { UN Comtrade }\end{array}$ & $\begin{array}{c}2006- \\
2019\end{array}$ & $\begin{array}{l}\text { Average trade } \\
\text { concentration } \\
\text { index over } \\
\text { regional trading } \\
\text { partners }\end{array}$ & $\begin{array}{l}\text { Average trade } \\
\text { concentration } \\
\text { index over all } \\
\text { trading partners }\end{array}$ \\
\hline & $\mathrm{III}-\mathrm{C}$ & $\begin{array}{l}\text { Proportion of } \\
\text { intraregional } \\
\text { intermediate goods } \\
\text { exports to total } \\
\text { intraregional goods } \\
\text { exports }\end{array}$ & UN Comtrade & $\begin{array}{c}2000- \\
2018\end{array}$ & $\begin{array}{l}\text { Total } \\
\text { intraregional } \\
\text { intermediate } \\
\text { goods exports }\end{array}$ & $\begin{array}{l}\text { Total } \\
\text { intraregional } \\
\text { goods exports }\end{array}$ \\
\hline & III-d & $\begin{array}{l}\text { Proportion of } \\
\text { intraregional } \\
\text { intermediate goods } \\
\text { imports to total } \\
\text { intraregional goods } \\
\text { imports }\end{array}$ & UN Comtrade & $\begin{array}{c}2000- \\
2018\end{array}$ & $\begin{array}{l}\text { Total } \\
\text { intraregional } \\
\text { intermediate } \\
\text { goods imports }\end{array}$ & $\begin{array}{l}\text { Total } \\
\text { intraregional } \\
\text { goods imports }\end{array}$ \\
\hline & III-e & $\begin{array}{l}\text { Ratio between the sum } \\
\text { of the value-added } \\
\text { contributed by regional } \\
\text { trading partners and } \\
\text { that contributed by all } \\
\text { trading partners }\end{array}$ & $\begin{array}{l}\text { UNCTAD-Eora or } \\
\text { ADB-Multi-Region } \\
\text { Input-Output }\end{array}$ & $\begin{array}{c}2006- \\
2018\end{array}$ & $\begin{array}{l}\text { Sum of the } \\
\text { value-added } \\
\text { contributed by } \\
\text { regional trading } \\
\text { partners }\end{array}$ & $\begin{array}{l}\text { Sum of the } \\
\text { value-added } \\
\text { contributed by all } \\
\text { trading partners }\end{array}$ \\
\hline \multirow[t]{2}{*}{$\begin{array}{l}\text { IV. Infrastructure } \\
\text { and Connectivity } \\
\text { (5) }\end{array}$} & IV-a & $\begin{array}{l}\text { Ratio between the } \\
\text { averaged trade } \\
\text { cost over regional } \\
\text { trading partners and } \\
\text { the averaged trade } \\
\text { cost over all trading } \\
\text { partners }\end{array}$ & $\begin{array}{l}\text { World Bank/ } \\
\text { United Nations } \\
\text { Economic and Social } \\
\text { Commission for Asia } \\
\text { and the Pacific }\end{array}$ & $\begin{array}{c}2000- \\
2018\end{array}$ & $\begin{array}{l}\text { Average trade } \\
\text { cost over regional } \\
\text { trading partners }\end{array}$ & $\begin{array}{l}\text { Average trade } \\
\text { cost over all } \\
\text { trading partners }\end{array}$ \\
\hline & IV-b & $\begin{array}{l}\text { Ratio between the } \\
\text { averaged liner shipping } \\
\text { connectivity index } \\
\text { over regional trading } \\
\text { partners and the } \\
\text { averaged liner shipping } \\
\text { connectivity index over } \\
\text { all trading partners }\end{array}$ & UNCTAD & $\begin{array}{l}2006 \\
2008- \\
2018\end{array}$ & $\begin{array}{l}\text { Average liner } \\
\text { shipping } \\
\text { connectivity } \\
\text { index over } \\
\text { regional trading } \\
\text { partners }\end{array}$ & $\begin{array}{l}\text { Average liner } \\
\text { shipping } \\
\text { connectivity } \\
\text { index over all } \\
\text { trading partners }\end{array}$ \\
\hline
\end{tabular}


Table A1.1 continued

\begin{tabular}{|c|c|c|c|c|c|c|}
\hline \multicolumn{2}{|l|}{ Dimension } & Indicator & \multirow[t]{2}{*}{ Source of Raw Data } & \multirow{2}{*}{$\begin{array}{c}\text { Raw Data } \\
\text { Availability } \\
\text { 1995-2018 }\end{array}$} & \multirow{2}{*}{$\begin{array}{l}\quad \text { Numerator } \\
\text { Number of } \\
\text { passenger seats } \\
\text { sold on regional } \\
\text { flights }\end{array}$} & \multirow[b]{2}{*}{$\begin{array}{l}\text { Denominator } \\
\text { Number of } \\
\text { passenger } \\
\text { seats sold on } \\
\text { all international } \\
\text { flights }\end{array}$} \\
\hline & IV-c & $\begin{array}{l}\text { Proportion of } \\
\text { passenger seats sold } \\
\text { on regional flights } \\
\text { relative to those sold } \\
\text { on all international } \\
\text { flights }\end{array}$ & & & & \\
\hline & $I V-d^{*}$ & $\begin{array}{l}\text { Logistics Performance } \\
\text { index (overall) }\end{array}$ & World Bank & $\begin{array}{c}2007, \\
2010 \\
2012 \\
2014 \\
2016,2018\end{array}$ & $\begin{array}{l}\text { Logistics } \\
\text { performance } \\
\text { index (overall) }\end{array}$ & $\begin{array}{l}\text { N/A } \\
\text { (Denominator } \\
=1 \text { ) }\end{array}$ \\
\hline & $I V-e^{*}$ & $\begin{array}{l}\text { Doing Business Index } \\
\text { (overall) }\end{array}$ & World Bank & $\begin{array}{c}2009- \\
2018\end{array}$ & $\begin{array}{l}\text { Doing Business } \\
\text { Index (overall) }\end{array}$ & $\begin{array}{l}\mathrm{N} / \mathrm{A} \\
\text { (Denominator } \\
=1 \text { ) }\end{array}$ \\
\hline \multirow[t]{6}{*}{$\begin{array}{l}\text { V. People and } \\
\text { Social } \\
\text { Integration (6) }\end{array}$} & $V-a$ & $\begin{array}{l}\text { Proportion of } \\
\text { intraregional outbound } \\
\text { migration to total } \\
\text { outbound migration }\end{array}$ & $\begin{array}{l}\text { United Nations } \\
\text { Population Division }\end{array}$ & $\begin{array}{c}2000 \\
2005 \\
2010 \\
2015,2019\end{array}$ & $\begin{array}{l}\text { intraregional } \\
\text { outbound } \\
\text { migration }\end{array}$ & $\begin{array}{l}\text { Total outbound } \\
\text { migration }\end{array}$ \\
\hline & $V-b$ & $\begin{array}{l}\text { Ratio of intraregional } \\
\text { tourists to total } \\
\text { tourists (inbound plus } \\
\text { outbound) }\end{array}$ & $\begin{array}{l}\text { World Trade } \\
\text { Organization } \\
\text { (WTO) }\end{array}$ & $\begin{array}{c}2000- \\
2018\end{array}$ & $\begin{array}{l}\text { intraregional } \\
\text { tourists (inbound } \\
\text { plus outbound) }\end{array}$ & $\begin{array}{l}\text { Total tourists } \\
\text { (inbound plus } \\
\text { outbound) }\end{array}$ \\
\hline & $V-c$ & $\begin{array}{l}\text { Ratio of intraregional } \\
\text { remittances to total } \\
\text { remittances }\end{array}$ & World Bank & $\begin{array}{c}2006- \\
2018\end{array}$ & $\begin{array}{l}\text { intraregional } \\
\text { outward } \\
\text { remittances }\end{array}$ & $\begin{array}{l}\text { Total outward } \\
\text { remittances }\end{array}$ \\
\hline & $V-d$ & $\begin{array}{l}\text { Cultural proximity } \\
\text { with other economies } \\
\text { in the region relative } \\
\text { to that with all other } \\
\text { economies }\end{array}$ & $\begin{array}{l}\text { Centre d'Etudes } \\
\text { Prospectives et } \\
\text { d'Informations } \\
\text { Internationales } \\
\text { (CEPII) }\end{array}$ & $\begin{array}{l}2000- \\
2018\end{array}$ & $\begin{array}{l}\text { Average sum } \\
\text { of cultural } \\
\text { indicators } \\
\text { (dummies) } \\
\text { across all partner } \\
\text { economies in the } \\
\text { region }\end{array}$ & $\begin{array}{l}\text { Average sum } \\
\text { of cultural } \\
\text { indicators } \\
\text { (dummies) } \\
\text { across all partner } \\
\text { economies }\end{array}$ \\
\hline & V-e & $\begin{array}{l}\text { Ratio of intraregional } \\
\text { cultural goods trade } \\
\text { (exports plus imports) } \\
\text { to total cultural goods } \\
\text { trade }\end{array}$ & $\begin{array}{l}\text { UNCTAD, } \\
\text { UN Comtrade }\end{array}$ & $\begin{array}{c}2006- \\
2018\end{array}$ & $\begin{array}{l}\text { intraregional } \\
\text { cultural goods } \\
\text { trade }\end{array}$ & $\begin{array}{l}\text { Total cultural } \\
\text { goods trade }\end{array}$ \\
\hline & $V-f$ & $\begin{array}{l}\text { Ratio of trademark } \\
\text { applications made } \\
\text { with intraregional } \\
\text { residents to trademark } \\
\text { applications made with } \\
\text { all foreign residents }\end{array}$ & $\begin{array}{l}\text { World Intellectual } \\
\text { Property } \\
\text { Organization, World } \\
\text { Development } \\
\text { Indicators }\end{array}$ & 1980-2018 & $\begin{array}{l}\text { intraregional } \\
\text { trademark } \\
\text { applications }\end{array}$ & $\begin{array}{l}\text { Total trademark } \\
\text { applications }\end{array}$ \\
\hline $\begin{array}{l}\text { VI. Institutional } \\
\text { Arrangements (5) }\end{array}$ & VI-a & $\begin{array}{l}\text { Proportion of } \\
\text { intraregional } \\
\text { economies that have } \\
\text { signed free trade } \\
\text { agreements with }\end{array}$ & $\begin{array}{l}\text { Design of Trade } \\
\text { Agreements } \\
\text { (DESTA) }\end{array}$ & $\begin{array}{l}2000- \\
2018\end{array}$ & $\begin{array}{l}\text { Number of partner } \\
\text { economies in the } \\
\text { region that have } \\
\text { signed free trade } \\
\text { agreements }\end{array}$ & $\begin{array}{l}\text { Number of } \\
\text { economies in the } \\
\text { region }\end{array}$ \\
\hline
\end{tabular}


Table A1.1 continued

\begin{tabular}{|c|c|c|c|c|c|c|}
\hline \multicolumn{2}{|l|}{ Dimension } & Indicator & Source of Raw Data & $\begin{array}{c}\text { Raw Data } \\
\text { Availability }\end{array}$ & Numerator & Denominator \\
\hline & VI-b & $\begin{array}{l}\text { Proportion of } \\
\text { intraregional } \\
\text { economies that } \\
\text { have signed bilateral } \\
\text { investment treaties } \\
\text { with }\end{array}$ & UNCTAD, DESTA & $\begin{array}{c}2000- \\
2018\end{array}$ & $\begin{array}{l}\text { Number } \\
\text { of partner } \\
\text { economies in the } \\
\text { region that have } \\
\text { signed bilateral } \\
\text { investment } \\
\text { treaties }\end{array}$ & $\begin{array}{l}\text { Number of } \\
\text { economies in the } \\
\text { region }\end{array}$ \\
\hline & $\mathrm{VI}-\mathrm{c}$ & $\begin{array}{l}\text { Proportion of } \\
\text { intraregional } \\
\text { economies that have } \\
\text { signed double taxation } \\
\text { treaties with }\end{array}$ & UNCTAD & $\begin{array}{c}2000- \\
2018\end{array}$ & $\begin{array}{l}\text { Number } \\
\text { of partner } \\
\text { economies in the } \\
\text { region that have } \\
\text { signed double } \\
\text { taxation treaties }\end{array}$ & $\begin{array}{l}\text { Number of } \\
\text { economies in the } \\
\text { region }\end{array}$ \\
\hline & $\mathrm{VI}-\mathrm{d}^{*}$ & $\begin{array}{l}\text { Number of } \\
\text { international } \\
\text { intergovernment } \\
\text { organizations in which } \\
\text { an economy is a } \\
\text { member }\end{array}$ & $\begin{array}{l}\text { The CIA World } \\
\text { Factbook }\end{array}$ & $\begin{array}{c}2000- \\
2018\end{array}$ & $\begin{array}{l}\text { Number of } \\
\text { international } \\
\text { intergovernment } \\
\text { organizations } \\
\text { in which an } \\
\text { economy is a } \\
\text { member }\end{array}$ & $\begin{array}{l}\mathrm{N} / \mathrm{A} \\
\text { (Denominator } \\
=1 \text { ) }\end{array}$ \\
\hline & VI-e & $\begin{array}{l}\text { Proportion of } \\
\text { intraregional } \\
\text { economies that have } \\
\text { an embassy }\end{array}$ & $\begin{array}{l}\text { Huh (2020) based } \\
\text { on The Europa } \\
\text { World Year Book }\end{array}$ & $\begin{array}{c}2006, \\
2010,2016\end{array}$ & $\begin{array}{l}\text { Number } \\
\text { of partner } \\
\text { economies in the } \\
\text { region that have } \\
\text { an embassy }\end{array}$ & $\begin{array}{l}\text { Number of } \\
\text { economies in the } \\
\text { region }\end{array}$ \\
\hline \multirow[t]{4}{*}{$\begin{array}{l}\text { VII. Technology } \\
\text { and Digital } \\
\text { Connectivity (6) }\end{array}$} & VII-a & $\begin{array}{l}\text { Proportion of } \\
\text { intraregional } \\
\text { information and } \\
\text { communication } \\
\text { technology (ICT) } \\
\text { goods trade (exports } \\
\text { plus imports) to total } \\
\text { ICT goods trade }\end{array}$ & $\begin{array}{l}\text { UNCTAD, } \\
\text { UN Comtrade }\end{array}$ & $\begin{array}{c}2006- \\
2018\end{array}$ & $\begin{array}{l}\text { intraregional ICT } \\
\text { goods trade }\end{array}$ & $\begin{array}{l}\text { Total ICT goods } \\
\text { trade }\end{array}$ \\
\hline & VII-b & $\begin{array}{l}\text { Proportion of } \\
\text { research outputs } \\
\text { with intraregional } \\
\text { collaborators relative } \\
\text { to research outputs } \\
\text { with all international } \\
\text { collaborators }\end{array}$ & $\begin{array}{l}\text { Huh (2020) based } \\
\text { on Web of Science } \\
\text { data }\end{array}$ & $\begin{array}{c}2006- \\
2018\end{array}$ & $\begin{array}{l}\text { Number of } \\
\text { research outputs } \\
\text { with intraregional } \\
\text { collaborators }\end{array}$ & $\begin{array}{l}\text { Number of } \\
\text { research } \\
\text { outputs with all } \\
\text { international } \\
\text { collaborators }\end{array}$ \\
\hline & VII-c & $\begin{array}{l}\text { Proportion of patent } \\
\text { applications made with } \\
\text { intraregional residents } \\
\text { to patent applications } \\
\text { made with all foreign } \\
\text { residents }\end{array}$ & $\begin{array}{l}\text { World Intellectual } \\
\text { Property } \\
\text { Organization, WDI }\end{array}$ & 1980-2018 & $\begin{array}{l}\text { intraregional } \\
\text { patent } \\
\text { applications }\end{array}$ & $\begin{array}{l}\text { Total patent } \\
\text { applications }\end{array}$ \\
\hline & VII- d* & $\begin{array}{l}\text { Proportion of persons } \\
\text { using the internet }\end{array}$ & $\begin{array}{l}\text { International } \\
\text { Telecommunication } \\
\text { Union }\end{array}$ & $\begin{array}{c}2000- \\
2018\end{array}$ & $\begin{array}{l}\text { Internet } \\
\text { penetration rate }\end{array}$ & $\begin{array}{l}\text { N/A } \\
\text { (Denominator } \\
=1 \text { ) }\end{array}$ \\
\hline
\end{tabular}


Table A1.1 continued

\begin{tabular}{|c|c|c|c|c|c|c|}
\hline Dimension & & Indicator & Source of Raw Data & $\begin{array}{c}\text { Raw Data } \\
\text { Availability }\end{array}$ & Numerator & Denominator \\
\hline & VII- $e^{*}$ & $\begin{array}{l}\text { Proportion of mobile } \\
\text { subscriptions per } 100 \\
\text { persons }\end{array}$ & $\begin{array}{l}\text { International } \\
\text { Telecommunication } \\
\text { Union }\end{array}$ & $\begin{array}{l}2000- \\
2018\end{array}$ & $\begin{array}{l}\text { Mobile } \\
\text { subscriptions per } \\
100 \text { persons }\end{array}$ & $\begin{array}{l}\mathrm{N} / \mathrm{A} \\
\text { (Denominator } \\
=1 \text { ) }\end{array}$ \\
\hline & VII-f* & $\begin{array}{l}\text { International internet } \\
\text { bandwidth }\end{array}$ & $\begin{array}{l}\text { International } \\
\text { Telecommunication } \\
\text { Union/ } \\
\text { Telegeography }\end{array}$ & $\begin{array}{c}2005- \\
2019\end{array}$ & $\begin{array}{l}\text { International } \\
\text { internet } \\
\text { bandwith }\end{array}$ & $\begin{array}{l}\mathrm{N} / \mathrm{A} \\
\text { (Denominator } \\
=1 \text { ) }\end{array}$ \\
\hline \multirow[t]{4}{*}{$\begin{array}{l}\text { VIII. } \\
\text { Environmental } \\
\text { Cooperation (4) }\end{array}$} & VIII-a & $\begin{array}{l}\text { Proportion of } \\
\text { intraregional } \\
\text { environmental goods } \\
\text { trade (exports plus } \\
\text { imports) to total } \\
\text { intraregional goods } \\
\text { trade }\end{array}$ & $\begin{array}{l}\text { UNCTAD, } \\
\text { UN Comtrade }\end{array}$ & $\begin{array}{c}2006- \\
2018\end{array}$ & $\begin{array}{l}\text { Intraregional } \\
\text { environmental } \\
\text { goods trade }\end{array}$ & $\begin{array}{l}\text { Total } \\
\text { environmental } \\
\text { goods trade }\end{array}$ \\
\hline & VIII-b* & $\begin{array}{l}\text { Number of } \\
\text { international } \\
\text { environmental } \\
\text { agreements ratified }\end{array}$ & $\begin{array}{l}\text { The CIA World } \\
\text { Factbook }\end{array}$ & $\begin{array}{c}2006- \\
2018\end{array}$ & $\begin{array}{l}\text { Number of } \\
\text { international } \\
\text { environmental } \\
\text { agreements } \\
\text { ratified }\end{array}$ & $\begin{array}{l}\text { N/A } \\
\text { (Denominator } \\
=1 \text { ) }\end{array}$ \\
\hline & VIII- $c^{*}$ & $\begin{array}{l}\text { Environmental health } \\
\text { score }\end{array}$ & $\begin{array}{l}\text { Environmental } \\
\text { Performance Index } \\
\text { at http://epi.yale.edu }\end{array}$ & $\begin{array}{c}2006- \\
2018\end{array}$ & $\begin{array}{l}\text { Environmental } \\
\text { health score }\end{array}$ & $\begin{array}{l}\text { N/A } \\
\text { (Denominator } \\
=1 \text { ) }\end{array}$ \\
\hline & VIII- $d^{*}$ & $\begin{array}{l}\text { Ecological footprint of } \\
\text { production as a share } \\
\text { of biocapacity }\end{array}$ & $\begin{array}{l}\text { Global Footprint } \\
\text { Network }\end{array}$ & 1961-2016 & $\begin{array}{l}\text { Ecological } \\
\text { footprint of } \\
\text { production }\end{array}$ & Biocapacity \\
\hline
\end{tabular}

ARCII = Asia-Pacific Regional Cooperation and Integration Index; N/A = not available.

Notes: Highlighted rows in green indicate new indicators and dimensions included in the enhanced ARCIl framework. Indicators marked with an asterisk are national-level indicators. The indicators are computed by taking the ratio of the numerator to the denominator. For example, indicator $\mathrm{I}$-a is computed for each economy $i$ at time $t$ as $\frac{\sum_{j=1}^{n} X_{i j}}{\sum_{\forall k} X_{i k}}$ where $X_{i j}$ represents exports of economy $i$ to regional partners $j=1, \ldots, n$ and $X_{i k}$ represents exports of economy $i$ to all partners $k=1, \ldots, N^{\sum_{\forall k} x_{i k}}$

Source: Asian Development Bank. 
Table A1.2: ARCII Dimensions and Indicators-Baseline Framework

\begin{tabular}{|c|c|c|c|}
\hline Dimension & & Indicator & Source of Raw Data \\
\hline \multirow{5}{*}{ 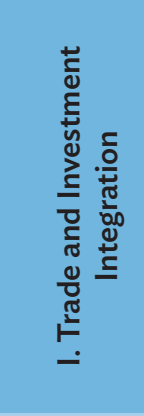 } & $\mathrm{I}-\mathrm{a}$ & $\begin{array}{l}\text { Proportion of intraregional goods exports to total } \\
\text { goods exports }\end{array}$ & $\begin{array}{l}\text { Direction of Trade, International Monetary } \\
\text { Fund (IMF) }\end{array}$ \\
\hline & $1-b$ & $\begin{array}{l}\text { Proportion of intraregional goods imports to total } \\
\text { goods imports }\end{array}$ & Direction of Trade, IMF \\
\hline & $\mathrm{I}-\mathrm{C}$ & Intraregional trade intensity index & Direction of Trade, IMF \\
\hline & $I-d$ & $\begin{array}{l}\text { Proportion of intraregional Foreign Direct Investment } \\
\text { (FDI) inflows to total FDI inflows }\end{array}$ & \multirow{2}{*}{$\begin{array}{l}\text { Greenfield FDI: FDI Markets, Mergers and } \\
\text { acquisitions (M\&A) FDI: Zephyr }\end{array}$} \\
\hline & $\mathrm{I}-\mathrm{e}$ & $\begin{array}{l}\text { Proportion of intraregional FDI inflows plus outflows } \\
\text { to total FDI inflows plus outflows }\end{array}$ & \\
\hline \multirow{4}{*}{ 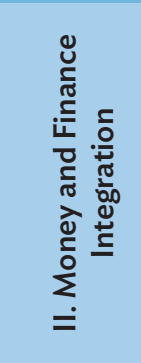 } & $\| 1 \mathrm{-a}$ & $\begin{array}{l}\text { Proportion of intraregional cross-border equity } \\
\text { liabilities to total cross-border equity liabilities }\end{array}$ & $\begin{array}{l}\text { Coordinated Portfolio Investment Survey, } \\
\text { IMF }\end{array}$ \\
\hline & $I I-b$ & $\begin{array}{l}\text { Proportion of intraregional cross-border bond } \\
\text { liabilities to total cross-border bond liabilities }\end{array}$ & $\begin{array}{l}\text { Coordinated Portfolio Investment Survey, } \\
\text { IMF }\end{array}$ \\
\hline & $\| \mathrm{II}$ & $\begin{array}{l}\text { Pair-wise dispersion of deposit rates averaged } \\
\text { regionally relative to that averaged globally }\end{array}$ & $\begin{array}{l}\text { Asian Development Bank (ADB) using } \\
\text { various sources }\end{array}$ \\
\hline & $I I-d$ & $\begin{array}{l}\text { Pair-wise correlation of equity returns averaged } \\
\text { regionally minus that averaged globally }\end{array}$ & ADB using various sources \\
\hline \multirow{4}{*}{ 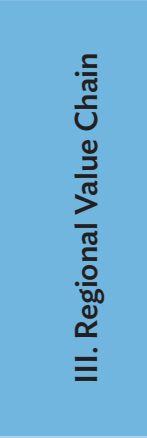 } & III-a & $\begin{array}{l}\text { Ratio between the averaged trade complementarity } \\
\text { index over regional trading partners and the averaged } \\
\text { trade complementarity index over all trading partners }\end{array}$ & $\begin{array}{l}\text { United Nations Conference on Trade and } \\
\text { Development (UNCTAD) }\end{array}$ \\
\hline & III-b & $\begin{array}{l}\text { Ratio between the averaged trade concentration } \\
\text { index over regional trading partners and the averaged } \\
\text { trade concentration index over all trading partners }\end{array}$ & UNCTAD \\
\hline & $\mathrm{III}-\mathrm{C}$ & $\begin{array}{l}\text { Proportion of intraregional intermediate goods } \\
\text { exports to total intraregional goods exports }\end{array}$ & UN Comtrade \\
\hline & III-d & $\begin{array}{l}\text { Proportion of intraregional intermediate goods } \\
\text { imports to total intraregional goods imports }\end{array}$ & UN Comtrade \\
\hline \multirow{4}{*}{ 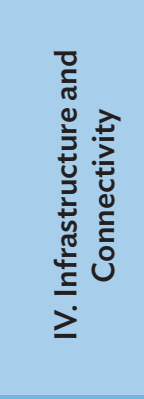 } & IV-a & $\begin{array}{l}\text { Ratio between the averaged trade cost over regional } \\
\text { trading partners and the averaged trade cost over all } \\
\text { trading partners }\end{array}$ & $\begin{array}{l}\text { World Bank/United Nations Economic and } \\
\text { Social Commission for Asia and the Pacific }\end{array}$ \\
\hline & IV-b & $\begin{array}{l}\text { Ratio between the averaged liner shipping } \\
\text { connectivity index over regional trading partners and } \\
\text { the averaged liner shipping connectivity index over all } \\
\text { trading partners }\end{array}$ & UNCTAD \\
\hline & IV-c & Logistics performance index (overall) & World Bank \\
\hline & IV-d & Doing Business Index (overall) & World Bank \\
\hline \multirow{4}{*}{ 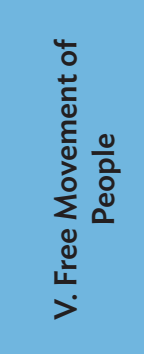 } & V-a & $\begin{array}{l}\text { Proportion of intraregional outbound migration to } \\
\text { total outbound migration }\end{array}$ & United Nations Population Division \\
\hline & $\mathrm{V}-\mathrm{b}$ & $\begin{array}{l}\text { Proportion of intraregional tourists to total tourists } \\
\text { (inbound plus outbound) }\end{array}$ & World Trade Organization (WTO) \\
\hline & $V-c$ & $\begin{array}{l}\text { Proportion of intraregional remittances to total } \\
\text { remittances }\end{array}$ & World Bank \\
\hline & $V-d$ & $\begin{array}{l}\text { Proportion of partner economies in the region that do } \\
\text { not require an entry visa }\end{array}$ & National sources \\
\hline
\end{tabular}


Table A1. 2 continued

\begin{tabular}{|c|c|c|c|}
\hline Dimension & & Indicator & Source of Raw Data \\
\hline \multirow{4}{*}{ 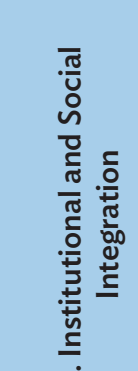 } & VI-a & $\begin{array}{l}\text { Proportion of partner economies in the region that } \\
\text { have signed free trade agreements }\end{array}$ & Design of Trade Agreements (DESTA) \\
\hline & VI-b & $\begin{array}{l}\text { Proportion of partner economies in the region that } \\
\text { have an embassy }\end{array}$ & $\begin{array}{l}\text { Huh (2020) based on The Europa World } \\
\text { Year Book }\end{array}$ \\
\hline & $\mathrm{VI}-\mathrm{c}$ & $\begin{array}{l}\text { Proportion of partner economies in the region that } \\
\text { have signed bilateral investment treaties }\end{array}$ & UNCTAD, DESTA \\
\hline & VI-d & $\begin{array}{l}\text { Proportion of partner economies in the region that } \\
\text { have signed double taxation treaties }\end{array}$ & UNCTAD \\
\hline$\dot{>}$ & VI-e & $\begin{array}{l}\text { Cultural proximity with other economies in the region } \\
\text { relative to that with all other economies }\end{array}$ & $\begin{array}{l}\text { Centre d'Etudes Prospectives et } \\
\text { d'Informations Internationales (CEPII) }\end{array}$ \\
\hline
\end{tabular}

ARCII = Asia-Pacific Regional Cooperation and Integration Index.

Note: FDI Markets at www.fdimarkets.com, Zephyr at www.bvdinfor.com, DESTA at www.designoftradeagreements.org, and CEPII at www.cepii.fr.

Source: H. S. Huh and C. Y. Park. 2018. Asia-Pacific Regional Integration Index: Construction, Interpretation, and Comparison. Journal of Asian Economics 54 (C). pp. 22-38. https://doi.org/10.1016/j.asieco.2017.12.001. 


\section{References}

Gygli, S., F. Haelg, N. Potrafke, and J.E. Sturm. 2019. The KOF Globalisation Index-Revisited. The Review of International Organizations. 14 (3) pp. 543-574. https://doi.org/10.1007/s11558-019-09344-2.

Huh, H. S. 2020. Memo and Computed Indicators and Estimates Using the Enhanced Asia-Pacific Regional Cooperation and Integration Index Framework (Consultant Report for TA-9763). 4 December.

Huh, H. S. and C. Y. Park. 2017. Asia-Pacific Regional Integration Index: Construction, Interpretation, and Comparison. ADB Economics Working Paper Series. No. 511. Manila: Asian Development Bank. https://ideas. repec.org/p/ris/adbewp/0511.html.

- 2018. Asia-Pacific Regional Integration Index: Construction, Interpretation, and Comparison. Journal of Asian Economics. 54 (C). pp. 22-38. https://doi.org/10.1016/j.asieco.2017.12.001.

Lockwood, B. 2004. How Robust Is the Kearney/Foreign Policy Globalisation Index? The World Economy. 27 (4). pp. 507-523. https://doi.org/10.1111/j.0378-5920.2004.00611.x.

OECD and Joint Research Centre-European Commission. 2008. Handbook on Constructing Composite Indicators: Methodology and User Guide. Paris: OECD. https://doi.org/10.1787/9789264043466-en.

Park, C. Y. and R. Claveria. 2018. Constructing the Asia-Pacific Regional Cooperation and Integration Index: A Panel Approach. SSRN Electronic Journal. https://doi.org/10.2139/ssrn.3188636.

UNCTAD, DITC. 2007. Developing Countries in International Trade 2007: Trade and Development Index. United Nations. https://doi.org/10.2139/ssrn.1283665. 


\section{APPENDIX 2}

\section{Dimensional Weights and Overall ARCII Estimates by Economy}

Table A2: Dimensional Weights by Region

\begin{tabular}{|c|c|c|c|c|c|c|}
\hline Dimension & $\begin{array}{l}\text { Asia and } \\
\text { the Pacific }\end{array}$ & $\begin{array}{c}\text { European } \\
\text { Union }\end{array}$ & $\begin{array}{c}\text { Latin } \\
\text { America }\end{array}$ & Africa & $\begin{array}{c}\text { North } \\
\text { America }\end{array}$ & Middle East \\
\hline Trade and Investment Integration & 0.13 & 0.14 & 0.13 & 0.10 & 0.13 & 0.12 \\
\hline Money and Finance Integration & 0.09 & 0.06 & 0.14 & 0.15 & 0.13 & 0.09 \\
\hline Regional Value Chain & 0.13 & 0.13 & 0.14 & 0.09 & 0.13 & 0.15 \\
\hline Infrastructure and Connectivity & 0.14 & 0.15 & 0.13 & 0.11 & 0.13 & 0.12 \\
\hline People and Social Integration & 0.14 & 0.13 & 0.14 & 0.13 & 0.13 & 0.15 \\
\hline Institutional Arrangements & 0.13 & 0.13 & 0.13 & 0.15 & 0.13 & 0.11 \\
\hline Technology and Digital Connectivity & 0.12 & 0.14 & 0.08 & 0.13 & 0.13 & 0.13 \\
\hline Environmental Cooperation & 0.13 & 0.13 & 0.12 & 0.13 & 0.13 & 0.14 \\
\hline
\end{tabular}

Source: Asian Development Bank. Asia-Pacific Regional Cooperation and Integration Index Database. https://aric.adb.org/database/arcii (accessed May 2021). 
Figure A2: Economy-Level Regional Integration Indexes

Overall Index

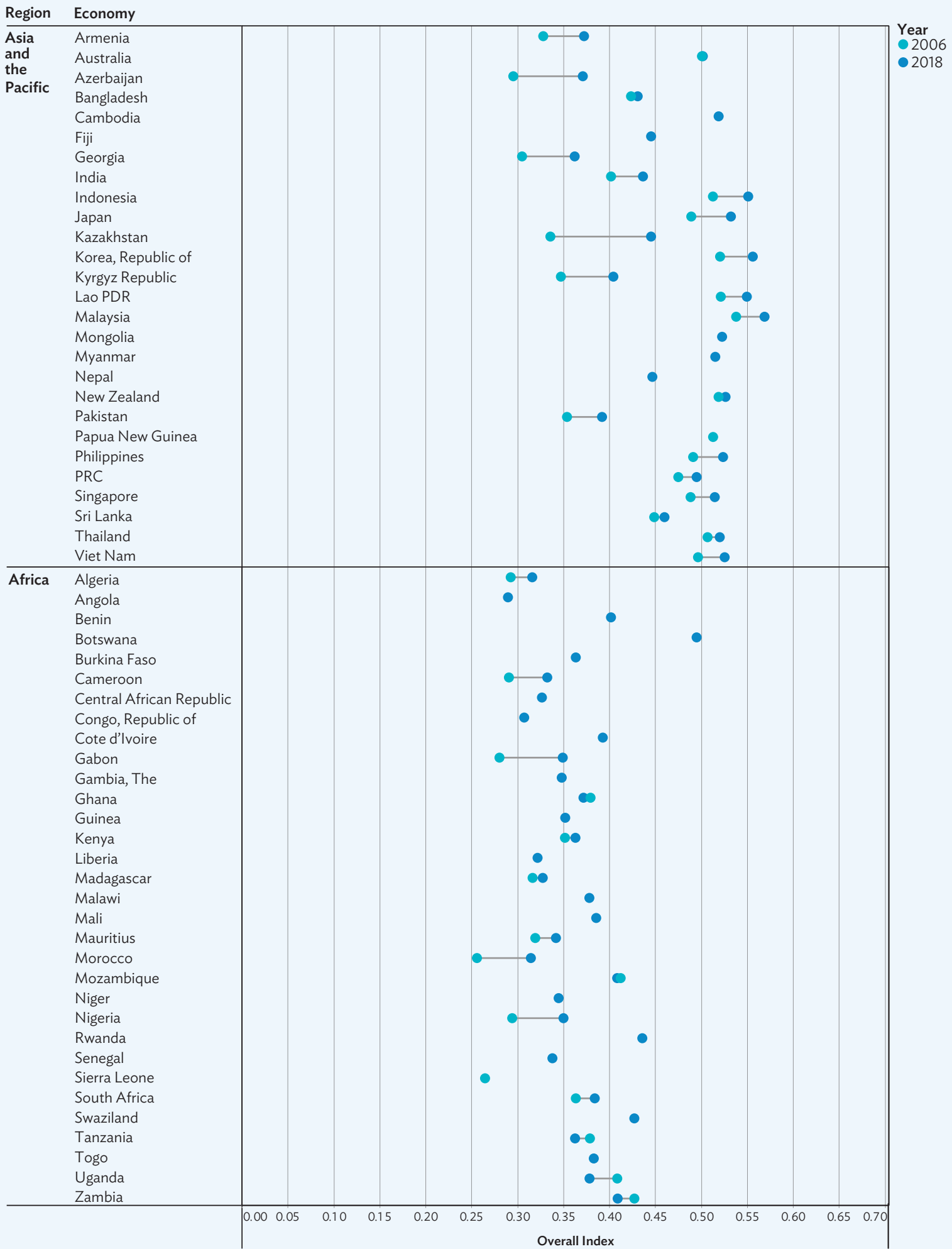


Figure A2.2 continued

Overall Index

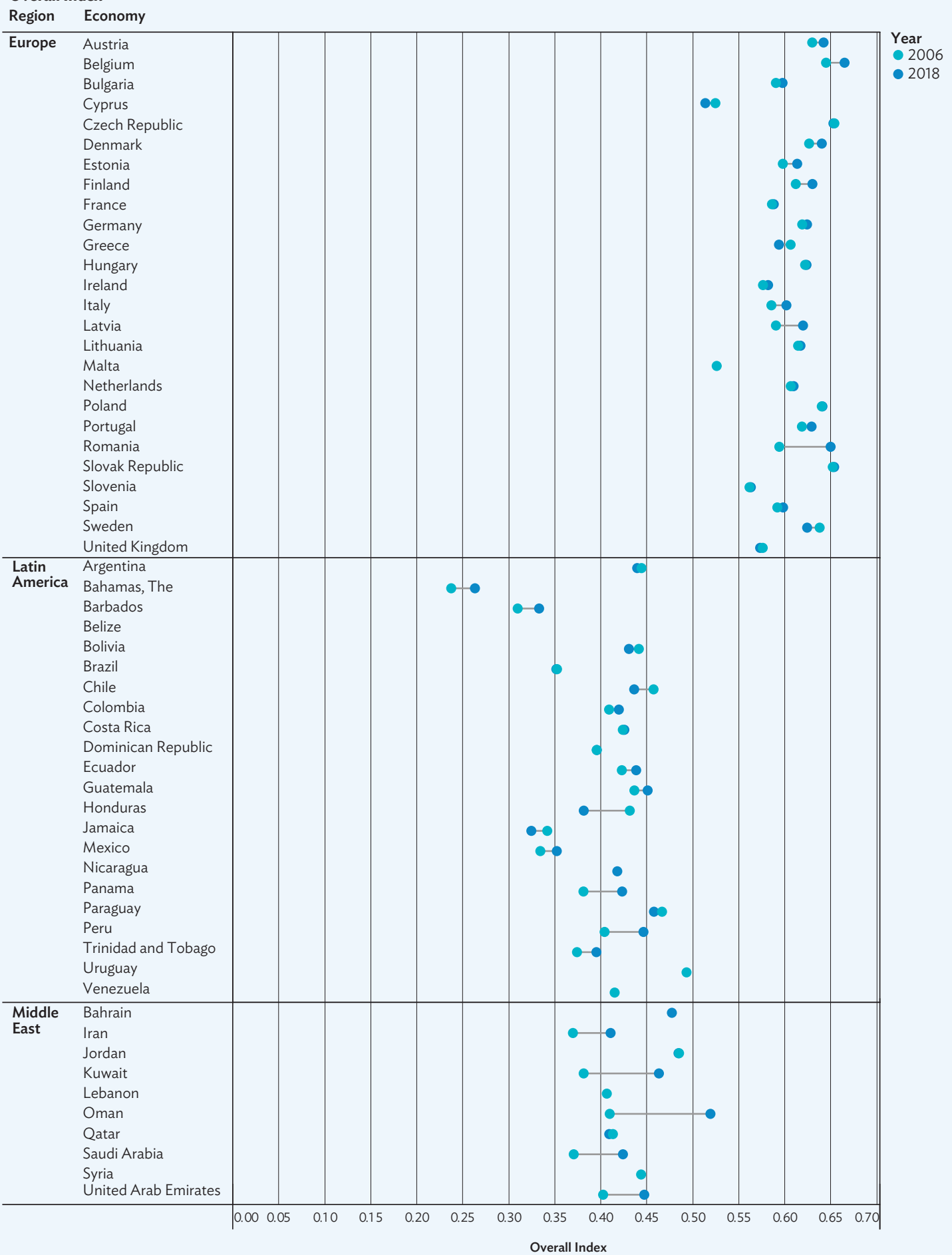

Note: Some economies in the Asia-Pacific Regional Cooperation and Integration Index list are not displayed in the graph due to lack of index values for 2006 and 2018.

Source: Asian Development Bank. Asia-Pacific Regional Cooperation and Integration Index Database. https://aric.adb.org/database/ arcii (accessed May 2021). 


\section{APPENDIX 3 \\ Supplementary Information on Alternative Indicators}

Table A3: Dimensions and Indicators in the Enhanced

ARCII Framework using Gross Domestic Product or Population as the Denominator

\begin{tabular}{|c|c|c|c|}
\hline Dimension & & Indicator & Source of Raw Data \\
\hline \multirow{5}{*}{$\begin{array}{l}\text { I. Trade and } \\
\text { Investment } \\
\text { Integration (5) }\end{array}$} & $\mathrm{I}-\mathrm{a}$ & Ratio of intraregional goods exports to GDP & $\begin{array}{l}\text { Direction of Trade (IMF), World } \\
\text { Development Indicators (WDI) }\end{array}$ \\
\hline & $\mathrm{I}-\mathrm{b}$ & Ratio of intraregional goods imports to GDP & Direction of Trade (IMF), WDI \\
\hline & $\mathrm{I}-\mathrm{c}$ & Intraregional trade share & Direction of Trade (IMF) \\
\hline & $\mathrm{I}-\mathrm{d}$ & Ratio of intraregional FDI inflows to GDP & Greenfield FDI (FDI Markets), \\
\hline & $\mathrm{l}-\mathrm{e}$ & $\begin{array}{l}\text { Ratio of intraregional FDI inflows plus outflows } \\
\text { to GDP }\end{array}$ & M\&A FDI (Zephyr), WDI \\
\hline \multirow[t]{5}{*}{$\begin{array}{l}\text { II. Money and } \\
\text { Finance Integration } \\
\text { (5) }\end{array}$} & $\|-\mathrm{a}$ & $\begin{array}{l}\text { Ratio of intraregional cross-border equity } \\
\text { liabilities to GDP }\end{array}$ & $\begin{array}{l}\text { Coordinated Portfolio Investment } \\
\text { Survey, International Monetary Fund } \\
\text { (IMF); WDI }\end{array}$ \\
\hline & $I I-b$ & $\begin{array}{l}\text { Ratio of intraregional cross-border bond liabilities } \\
\text { to GDP }\end{array}$ & $\begin{array}{l}\text { Coordinated Portfolio Investment } \\
\text { Survey, IMF; WDI }\end{array}$ \\
\hline & $\| \mathrm{II}$ & $\begin{array}{l}\text { Pair-wise dispersion of deposit rates averaged } \\
\text { regionally relative to that averaged globally }\end{array}$ & $\begin{array}{l}\text { Asian Development Bank (ADB) } \\
\text { using various sources }\end{array}$ \\
\hline & $I I-d^{*}$ & Capital account openness: Chinn-Ito Index & $\begin{array}{l}\text { http://web.pdx.edu/ ito/chinn-ito_ } \\
\text { website.htm }\end{array}$ \\
\hline & II-e & $\begin{array}{l}\text { Correlations of exchange rates relative to US } \\
\text { dollar averaged regionally minus those averaged } \\
\text { globally }\end{array}$ & $A D B$ using various sources \\
\hline \multirow[t]{5}{*}{$\begin{array}{l}\text { III. Regional Value } \\
\text { Chains (5) }\end{array}$} & III-a & $\begin{array}{l}\text { Ratio between the averaged trade } \\
\text { complementarity index over regional } \\
\text { trading partners and the averaged trade } \\
\text { complementarity index overall trading partners }\end{array}$ & UN Comtrade \\
\hline & III-b & $\begin{array}{l}\text { Ratio between the averaged trade concentration } \\
\text { index over regional trading partners and the } \\
\text { averaged trade concentration index overall } \\
\text { trading partners }\end{array}$ & UN Comtrade \\
\hline & III-C & $\begin{array}{l}\text { Ratio of intraregional intermediate goods exports } \\
\text { to total intraregional goods exports }\end{array}$ & UN Comtrade \\
\hline & III-d & $\begin{array}{l}\text { Ratio of intraregional intermediate goods imports } \\
\text { to total intraregional goods imports }\end{array}$ & UN Comtrade \\
\hline & III-e & $\begin{array}{l}\text { Ratio between the sum of the value-added } \\
\text { contributed by regional trading partners and that } \\
\text { contributed by all trading partners }\end{array}$ & $\begin{array}{l}\text { United Nations Conference on Trade } \\
\text { and Development (UNCTAD)-Eora }\end{array}$ \\
\hline
\end{tabular}


Table A3 continued

\begin{tabular}{|c|c|c|c|}
\hline Dimension & & Indicator & Source of Raw Data \\
\hline \multirow[t]{5}{*}{$\begin{array}{l}\text { IV. Infrastructure and } \\
\text { Connectivity (5) }\end{array}$} & IV-a & $\begin{array}{l}\text { Ratio between the averaged trade cost over } \\
\text { regional trading partners and the averaged trade } \\
\text { cost overall trading partners }\end{array}$ & $\begin{array}{l}\text { World Bank/United Nations } \\
\text { Economic and Social Commission for } \\
\text { Asia and the Pacific (UNESCAP) }\end{array}$ \\
\hline & $\mathrm{IV}-\mathrm{b}$ & $\begin{array}{l}\text { Ratio between the averaged liner shipping } \\
\text { connectivity index over regional trading partners } \\
\text { and the averaged liner shipping connectivity } \\
\text { index overall trading partners }\end{array}$ & UNCTAD \\
\hline & $\mathrm{IV}-\mathrm{c}$ & $\begin{array}{l}\text { Ratio of passenger seats sold on regional flights } \\
\text { to population }\end{array}$ & $\begin{array}{l}\text { International Civil Aviation } \\
\text { Organization }\end{array}$ \\
\hline & $I V-d^{*}$ & Logistics performance index (overall) & World Bank \\
\hline & $I V-e^{*}$ & Doing Business Index (overall) & World Bank \\
\hline \multirow[t]{6}{*}{$\begin{array}{l}\text { V. People and Social } \\
\text { Integration (5) }\end{array}$} & $\mathrm{V}-\mathrm{a}$ & $\begin{array}{l}\text { Ratio of intraregional outbound migration to } \\
\text { population }\end{array}$ & $\begin{array}{l}\text { United Nations Population Division, } \\
\text { WDI }\end{array}$ \\
\hline & $V-b$ & $\begin{array}{l}\text { Ratio of intraregional tourists } \\
\text { (inbound plus outbound) to population }\end{array}$ & $\begin{array}{l}\text { World Trade Organization (WTO), } \\
\text { WDI }\end{array}$ \\
\hline & $\mathrm{V}-\mathrm{c}$ & Ratio of intraregional remittances to GDP & World Bank, WDI \\
\hline & $V-d$ & $\begin{array}{l}\text { Cultural proximity with interregional economies } \\
\text { relative to that with all other economies }\end{array}$ & $\begin{array}{l}\text { Centre d'Etudes Prospectives et } \\
\text { d'Informations Internationales } \\
\text { (CEPII) }\end{array}$ \\
\hline & V-e & $\begin{array}{l}\text { Ratio of intraregional cultural goods trade } \\
\text { (exports plus imports) to total goods trade }\end{array}$ & UNCTAD, UN Comtrade \\
\hline & V-f & $\begin{array}{l}\text { Ratio of trademark applications made with } \\
\text { intraregional residents to GDP }\end{array}$ & $\begin{array}{l}\text { World Intellectual Property } \\
\text { Organization, WDI }\end{array}$ \\
\hline \multirow[t]{5}{*}{$\begin{array}{l}\text { VI. Institutional } \\
\text { Arrangements (5) }\end{array}$} & $\mathrm{VI}-\mathrm{a}$ & $\begin{array}{l}\text { Ratio of intraregional economies that have signed } \\
\text { FTAs with }\end{array}$ & $\begin{array}{l}\text { Design of Trade Agreements } \\
\text { (DESTA) }\end{array}$ \\
\hline & VI-b & $\begin{array}{l}\text { Ratio of intraregional economies that have signed } \\
\text { bilateral investment treaties with }\end{array}$ & UNCTAD, DESTA \\
\hline & $\mathrm{VI}-\mathrm{c}$ & $\begin{array}{l}\text { Ratio of intraregional economies that have signed } \\
\text { double taxation treaties with }\end{array}$ & UNCTAD \\
\hline & VI-d & $\begin{array}{l}\text { Number of international intergovernment } \\
\text { organizations in which an economy is a member }\end{array}$ & The CIA World Factbook \\
\hline & VI-e & $\begin{array}{l}\text { Ratio of intraregional economies that have } \\
\text { an embassy }\end{array}$ & $\begin{array}{l}\text { Huh (2020) based on The Europa } \\
\text { World Year Book }\end{array}$ \\
\hline \multirow{5}{*}{$\begin{array}{l}\text { VII. Technology and } \\
\text { Digital Connectivity } \\
\text { (6) }\end{array}$} & VII-a & $\begin{array}{l}\text { Ratio of intraregional ICT goods trade } \\
\text { (exports plus imports) to total goods trade }\end{array}$ & UNCTAD, UN Comtrade \\
\hline & VII-b & $\begin{array}{l}\text { Ratio of research outputs with intraregional } \\
\text { collaborators to GDP }\end{array}$ & $\begin{array}{l}\text { Huh (2020) based on Web of } \\
\text { Science data; WDI }\end{array}$ \\
\hline & VII-c & $\begin{array}{l}\text { Ratio of patent applications made with } \\
\text { intraregional residents to GDP }\end{array}$ & $\begin{array}{l}\text { World Intellectual Property } \\
\text { Organization, WDI }\end{array}$ \\
\hline & VII- $d^{*}$ & Ratio of persons using the internet & $\begin{array}{l}\text { International Telecommunication } \\
\text { Union (ITU) }\end{array}$ \\
\hline & VII-e & Ratio of mobile subscriptions per 100 persons & ITU \\
\hline
\end{tabular}


Table A3 continued

\begin{tabular}{|c|c|c|c|}
\hline \multirow{2}{*}{ Dimension } & \multicolumn{2}{|r|}{ Indicator } & Source of Raw Data \\
\hline & VII-f* & International internet bandwidth & $\begin{array}{l}\text { ITU/TeleGeography(https://www. } \\
\text { telegeography.com) }\end{array}$ \\
\hline \multirow[t]{4}{*}{$\begin{array}{l}\text { VIII. Environmental } \\
\text { Cooperation (4) }\end{array}$} & VIII-a & $\begin{array}{l}\text { Ratio of intraregional environmental goods trade } \\
\text { (exports plus imports) to total intraregional } \\
\text { goods trade }\end{array}$ & UN Comtrade \\
\hline & VIII-b* & $\begin{array}{l}\text { Number of international environmental } \\
\text { agreements ratified }\end{array}$ & The CIA World Factbook \\
\hline & VIII-c* & $\begin{array}{l}\text { Ecological footprint of production as a share of } \\
\text { biocapacity }\end{array}$ & Global Footprint Network \\
\hline & VIII- $d^{*}$ & Environmental health score & $\begin{array}{l}\text { Environmental Performance Index at } \\
\text { http://epi.yale.edu }\end{array}$ \\
\hline
\end{tabular}

ARCII = Asia-Pacific Regional Cooperation and Integration Index, FDI = foreign direct investment, FTA = free trade agreement, GDP = gross domestic product, ICT = information and communication technology, M\&A = mergers and acquisitions.

Notes: Highlighted rows in green indicate new indicators and dimensions included in the enhanced ARCII framework. Indicators marked with an asterisk are national-level indicators.

Source: Asian Development Bank. 


\section{Asia-Pacific Regional Cooperation and Integration Index}

Enhanced Framework, Analysis, and Applications

Since 2017, the Asia-Pacific Regional Cooperation and Integration Index (ARCII) has been used for tracking progress in various dimensions of regional cooperation and integration $(\mathrm{RCI})$. This report discusses how the enhanced ARCII framework incorporates two new dimensions (digital connectivity and environmental cooperation) and other methodological innovations to capture the increasingly complex nature of $\mathrm{RCl}$. With these new features, the report explores the links between regional and global economic integration and sheds light on the application of the index to $\mathrm{RCl}$ analysis and policy strategies for Asia and Pacific economies.

\section{About the Asian Development Bank}

ADB is committed to achieving a prosperous, inclusive, resilient, and sustainable Asia and the Pacific, while sustaining its efforts to eradicate extreme poverty. Established in 1966, it is owned by 68 members -49 from the region. Its main instruments for helping its developing member countries are policy dialogue, loans, equity investments, guarantees, grants, and technical assistance. 